DECONSTRUCTING DOMINANT ENGLISH LANGUAGE DISCOURSES IN THE GHANAIAN CURRICULUM: REIMAGINING A CURRICULUM CENTERED ON GHANAIAN LANGUAGES AND LITERACIES

A Dissertation presented to the Faculty of the Graduate School at the University of Missouri-Columbia

In Partial Fulfillment of the Requirements for the Doctor of Philosophy Degree

by

EDWIN NII BONNEY

Dr. Lisa Dorner, Dissertation Chair

Drs. Emily Crawford-Rossi, James Sebastian, and Angie Zapata, Committee Members May 2021 
The undersigned, appointed by the dead of the Graduate School, have examined the dissertation entitled

\section{DECONSTRUCTING DOMINANT ENGLISH LANGUAGE DISCOURSES IN THE GHANAIAN CURRICULUM: REIMAGINING A CURRICULUM CENTERED ON GHANAIAN LANGUAGES AND LITERACIES}

presented by Edwin Nii Bonney, a candidate for the degree of doctor of philosophy, and hereby certify that, in their opinion, it is worthy of acceptance.

Dr. Lisa M. Dorner

Dr. Emily Crawford-Rossi

Dr. James Sebastian

Dr. Angie Zapata 


\section{DEDICATION}

I dedicate this work first to God who continues to guide my path and is faithful in making all things work together for my good (Romans 8:28). To my wife and partner, Vida, who has made countless sacrifices for me in pursuing this $\mathrm{PhD}$ and writing my

dissertation. To my son, Teddy, who says he wants to be a research doctor and a medical doctor. To my daughter, Isabella, whose impending birth eight days after my defense pushed me to finish this work. To my parents, Solomon and Henrietta Bonney, for their constant nightly prayers and frequent counsel throughout. Finally, to all people working to in and with minoritized communities everywhere to overcome the marginalization and silencing of their languages, cultures, histories, and knowledge, this work is for you. 


\section{ACKNOWLEDGEMENTS}

I would like thank Dr. Lisa M. Dorner, my advisor. When I came into the $\mathrm{PhD}$ program, not knowing much about education policy issues, she took me under her wing, pulled me into research projects, invited me to collaborate on book chapters, and helped me secure funding when there no opportunities. She has been my champion through this journey, and I am forever grateful to her.

I would also like to thank my advisor in my Masters program, the late Professor Flore Zephir whose words still echo in my head, "Good things happen to good people." Unfortunately, she passed away the year I gained admission into the PhD program. I am grateful for her wisdom and vision in pointing the way to ELPA and for her leadership and advocacy to get things done for her students even when policies were unfavorable. I would like to thank my committee members, Dr. Emily Crawford-Rossi, Dr. James Sebastian, and Dr. Angie Zapata, for their belief in my work and their critical insights, conversations, comments, and feedback in fine-tuning and pushing me to be more critical in my work and in my approach to research.

I would also like to thank my mother in-law, Rebecca Egyir, who helped me find the last piece of data I needed for my analysis, the kindergarten curriculum. I am grateful to my colleagues in the ELPA program for their input in class discussions, conversation over txt and email, and also in 218. To Dr. Ransford Pinto, Justin Kumbal, Jeong-Mi Moon, Tricia Joseph, Xinyi Mao, Jason McKinney, Palwasha Marwat, Isabel Montes, Jared Beasley, Heather Sweeney, Elizabeth Knight, Dorcas Qian, Brandon Wolak and Sarah Hairston, thank you for inspiring and supporting me. Finally, to Dr. Michael Marlo who questions about languages in Africa started all this, I am most grateful. 


\section{TABLE OF CONTENTS}

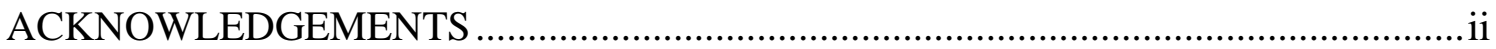

LIST OF TABLES AND FIGURES..................................................................... viii

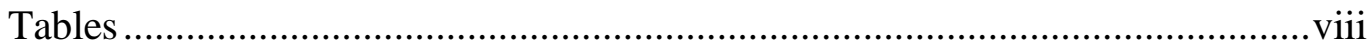

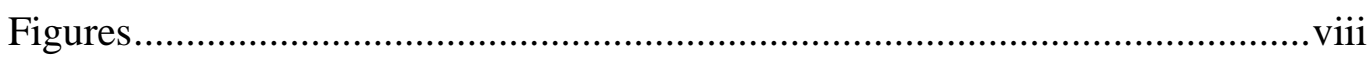

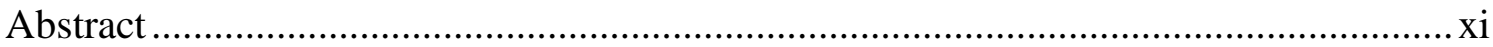

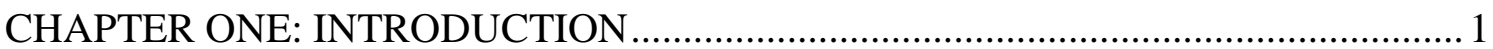

Rationale for the Study ............................................................................................. 3

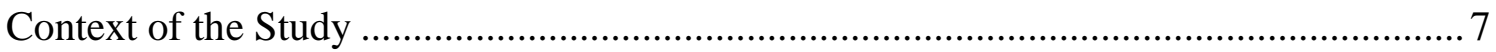

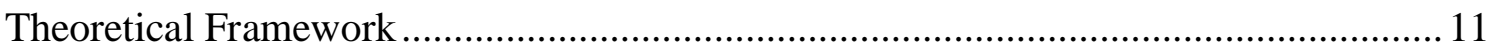

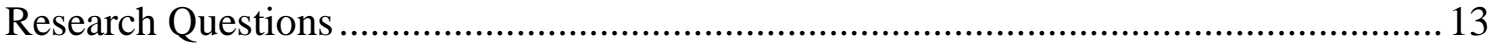

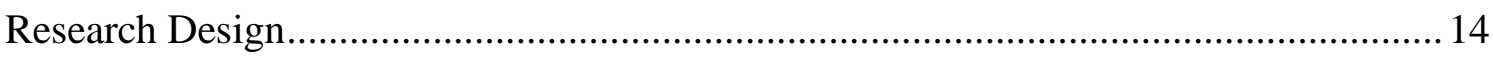

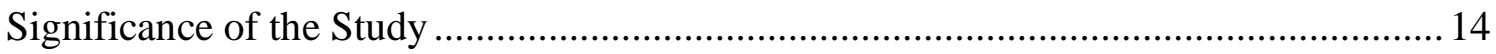

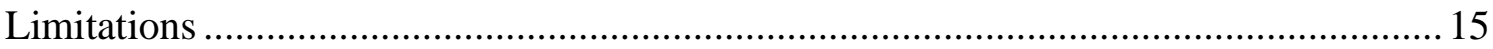

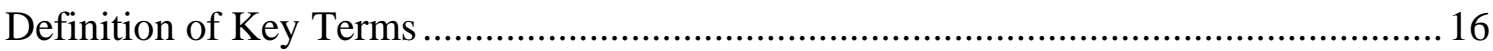

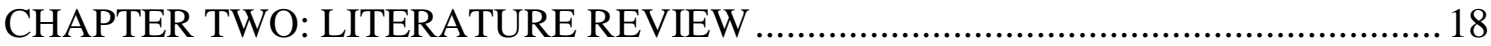

Section A: History of English in Ghanaian Education ..................................................2 20

Language in the Missionary and Castle Schools ................................................22

Converting and Civilizing the Native Through Education. ..................................24

The Basel and Bremen Mission ........................................................................... 24

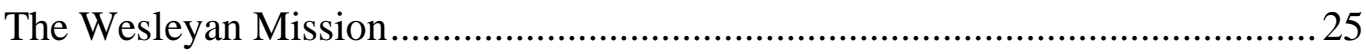

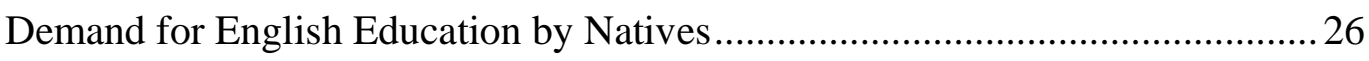

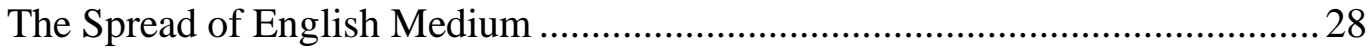


The Phelps-Stokes Commission .......................................................................... 29

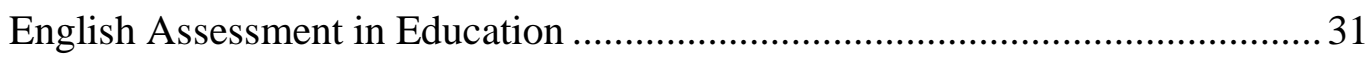

Making Policy and Curriculum Changes to Education $(1971-2001) \ldots \ldots \ldots \ldots \ldots . . . .36$

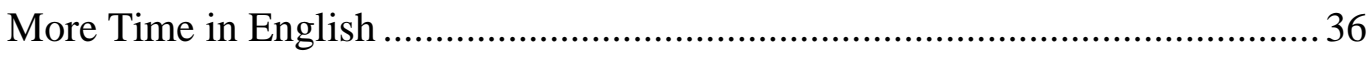

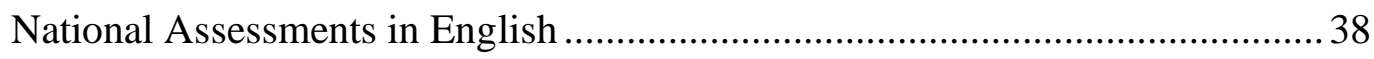

Ghanaian Language Courses Made Optional .......................................................... 39

English Only Language-in-Education Policy $(2002$ - 2007)................................ 39

Ghanaian Languages, Where Necessary but Not Required (2007 to date)...........40

Section B: Ghanaian Languages Through Research..................................................... 42

Students Would Fall Behind ……………………………............................. 51

Using Ghanaian Languages Feels Like an External Imposition .............................52

Literacy in Ghanaian Languages is Illiteracy …………………….......................54

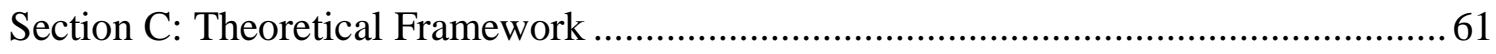

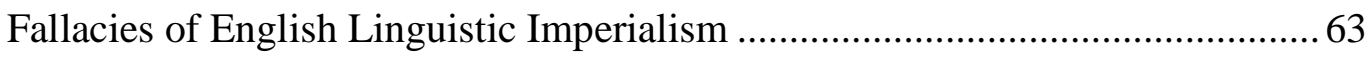

Globalization of English Education After Independence ......................................64 64

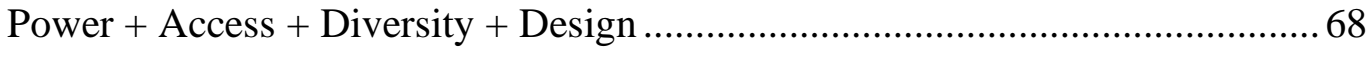

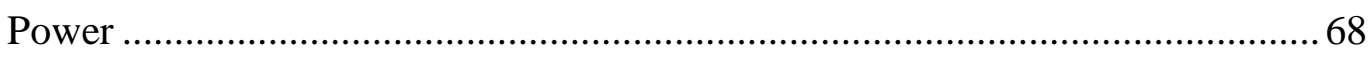

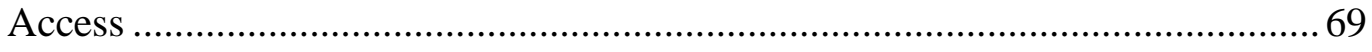

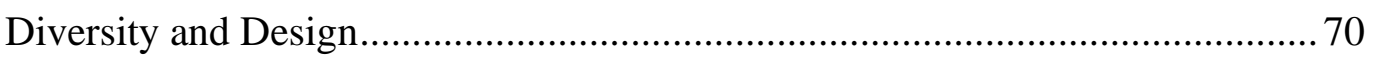

Identifying False Discourses + Power + Access + Diversity + Design $=$

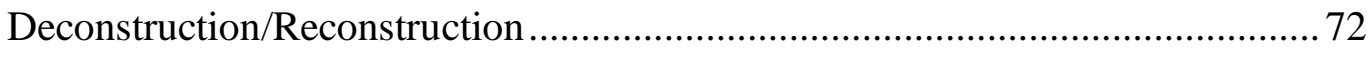

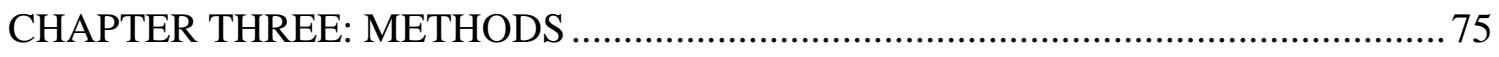

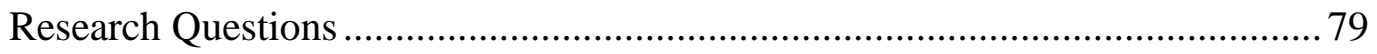




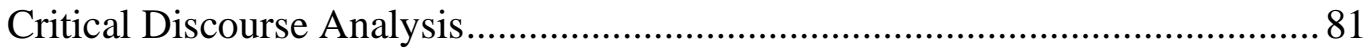

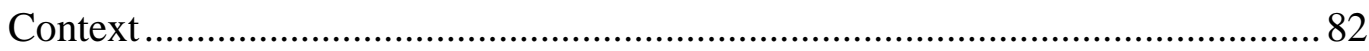

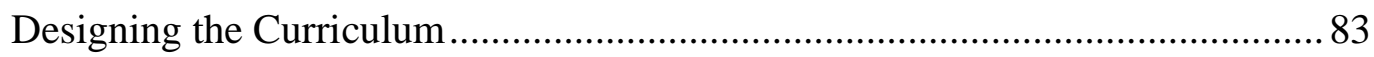

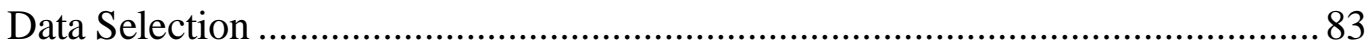

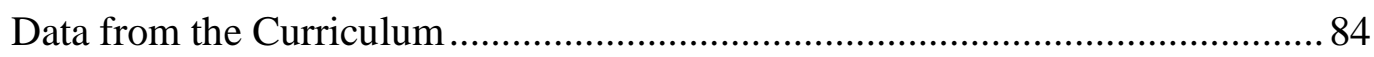

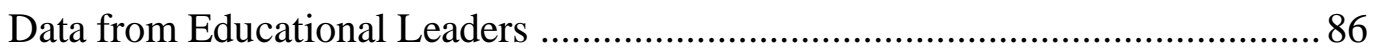

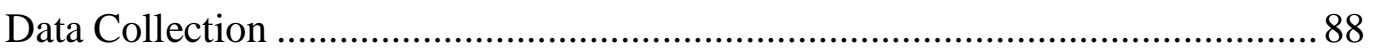

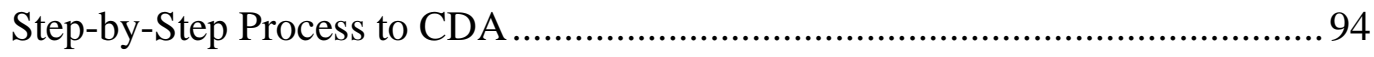

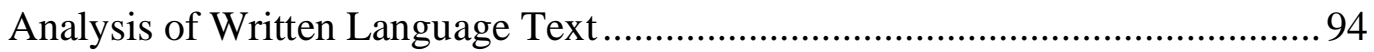

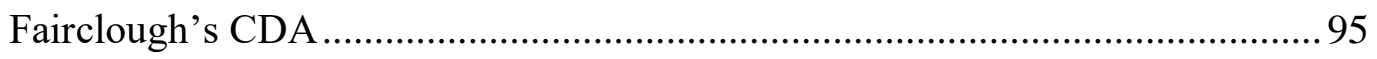

Analysis of Spoken Language Text ............................................................ 95

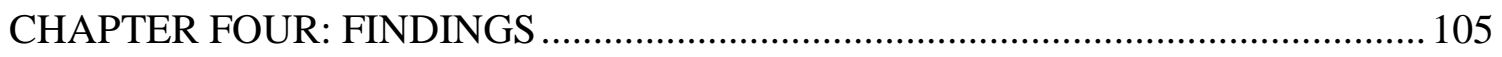

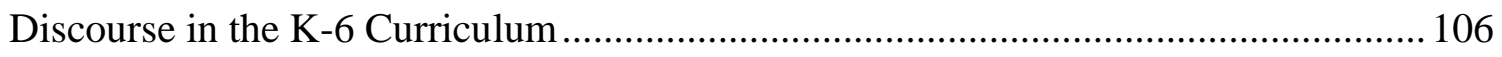

Discourses of English Linguistic Imperialism ........................................... 107

Flexible or Vague: What Exactly is the Language Policy? ............................. 107

More Time in English ...................................................................... 110

More Content in English .................................................................... 115

Ghanaian Language Curriculum, Written in English ................................... 126

Higher Expectations from Students in English ......................................... 128

The High Weight in Assessing Languages ................................................ 142

Discourses of Ghanaian Languages and Literacies ...................................... 146

Development Begins When the Colonizers Arrive ......................................... 148

Knowledge about Ghanaian Cultures Emerges in Other Content Areas ........... 157 
Discourse from Educational Leaders 163

There are Many Problems in Education and [Ghanaian] Language is not one of them. 164

Students Should Wait till They are Proficient in English to Progress ..... 164 Student Get Access to Higher Levels of Education if They Pass Exams Written in English 166

Students Need to Embody English Literacies in Primary Two 169

"The Singapores, the Malaysia and the South Koreans...Have Left Us".... 172

English Proficiency for Employability 175

Summary of Findings 179 CHAPTER FIVE: DISCUSSION 181

Interpretation of the Findings 183

The Persistent Dominance of the English Language 183

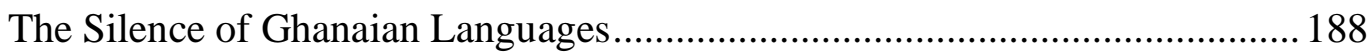

History Repeats Itself ................................................................... 190

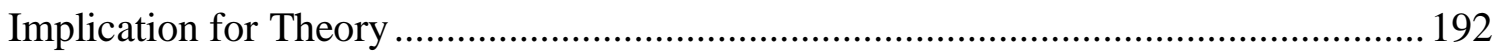

One Fallacy is Enough for English Linguistic Imperialism............................ 194

Critical Literacy Without 'Critical' is not just Literacy................................... 196

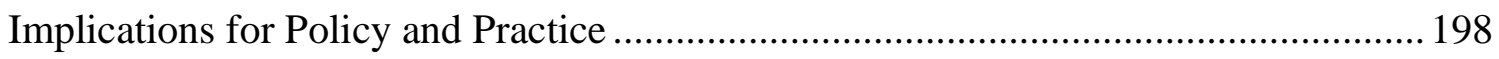

Reimagining a Non-Language Subject Taught in Ghanaian Languages ........... 200

Reimagining a Language-in-Education Policy ........................................... 203

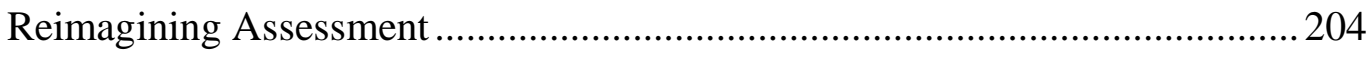

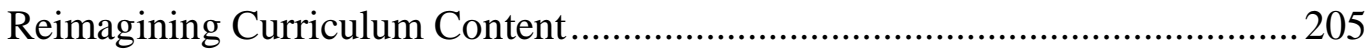


Changing the Public Discourse Through Educational Leaders

Limitations and Future Research Directions............................................................. 207

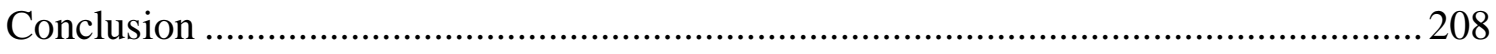

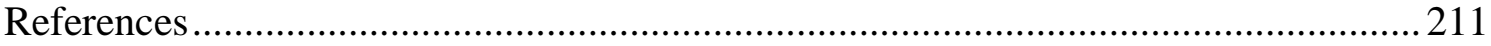

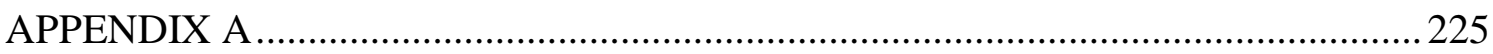

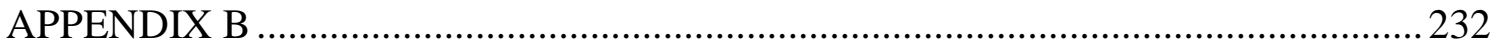

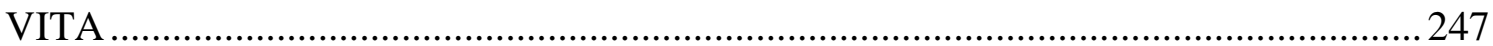




\section{LIST OF TABLES AND FIGURES}

\section{Tables}

Table 2.1: The Interdependent Model of Critical Literacy 73

Table 3.1: Data from the Curriculum 85

Table 3.2: Data from Educational Leaders 89

Table 3.3: Sample CDA Analysis 96

Table 4.1: Period Allocation 112

Table 4.2: Period Allocation for Languages $\quad 114$

Table 4.3: When Writing is Introduced 116

Table 4.4: Comparison 1: Content Strands in the Ghanaian Languages 119 and English K-6 Curriculum

Table 4.5 Comparing Teaching Content for Primary 4

Table 4.6: Comparison 2: Differences Across Various Content Strand 134 in English and Ghanaian languages

Table 4.7: Weights for Continuous Assessment and Examination for 145 Upper Primary

Table 4.8: Strands and Sub-Strands in the History Curriculum 148

Table 4.9: Educational Leaders References to Other Countries 177

Figures

Figure 4.1: Content Strands in the English Curriculum 117 
Figure 4.2: Content Strands in the Ghanaian languages Curriculum

Figure 4.3: Lesson on Adjectives in the Ghanaian languages

Curriculum

Figure 4.4: Lesson on Adjectives in the English Curriculum

Figure 4.5: More Opportunities for Writing in English

Figure 4.6: Sample Worksheet for Ghanaian languages

Figure 4.7: How Curriculum Teaching is Organized

Figure 4.8: Ghanaian languages Curriculum Content for Primary 4

Figure 4.9: English Language Curriculum Content for Primary 4

Figure 4.10: Lesson Plan Exemplar for Ghanaian Languages

Figure 4.11: Lesson Plan Exemplar for English

Figure 4.12: Grading Scheme for Primary Schools

Figure 4.13: Developments in Ghana under Colonial Rule

Figure 4.14: Economic Development in Ghana under Colonial Rule

Figure 4.15: Education and Health Development in Ghana under Colonial Rule

Figure 4.16: Introduction to the Slave Trade

Figure 4.17: Impact of Colonization in Ghana 
Figure 4.18: Sample Assessment in History

Figure 4.19: Strand in History Curriculum Focused on Ghana's People

Figure 4.20: Content Strand in RME

Figure 4.21: Strands and Sub-strands in OWOP

Figure 5.1: Content Strands in the Creative Arts Curriculum 


\begin{abstract}
Decades of research in language-in-education policies in Ghana can be summed up in the statement: "Ghanaian languages matter but they matter only as tools for learning English.” Although researchers continue to call to include more content delivery in Ghanaian languages in schools, educational policies and practices in Ghana continue to prioritize English education inherited from Ghana's colonial past while devaluing and deprivileging Ghanaian languages and cultures (Dei \& Asgharzadeh, 2001). Scholars continue to call for stakeholders to decolonize the curriculum by centering Ghanaian languages, culture, and knowledge in schools (Dei, 2005). This study heeds that call. Grounded in studies and theories of English linguistic imperialism and critical literacy, I first examine the discourse of the newly implemented 2019 K-6 primary school curriculum and public discourses of educational leaders to learn how curricular policies, content, assessment, and teaching and learning activities continue to center Englishcentric language practices and policies. Second, I reimagine how to center Ghanaian languages in education. I found that the curriculum does not resist English language dominance or question it but treats it as normal and aspirational for Ghanaian students. The topic of Ghanaian languages is absent in the public discourse of educational leaders including when they are addressing how to make education more equitable for students. This study is significant because it shows how formerly colonized spaces like Ghana through their own educational curriculum might be silencing and devaluing their own indigenous languages (and cultures) and it also demonstrates the role of educational leaders in shaping public discourse.
\end{abstract}




\section{CHAPTER ONE: INTRODUCTION}

"Nsateaa nyinaa nnye $\varepsilon^{1 "}$

In many Ghanaian cultures, wise sayings are used to convey complex matters in simple statements. These sayings are often spoken by elders and older adults to pass on ways of speaking, doing, and being in society to younger generations. I start this chapter with the wise saying in the Akan language above that translates literally as "All fingers are not the same." This statement can be applied to multiple situations, for example, to explain that each person in society has different needs and also that each person brings different capacities and abilities but together we all contribute to society. This is just one example of how Ghanaians' languages are tightly and lovingly connected with doing, being, and saying in Ghana - and so, one would expect them to be a central part of Ghana's education system. However, as in many parts of colonized Africa, the schooling mainly happens in English, and Ghana's official language is English, with French recently chosen as its second language.

Recently, a Ghanaian music artiste, Okyeame Kwame, who sings mostly in the Akan language, critiqued the government's decision to make the French language Ghana's other official language after English (“Adopting French,” 2019). Okyeame Kwame said that Ghana quietly accepted English as its first language and as such making another foreign language an official language instead of promoting Ghanaian languages causes them to lose their value. He is right, but even more than that, pushing the use and study of Ghanaian languages and literacies out of mainstream education hampers the educational attainment and progress of many Ghanaian students (Ahadzi, Ameka, \&

\footnotetext{
${ }^{1}$ This Akan proverb translated literally means "All fingers are not the same."
} 
Essegbey, 2015; Opoke-Amankwa, 2009a, 2009b; Owu-Ewie \& Eshun, 2015; Owu-Ewie \& Eshun, 2019).

Moreover, Okyeame Kwame expressed that his Ghanaian language is a part of his identity and cannot, therefore, be separated from how he interacts with the world. He said, "when you talk to me in Twi, the amount of knowledge that I reserve because the language is not [just] words that come out of your mouth, it is a combination of a shared history and a shared culture so it is important that we don't only speak our language, we learn [and] we understand the idioms and the proverbs and the etymologies behind our language [and] that is when we will develop" ("Adopting French," 2019, para. 13). Many Ghanaian students as well learn that the knowledge and competencies they have in their local Ghanaian languages are invisible when they enter the Ghanaian classroom (OpokuAmankwa, 2009a, 2009b). Like Okyeame Kwame recognized, when students are denied the opportunity to bring their languages into the classroom as part of the learning process, they fall behind (Collison 1974); the curriculum forces them to see the English language as the only way to succeed in education even if they do not understand the content they are learning in English (Davis \& Agbenyegah, 2012; Edu-Buandoh \& Otchere, 2012; Owu-Ewie \& Eshun 2019), and as a result they acquire little literacy in both English and Ghanaian languages (Opoku-Amankwa, 2009a, 2009b).

While there is much in the literature about why Ghanaian languages are useful in instructing curriculum content to Ghanaian students, there is little discussion in the literature about how English language dominant discourses became so ingrained in the curriculum such that there is resistance to Ghanaian language use from educational leaders, parents, and even students (Mfum-Mensah, 2005; Opoku-Amankwa \& Brew- 
Hammond, 2011). Therefore, this study examined how dominant discourses of the English language are supported by the educational curriculum and explored how these discourses can be deconstructed in order to reconstruct a new curriculum that highlights languages, literacies, cultures, and histories of Ghanaians in a way that changes what the society thinks of as dominant. To understand the position of the English language and Ghanaian languages in the curriculum I was guided by the following question: What are the discourses of English and Ghanaian languages in the curriculum?

The rest of this chapter starts with how my own personal and research experiences have shaped this research. Then, I briefly discuss the pertinent literature that framed this study, and I also identify the knowledge gap, and explain the research problem I address in this study. I also state the purpose of the study and outline the research questions that guided this inquiry, then I briefly introduce and discuss my theoretical framework, research design, and method that framed this study. Finally, I conclude the chapter with a definition of key terms that I use throughout the paper.

\section{Rationale for the Study}

As a student in primary school, I did not enjoy my Ga ${ }^{2}$ language class. I did not know whether it had to do with just the content of the class or the teaching style. There was so much emphasis on teaching Ga language grammar that did not reflect how I spoke Ga outside school. I remember questioning why as a $\mathrm{Ga}^{3}$, I had to learn Ga in school. I felt I already spoke Ga (and English) at home with my parents, so I did not need to learn it in school. I remember that among my friends we threatened to report anyone to the class teacher when any of us spoke in Ga or Twi outside the classroom during recess. On

\footnotetext{
${ }^{2} \mathrm{Ga}$ is a Ghanaian language spoken by the Ga ethnic group in Ghana.

${ }^{3} \mathrm{Ga}$ here refers not to the language but my identity as part of the Ga ethnic group
} 
the other hand, I enjoyed my French and English classes. I was always excited to learn new ways of saying something in French and "big words" in English that were rarely spoken. I was happy to be done with the Ghanaian language requirement when I passed the Basic Education Certification Education (BECE) by the end of junior high school (JHS). I had what was equivalent to a B-grade in the Ga language subject - my own language - and I was just happy to be done with it.

I was still fascinated by other languages after JHS. I spent a year in Cote d'Ivoire after senior high school and I picked up more proficiency in the French language. Later in college I double majored in Spanish and Psychology. I enjoyed Spanish more. I spent a year abroad in Cuba between my penultimate and last year of undergraduate studies and that quickly increased my speaking and writing proficiencies in Spanish. After college, I pursued a master's degree abroad in Spanish language teaching and it was not until I had almost graduated from my master's degree program in teaching Spanish that I began to reflect on my educational journey. That reflection started with a question posed by a professor of Linguistics in my university who studies how to preserve and codify oral African languages. He asked me, "why are you studying Spanish? We need people who will study African languages and help bring value to them in society so that they will not become extinct." I did not know how to answer that question that day but looking back at my educational journey I begun notice a few things.

I noticed that I knew very little in Ga compared to English and Spanish. I could write, speak, and read better in English and Spanish than in Ga. The Ghanaian educational curriculum made my own language feel like an additional burden - another subject that I had to get through quickly to check off. I realized that apart from the 
Ghanaian language classroom, speaking and writing in Ghanaian languages was not encouraged widely in school. I also noticed that I was not the only one experiencing the loss because when my family and peers conversed in $\mathrm{Ga}$, we mostly spoke English with a few phrases of Ga sprinkled into our conversations.

I grew curious about how my education had focused so much on English proficiency and literacy including those in other languages but not my own. In Ga, there

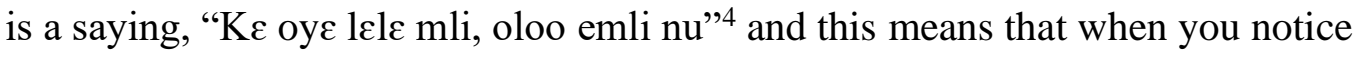
something wrong in society and you do not help to fix the problem, the consequences affect everyone including you. As a result, I conducted two research studies that examined some aspects of the Ghanaian curriculum to understand how dominant discourses in English were situated in the curriculum. First, I conducted a critical discourse analysis of the English language and Ghanaian language curricula at the senior high school level specifically examining the teaching and assessment syllabi (Bonney, 2020a). I found in this paper that the English language was considered a need for students whereas Ghanaian languages were seen as an option. Teaching and assessment practices supported these positions as students were expected to produce more in English and less in Ghanaian languages. There was also an English emphasis in the Ghanaian language curriculum that focused on students translating from Ghanaian languages into English (Bonney, 2020a).

The next study focused on books students were required to read as part of the literature curriculum which was considered a part of the English curriculum (Bonney, 2020b). Conducting a content analysis of the Literature curriculum including required

\footnotetext{
${ }^{4}$ This is Ga proverb, translated literally into English it means "When you are in a canoe, you bail out water from it"
} 
books, I found that Ghanaian languages were under-represented and characters in these books who were speakers of languages other than standard forms of English in these Ghanaian books authored by Ghanaians were described and portrayed as uneducated and poor. Also, because classroom teaching and learning practices, in addition to, national assessments emphasized identifying literary devices rather than a critique of social and institutional practices, students might read the underrepresentation and misrepresentation of Ghanaian languages as a normal discourse in society. Both studies drew my attention to how dominant English discourses were cemented into the content of the curriculum, teaching and learning practices, and assessment policies at the senior high school level.

In the same year, 2019, when I conducted these studies, the National Council for Curriculum and Assessment ( $\mathrm{NaCCA}$ ), the agency responsible for designing the Ghanaian educational curriculum revised the primary school (K-6) curriculum and implemented a new curriculum for Ghanaian primary schools. Because of my personal experience in primary school and my research studies examining parts of the senior high school curriculum, I began to wonder how much of these dominant English discourses are transmitted to students at the onset of their schooling years through the curriculum. I also wondered how Ghanaian languages and literacies are presented to Ghanaian students. This study builds on my previous studies (Bonney, 2020a, 2020b) in examining how dominant English discourses are supported by the primary school curriculum through curricular content, teaching and learning, and assessment policies and practices. Additionally, through my examination of decades of research across formerly colonized multilingual countries, I argue that policymakers and educational leaders across the region have themselves learned discourse in favor of English through their own 
schooling, and this perhaps explains why policies supporting native languages are often poorly implemented and enforced (Davis \& Agbenyegah, 2012; Edu-Buandoh \& Otchere, 2012). As a result, this study also specifically examines the discourses of educational leaders about what should be included/excluded in the educational curriculum.

\section{Context of the Study}

In this section I present a brief overview of the literature outlining the history and present place of English in Ghanaian education from the 1500s to date. When the Portuguese, Dutch, Danes, and British settled on the Gold Coast (previous name for land that now includes Ghana) in their forts and castles from the 1500 s, they set up schools for mulattoes (mixed-race children born to European and African parents) and natives who were instructed in the home languages of these foreigners (Graham, 1971). Some missionaries like the Basel and Bremen who also came to the Gold Coast to evangelize and convert the natives recognized that religious instruction was best understood when taught in the indigenous languages of the native people on the Gold Coast (Martin, 1976). Unfortunately, as the British gained official control of the Gold Coast from the 1850s, curriculum content and policy favored English language education. Schools that desired colonial government funding had to provide instruction in the English language (Graham, 1971). Literacy in English was considered as the way to train and civilize the native and so even though a colonial government education review saw Ghanaian languages as helpful in instruction, it was restricted in its use in schools and mainly used for religious instruction in schools (George, 1976). Assessments in the Gold Coast during the colonial regimes were conducted by examination bodies in England (George, 1976). When 
Ghanaian scholars set up their own schools to provide education in the Fanti language of their local community, students did not want to attend these schools because they wanted an English language education from teachers who were certified by England (Anyidoho \& Kropp Dakubu, 2008).

The discourse in education right from the colonial era promoted the English language as the education and so by the time Ghana gained independence from the British, success in education meant one's ability to embody English literacy and proficiency (Mfum-Mensah, 2005; Miescher, 2005). The colonial education set up from the beginning marginalized Ghanaian languages and literacies, and because education was not widespread throughout the country, very few people had the opportunity to attend school. However, shortly before Ghana officially gained independence in 1957, the Ghanaian led-legislature provided tuition-free primary education for all students and that expanded the colonial educational enterprise across the country (George, 1976). A number of educational reviews by subsequent governments after independence highlighted the need to employ Ghanaian languages in teaching as research began to show how it helped students grasp complex concepts easily (Collison, 1974). Yet, colonial and post-independence language-in-education policies and the curriculum including assessment practices indicated that students were expected to be literate and proficient in English but not in Ghanaian languages (Bening, 1976; George, 1976; Opoku-Amankwa, 2009a).

Several research studies in Ghana and across the region in Tanzania, Kenya, Uganda, and South Africa with similar colonial histories have contradicted the discourse that a curriculum centered on the English language and literacies in English is better for 
students in formerly colonized multilingual countries in Africa (Brock-Utne, Desai, Qorro \& Pitman, 2010; Hilliard, 2015; Taylor \& von Fintel, 2016). On the contrary, the intentional, direct use, and centering of Ghanaian and African languages in educating students across the region has shown better academic outcomes (Cleghorn, Merritt, \& Abagi, 1989; Mazrui, 2012; Ssentanda, 2014; Tembe, 2006; Trudell \& Piper, 2013). Educational curriculum that focused mainly on students' literacy and proficiency in English only, in the literature, seemed to hinder a majority of students from moving up the educational ladder (Drummond, 2016; Nyika, 2015). Unfortunately, even though researchers have found positive impacts of using Ghanaian and African languages in education, the larger discourse in society suggests that the use of Ghanaian languages feels like an imposition on parents by educational and government leaders and more importantly, that English proficiency and literacy has real tangible benefits in society (Mfum-Mensah, 2005). In South Africa, for instance, Casale and Posel (2011) found that South Africans who were proficient in English had higher income earnings compared to those who were not proficient in English. In Ghana, parents and students also expressed that English proficiency and literacy meant opportunities for better jobs and social prestige (Mfum-Mensah, 2005).

While English proficiency and literacy is prioritized in the curriculum and other ways of speaking, being, and doing are marginalized as a result of colonialism, Quijano (2007) argues that political independence from colonial rulers did not end "coloniality" the consequences of colonialism. In other words the structure of education, including the curriculum that privileges English education in the colonial enterprise, for social and 
economic upward mobility continues to exist because of the beliefs and images shown to the colonized. Quijano (2007) explains:

"In the beginning colonialism was a product of a systematic repression, not only of the specific beliefs, ideas, images, symbols or knowledge that were not useful to global colonial domination, while at the same time the colonizers were expropriating from the colonized their knowledge, especially in mining, agriculture, engineering, as well as their products and work... It was followed by the imposition of the use of the rulers' own patterns of expression, and of their beliefs and images with reference to the supernatural. These beliefs and images served not only to impede the cultural production of the dominated, but also as a very efficient means of social and cultural control, when the immediate repression ceased to be constant and systematic (p. 169)."

The research problem is therefore stated as follows: English provides real benefits in the Ghanaian society like high-income earnings and social prestige, but because of the current educational practice of favoring dominant English proficiency and literacy, a majority of Ghanaian students cannot fully access those benefits via education provided only in English. That is, the curriculum including content, teaching and learning practices, and assessment practices are set up to support students who may already speak English from home - like me. However, such policy design marginalizes and excludes the literacies and multilingual competences of many Ghanaian students who mainly speak Ghanaian languages. Restated in other words, English seems to provide real benefits in society because colonial, historical, and present educational practices and policies have privileged the language over indigenous Ghanaian languages and continue 
to do so. The purpose of this study, therefore, was to identify how the educational curriculum continues to reinforce the dominance of English and deconstruct the ways that dominant discourses in English are embedded in the curriculum in order to reconstruct a curriculum that de-centers English and re-centers Ghanaian literacies, languages, histories, and knowledge.

\section{Theoretical Framework}

I framed this inquiry in studies of English linguistic imperialism and Janks’ (2000, 2013) theory of critical literacy. Studies of English linguistic imperialism examine how English dominates globally and locally. Scholars such as Pennycook (1998) and Phillipson (1992, 2009) who study English linguistic imperialism have observed that in most countries where English is dominant, the language is touted as the language of modernity, technological progress, and national unity. English in these contexts is seen as neutral and promises equitable distribution of success (Pennycook, 1998). As a result, there is also less focus on the development of local languages and often the historical practices of colonizers are seen as efforts in helping educate and civilize the native. These observations from studies in English linguistic imperialism are similar to discourses about the need for English in Ghanaian education. I, therefore, applied Phillipson's (2009) five principles of English linguistic imperialism to identify fallacies of dominant English discourses in the curriculum. These principles are (1) the monolingual fallacy English is better taught monolingually; (2) the native speaker fallacy - the ideal teacher of English is a native speaker; (3) the early start fallacy - the earlier English is taught, the better the results; (4) the maximum exposure fallacy - the more English is taught, the better the results; and (5) the subtractive fallacy - if other languages are used much, 
standards of English will drop (Phillipson, 2009, p. 12). Phillipson (2009) suggests that these false narratives are present in multilingual contexts where English is dominant and other languages are devalued.

While I used Phillipson's (2009) tenets in examining the curriculum, identifying English discourses alone does not lead to a reconstruction that decenters English, and so I also framed this study in South African scholar Hilary Janks' $(2000,2013)$ theory of critical literacy. She explains that the process of deconstruction and reconstruction of the curriculum needs to critically examine issues concerning power, access, diversity, and design at the same time. She argues that an educational orientation towards one without the other does not change dominant discourses in education. With regards to power, researchers are to examine whose language has power and whose interests are being privileged in order to bring awareness to whose interests are not being met. A focus simply on providing access without examining power and diversity means that the curriculum will only emphasize and provide access to what is already dominant. Diversity looks at whether other voices and representation of the multiple realities are included in teaching and learning. Questions about diversity ask, for example, if the texts being read in the classroom are representative of the different ways of speaking, doing, and being or whether some voices are left out. Design is critical because it looks at how the structure of the curriculum, teaching and learning practices and policies foster an environment that supports the multilingual competences of students and different ways of reading and writing the world. Applying Jank's $(2000,2013)$ theory of critical literacy in this inquiry by examining power, access, diversity, and design issues in the curriculum allowed me to deconstruct dominant English discourses including policies and practice in 
education that can be reconstructed to privilege Ghanaian languages and literacies to best serve Ghanaian students.

\section{Research Questions}

My goal was that by understanding how English is centered in the curriculum, I could identify how to redesign policies, practices, and curriculum content to reflect the diverse languages and literacies in Ghana. My research questions were guided by my theoretical framework of critical literacy and English linguistic imperialism explained in chapter two. There were three main and four sub-questions that guided this study:

1. What discourses of English linguistic imperialism are in the Ghanaian primary school (K-6) curriculum?

a. How does the curriculum including content, assessment, and teaching and learning activities maintain the exclusionary force of dominant English practices and discourses? (Design/Power)

b. In what ways does the discourse of the curriculum critically resist English linguistic imperialism? (Power/Design)

2. What is the discourse about Ghanaian languages and literacies in the Ghanaian primary school (K-6) curriculum?

a. How are Ghanaian languages and literacies including various Ghanaian cultures and their histories, represented in the curriculum? (Diversity)

b. How does the design of the curriculum provide students access to diverse Ghanaian languages, literacies, cultures, and histories?

(Access/Diversity/Design) 
3. How do educational leaders talk about the K-6 curriculum and what it should include/exclude?

\section{Research Design}

This study used a Critical Discourse Analysis (CDA) approach (Fairclough, 2013; Gee, 2014) to examine how dominant English discourses are centered in the Ghanaian curriculum and to investigate how these dominant English discourses can be decentered in a way that incorporates Ghanaian languages and literacies into the curriculum. CDA mainly asks multiple questions of data in order to uncover both overt and covert discourses that shape how people interact with the world around them (Fairclough, 2013). Because CDA examines the language-in-use in different forms of texts (Gee, 2014), this study examined the various curricular documents making up the curriculum for K-6 primary school education including the National Pre-tertiary Education Framework, the curriculum for specific subject areas in K-6 education, and teacher resource packs for those subject areas. There are 19 different documents that make up the entire primary school education curriculum. I also examined the public discourse educational leaders, curriculum designers, and policymakers put out about the curriculum through radio and TV interviews and public speeches. I used these two sources of data - the data from the curriculum and the data from educational leaders - to serve as a means of triangulation and also to examine if there was consistency or discrepancy between what educational leaders said publicly and what ended up in the written curriculum.

\section{Significance of the Study}

Without an examination of the curriculum to learn how dominant English discourses are supported - and countered - by policies and practices in education, 
Ghanaian education runs the risk of continuing to deny a majority of students an opportunity to climb up the educational ladder. Findings from this study inform new ways of thinking about education across the African region in countries that have had a colonial history similar to like Ghana's. This study adds to much-needed knowledge, about how well-intentioned practices and policies in education might worsen the educational achievement of a majority of students whose home language is not English. Finally, findings from this study lay a platform to resolving the problem where only English is seen as a vehicle for upward social and economic mobility but it is only accessible to a few people whose home language practices include English. This study also highlights how reimagining a curriculum that values Ghanaian languages and literacies can decenter English as a dominant language in the Ghanaian society. The study also theorizes and strengthens the call for educational stakeholders in formerly colonized countries to take a decolonizing approach to education rather than a restructuring/revising of education that fails to address deeply grounded colonial practices in education.

\section{Limitations}

Even though my research design allows me to answer my research questions, it should be recognized that the discourse of the written curriculum might look different in practice in classrooms and schools across the country. In Davis and Agbenyegah (2012), for example, school leaders were flexible in practice with the national language-ineducation policy that required Ghanaian languages for K-3 schooling. However, also in the literature, we see that even though teachers might alter certain pedagogical practices (Owu-Ewie \& Eshun, 2015, 2019), the national curriculum content and assessment policies are strictly adhered to by most educators (Edu-Buandoh \& Otchere, 2012; 
Opoku-Amankwa, 2009a) because of national assessments. As such it is important to examine the language of the curriculum in its entirety regarding the place of English and Ghanaian languages in education.

\section{Definition of Key Terms}

Colonial/Post-colonial: McClintock (1994) argues that post-colonial assumes that the colonialism ended when countries gained independence from their colonial masters. She argues that there are many "post-colonial" countries today that have experienced Western military invasion very recently and so the term post-colonial does not adequately capture people and countries still under "direct territorial appropriation of another geopolitical entity” (p. 257). In this study, however, I use the term colonial to refer to the period (including policies and practices) when the British had direct territorial and political control of the Gold Coast and postcolonial to refer to the period after Ghana gained independence from the British.

Curriculum: Broadly speaking the school curriculum includes both spoken and unspoken rules that govern practices in school (Anyon, 1981; Giroux \& Penna, 1979). In this paper, however, curriculum refers to a set of documents detailing the goals, policies, practices, and structure of an educational program including courses that will be studied at each level of schooling. Each course also has its own document that includes policies and practices that should guide teaching and learning in addition to topics that students should know by the end of a specific period and information about how students will be assessed. 
Discourse: Discourse is considered language-in-use (Gee, 2014), and how the meaning implied by the language we use shapes identities, relationships, what we consider significant or not, and our ways of being in the world.

Ghanaian languages and cultures: Ghanaians speak about 68 languages (Batibo, 2005). Looking at varieties of these languages or dialects among the 68 languages extends the number to approximately over 200 distinct cultural and linguistic ways of being. The term, Ghanaian languages and cultures, does not capture all the differences about the many linguistic groups in Ghana, but I use Ghanaian languages and cultures as an umbrella to group them as different from the languages brought by colonialism to the region.

Linguistic imperialism: This describes how languages impose their dominance in social contexts in a way that marginalizes and devalues not only other languages within that context but other non-dominant ways of speaking, doing, and being (Phillipson, 2009).

Literacy: This refers to people's interactions and practices with texts. Traditionally, literacy referred to being able to speak and read in the standard form of a national language. Today, literacy extends beyond just reading and writing in one standard national language with a pen or pencil on a paper (Knobel \& Lankshear, 2006, 2014). Scholars view literacy today as "multi-literacies" and that implies having different ways of reading and writing the world in different languages, modes, and cultures (Gee, 2006; New London Group, 1996). In this paper, this expanded view of literacy is what I refer to when I discuss incorporating Ghanaian literacies into the curriculum 


\section{CHAPTER TWO: LITERATURE REVIEW}

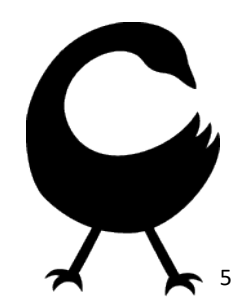

It is impossible to discuss current educational issues including policies, practices, and curriculum reform in Ghanaian education without looking back into history to learn how those issues were shaped in the first place (Aziabah, 2018; Dei \& Asgharzadeh, 2001). Pennycook (1998) argues that because colonialism is deeply rooted and intertwined in the daily life and practices of formerly colonized nations, the effects of colonialism did not end when the colonial master metaphorically sailed away from their former colonies. Pennycook (1998) suggests that by the time colonies gained independence, colonial policies, practices, and preferences had already become ingrained in the day-to-day life of the formerly colonized. Therefore, any study into how to address inequities in the current educational systems in former colonized countries must look back into how both colonial and post-colonial policies and practices created these inequities in the first place (Aziabah, 2018). I recognize that the words colonial and postcolonial are viewed as problematic because they center history around the single framework of an European time, which assumes colonialism had a final endpoint (McClintock, 1994). However, in this chapter, colonial refers to the period before a country gained its political independence from an European colonial ruler, and postcolonial refers to the period after independence.

\footnotetext{
${ }^{5}$ This symbol of the Akan people in Ghana is called "Sankofa" which means the need to learn from history. This knowledge shapes my literature review to understand historically how dominant discourses in English came to exist in Ghanaian education and society (see adinkra.org).
} 
The goal of this literature review is to show how the current preference for English in Ghanaian education was established and to identify where the educational curriculum including content, teaching and learning activities, and assessment policies falls short in privileging, affirming, and valuing Ghanaian languages and cultures. The underlying question I asked throughout this chapter is, how can the national curriculum in a formerly colonized country like Ghana change dominant discourse about the English language and bring value to Ghanaian languages and ways of being in education? I recognize the tension of providing students access to a code of power because of its economic and social power at their expense of their own language and culture and so I draw from South African scholar, Hilary Janks, who grapples with these issues in postapartheid South Africa and theorizes how a critical approach to education in formerly colonized countries might deconstruct dominant English discourse to make way for a reconstruction in education that centers the native languages, cultures, and ways of being (Janks, 2000, 2013).

In this review, I discuss the history of the education in Ghana and how colonial and missionary policies and practices in education created and strengthened discourses of English education. I also review the work of Ghanaian scholars who challenge the discourse that a dominant English education leads to educational achievement and social mobility for Ghanaian students. Finally, this review covers language policies across the African region and discusses how other countries with Ghana's similar legacy of colonial policies, practices, and influences in education have continued to struggle to privilege their own languages and culture in mainstream education. This chapter demonstrates how dominant discourses of English superiority and the inferiority of Ghanaian languages and 
cultures are transmitted to students and to society through the curriculum which explains the need to study the curriculum to learn how these discourses are reinforced. I divide this chapter into three main sections. Sections A focuses on the history of Ghana's educational system and how the history of how English invaded the Gold Coast (former name for Ghana) and stayed until current times. Section B focuses on empirical research on the impact of maintaining English in education and how Ghanaian languages centered in the curriculum promote student participation, engagement, and achievement. In the final section, Section C, I apply the theory of English linguistic imperialism that studies how English continues to dominate in formerly colonized countries, to explain how false narratives about English maintain the discourse of English as best in multilingual countries. I also combine Janks' $(2000,2013)$ work in critical literacy with false narratives of English linguistic imperialism to discuss how an examination of Ghana's curriculum can begin to deconstruct the discourse that the English language is best in educating Ghanaian in order to reconstruct a new discourse where the curriculum centers Ghanaian languages, cultures, histories, and local knowledge.

\section{Section A: History of English in Ghanaian Education}

In this section, I discuss how the first schools were established by missionaries and traders who arrived at the Gold Coast ${ }^{6}$ in the $16^{\text {th }}$ century. I explain how their decisions and policies to use either the local language or a foreign language in instruction primarily served the interests of these foreigners and colonialists on the Gold Coast. I also discuss how the British colonial government after solidifying their rule over much of the Gold Coast from the 1850s, promoted and encouraged the use of English throughout

\footnotetext{
${ }^{6}$ Gold Coast was Ghana's name before independence.
} 
schools in the colonies. Together, the colonial government and missionaries work in education, created discourses that portrayed Ghanaian languages and cultures as inessential to educating and civilizing the native.

\section{The First Schools and the First Language Policies (1500s - 1850s)}

From the $16^{\text {th }}$ century, various European traders and missionaries arrived on the Gold Coast to trade, evangelize, and eventually to colonize the Gold Coast. The Portuguese were one of the first groups to arrive on the Gold Coast as traders in the 1500s at Elmina (a southern coastal town). The Dutch took over their forts in 1644 while the Danes established their settlements in Christianborg in 1727. The British, on the other hand, set up their settlements in 1751 in Cape Coast. All these groups established schools along the coast, either in their forts, castles or within their settlements initially for youth called "mulattoes" (children of both European and African parents) and some children of African traders (George, 1976; Martin, 1976). The lands on which these forts, castles, and schools were built were often purchased from the local community or given by the native rulers in exchange for protection from invaders, and other local rival tribes and kingdoms. In exchange, some native rulers also requested that children of elders and rulers receive the western education provided by these foreign traders in their forts and castles (Graham, 1971).

It should be noted that each of these foreign groups used their own national languages in instruction within these first schools (Graham, 1971; Martin, 1976). There is also evidence that some of these traders schooled and trained children of African traders and rulers in their own countries abroad as missionaries, interpreters, and priests (Graham, 1976). This system of using a foreign language benefitted a handful of people 
but it inevitably started distinguishing those who had access to western education in these languages from those who did not.

There are accounts of the Dutch for example who sent children to Holland for further education. Jacobus Capiten, a native with a Dutch name, was one of these students. It is recorded that at the age of nine Capiten was sent by a Dutch trader to Holland and after nine years of schooling he was admitted to Leyden University in 1737 (Martin, 1976). He was later ordained as the first African Protestant priest and then sent back to the Dutch Company, a mercantile company at Elmina, where he conducted services in the Castle. His story is important because it is recorded that his main contribution was in codifying and writing the local Fanti language. He later had the Lord's Prayer, the Ten Commandments, and part of the catechism published in Fanti. His work went a long way in the development and promotion of the Fanti language a century later (Graham, 1971; Martin, 1976).

At the time of Capiten's death at the age of 30, the Elmina School was well established and had a stable population of about 400 boys and girls (Graham, 1971). There is no evidence, however, that Fanti was used as a language of instruction at the school because although he taught natives, the school mainly included children of mixed parentage - mulattoes. This meant because one of their parents was a member of the Royal Dutch Company, the Dutch Charter of 1621 required their children to be proficient in Dutch (Graham, 1971). According to the charter, Christian schools were to be established wherever the Dutch traded in accordance with the teaching of the Dutch Reformed Church. Children in these schools were taught to advance the Christian faith, 
respect Dutch Authority, and they also had to become experts and proficient in the Dutch language (Graham, 1971).

\section{Language in the Missionary and Castle Schools}

Ralph Wiltgen, who wrote Gold Coast Missionary History from 1571-1880, recorded that the year 1529 saw the conversion of the settlement of the Elmina to Catholicism (Martin, 1976). King John III of Portugal instructed the Governor at Elmina in 1529 to provide reading, writing and religious instruction for native children (Graham, 1971). The medium of instruction was Portuguese. The Danes through the Moravian Protestant Church had also set up a Castle school in 1737 and as expected education was instructed in the Danish language (Martin, 1976). The Danish governor, Major de Richelieu, who governed the Christianborg Castle from 1822 to 1825 is reported to have even taught some of the students at the castle himself (Martin, 1976). When he returned to Denmark, he advocated for more education and missionary work at Christianborg and this led to the arrival of the Basel missionaries whose work revolutionized education in Ghana.

Unlike other missions, the Basel missionaries were the first to intentionally adopt the native language of their local settlements as a language of instruction in education because they believed it was relevant for the education of the natives and a proper teaching of their religious faith (Martin, 1976). While European traders and colonialists had initially offered education only in their language to a few people, the Basel missionaries, with the intent to strengthen and ensure that their evangelizing efforts were successful, used the native language in educating the natives specifically to convert them. 
Converting and Civilizing the Native Through Education. The increasing

presence of trade and established trading posts brought missionaries to the Gold Coast to convert the native often through schooling. The three main groups were the Basel at Christianborg in 1843, the Wesleyan Methodist at Cape Coast in 1835/8, and the Bremen in the Volta in 1847. These groups differed on how they approached their mission work in converting the natives. The Wesleyan Methodist in Cape Coast, where the British settled, insisted on using English for instruction in their schools. The Basel mission, on the other hand, believed that the gospel would be spread effectively if converts were taught to read the Bible in their own language. As a result, their curriculum was developed in the local language of the Akuapem and Ga areas where they were established (Anyidoho \& Kropp-Dakubu, 2008). The Bremen mission would do the same with the Ewe language in Ewe-speaking communities near the Volta River (George, 1976).

The Basel and Bremen Mission. The Bremen mission established schools in 1847 among the Ewe who lived further inland, away from the coast. They also adopted the Ewe local language as a language of instruction in their schools. Anyidoho \& KroppDakubu (2008) suggest that the Bremen adopted Ewe as a language of instruction in schools because, being German, they did not want to encourage the language of their British competitors on the coast. Scholars argue that these two missions - the Basel and Bremen - laid the foundation for indigenous language education in Akuapem Twi, Ga, and Ewe. Between 1853 and 1905, they produced primers and readers for school children, grammars, dictionaries, Bible and many reading materials in these local languages (Anyidoho \& Kropp-Dakubu, 2008). Here, what scholars of history often miss 
is that the foundation that these missionaries laid for indigenous language education by codifying and creating the script for these Ghanaian languages also restricted the use of Ghanaian languages because the materials produced in Ghanaian languages mostly focused on religious teaching in schools (Bening, 1976). As such, Ghanaian languages would not be seen as inherently valuable for mainstream education for many decades. On the one hand, while indigenous language education is attributed to these missionaries, their efforts determined the scope and place of these indigenous languages in educating Ghanaians. These scripts were primarily tied to religious instruction and learning the ways of being of these missionaries (Bening, 1976).

Miescher's (2005) collection of life stories of eight Ghanaian men who lived during the colonial period included accounts of how missionaries set up separate settlements to house and separate local converts and their children from the outside community so that they would not be influenced by the falsely labeled barbaric, uncivilized, and evil ways of the unconverted native. Some of these men recounted as children how they were prevented by missionaries from playing with other young children who lived in the community (Miescher, 2005). These practices, for instance, started to categorize or divide the natives into camps, the converted versus the sinner, the educated versus the illiterate, and the one who behaved like the missionary versus the one who did not.

The Wesleyan Mission. The Wesleyan mission, unlike their Basel and Bremen counterparts, emphasized English in their school curriculum. Graham (1971) included a prospectus of the Wesleyan High School founded by the Wesleyan mission in Cape Coast dated 19th March 1876 in Appendix D of his book (p. 192). The first subject listed in the 
school prospectus was English. All other subjects offered and studied at the school apart from English were grouped as "extra studies." These subjects were Classics, Mathematics, Sciences, and Modern Languages. Under Classics, the subjects studied were Latin and Greek. Geometry and Mensuration, Algebra and Trigonometry were studied under Mathematics. Chemistry, Animal Physiology and Natural Philosophy were part of the Sciences and French was the only other language studied at the school under Modern Languages. All subjects were instructed in English except French. No native languages were taught in the school (Graham, 1971).

Although it is not stated in the prospectus, a reader can infer that English was compulsory for all students because it was separated from Extra Studies. The cost of English education was also higher compared to other subjects. English cost 20 to 21 shillings, about $£ 59$ in today’s currency. The other subjects under Extra Studies, on the other hand, cost only 7 shillings and sixpence each, only about $£ 23$ in today’s currency. It can also be deduced that parents who could barely afford to educate their children would probably pay for them to study just English as opposed to paying extra for the rest of the subjects. There is, however, no evidence to support this assertion. What is obvious is that the cost of an English education was valued higher than any other subject and in addition, no native languages were either taught in the schools controlled by the Wesleyan mission or used as a language of instruction by this time.

\section{Demand for English Education by Natives}

By the 1870 s, the Wesleyan Mission briefly produced books in the Fanti language for use in schools it was because they realized it helped in convert the natives to Christianity (Wriggley to the Secretaries, 1835-71, as cited in Graham 1971, p. 126). 
According to historians, it was Africans, who were educated abroad who questioned the production of these primers in the Fanti language. Anyidoho and Kropp Dakubu (2008) suggested that perhaps it was because these African educated elites wanted similar English instruction for Ghanaian locally as they had received abroad. Another explanation could be that these African elites felt denying the native English instruction would deny Ghanaians access to places of power in the struggle for independence. However, there is no concrete evidence to support this explanation as well.

Historians recorded that two Ghanaian scholars who were educated abroad, J.E. Casely-Hayford and John Mensah Sarbah opened their own schools in the south using the Fanti language as a medium of instruction in the latter part of the $19^{\text {th }}$ century (Anyidoho \& Kropp-Dakubu, 2008). Scholars suggest that their schools failed because students demanded English-style professors certified by examining bodies in England (Anyidoho \& Kropp-Dakubu, 2008). This suggests that by this time during the $19^{\text {th }}$ century, the discourse about an English education being better than an indigenous language education had seeped at least into territories controlled by the British. So as the British gained control over the Gold Coast and the Crown actively increased its role in education by setting up schools, the English language medium became increasingly common in schools in the colony and it spread quickly as education was tied to funding and support from the colonial government.

\section{Summary}

The practices and policies of missionaries in using Ghanaian languages raises several questions. Why were Ghanaian languages utilized by these missionaries and educational institutions only when it promoted their own evangelizing agenda - to make 
the natives better understand religious materials and instruction in order to convert them? If Ghanaian languages helped the natives better understand, in general, what they are learning, why not use it throughout education? In this section, we see that Ghanaian languages from start were seen only as tools in teaching English but especially to convert the native.

\section{English in the Colonial Schools (1850 - 1951)}

\section{The Spread of English Medium}

During the latter half of the $19^{\text {th }}$ century, the British claimed the Southern territory of the Gold Coast as an official colony of the Crown (Martin, 1976). The British colonial government started setting up schools and also assisted missionaries and individuals to open up schools with certain conditions. English medium instruction was one of the conditions for government support. Graham (1971) recorded that support from the government included textbooks and school supplies that were brought from England. By

1881 both government and government-assisted schools were 139 but there were also about 120 non-government schools in the Gold Coast (George, 1976). These nongovernment schools were often started by native rulers who hired missionaries or English trained teachers to teach children in their schools.

Also included in the non-government schools were schools started by missionaries in the northern half of the Gold Coast where British presence was absent (Bening, 1976). English medium still dominated instruction in these schools (Graham, 1971). From 1909 to 1925 , the curriculum in the north covered these subjects: English language reading, writing, some elementary arithmetic, and history (Bening, 1976). In terms of the history course, for example, history referred to the history of the British 
empire and so students were required to learn about the empire that had colonized them (Bening, 1976).

Teaching the English language and history of the empire was considered the way to civilize the native but when these missionaries realized that to properly convert the native they needed to use the native languages (Bening, 1976), Ghanaian languages were then introduced in religious instruction and elementary education. Dagaare was used in the Wa area, Mampruli in Gambaga, Kasem, Buli and Nankan languages in Navrongo, Hausa and Gonja in Salaga, and Dagbani and Hausa were used in schools in Tamale. These missionaries spearheaded efforts to develop the codes and scripts for these languages. By the 1940s, in the north, the progressive use of English in education called for more English medium from students and parents even though "the use of these [Ghanaian] languages was marked by quick grasping, increased pleasure and interest in learning" (Bening, 1976, p. 69). On a visit to one of schools in the Wa community, the governor of the Gold Coast colony, insisted that "the school should aim at thoroughness in speaking, reading and understanding of English and no pupil was to be promoted until his progress in the English language was satisfactory" (Bening, 1976, p. 67). Once again, we see that although the local languages were helpful, it was seen mainly as an evangelizing tool and English was touted as the standard of a good education.

\section{The Phelps-Stokes Commission}

The British colonial administration had a great interest in education in their colonial territories and in order to improve their efforts they invited the Phelps-Stokes Commission from America to conduct a review of education in West, South, and Equatorial Africa and to make recommendations in the early 1920s. The members of the 
committee were scholars based outside of Africa, medical and educational missionaries, supporters of industrial-type education for Negroes in America or supporters of separate educational development for people based on their race. The only Ghanaian who was on this committee was a Ghanaian who studied abroad and lived most of his adulthood outside of Africa as a professor in America. Brown (1964) argued that the interests of the members of the committee made its way into the reports they produced, one in 1922 and another later in 1925. According to Brown (1964), the interest of the African was not represented in these reports as described in the following paragraph.

The Phelps Stokes Commission recommended to the British Colonial government that local languages should be employed in education as languages of instruction in British Africa. However, they insisted on the need for mass education that was centered in teaching "elements of good agriculture, and good hygiene, and to give them [natives] training in simple crafts and home economics" in addition to "decencies of home life, healthful recreations, and character" (Brown, 1964, p. 367). Even though the commission claimed that education should be tied to the indigenous culture of the native, their recommendation suggested that the ways of being, practices, and the character of the natives did not match what they felt was a decent and hygienic home life and character. In other words, education should focus on helping the natives to become civilized as the colonialists. Clearly, education, similar to the practice of the missionaries, was to use the local languages not only to convert the natives but also to make the natives change their ways and practices to become like those of their educated and "decent" colonizers. Brown (1964) discussed that the Phelps Stokes Commission did not even consider that Negro scholars in America were critiquing the industrial type of education promoted by 
the Tuskegee Institute because it affirmed the inferiority of the negro in mainstream education because their recommendations for education in British Africa suggested the same type of education.

\section{English Assessment in Education}

By 1937, the colonial administration required that all teachers in training complete a certification examination in a Ghanaian language. Ghanaian languages were to be taught as subjects for the first three years but progressively reduced because assessments to ensure further education were being conducted solely in English. We know from George (1976) that by 1949 the students taking the external Cambridge school certificate examination after completing basic secondary school were close to double the 400 students who sat the exam in 1940. Although we do not know how many passed, these examinations that certified completion of secondary education were conducted from England and that reaffirmed the need for English education and English literacy and proficiency in the Ghanaian society.

\section{The Acceleration of English Towards Independence (1951-1956)}

By 1951, Ghanaian elites had gained representation in the colonial government and also led the legislative assembly in the Gold Coast. They created the Acceleration Development Plan (ADP) of 1951 to speed up educational efforts in the colony. What was different about this educational policy from earlier policies and practices was that the government would assume control of all schools under the colonial territories and protectorates. Schools that were then approved by the government would be eligible for public funds such that approved schools had to cancel tuition fees (George, 1976). According to the policy, the government would support a tuition-free 6-year primary 
school education for every child. What was similar to earlier colonial practices is that this Acceleration Development Plan insisted on English instruction while maintaining the use of local languages only during the first year of schooling (George, 1976).

The Ghanaian-led legislature who created this educational developmental plan wanted to achieve rapid expansion of education at least by 1957 . The plan was not realized. In most schools, pupil teachers were placed in charge of instruction while the government increased facilities to train teachers who would administer instruction in English (George, 1976). These pupil teachers were not trained teachers but anyone who had received 10 or more years of schooling and that meant that students could go through schooling having proficiency neither in English nor in their own languages.

The ADP focused on mass education quickly in the English language. It did not stress any change in curriculum that would emphasize local histories and knowledge but was mostly an expansion of the existing colonial educational practice. Scholars of history seldom discuss the content of the curriculum because western education mainly referred to western practices and forms of knowledge in teaching and learning (Graham, 1976). It is not surprising that the ADP changed little about the content of the curriculum. What is obvious is rapid mass education, mostly in the south and middle belt of the country, and little education in the northern territories (George, 1976). The ADP also did not include any reform or change in curriculum content (Aziabah, 2018), that suggests that there was not a focus on the development of local literacies, languages, and knowledge. Rather what we see is the spread of the missionary and colonial educational practice coupled with earlier recommendations by the Phelps Stokes Commissions.

\section{Rapid Expansion of English Education After Independence (1957 - 1966)}


By the independence year in 1957, there were about 425,000 students who had received primary education compared to the 120,000 in 1951 (George, 1976). A Ghanaian government appointed in 1956 committee, tasked to review the use of English medium stipulated in the Accelerated Development Plan and the possibility of using English from the first year of schooling, found that it was not feasible to use English from the first year of schooling because of a lack of competent trained teachers with English proficiency. Out of 1652 schools, the committee found that more than 76 percent never use English as a medium of instruction. Only about 16 percent used English in the fourth or fifth year, that meant students were inadequately prepared for national examinations in English to even progress to middle school. They recommended a gradual shift to English only medium for all subjects in the fifth year but they still insisted that religious knowledge should be instructed in the Ghanaian language (George, 1976).

Even though the government did not follow the recommendations of the report and insisted on English instruction by the second year of schooling, the committee's position on the continual use of Ghanaian language for religious instruction reflects the colonial and missionary practice of using Ghanaian languages. Ghanaian languages were deemed useful to help students understand religious practices and behavior, I argue, of foreign missionaries and Europeans, but the same argument was not used for other subjects. If Ghanaian languages were that helpful to train and convert the native because it facilitated easy comprehension, it could have been even more helpful in imparting academic knowledge as well.

Nevertheless, George (1976) noted that there were disparities in educational infrastructure and trained teachers especially in some areas in the middle and in the 
northern half of Ghana, which indicates that the Accelerated Development Plan had still not captured every child of schooling going age. A lot of the literature on Ghana's history in education omits the fact that the government recruited teachers from the UK and the US including the Peace Corps as part of providing mass free education to students during this period to fill the void of locally trained teachers competent in English (George, 1976). This practice continued into the 1960 s because there were still not enough Ghanaian qualified teachers for all levels of education and this meant that a large portion of students did not have a Ghanaian teacher in front of them. This practice, I argue had implications for whose ways of speaking, doing, and being Ghanaian students were to embody. However, there is not enough discussion in the literature about this import of foreign teachers to make this argument. Yet from what we know from George's (1976) history of education in Ghana, because of the Ghanaian government's stress of English and the lack of reform in curriculum content that privileged Ghanaian literacies, languages, and knowledge, it was more likely that students learned to value their foreign teacher's ways of speaking, doing, and being more than their own. This discourse of English education (and English/Anglo teachers) being the best form of education was not new at this point but a reinforcement of colonial educational practices (Anyidoho \& Kropp Dakubu, 2008; Bening, 1976).

By 1961 the administration of the now independent Ghana introduced fee-free education for middle and secondary schools like it had done for primary schools through the ADP in 1951. The government, however, could not expand middle school education as it had done for primary school education because the government had undertaken so many developmental projects like establishing teacher training colleges, universities, and 
secondary schools at the same time (George, 1976). By 1966, as the economy slowed, the first Ghanaian president was overthrown by the military because the president was establishing himself as a dictator and the economy was also in decline largely due to the many developmental projects the administration had overtaken. Education had been the largest single expenditure on the budget (George, 1976) and the largest portion went to fund higher education and scholarships for a few qualified students to study abroad.

The military government complained that there not nearly enough students in higher education to justify government expenditures in higher education. George (1976) suggests that the previous administration "had paid a very high price...expenditures on education had spiraled upwards because the system had grown so fast and also because the central government had assumed responsibility for certain costs previously borne by parents and the local governments" (p. 52). The subsequent military and democraticelected governments scrutinized the entire educational system from 1966 to 1989 and made certain changes to education both in curricular content and policy.

\section{Cementing English Medium in the Curriculum (1966 till date)}

This section details the specific changes made to education in the content of the curriculum, policies, and the structure of education on how these practices solidified English medium moving forward. Although the government policies and the curriculum indicated that Ghanaian languages were helpful in education, they did not promote it as useful in teaching and learning beyond earlier years of schooling, and they did not deem it as central to the entire educational process. Ghanaian languages when used, were a means to help students transition to English and afterward they were progressively reduced as Phelps Stokes Commission had recommended during the colonial period. 
It should also be noted that from 1966 to 1992 Ghana had seven governments five military regimes and three democratically elected governments who were overthrown by some of these military regimes, so this was a period of political and economic instability. Almost all governments during this period reviewed the entire educational system and made changes either to the structure, curriculum, or policies in Ghanaian education. In the following paragraphs, I only discuss changes that directly or indirectly highlighted the position of English and Ghanaian languages in education.

\section{Making Policy and Curriculum Changes to Education (1971 - 2001)}

K. A. Busia's government of 1971, after their review of education, recognized that even though the ADP of 1951 and the first Ghanaian administration had required Ghanaian languages to be used during the first year of schooling, the policy was applied loosely (George, 1976). Busia's government, therefore, specified a new language-ineducation that required teaching in Ghanaian languages for the first three years of schooling (Ansah, 2014; George, 1976). The government and the Ministry of Education outlined goals in English that students should still attain during the first three years of schooling nevertheless. For example, "reading and writing in English, as well as speaking and listening [in English], should begin in the first year" (George, 1976, p. 120).

However, looking at the curriculum it is clear that the number of minutes per week spent in Ghanaian language instruction was similar to instruction in English for the first three years so while the language of the policy seemed to champion Ghanaian language medium for the first three years, the practice was far from the policy (George, 1976).

More Time in English. Apart from the language-in-education policy, the structure of schooling and the curriculum including the courses offered to students for 
pre-tertiary education is indicative not only of the value placed on English and Ghanaian languages, but also of what students were expected to learn about their own languages, cultures, and history. The elementary and middle school period by 1972 spanned 10 years. Students were to study the following courses: Ghanaian language, English, Mathematics, Elementary Social Studies, Nature Study or Experimental Science, Health Education, Arts, Crafts or Needlework, Music, Physical Education, and Religious Instruction. According to Ansah (2014), the military government in 1972 added the study of French to the curriculum, "to promote regional communication with neighboring Francophone countries" (p. 6). Languages took a greater portion of the time allotted for study which progressively favored English in practice in education. Even in the English syllabus for elementary schools in 1972, it was stated that "citizens with little or no knowledge of English are handicapped, sometimes severely" (as quoted in George, 1976, p. 114).

According to George (1976), "throughout the first 6 years more than half the time devoted to all subjects in the curriculum (full time less that for assembly, registration, and breaks) in schools not on a shift system is devoted to language and mathematics" (p. 122), which increasingly favored English instruction. The textbooks being used by this time were developed in the 1960s and were mostly written in the English language (George, 1976). George (1976) also records that for the 10 years of primary and middle schooling, there was one textbook for every year in these Ghanaian languages: Akan (Asante Twi, Akuapem Twi, and Fanti varieties), Ewe, Ga, Nzema, Gonja, and Adangbe. By 1974 an additional component was added to the language-in-education policy that increased the number of Ghanaian languages offered as courses of study in primary and 
middle schools. The added languages were Kasem, Dagbani, and Dagaare. The 1974 policy still supported Ghanaian languages as mediums of instruction in the first three years of education depending on the majority language spoken in the school's community (Ansah, 2014). However, the increase in policy support for Ghanaian languages did not translate into the development and production of teaching and learning materials for content subjects in Ghanaian languages especially since national assessments were in English.

National Assessments in English. In the 1970s, students in pre-tertiary education who wanted to go further in education had to pass three national examinations that were conducted in English. The Common Entrance Examination (CEE) was the first exam that determined progress into secondary education. Between the $8^{\text {th }}$ and $10^{\text {th }}$ years of schooling, any student could sit for the CEE. George (1976) argues that given its importance, teachers perhaps spent most of the time during these years preparing for the CEE. The examinations were conducted solely in English and they examined only English and Math ability. It consisted of "an objective test in English, an objective test in mathematics, an English composition paper, and verbal and quantitative aptitude tests" (George, 1976, p. 133). Because the CEE gave an advantage to students who had been well prepared in English, policies that favored Ghanaian languages medium even though helpful, failed students who were not proficient in English and that strengthened parents' and students' demands for more English instruction (Mfum-Mensah, 2005). The number of Ghanaian languages as courses of study increased but their value did not because of the structure of education and curriculum including assessments favoring those with English proficiency. Although in recent times, students are only required to pass only two 
national exams to gain admission into senior high school and another for college, these assessments are conducted in English except for the French and Ghanaian language subjects. This suggests that there is a need to study how the curriculum in its entirety silences Ghanaian languages and literacies and props up English in its content, teaching and learning activities, and assessment practices.

Ghanaian Language Courses Made Optional. In 1989 that another military government, the Provisional National Defence Council (PNDC) required that Ghanaian languages become examinable in junior and senior secondary schools in public schools. By 1994, however, the democratically elected government determined after conducting a review of education that because the number of courses students were studying were too many, Ghanaian languages as a course was made optional, in order to focus more on the other subjects in education. No new substantive changes were made to education until 2002.

English Only Language-in-Education Policy (2002 - 2007)

The 1974 language-in-education policy discussed above with nine Ghanaian languages used as mediums of instruction lasted till 2002. In 2002 the newly elected government instituted a new language-in-education policy that required that all instruction in education at all levels was to be conducted in English (Opoku-Amankwa, 2009a). The government's position was that a majority of schools did not transition to English by the third grade such that teachers continued to use the Ghanaian languages in teaching in later years and that left students unprepared for national assessments conducted in English (Opoku-Amankwa, 2009a). The government argued that there were not enough textbooks and teaching materials in Ghanaian languages and they were also 
not enough teachers trained to instruct in Ghanaian languages, which was a similar reason used by the first Ghanaian government to justify the emphasis on English instruction in the 1950s and 1960s. Decades later the same reason was being used to undo Ghanaian languages medium for English only medium rather than developing teachers who could instruct in Ghanaian languages.

The government's position was therefore not new, and it generated debates on the value of Ghanaian languages and African languages in general. Some policymakers, parents, and children, on one hand, supported an English-only policy because they believed students would be better prepared to pass examinations that are conducted in English to further their education (Ansah, 2014; Mfum-Mensah, 2005). On the other hand, researchers, scholars, linguists, educators, and other policymakers argued that stripping Ghanaian languages in education worsened the disparities in educational attainments for many students whose home language was not English. In section B, I present and discuss some of the findings of these studies to highlight the two positions.

\section{Ghanaian Languages, Where Necessary but Not Required (2007 to date)}

I will add, however, that the government reversed their decision in 2007 to use English only medium in education after strong opposition and criticism from Ghanaian scholars, researchers across the continent, and the African Union which declared 2006 as a year of African languages (Ansah, 2014; Opoku-Amankwa, 2009a). The government re-instituted the previous language-in-education policy of 1974 with some changes. Rather than require Ghanaian language medium for the first three years of schooling, the rule was to be applied loosely where necessary depending on the school and the locality. English medium was, however, required by the fourth grade. Ghanaian languages 
medium, the government suggested, were now to begin in kindergarten, but English was also to be introduced at this point to students (Ansah, 2014). While this policy stands till date, there is neither government enforcement of Ghanaian language medium in these first years of primary education nor is there increased training of teachers who can carry out these instructions nor extensive development of textbooks and teaching resources in the Ghanaian languages (Owu-Ewie \& Eshun, 2019).

\section{Summary}

This history of English in Ghanaian education might seem like a long one but it is not. In the $18^{\text {th }}$ and $19^{\text {th }}$ centuries missionary and colonial schools, working together, eventually championed the need for the natives to be educated in the English language because English was touted as the language of the civilized and the way to civilize and train the African native (Fanon, 1952/2008). The script for Ghanaian languages in education was developed by these missionary and colonial forces when they recognized that for the natives to deeply understand religious instruction, they needed to learn it in their own native languages. Ghanaian languages were, therefore, primarily developed in education as a tool to evangelize and convert the native, yet English was heralded as a language the native had to learn to become civilized. This contradiction would set the set up the stage for English as the language of commerce, jobs, and education while Ghanaian languages were deemed only as helpful for religious instruction.

By independence however the colonial practice of using English even though it disadvantaged many students had become entrenched. English was considered by policymakers as essential for literacy and national development but the lack of infrastructure, teachers, and teaching resources in English meant that few people 
benefitted from an English education creating inequities. Later educational policies recognized the importance of Ghanaian languages, but it was also built on the assumption that students' attainment of English proficiency and literacy was the only way to set up an educational system (Bening, 1976; George, 1976). I agree with Aziabah (2018) that our educational system has been systemically and historically built on this assumption that educational success means English proficiency and literacy and because of our colonial legacy we have been on autopilot since independence solidifying a system that was built not with our best intentions, cultures, languages, and knowledge at the core. This next section, focusing on empirical research, will address how scholars are beginning to question the practices at the core of Ghanaian education.

\section{Section B: Ghanaian Languages Through Research}

In this section, I present and discuss a variety of empirical studies that have questioned the place of English in education in Ghana by looking at how using Ghanaian languages and teaching literacy in Ghanaian languages to students affect the educational experience and performance of students. I discuss literature on what students, parents, and educators believe an English education or a Ghanaian language and literacy centered education affords them. I contrast these two views with the empirical literature on students' performance in both orientations to education. I also discuss literature from other countries in the African region like Tanzania and South Africa with a similar legacy of colonialism to demonstrate how an English or African languages centered policy and practice in education shape students learning.

\section{Ghanaian Languages Improve Learning}


From the history of Ghanaian education, we know that early missionaries and the colonial government, based on the Phelps-Stokes Commission report, felt that using the native languages helped students understand better what they were taught (Brown, 1964). We also know missionaries, and later colonial schools used Ghanaian languages as a tool to Christianize and civilize the natives who they felt were savage in order to give "them the ways to come out of their state of degradation, idleness and inertness" (Bishop Morin, as quoted in Bening, 1976, p. 61). Ghanaian languages, cultures, and history, however, were not considered vital to the entire educational process because English literacy, the language of the colonizer, was considered the language of educational success. What I must therefore ask is, how helpful are Ghanaian languages even as mediums of instruction for students?

The first major study that compared instruction in English to instruction in a Ghanaian language was Collison (1974). This Ghanaian scholar conducted an experiment to test the idea that students were able to express themselves better when they received instruction in a Ghanaian language than when they were instructed in English. Eightyfive students in the sixth grade from two schools participated in the study. One school was in a Ga-speaking community and the other in a Twi-speaking community. These students had studied English for about 6 years. In each school all students were randomly placed in two groups, one group observed and participated in a science lesson conducted solely in English and the other group observed and participated in the same science lesson but conducted either in Twi or Ga depending on their community language. Students were then asked to describe and write down what they had observed in the language they were instructed. The findings were significant. The group who received 
instruction in either Twi or Ga made more and complex statements using analogies to describe what they learned. In the English group, however, students could not fully express what they had learned. The study also reported more errors in English than in the Ga or Twi. Qualitatively, Collison (1974) also found out that teaching complex science experiments in English impeded understanding of simple concepts and as a result concluded that Ghanaian languages helped students learn better at even higher levels of schooling.

More recently, Opoku-Amankwa (2009a) conducted 60 classroom observations of teachers' and students' interaction in a fourth-grade classroom in addition to interviews with 11 teachers, two school leaders, and 20 students in a public primary school in Ghana. Although all the students in the study came from different language groups, they all spoke and understood Twi, the local language of the area. What is unique about this study is that Opoku-Amankwa (2009a) observed how language policy requiring the use of English at this point in education was enacted in the classroom. The study found that students who were unable to read fluently in English without any teacher support were often ignored, less likely to be praised, and quickly passed over by their teachers to allow a more competent English student to contribute in class discussions. Teachers selectively chose students who they knew would answer and speak English proficiently over students who they knew struggled with English. Opoku-Amankwa (2009a) asked teachers about how they felt their selective attention to highly proficient English students might negatively affect their students who were not as proficient. The teachers blamed students' lack of English proficiency on "poor parental and home support and other factors, 
indicating most of the children are lazy" (p. 255). Because teachers felt that students who could not speak English proficiently were lazy, they often punished them in class.

One teacher referenced the Bible saying that "when you spare the rod, you spoil the child" to justify their use of corporal punishment to make sure students learn how to say English words. The teachers were seemingly frustrated that a majority of students could not even "read a simple sentence or even spell a three letter word like boy" (p. 256). A student when asked by the author complained that each time he tried to contribute in class and he made a mistake, the teacher "whips me [with a cane] so I always feel shy and reluctant to take part in class discussions" (Opoku-Amankwa, 2009a, p. 256). This notion that a student who cannot speak English well because they are lazy is not new; missionaries before independence felt that the native was idle, uncivilized, and savage and as a result needed training through religious instruction and English to instill a sense of civility and discipline, as shown in the previous section of this chapter. Miescher's (2005) ethnographic life stories of Ghanaian men who lived in the colonial, independence, and post-colonial periods also include accounts of the strict disciplinary practices and rules of missionary school so children of converts would not mix and behave the same as their non-converted neighbors.

In Opoku-Amankwa's (2009a) study even though the teachers in the fourth-grade classroom identified only 7 students out of their combined 70 as proficient in English, they did not recognize that the English language was a barrier to classroom participation and comprehension. In a second paper, Opoku-Amankwa (2009b) used a case study approach this time to highlight the experiences of these students in Opoku-Amankwa (2009a) who could not speak English proficiently. During his observations, there was one 
time a student, Amakpor, who came late to class was asked by this teacher why he was late in English. The student stood speechless and did not utter a word. The teacher called him a truant and told him to go and sit down. The teacher immediately involved him in the ongoing lesson. He was asked to identify "hers" and "his" on the board. He could not. He was silent. After the lesson, the author realized in an interview that Amakpor was delayed because he wanted to collect money for his school's examination printing fees from his father. Amakpor could not explain this to the teacher in the English language because students were not permitted to speak their Ghanaian language in the classroom. The author learned that Amakpor was of the Ewe language group and though he also spoke Twi, the language of the area fluently, his bilingual language and literacy knowledge and proficiency was without value in school. Owu-Ewie (2017) argued that the "excessive use of English over Ghanaian language in school has resulted in many Ghanaian children despising their own language because their indigenous languages are not deemed appropriate for education" (p. 160).

It is not surprising that when Edu-Buandoh and Otchere (2012) surveyed eighty pre-tertiary education students, forty-three students said they chose to speak English voluntarily while only 12 students said they did so because it was prescribed by the school. Because schools prescribe English and classroom practices largely favor English, students learn that their own languages and literacies in Ghanaian language although diverse are not valued in education (Opoku-Amankwa, 2009a, 2009b). What is unique about Edu-Buandoh and Otchere's (2012) self-reported choice of students is that, we learn that sixty-eight out of the eighty say that in their last school attended English was the only prescribed language while seventy-five students report that English is the 
prescribed language in their present school (Edu-Buandoh \& Otchere, 2012). As a result of former schools prescribing English, it is not surprising that some of these students have learned to choose English "voluntarily" because policies and practices have forced them to. When asked about their motivations to choose English, the students' top three reasons include English's status as an international language, its official status in Ghana, and English being a "mark of the educated" (p. 306). These young students are also learning the discourse that English is the only way and they need to choose it because that is what the school and society seem to value more (Edu-Buandoh \& Otchere, 2012). There is, therefore, the need to critically study the curriculum to learn how curricular content, policies, teaching and learning activities, and assessment practices foster an English dominant discourse that negates the languages and literacies in the home languages of Ghanaian students.

Studying the curriculum is important because typically when the curriculum, language policies, and practices in education center English, students say they prefer English medium instruction even if it impedes comprehension of course concepts. Davis, Bishop, and Seah (2015) conducted a study where 16 students at the fourth-grade level were asked to solve math word problems. These problems were set at grade level and in English. Remember that English is supposed to be the language of instruction for all subjects at this grade level. The study examined linguistic problems that might hinder solving these math problems. The students were divided into four groups combining high and low-achieving students and each group presented their answers after. All four groups had difficulty reading the question and were not able to solve the word problems they were given. Some groups had troubled understanding the meaning of certain words like 
"altogether," "gave," "much," and "quantity." One group thought they understood the word problem but they misinterpreted the question. Another group verbalized "quantity" thinking it was "canteen." An earlier study in Davis and Hisashi (2007) found that when questions were translated even orally from English to the Ghanaian language spoken by students, they performed better on tests (cited in Davis, Bishop, and Seah, 2015). In this study, however, we learn that English impeded comprehension of questions even when high and low achieving students worked together to try and solve the problem (Davis, Bishop, and Seah, 2015). Unsurprisingly, these students when interviewed by the researchers said that they wanted to learn mathematics in English "to be able to speak English well” (p. 595). Only one student said they preferred to learn Mathematics in the Fanti language. What is troubling is that even though English impeded comprehension and being able to solve the math problems handed to them, by the grade fourth these students had already learned what the teachers voiced in Opoku-Amankwa (2009a, 2009b) that they need to stick with it, not be lazy, and keep practicing it to be better. On the other hand, if these students could rely on and/or bring their own Ghanaian language and literacy skills it might serve them better (Owu-Ewie \& Eshun, 2019). A study of the curriculum will indicate where and how Ghanaian languages and literacies can be included across all subjects.

Owu-Ewie and Eshun (2015) show how important it is for teachers to bring Ghanaian languages and literacy skills in teaching content in the classroom. In this study of 10 schools focusing on grades four to grades nine, the authors conducted semistructured interviews of teachers and students in addition to classroom observations. Interviews were conducted both in English and in Fanti because it was the local language 
of the area. From students, the researchers learned that when the teachers taught completely in English or posed questions in English they could not participate because they did not fully understand. When teachers realized it, and re-asked questions in Fanti, students answered in Fanti and teachers helped them say it in English. When that was the dynamic of the classroom teachers confirmed that they saw increased participation from students. One teacher said, "When you use only English the class becomes quiet but when you say they can use Fante everybody contributes and the class becomes lively. The use of English inhibits understanding and also obstructs pupils from communicating in class" (p. 78).

Another study by the authors found that even in a school with students from different language backgrounds, students tended to speak the Ghanaian language of the community fluently. Owu-Ewie and Eshun (2019) realized that this was important in language policy planning. From their observations, they recognized teachers who could not speak all the languages represented in the classroom but were able to use the language of the area to teach complex concepts, helped students understand what they were learning much better. This confirms how a pedagogical approach in Ghana that embraces and centers the language and literacy ability of students could foster better learning outcomes for students.

There are many studies in Ghana that have continued to show that centering Ghanaian languages in education lead to better outcomes. Ahadzi, Ameka, and Essegbey (2015) found, by examining English argumentative essays of 92 students from senior high schools, that students who reported that their home language practices included a Ghanaian language wrote better argumentative essays than students who only use English 
at home. When the authors looked at content, word count, balanced arguments, and expressions, students whose literacy practices included speaking, reading, and writing in Ghanaian languages outperformed their English only counterparts in writing English essays.

Similarly, Casely-Hayford and Hartwell (2010) conducted an evaluation of an alternative school program in the rural community, that offered nine-month intensive instruction in basic literacy and numeracy in Ghanaian languages to students aged 8 to 14 years. The authors reported that the curriculum of this program centered Ghanaian languages and encouraged students to participate in the learning process rather than being passive learners. The evaluation found that about 80 percent of students at the end of the program met minimum standards for literacy and numeracy by grade 3 to enable them transition to mainstream school that used only English by grade four. Interviews with their new teachers and literacy tests revealed that students who had received intensive instruction in Ghanaian language in the alternative school program outperformed their peers in English and mathematics even in grade 6 and in junior high school (grade 9) (Casely-Hayford \& Hartwell, 2010).

These studies discussed above highlight an important but often overlooked idea in education in Ghana. Ghanaian languages and literacies are not only important to help students understand academic concepts better and they are not just useful to help students acquire English. More importantly, allowing students to bring in their own languages into the classroom disrupts the idea that Ghanaian languages are not appropriate for education. Using Ghanaian languages shows students that their associated cultures, practices, and knowledge of their culture are valuable. However, decades plus a century 
of missionary and colonial practice have entrenched the discourse that being educated in Ghanaian language is a deficit. In order to undo this negative discourse, there is a need to study the entire curriculum to identify how dominant English practices exclude positive discourses of Ghanaian languages and literacies. I now turn to highlight in the following paragraphs some research studies that have captured discourses that suggest that more English is best for students.

\section{Perception of Ghanaian Languages in Education}

\section{Students Would Fall Behind}

Mfum-Mensah (2005) conducted research on an elementary school program sponsored by an international non-governmental organization (NGO) in seven communities in Northern Ghana to learn the perspectives of various members of the communities about the program. The curriculum of the program included Math, Kusaal (the language of the people), writing and oral English for grades one to three. By the third grade, the science curriculum covered basic health issues, sanitation, and environment protection. The curriculum for grades one to grade three was translated into the Kusaal language of the local people. The school used the Kusaal language exclusively in grades one to three apart for the English subject. English was, however, used exclusively from grades four to six for the following subjects Mathematics, Social Studies, and Science except Kusaal which continued at this level only as a subject. This study is important because the school program reflected the long-standing national language-in-education policy that recommends Ghanaian language medium at the lower levels but not for high levels. What was unique about the program however was that the local community had 
the opportunity to decide school schedules and the recruitment of teaching personnel through the PTA and school management committees.

Mfum-Mensah (2005) interviewed 42 stakeholders in the program including parents, community members, staff of the NGO, school leaders and educators, and a community leader. In all the interviews there were no complaints that teaching in Kusaal affected students' performance. The study seemed to suggest the Kusaal language medium helped students positively. However, many of the interviewees complained that using Kuusal was a disadvantage for students since national assessments were conducted in English. Even the school administrator, a member of the community, felt that students would lack behind students enrolled in mainstream public schools when it came to English proficiency. The research, we know, does not support this argument (see CaselyHayford \& Hartwell, 2011; Owu-Ewie \& Eshun, 2015, 2019). However, parents, students, and community members always made reference to how English allowed people to travel and go beyond the community, to find jobs, and to live in urban cities and towns. Parents rightly pointed out that on radio and TV broadcasts everything seemed to be in English, hence even if Kusaal was helpful, it was inutile in the long run. These interviews revealed that English was so important to these parents because it guaranteed, in a way, further education and social mobility (Mfum-Mensah, 2005).

\section{Using Ghanaian Languages Feels Like an External Imposition}

The interviews conducted by Mfum-Mensah (2005), however, revealed another issue in relation to the use of Kuusal as a medium of instruction. Community members felt that the foreign NGO imposed the language medium on them. The complaints from community members hinted at the idea that this external organization was telling them 
what was good for them. The study also suggested that there was not enough education on why the use of Kuusal was important for students. This external imposition of Kusaal indicates that to perhaps to bring in Ghanaian languages and literacies into education, school leaders and policymakers must recognize that there is already a hegemonic discourse surrounding the value of English handed down from colonialism and therefore using Ghanaian languages without community understanding and acceptance of why, fosters resistance, even if students are performing well in their home languages at school.

The work of undoing the negative perception of Ghanaian languages needs to be widespread. In Mfum-Mensah's (2005) study school leaders and teachers themselves were not convinced Ghanaian languages medium was helpful in educating students. Davis and Agbenyegah's (2012) interviews of 10 headteachers (principals) of primary schools revealed that even though the language-in-education policy stipulated the use of Ghanaian languages medium at lower levels of schooling, in practice, school headteachers did not enforce the policy. Most of the headteachers at lower levels said their teachers either used a mix of English and Ghanaian languages or more of the former. One admitted that in upper primary levels when students have difficulty understanding Ghanaian languages, teachers used Ghanaian languages to explain concepts. Once again, we see that Ghanaian languages continue to be helpful in teaching and learning to enable students to understand the curriculum content better but because the curriculum and policy favor English in assessments, further education, and content learning, students are disadvantaged. If Ghanaian languages are helpful for students, why restrict them, why not center it throughout? This is a question I asked earlier in Section A 
when missionary and colonial practices in education restricted Ghanaian languages to religious instruction and as tools in converting the native (Bening, 1976; George, 1976).

\section{Literacy in Ghanaian Languages is Illiteracy}

Perhaps one reason why policies and practices continued to restrict Ghanaian languages and recommend using it only to explain difficult course concepts is that literacy is viewed as the ability to read, write, and speak only in English (OpokuAmankwa \& Brew-Hammond, 2011). Opoku-Amankwa and Brew-Hammond (2011) conducted focus group interviews of teachers in schools in two of the largest cities in Ghana to explore their perceptions, beliefs, and approaches to teaching, learning, and assessment of literacy. Generally, these teachers were also responsible for teaching literacy in Ghanaian languages in primary schools as required by the language-ineducation policy. These teachers, however, said that if students can read and write in a Ghanaian language, they do not consider them literate because they cannot take it beyond Ghana. One teacher said that "you can only use it [Ghanaian languages] in the class situation if you're a teacher and in some churches where local language Bible are read" (p. 95). The teachers also saw literacy in Ghanaian languages as useful only for teachers who taught Ghanaian languages and in churches, eerily striking of the colonial and missionary position of Ghanaian languages in religious instruction (Graham, 1971).

We know from many research studies that literacy in Ghanaian languages is even more essential for students' achievement in schools (Opoku-Amankwa, 2009a, 2009b, Owu-Ewie \& Eshun, 2019). Unfortunately, the same perception of English literacy as the only valuable form of literacy exists among parents who have children in pre-schools, 
that more English is better for further learning (Tackie-Ofosu, Mahama, Vandyck, Kumador, \& Toku, 2015).

\section{Ghanaian Students Perform Poorly with English Medium}

What is troubling and often not discussed in the literature is that very few students are found to be proficient in English and in Math when curricular policies, content, and assessment, primarily center English instruction education. National Education Assessments (NEA) in English and Math conducted in 2007, 2009, 2011, and 2013 have confirmed that a majority of students tested, failed to pass national assessments (See NaCCA, 2019b). NEAs are large national representative assessments of students in Ghana. NEA assesses students in the third and sixth grades to determine whether students are on grade-level proficiency (NaCCA, 2019b).

In the recent NEA study in 2013, out of the almost 17, 500 students in primary 6 (grade 6) who took the test in English and in Math, only 39\% in English and $11 \%$ in Mathematics were classified as proficient. Proficient referred to students who scored 55\% and above on the test (See NEA, 2014). Two years later in 2015, an Early Grade Reading Assessment (EGRA) and Early Grade Mathematics Assessment (EGMA) was conducted in conjunction with the Ghanaian Education Service (GES) and USAID. What was different here from the NEA studies is that EGRA and EGMA assessed students in Ghanaian languages and in English. This assessment sampled 7311 students in primary 2 (grade 2) across the country in Ghanaian languages (Akuapem Twi, Asante Twi, Dagaare, Dagbani, Ewe, Ga, Gonja, Fante, Kasem, Nzema) and in English. In general, across all languages, a majority of students were not on a grade 2 reading level. Less than $2 \%$ of students examined were found to be proficient, except for schools in the Ewe 
speaking community where it was $5 \%$. While students did better on oral exams in Ghanaian languages, overall assessments on both EGRA and EGMA indicated that students were not on grade two reading and math levels in either Ghanaian languages or English (EGRA \& EGMA, 2015).

The NEA, EGRA, and EGMA studies do not refute the importance of Ghanaian languages or education centered in the language and literacy of these students. Some might be tempted to think that EGRA and EGMA (2015) prove that Ghanaian languages as mediums of instruction do not work (Davis \& Agbenyegah, 2012). However, looking at the literature in general, we know that some teachers and leaders believe that Ghanaian languages are not helpful for students and so instead of helping students develop literacy skills in these languages, they revert to using an English medium. Owu-Ewie and Eshun (2015) found in their observations of classes that some teachers felt were not proficient even in English but they still insisted on using it to teach. These teachers felt that they had only learned English to pass exams but not enough to teach it well. Some teachers were also not proficient in the language of the community they were assigned to teach. Ansah and Agyeman (2015) also confirmed the lack of proficiency and confidence in using the language of the community in teaching.

Here, it is important to recognize that while Ghanaian languages have been proven to be vital in education (Casely-Hayford \& Hatwell, 2010; Davis, Bishop, \& Seah, 2015; Opoku-Amakwa, 2009a, 2009b), the poor performance of students in Ghanaian languages as seen in EGRA and EGMA (2015), can be attributed to the lack of strict adherence of Ghanaian languages medium in lower level of primary schools (EduBuandah \& Otchere, 2012; Opoku-Amankwa \& Brew-Hammond, 2011). This lack of 
strict adherence can also be attributed to the perception of educators, leaders, and community members that more English is better for further learning even if teachers do not feel proficient in teaching ability in English (Ansah \& Agyeman, 2015; Owu-Ewie \& Eshun, 2015). This problem creates a disadvantage to learning because the poor English taught hinders students' comprehension of course concepts and literacy development. It also makes irrelevant students' own languages, denies students from bringing into the classroom their full multilingual competences in Ghanaian languages - their literacies in these languages, and knowledge transmitted from the community and people in which they live (Owu-Ewie \& Eshun, 2019). A study of the curriculum must, therefore, examine how Ghanaian languages can be extended beyond the early primary school years and how to include teaching and learning of Ghanaian histories, cultures, and literacies across all subjects in the curriculum. This study must also examine how policies can create new discourses about the importance of Ghanaian languages in the curriculum.

\section{The Place of English in Education Across the Region}

Other countries in Africa with a colonial legacy like Ghana face similar issues with using their own languages in instruction because of colonial practices in education that favored English. Tanzania, for example, requires that Swahili is used as the language of instruction in primary education (Swilla, 2009) and although students can take final assessments to progress to secondary schools in Swahili, the rest of secondary education till higher education is instructed in only English. Students, therefore, demand more English medium at the primary level to prepare them for further education in English (Hilliard, 2015). 
Several studies found however that even though Swahili is helpful to students in understanding content, some teachers still use English when they are supposed to instruct in Swahili which impedes comprehension of class content (Brock-Utne \& Holmarsdottir, 2004). Similar to the Ghanaian context, even when policies require the use of African languages, there is a discourse and belief in the value that English-only teaching practices are best for students (Davis \& Agbenyegah, 2012). Brock-Utne (2010), Brock-Utne and Holmarsdottir (2004) and Qorro (2013) found that often these teachers were not sufficiently trained to instruct in English and that even when teachers were sufficiently trained in English, abandoning the use of Swahili for more English instruction worsened the educational achievement of students. Brock-Utne (2010) makes the point that often findings based on empirical research that shows the need for instruction in Swahili are not heeded by policymakers. She argues that this present status quo maintains the power of the elites over the masses (Brock-Utne, 2010).

Also in South Africa, the English language had official language status for close to a century before the end of apartheid. Apartheid enforced the idea that anything to do with Black Africans was negative including African languages. Even though African languages received official language status after apartheid, Black Africans still preferred English in instruction because of the discourses of societal success associated with English (Mutasa, 2015; Phaahla, 2014; Plüddemann, 2015; Webb, Lafon, \& Pare, 2010). Yet Drummond (2016) and Nyika (2015) also found in their studies that Blacks in South Africa performed poorly on standardized tests administered in English. Still, similar to Ghana and Tanzania, parents and students called for more English in the curriculum (Taylor \& von Fintel, 2016). Colonial legacies of English in education are still dominant 
today such that it shapes what students are expected to learn in school - the goal being English proficiency - without much emphasis on the local context, on literacies, knowledge, histories, and knowledge of these post-colonial countries. Ghana, Tanzania, and South Africa are not the only countries facing these issues in Africa. Other countries with similar colonial history like Kenya, Uganda, and Botswana are a few of these countries where although English does not seem to help a majority of students, it is still preferred by many (See Arthur, 1997, 2001; Cleghorn, Merritt, \& Abagi, 1989; Mazrui, 2012; Ssentanda, 2014; Tembe, 2006; Trudell \& Piper, 2013).

\section{Summary}

It is important to note that in all these countries, at some point, policymakers implemented policies that suggested that incorporating the language and literacies of the local context was helpful for education. Yet, at the same time, the educational curriculum including teaching and learning practices, assessment, and policies failed to decenter English. The colonial and historical practices, where English was mainly seen as the mark of the educated, are still reinforced by practices that maintain its dominance. Because English is seen as the language of social mobility by students, parents, educators, and leaders in these former colonized contexts, any poor and superficial attempts to incorporate local languages only strengthen parents' and students' demand for more English (Mfum-Mensah, 2005; Tackie-Ofosu et al., 2015). English proficiency has been shown in South Africa, for example, to lead to higher income earnings (Casale and Posel, 2011) and prestige in Tanzania (Billings, 2011), as such English in the current societal structure has real benefits, but unfortunately, a majority of people do not have 
access to that privilege because of the disparities with the use of English only in school discussed above in the literature.

Examining the research across these formerly colonized multilingual countries, I would argue that policymakers and educational leaders across the region have themselves learned discourse in favor of English through their own schooling and this perhaps explains why policies supporting native languages are often poorly implemented and enforced (Davis \& Agbenyegah, 2012; Edu-Buandoh \& Otchere, 2012). This also perhaps explains why throughout the literature, assessments and content instruction in English are still maintained in post-primary education, indicating to students and society that the goal is of education is English literacy and proficiency. There is, therefore, a need to study the curriculum to identify and understand how learning and teaching practices, content, assessment, and curricular policies foster a dominant English language approach in education. By identifying and understanding how it persists, we can deconstruct practices that favor dominant English discourses and reconstruct and redesign new learning and teaching practices, content, and assessment, and curricular policies that are representative of the diverse multilingual landscape of the region. Since we know from research that centering Ghanaian languages empower and equip students to do well in school, there is a need to study how current policies and practices perpetuate the dominance of English even though it serves few people. We also have to approach education differently especially in the curriculum by examining four specific areas power, access, diversity, and design (Janks, 2000, 2013) that I discuss in the next section. In the next section, I discuss how studies in English linguistic imperialism and critical literacy will help me study the discourses in education and how they have remained 
unchangeable so that by identifying how, we can change the discourse in education in a way that valorizes Ghanaian languages and cultures.

\section{Section C: Theoretical Framework}

In this section, I discuss the theories that explain how English continues to persist in countries like Ghana with a legacy of colonialism. First, I discuss studies of English linguistic imperialism and how they guide this study and I also explain how the false narratives of English linguistic imperialism will help them identify dominant English discourse and practices in curricular practices and policies that marginalize Ghanaian languages. Janks (2000) argues that identifying these dominant discourses alone does not change their dominance in the curriculum and so to begin the process of deconstruction of English dominant discourse and the reconstruction of a curriculum centering Ghanaian languages, literacies, histories, and cultures, I merge theories about the false narratives of English linguistic imperialism with South African scholar Hilary Janks' (2000, 2013) post-apartheid work in critical literacy. Janks $(2000,2013)$ recommends that the deconstruction/reconstruction of the curriculum starts with examining issues such as power, access, diversity, and design in curricular policies, content, teaching and learning activities, and assessment practices. I discuss in this section how power, access, diversity, and design are critical to decentering English dominant discourses and practices in education. By merging these two theories as my guiding framework, I reimagine a critical approach to education in formerly colonized countries like Ghana where we can begin to change what society thinks of as dominant.

\section{English Linguistic Imperialism}


Pennycook (1998) suggested that "colonialism still warrants visiting many more times in order to better understand the colonial past and to see how it echoes into the present" (p.17). Studies of English linguistic imperialism examine whether nations who have gained independence have enjoyed linguistic freedom in their day-to-day affairs. Scholars such as Phillipson (2009) and Pennycook (1998) question whether colonial languages used in formerly colonized countries are useful in the local context. Both scholars argue that the use of imperial languages such as English mainly serves the interests of Western countries and the Global North. After independence, even though the colonialists might have left their former colonies, their practices, languages, and policies, on which a majority of the elite and ruling class have been trained, continues to stay despite their departure (Pennycook, 1998). Colonialism and its effect run deeper still, as such, independence did not come with linguistic and cultural freedom for the native person and her community (Pennycook, 1998). In Ghana, for example, colonial practices and policies in education that favored the study of English and certification in English were maintained as the only way to educational success and social mobility after independence (George, 1976). Ghanaian languages, therefore, remained underdeveloped because colonial and missionary practices in education limited their use mainly to religious instruction and civilizing the "savage native" (Bening, 1976).

Missionaries, to a large extent, wrote the scripts for Ghanaian languages by producing the written forms of the language including dictionaries, premiers, and religious artifacts (Bening, 1976; Graham, 1971). However, they upheld English proficiency and literacy as a mark of civilization which perpetuated practices that saw curriculum content and practices prioritizing English ways of speaking, doing, and being. 
In both Phillipson (2009) and Pennycook (1998), they examined how English texts produced in the West positioned the colonized as barbaric and savage until they learned the English ways of the colonizer. In education, the native person also learns "colonizing English words" in which he starts describing his own ways of being, and so for the first time the native person culture and language are called savage, barbaric, and uncivilized because he does not behave, speak, and embody English practice (Pennycook, 1998). Fanon (1952/2008) also describes the colonizing approach towards the native language and practices as factors that make the native want to distance himself from his language and culture.

\section{Fallacies of English Linguistic Imperialism}

Grounding this paper in linguistic imperialism is central to uncovering how and why English dominates in education in Ghana. Phillipson (1992, 2009) has outlined false discourses that exist in educational contexts including policies and practices where English linguistic imperialism dominates. He explains that first and foremost, there is the underlying discourse that English is best taught monolingually. In several of the reviewed studies in Section B we saw that even though policies required Ghanaian language medium, teachers, parents, and leaders felt that using only English was best (see Davis \& Agbenyegah, 2012; Mfum-Mensah, 2005; Opoku-Amakwa \& Brew-Hammond, 2011). A second false narrative is that the ideal teacher of English is a native speaker. When two Ghanaian scholars opened schools during the colonial period in the late $19^{\text {th }}$ century, using the local language of the people, in Anyidoho and Kropp-Dakubu (2008) we learned that students refused to attend their schools unless the school offered English taught by teachers who were certified by the examining body in England. 
Two other common but false narratives are that the more English is taught, the better the results and also that the earlier English is taught the better the results. In Ghana, Uganda, South Africa, and Kenya multiple studies have not found this to be true for a majority of students in schools (See Arthur, 1997, 2001; Cleghorn, Merritt, \& Abagi, 1989; Mazrui, 2012; Ssentanda, 2014; Tembe, 2006; Trudell \& Piper, 2013). Finally, in a lot of the literature where parents, students, and some educators are interviewed, we learn another false narrative of English linguistic imperialism - that if other languages are used much, standards of English drop. In several studies, like Collison (1974), Davis and Agbenyegah (2012), Davis et al. (2015), and Owu-Ewie and Eshun (2019), researchers found the opposite to be true - that supporting students in their home languages increased students' participation and performance.

\section{Globalization of English Education After Independence}

Pennycook $(1994,1998)$ and Phillipson $(1992,2009)$ found that after many countries gained their independence from the colonialists, there were Western efforts to promote the spread of English through non-governmental organizations such as the British Council and US institutions like the Ford Foundation, Fulbright, the Defense Department and the Peace Corps, Rockefeller, Carnegie, US Agency for International Development, and the US Office of Education. Pennycook's (1994) study of the mission and reports of the British Council, for example, revealed how the organization through educational aid to former colonies and countries in the Global South saw British culture, language, and political systems as the solution to halt the spread of fascism post-second world war. Today the British Council, established in 1934, operates in "more than 100 
countries of the world in the fields of arts and culture, the English language, education and civil society" (British Council, 2019, About Us).

In the reports of the British Council, Pennycook (1994) found that this nongovernmental organization established by a Royal Charter right around the time British colonies were protesting and fighting for their independence sought to continue their influence through a non-political arm. The British Council is directly involved in examination and inspections in these former colonies to "maintain the standards of English teaching," providing teaching materials including literatures, teaching English in its centers, offering teaching training courses, sending British experts to these countries, and offering scholarships for people to study in the UK (Pennycook, 1994, p. 150). While seemingly benign, in their reports, British Council's goal was to make English a global language and a commodity in the marketplace and it did this with the underlying discourse that English education is the only way to bring civilization to their former colonies (Pennycook, 1994).

This direct involvement in education in their former colonies, Pennycook (1998) argues, also allows the colonialists to rewrite history that views the colonizers as only helping to educate the native, similar to the position of missionaries and colonialists during the colonial period (Bening, 1976). Now, this colonial approach of "educating the native" in English ways of speaking, doing, and being is funded at a global level. It is impossible to say that English is neutral in these post-colonies because underlying the imperialism of English is the assumption that the cultures and languages of the native do not bring civilization and enlightenment. 
Western globalization agendas via organizations like the International Monetary Fund and the World Bank have also contributed to the underdevelopment of Ghanaian and African languages. In Ghana for example, at the height of economic decline during the period after independence, these international organizations through structural adjustment policies (SAP) and debt servicing practices recommended cuts to publicly funded education (Aziabah, 2018). In Ghana's history, few years after independence, where education and educational infrastructural development had the largest part of the budgets, later governments made cuts to education funding because the government argued that Ghana could not continue to fund education as it had done after independence (George, 1976).

Today we know that these structural adjustment programs (SAP) and economic recovery programs (ERP) were blanket approaches that conditioned developing countries to rather strengthen raw material production to serve the economies of the West (Chabal, 1996; McClintock, 1994; Phillipson, 2009). McClintock (1994) found that "during 1986, Africa lost \$19 billion through collapsed export prices alone," but on the other hand, in 1988 and 1989, debt service payments from the Third World to the USA were $\$ 100$ billion" (p. 263). So while African countries gained very little from exports to the Global North, they owed more to the West, yet bodies such as the IMF and World Bank insisted, in the late $20^{\text {th }}$ century, not long after many countries had gained independence from their Western colonizers, that making cuts to public education and engaging the West would stimulate economic growth but they did not (Birdsall, Rodrik, \& Subramanian, 2005; McClintock, 1994). 
The false narratives of English linguistic imperialism, therefore, about English being best for post-colonial multilingual countries outlined in Phillipson $(1992,2009)$ put in context of history and colonial and post-colonial practice help bolster the discourse that English is as language of modernity, national unity, and process, and that places less focus on the development of local languages in education. Where English linguistic imperialism reigns, English is seen as neutral and it promises equitable distribution of success which Pennycook (1998) argues is impossible in a multilingual nation because English linguistic imperialism asks other languages and cultures to set aside their ways of speaking, being, and doing and shift to the colonizing language before they can participate in education and in society. Success in education is therefore conditioned on only English proficiency and literacy, a notion that was spearheaded initially by colonialists and missionaries (Martin, 1976; Phillipson 1992, 2009).

In order to undo this idea, South African scholar Hilary Janks (2000, 2013) theorizes how a critical approach to education in post-colonial contexts that critiques language and power but also suggests how to disrupt dominant Western discourses and valorize the ways and being of the formerly colonized in education. Her work in critical literacy helps to critique and deconstruct the false narratives of English linguistic imperialism. I discuss her theory and also explain in the next section how her theory of critical literacy frames my study.

\section{Critical Literacy}

Critical literacy at its core questions and examines "the ways in which meaning systems are implicated in reproducing domination" (Janks, 2000, p. 178). English dominant forms of speaking, doing, and being are deeply intertwined in Ghanaian 
education and society such that denying access to these forms may have implications for social mobility and higher education. Janks (2000) argues that while providing access to the English language, literacy and genre is helpful, educational policies and practices must "simultaneously use diversity as a productive resource for redesigning social futures" such that it changes what discourses and ways of speaking, doing, and being are dominant (p. 178). When learning in multilingual classrooms and spaces, "is multimodal, multisensory, multilateral, and multidimensional" and also relies on multiliteracies, it allows students to take up dominant forms blended with their own ways of speaking, doing, and being, in a way that changes what is seen as dominant (Canagarajah, 2007). Janks $(2000,2009)$ insists that critical approaches to education that want to decenter dominant forms must balance and be intentional about how power, diversity, access, and design work together to either reinforce dominant forms or deconstruct/reconstruct what is seen as dominant. She argues that emphasis on one without the other creates an imbalance that either reinforces dominant forms or marginalizes other forms in education (See Janks' interdependent model of critical literacy below, Janks, 2013, p. 2013).

\section{Power + Access + Diversity + Design}

The model should be conceptualized as interdependent because a focus one part without the other does not change dominant discourses and practices. I explain individually what each concept seeks to analyze and finally how together they can reimagine a curriculum that centers Ghanaian languages and cultures.

Power. Power in this model focuses on bringing awareness to how power works in education. It asks whose interests, whose language(s), and ways of being are being 
served and met in education. From the history of education in Ghana and the research about language use covered in this chapter, we know that the curriculum, policies, and practices in education privilege those who already embody dominant English forms. Questions about language and power in education such as Fairclough's (2013) Critical Language Awareness examine whose language has power and even though such approaches suggest being aware of the presence of other languages present it does not disrupt dominant languages. Only looking at power, therefore, reinforces its dominance and also marginalizes the ways and beings of students who do not embody dominant forms (Opoku-Amankwa, 2009a, 2009b). Janks' (2000) critiques approaches to education that only look at power. She argues that simply recognizing that there are other languages and ways of being in the classroom do not lead to curricular policies and practices naturally accepting and incorporating them nevertheless researchers are encouraged to examine how power works to support dominant languages and exclude others as the first step in deconstruction.

Access. Janks (2000) highlights the tension that providing students access to dominant forms "contributes to maintaining their dominance" (p. 176), but on the other hand, denying them access to dominant forms would also marginalize students in society by denying them opportunities that dominant forms afford. To resolve this tension however, she recommends that curricular policies and practices including content, teaching and learning activities, and assessment practices should grant student access to both dominant and non-dominant forms.

The iterations of language policies to date in Ghana have primarily focused on providing students access to the only English forms and so even when Ghanaian 
languages are suggested in lower levels of primary education, final assessments in only English indicated that English proficiency was the desired outcome (Ansah, 2014). This is one instance where access to both English and Ghanaian languages on assessments would alter discourse about only English proficiency as the desired outcome in education. Still, as discussed in the previous section we know that providing access to only codes of power such as English in education, undermined the education of a majority of students (Ahadzi, Ameka, \& Essegbey, 2015; Collison, 1971; Davis, Bishop, \& Seah, 2015; Opoku-Amankwa, 2009a, 2009b). Janks (2000, 2013) argues that an orientation of education that only looks at providing students' access to education, only guarantees that whatever is already dominant is what the curriculum would provide and enforce. With access, therefore, I will examine the ways that the curriculum makes it possible for students to learn about Ghanaian languages, cultures, literacies, and histories in addition to English.

Diversity and Design. As discussed earlier, only recognizing that there are diverse languages, cultures, and ways of speaking, doing, and being in the classroom without actively including them in the curriculum, as part of teaching and learning, would only reinforce dominant forms. Here, researchers are encouraged to question how teaching and learning practices are representative of the multiple realities and ways of people, texts, and knowledge (Botelho \& Rudman, 2009). This means, for example, allowing students access to diverse and multicultural texts that represent the multilingual competences of Ghanaians, that is, texts that show Ghanaians using Ghanaian languages in multiple spaces (Thomas, 2016; Vasquez, 2000, 2010). 
Considering the above concepts, it is imperative that curricular policies and practices include content, teaching and learning activities, and assessment practices are structured in a way that allows students to bring their own languages and ways of speaking, doing, and being into the classroom and learn about other's ways of speaking, doing, and being such that they when they leave the class they have competences in multiliteracies. Janks (2000) insists that an intentional design or redesign of educational curriculum, policies, and practices for all students must highlight the diversity and multiplicity of semiotic systems including diverse languages, cultures, and histories and "different ways of reading and writing the world" while recognizing how power works.

The concept of diversity and design is grounded in New Literacy Studies (NLS) (Street, 2003) and pedagogy of multiliteracies (New London Group, 1996; Cope and Kalantzis, 2015). NLS scholars argue that what we think of as literacy in today world should be more than being able to read and write standard forms of a language because there are various kinds of literacies including digital literacies and multicultural artifacts and texts that convey meaning (Knobel \& Lankshear, 2014; Street, 2003). In analyzing the curriculum in terms of diversity and design, researchers are encouraged to look beyond literacy as "focus solely on the rules of standard forms of the national languages" because "communication and representation of meaning today increasingly require that learners become able to negotiate differences in patterns of meaning from one context to another" (Cope and Kalantzis, 2003 p. 3). As such, I will examine in this study how the curriculum is designed in a way that allows students to learn not just literacy in English but in "different ways of reading and writing the world" especially in Ghanaian languages and cultures. 


\section{Identifying False Discourses + Power + Access + Diversity + Design =}

\section{Deconstruction/Reconstruction}

When power, access, diversity, and design all work together they progressively and radically alter what students come to think of as dominant, valued, and important (Janks, 2000). When students are exposed to diverse literacies and languages especially Ghanaian languages, cultures, and histories in education, Janks (2000) suggests that these multiliteracies and multilingual competencies become the new normal and by doing so disrupts dominant English only discourses and practices in education and in society. That can only be accomplished not just by examining at power or diversity issues in the curriculum but also by examining access and design issues as well. Janks (2000) puts it this way: "we need to find ways of holding all of these elements in productive tension to achieve what is a shared goal of all critical [education and] literacy work: equity and social justice. We need to weave them together in complex moves from deconstruction to reconstruction to deconstruction, from access to deconstruction to redesign, from diversity to deconstruction to new forms of access. These different moves need to inform and balance one another" (p. 179). In other words, we need to keep asking questions of practices and policies in education to take into account how power works to upholds certain discourses and marginalizes others. We constantly have to deconstruct and reconstruct as we learn whose voices and whose ways are left out on the margins. Before examining issues of power, access, diversity, and design, it is equally important to identify whether there are false narratives of English linguistic imperialism, as discussed earlier, considering the historical colonial legacy of education in Ghana (Phillipson, 2009). Therefore, in this paper, I rely on these components of critical literacy and the 
fallacies of English linguistic imperialism in framing my research questions, method, and analysis in the study of the Ghanaian curriculum.

Table 2.1

The Interdependent Model of Critical Literacy

\begin{tabular}{|c|c|}
\hline Power without access & $\begin{array}{l}\text { This maintains the exclusionary force of } \\
\text { powerful discourses and powerful practices }\end{array}$ \\
\hline Power without diversity & $\begin{array}{l}\text { Loses the ruptures that produce contestation } \\
\text { and change }\end{array}$ \\
\hline Power without design or redesign & $\begin{array}{l}\text { The deconstruction of powerful texts and } \\
\text { practices, without reconstruction or redesign, } \\
\text { removes human agency }\end{array}$ \\
\hline Access with power & $\begin{array}{l}\text { Access with a theory of power leads to the } \\
\text { naturalization of powerful discourses without } \\
\text { an understanding of how these powerful } \\
\text { forms came to be powerful. }\end{array}$ \\
\hline Access without diversity & $\begin{array}{l}\text { This fails to recognize that difference } \\
\text { fundamentally affects who gets access to what } \\
\text { and who can benefit from this access. History, } \\
\text { identity, and value are implicated in access }\end{array}$ \\
\hline Access without design or redesign & $\begin{array}{l}\text { This maintains and reifies dominant forms } \\
\text { without considering how they can be } \\
\text { transformed. }\end{array}$ \\
\hline Diversity without power & $\begin{array}{l}\text { This leads to a celebration of diversity } \\
\text { without any recognition that difference is } \\
\text { structured in dominance and that not all } \\
\text { discourses/genres/languages/literacies are } \\
\text { equally powerful. }\end{array}$ \\
\hline Diversity without access & $\begin{array}{l}\text { Diversity without access to powerful forms of } \\
\text { language ghettoizes students }\end{array}$ \\
\hline $\begin{array}{l}\text { Diversity without design or } \\
\text { redesign }\end{array}$ & $\begin{array}{l}\text { Diversity provides the means, the ideas, the } \\
\text { alternative perspectives for reconstruction and } \\
\text { transformation. Without design, the potential } \\
\text { that diversity offers is not realized. }\end{array}$ \\
\hline Design/redesign without power & $\begin{array}{l}\text { Designs or redesigns that lack power are } \\
\text { unable to effect change. }\end{array}$ \\
\hline Design/redesign without access & $\begin{array}{l}\text { This runs the risk of whatever is designed } \\
\text { remaining on the margins. }\end{array}$ \\
\hline Design/redesign without diversity & $\begin{array}{l}\text { This privileges dominant forms and fails to } \\
\text { use the design resources provided by } \\
\text { difference. }\end{array}$ \\
\hline
\end{tabular}

\section{Summary}


These two theories of English linguistic imperialism and Janks' (2000, 2013) critical literacy framework provided a lens to study how the curriculum of Ghana works to reify dominant forms of English and to examine how the policies and practices of teaching and learning can help decenter English forms and incorporate the multiliteracies, multilinguistic and multicultural ways and beings of Ghanaian students. By applying these frameworks, I examined the discourse of the curriculum for K-6 primary schools including teaching and learning activities, content goals and objectives, assessment policies and practices, and courses offered to students. In the next chapter, I explained in detail my specific research questions and the method - Critical Discourse Analysis (Fairclough, 2013) - that I used for conduct this study. 


\section{CHAPTER THREE: METHODS}

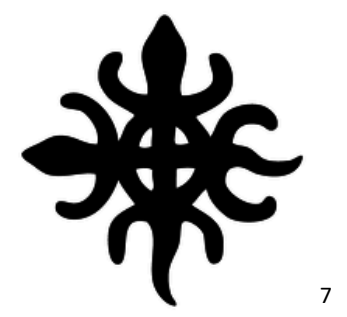

In this chapter, I first discuss why discourse is a powerful tool in shaping our ways of interacting with the world around us. Next, I discuss why it is important to examine why certain discourse in education can influence policies and practices around students. I also explain why a critical discourse analysis (CDA) is the best way in this study to understand how Ghanaian education via the curriculum fosters dominant preference for English in the face of evidence that shows that English use alone may hinder students' achievement. I also explain my research design, research questions, data collection methods, and data analysis procedures and conclude by addressing some ethical considerations in this study.

\section{Discourse in Society}

Discourse is all around us even if we are unaware of where that discourse originated and how much it influences our ways of interacting with the world (Fairclough, 2013). A recent examination of the coverage of Africa in Ghanaian newspapers a period of 2 years, for example, revealed Ghanaian news outlets sourced news of other African countries from European or American media houses (Serwornoo, 2019). As a result, Serwornoo (2019) found that in Ghanaian newspapers news of other

\footnotetext{
${ }^{7}$ This symbol of the Akan people of Ghana called "Funtunfunefu-Denkyemfunefu" is a reminder that society can be united when we recognize that our diversity is a strength. Applied to this chapter, it serves as a reminder that the curriculum needs to be inclusive of the diverse linguistic and cultural landscape of Ghana, not just the English language.
} 
African countries frequently covered themes such as war, crimes, violence including murders, crises, terrorism, and underdevelopment. Because most news about Africa in Ghanaian newspapers came from Western news sources, who highlighted mainly negative themes, the discourse about other African countries in the local media is largely negative. Serwornoo (2019) suggests that if Ghanaian newspapers visited online local news platforms in these African countries, the discourse would be more positive because local media sources would highlight both the positive and negative and not just the latter. I argue that this is an instance where Ghanaians from their own local media might be shaped on a daily basis by the unfavorable discourse of these other African countries and would view these countries as unsafe and politically or economically unstable unaware that their view of fellow African countries are obstructed because of Western media's emphasis on "bad" news in Africa.

Discourse is a powerful and unseen ideology that shapes our ways of seeing the world and ourselves. Gee (2014) describes discourse as language-in-use. He explains that the language we use or interact with builds our ways of speaking, doing, and being in the world. Gee (2014) says, for instance, that the way we interact with our parents is different from the way we interact with our peers. As such, there is a parent-to-child discourse that is different from a peer-to-peer discourse. There is a way of speaking, doing, and being at school or at work that is different from how we interact at home. To understand how they are different, Gee (2014) invites discourse analysts to study the language used in each context.

Fairclough (2013) also adds that there is a societal discourse that constantly shapes our view of society and what we think is "normal" in society. In Ghana recently, 
the Ministry of Education's plans to introduce a course in pre-tertiary education in sexual health were suspended because of large movements of Christian leaders who criticized the move as a Western agenda to normalize LGBTQ in society and to encourage sexual promiscuity (Peyton, 2019). I contend that because the societal discourse in Ghana generally views LGBTQ and school discussions of sex as not normal, the Comprehensive Sexuality Education (CSE) course was suspended because it did not match with the general societal discourse on sexuality even though the Ministry of Education insisted several times in press statement that it did not promote sexual promiscuity or homosexual sexual relations (Ngula, 2019; Satsi \& Siabour, 2019). Even though the CSE curriculum was publicly released to assuage fears, it only intensified resistance to the course until the president, speaking publicly at a church, vowed to never introduce CSE under his presidency (“Akufo-Addo reiterates," 2019). Since then all public discussions of CSE have died down.

\section{Discourse in Education}

Gee (2014) suggests that the language we see, read, think in, and interact with shapes the identities we enact, what we consider significant or not, practices and activities we embody or participate in, social relationships, politics, and knowledge. According to Gee (2014) discourse is also how words and ideas connect and relate to each other to create meaning. For example, students in the United States whose first or home language is not English, for a long time were labeled as limited English proficient (LEP). This label generated discourse that suggested that these students lacked the ability to achieve in education because they were linguistically deficient (Rosa, 2016), and this brought about deficit-oriented approaches to educating them by suggesting that their 
home languages failed them (Rosa \& Flores, 2017). More recently, research has relabeled these students as English Learners (EL) or Emergent Bilinguals (EB) because the home languages and literacies of these students have been found to be an advantage rather than deficit to their educational achievement when given enough academic support in their home languages (Garcia \& Wei, 2014). The new EL and EB designation alone did not change the former discourse about LEP students but over time as more research is finding that these students' first language did not create a disadvantage for them but that these students were hindered by systemic teaching practices and policies that discounted their languages in education, a new positive discourse is being created about what ELs and EBs can do (Dorner \& Layton, 2014; Menken \& Kleyn, 2010).

Discourses about the need for the native Ghanaian to become literate in English are rooted in Ghana's colonial legacy as the literature as shown (Bening, 1976; Graham, 1967 Martin, 1976). The legacy included educational assessments in English, school certification coming from examining bodies in England, the influx of English speakers from the United States who were brought in as teachers through the British Council and Peace Corps to teach in schools (George, 1976), and missionary practices in converting and civilizing the native. These practices, for instance, generated the discourse that Ghanaian students, without English proficiency, would not have social and economic mobility or have higher education (Bening, 1976). Opposing discourse in research that shows that pushing Ghanaian languages and literacies to the margins in education deprives a majority of students of actually climbing the social, economic, and educational ladder is not widely accepted even by the students and their teachers who would benefit 
from it the most (Ahadzi, Ameka, \& Essegbey, 2015; Davis, Bishop, \& Seah, 2015;

Mfum-Mensah, 2005).

\section{Research Questions}

As presented earlier, the goal of this study was to understand how the preference for the English language has been constructed through the policies, practices, and content of Ghanaian education. Through the literature, researchers and historians have shown how colonial practices and policies engineered the societal preference for English. What we do not know however is how our current policies and practices in education continue to create a discourse favorable to dominant English language and literacies and marginalize Ghanaian languages, literacies, cultures, and histories. I was interested in how the Ghanaian curriculum represents this dichotomy of English and Ghanaian languages to students in the curriculum and perhaps how it naturalizes preference for the English language and literacies. My goal in this paper was that by understanding how English is centered in the curriculum, I could identify how to redesign policies, practices, and curriculum content to reflect the diverse languages and literacies in Ghana. My research questions were guided by a combined theoretical framework of critical literacy theory and English linguistic imperialism explained in chapter two. There were three main and four sub-questions that guide this study:

1. What discourses of English linguistic imperialism are in the Ghanaian primary school (K-6) curriculum?

a. How does the curriculum including content, assessment, and teaching and learning activities maintain the exclusionary force of dominant English practices and discourses? (Design/Power) 
b. In what ways does the discourse of the curriculum critically resist English linguistic imperialism? (Power/Design)

2. What is the discourse about Ghanaian languages and literacies in the Ghanaian primary school (K-6) curriculum?

a. How are Ghanaian languages and literacies including various Ghanaian cultures and their histories, represented in the curriculum? (Diversity)

b. How does the design of the curriculum provide students access to diverse Ghanaian languages, literacies, cultures, and histories?

(Access/Diversity/Design)

3. How do educational leaders talk about the K-6 curriculum and what it should include/exclude?

\section{Research Design}

A qualitative research design was the most appropriate means of answering my research questions. Savin-Baden and Major (2013) explain that qualitative research focuses on understanding "individuals, cultures, and phenomena rather than to analyze relationships between variables or to test cause-and-effect relationships" (p. 13). Qualitative research often describes the complex and varied views of knowledge and reality of individuals, cultures, and phenomena in other to provide more in-depth understanding and insights into these individuals, cultures, and phenomena. Within this research tradition, this study drew on a critical discourse analysis (CDA) to examine how powerful discourses deprivilege, negate, devalue, or marginalize other discourses including other ways of being. CDA identifies how discursive practices, events, and texts 
work to oppress, silence, influence, or shape others often through institutions, signs, and systems of authority within a society (Fairclough, 2013).

\section{Critical Discourse Analysis}

Gee (2014) explains that, unlike discourse analysis, the goal of CDA "is not just to describe how language works or even to offer deep explanations, though they [critical discourse analysts] do want to do this. They also want to speak to and, perhaps, intervene in, institutional, social, or political issues, and problems, and controversies in the world" (p. 9). All language creates meaning, according to Gee (2014), and is therefore political and as such "any use of language gains its meaning from the 'game' or practice of which it is part and which it is enacting" (p. 10). Within institutions, signs, and systems of authority, the "game" or practice, as Gee (2014) explains, involves "potential social goods and the distribution of social goods" (p.10) and in this study, the social goods are languages and literacies that are either privileged or not. This study, therefore, examined how discourse around certain policies and practices in education affects the "centering" of which language and literacies.

Fairclough (2013) also adds that CDA, "aims to systematically explore often opaque relationships of causality and determination between (a) discursive practices, events, and texts, and (b) wider social and cultural structures, relations and processes; to investigate how such practices, events, and texts arise out of and are ideologically shaped by relations of power and struggles over power; and to explore the opacity of these relationships between discourses and society itself a factor securing power and hegemony" (p. 93). A CDA design was aptly fit for this study because of the power struggles between English and Ghanaian languages. From the history of colonial 
practices in education discussed in chapter two, the discourse of English emerges as a language of civilization and progress by which missionaries and the colonial governments shaped educational policies and practices. The narrative of Ghanaian languages as tools to only convert the natives to Christianity and for religious instruction ensured that more efforts were spent to make the native acquired literacy in English to best serve the interests of the colonial rulers. The discourse of Ghanaian languages and English are therefore ideologically shaped by relations of power and struggles over power such that a CDA approach was the best approach to investigate how to deconstruct the power and hegemony of English in order to reconstruct new educational practices with Ghanaian languages and literacies at the center.

\section{Data}

In order to answer my research questions and to begin the process of deconstruction, I fully examined the Ghanaian curriculum, specifically, the recently introduced 2019 primary school curriculum for Kindergarten to Primary Six. Before I discuss why I focused on this data, I first briefly explain the Ghanaian educational context and the place of the curriculum in shaping education.

\section{Context}

The curriculum in Ghana as discussed earlier in chapter two is determined to a large extent by the ruling government of the day. There have been as many reforms or reviews to education as governments because each government conducts a review of education when it assumes power and makes changes it sees fit (Aziabah, 2018). The curriculum of Ghana is created for the entire nation and as such, no local district or administrative region creates an independent curriculum. This is because each student, at 
least twice, during pre-tertiary education takes a standardized national examination based on the national curriculum and that determines students' advancement first to senior high school (SHS) and the other exam after SHS determines advancement to tertiary institutions. Currently, between kindergarten and the final year of junior secondary school (the eleventh year of schooling), apart from classroom assessments, there is no national assessment.

\section{Designing the Curriculum}

In 2007, the National Council for Curriculum and Assessment (NaCCA) was established first as an advisory board to the Curriculum Research Development Division (CRDD) whose primary responsibility was to "manage and implement the curriculum policy of the Ministry of Education" (NaCCA, 2019, “About Us”). However, in 2008, through a legislative act, Act 778 , the NaCCA became an independent statutory body responsible for creating, revising, approving, and implementing the national curriculum. The NaCCA, for the first time, began to undertake a comprehension revision of the national curriculum for pre-tertiary education. In September 2019, it implemented the new curriculum for only primary school education with plans to implement a new curriculum for junior and secondary schools in later years.

\section{Data Selection}

I limited the scope of the data therefore to only the K-6 primary school curriculum because, during this phase of education, Ghanaian languages are incorporated more in the curriculum initially as languages of instruction and then in upper primary school class as required subjects. Examining just the primary school curriculum helped explain how the discourse of English dominance and preference for English are transmitted on to students 
who are in the formative stages of education. This stage in education is crucial because as discussed in chapter two, students in upper primary levels (primary four to six) already prefer English instruction even though they comprehend course content in it less (Davis et al., 2015; Edu-Buandoh \& Otchere, 2012). Therefore, it was appropriate that in order to understand how dominant English discourses persist at such an early stage in education, there was a need to examine the main documents that set the agenda for primary school (K-6) education - the primary school curriculum.

Data from the Curriculum. The entire primary school curriculum for (K-6) comprises several individual documents. These documents are:

1) National Pre-tertiary Education Curriculum Framework, a 92-page document that details the expectations, goals, and standards of education in primary and secondary schools in Ghana in all subjects.

2) 17 individual curriculum documents for 12 subjects taught at the primary school level including kindergarten: English Language, Creative Arts, Computing, French, Ghanaian Language, History, Mathematics, Our World and Our People (OWOP), Physical Education (PE), Science, and Religious and Moral Education (RME).

3) Teacher Resource Pack for Kindergarten.

4) Teacher Resource Pack for Primary 1 to 6 subjects.

Out of the 12 subject areas I only focused on the subject curricula for English language, Ghanaian languages, History, Creative Arts, Our World and Our People, and Religious and Moral Education. I focused on these subject curricula because to understand how English is privileged and Ghanaian languages are marginalized, the English language 
curriculum and Ghanaian languages curriculum are key to this study. I included Creative Arts because it also suggested a literacy focus. From the literature discussed in chapter two, religion studies, history, and culture are subject areas that were wielded to present an unfavorable and negative view of indigenous and local ways of being. As a result, I also examined the History, OWOP, and RME curricula as part of my analyses. The teacher resource pack is as a complementary document that serves as a reference for teaching when preparing classroom lessons. While an examination of the national framework alone might answer my questions, a full examination of the curriculum for each subject area would provide more insight into how these discourses are strengthened by the content of teaching and learning and also by how students are assessed (See Table 1 for a full list of documents that make up the primary school curriculum and Appendix A for a sample of the History curriculum).

\section{Table 3.1}

Data from the Curriculum

1. National Pre-tertiary Education Curriculum Framework

2. Teacher Resource Pack for $\mathrm{K} 1$ and $\mathrm{K} 2$

3. Teacher Resource Pack for all primary subjects

4. English Language Curriculum for Primary Schools Basic 1-3

5. English Language Curriculum for Primary Schools Basic 4-6

6. Creative Arts Curriculum for Primary Schools Basic 4-6

7. Computing Curriculum for Primary Schools Basic 4-6

8. French Curriculum for Primary Schools Basic 1-6 
9. Ghanaian Language Curriculum for Primary School Basic KG1Basic 3

10. Ghanaian Language Curriculum for Primary School Basic 4-6

11. History Curriculum for Primary Schools Basic 1-6

12. Mathematics Curriculum for Primary School Basic 1-3

13. Mathematics Curriculum for Primary School Basic 4-6

14. Our World and Our People Curriculum for Primary School Basic $1-3$

15. Our World and Our People Curriculum for Primary School Basic 4-6

16. Physical Education Curriculum for Primary School Basic 1-6

17. Religious and Moral Education Curriculum for Primary School for Basic 1-6

18. Science Curriculum for Primary School for Basic 1-3

19. Science Curriculum for Primary School for Basic 4-6

20. Curriculum for Kindergarten 1 and 2

Data from Educational Leaders. Analyzing the curriculum data was essential because it showed what is valued or not in education. However, I also included in my data what educational leaders in government especially policymakers and curriculum designers say publicly is the goal of Ghanaian education, to more fully understand the place of English and Ghanaian languages and literacies. The data from educational leaders was important in understanding the discourse of the curriculum because as 
discussed earlier in chapter two the beliefs and practices of colonial government leaders and later Ghanaian government leaders shaped what was included and excluded in mainstream education (See discussion on Davis \& Agbebyegah, 2012; George, 1976). I focus on the discourse from 2017 to 2019 around the time when educational leaders were having public discussions about creating and implementing a new curriculum.

To give more context, in the past two years the government identified increasing access to senior secondary education as a way to solve inequities in education. The government created a Free SHS program where any junior secondary school student who passed the national Basic Education Certificate Examination (BECE) would be able to attend senior high school tuition free. The BECE is the first major exam in education that transitions students from junior high school (JHS) to senior high school (SHS). The Free SHS program increases access to senior secondary school from primary and junior secondary school but the program does not fails to address how the inequities came to exist early on in primary school. To pass the BECE in the last year of JHS, just three years after completing primary six, means that a student has become proficient in the English language. As discussed in the literature in chapter two, students in upper primary are shown to still struggle with teaching and learning in English (Owu-Ewie \& Eshun, $2015,2019)$. As a result, it was important for me to analyze the public discourses around this time when the new curriculum was also being created.

Therefore, I analyzed publicly available videos of members of the Ministry of Education (MoE), Ghana Education Service (GES), and NaCCA being interviewed or giving public speeches about the goals, future, and present state of education in Ghana 
including specific discussions about the curriculum. These videos are publicly available on Ghanaian news media websites and on their social media platforms.

\section{Data Collection}

The entire documents of the primary school curriculum except for the curriculum for kindergarten (K1 and $\mathrm{K} 2$ ) can all be found on the NaCCA website (nacca.gov.gh). I downloaded all the documents and saved them in my personal online drive. Because these documents were recently published in March 2019 and are currently being used in classrooms since September 2019, there are not revisions or changes to these documents without prior public announcements. However, I constantly kept checking the NaCCA website for any updates to these documents until I commenced my data analysis. By the time I finalized my results there were not any new revisions or changes and I expect there will not be any time soon. With regards to the kindergarten curriculum, the NaCCA has still not published the curriculum online and so I contacted a current kindergarten teacher in Ghana to send me a copy of the current curriculum since all teachers since the fall of 2019 received professional development workshops on the new curriculum and each received copies.

To collect the video data on educational leaders, I visited the websites and social media feeds of major news outlets in Ghana such as Myjoyonline, Citi News, Ghana News Agency, Graphic Online, and Ghanaweb. In the search engine of these news outlets, I used keywords such as "new curriculum," "NaCCA," "2019 curriculum ghana," "Ministry of Education + curriculum," "minister of education ghana," "education ministry speech," and "meet the press education ministry ghana". These news platforms also provided access to video content which included videos of public radio and 
television programs on their Youtube channels using the same keywords. An initial search on Youtube using the keywords above return over a page with over 50 videos. I went through each link and saved any video or audio published by any Ghanaian major news outlet that had a title and brief description that references the Ghanaian curriculum and or a member of the MoE, GES, or NaCCA in a discussion or speech specific to education. I also selected only videos published within the last four years because during this period is when the NaCCA began to review and implement the current primary school curriculum. I initially planned to analyze a minimum of five video or audio data but I included more data progressively in my analysis until the analysis from additional video and audio data does not include any new findings, following a typical grounded theory approach of saturation (Saunders et al., 2017). I excluded data that was less than 5 minutes in length because it did not contain enough information for an in-depth CDA. In Table 3.2, I have listed the data from educational leaders I used in my analysis.

\section{Table 3.2}

\section{Data from Educational Leaders}

\begin{tabular}{|c|c|}
\hline $\begin{array}{l}\text { Title of } \\
\text { video/audio found }\end{array}$ & Description Provided /Link/ Time and Duration \\
\hline 1. Dr. & At the Global Education \& Skills Forum, the global education \\
\hline Matthew & community, long underfunded, politicized, and out of the \\
\hline Opoku & spotlight, showed it was ready for change. Devex was there \\
\hline Prempeh, & with our ear to the ground to help the global development \\
\hline Ghana & community take stock of what these coming shifts might \\
\hline
\end{tabular}




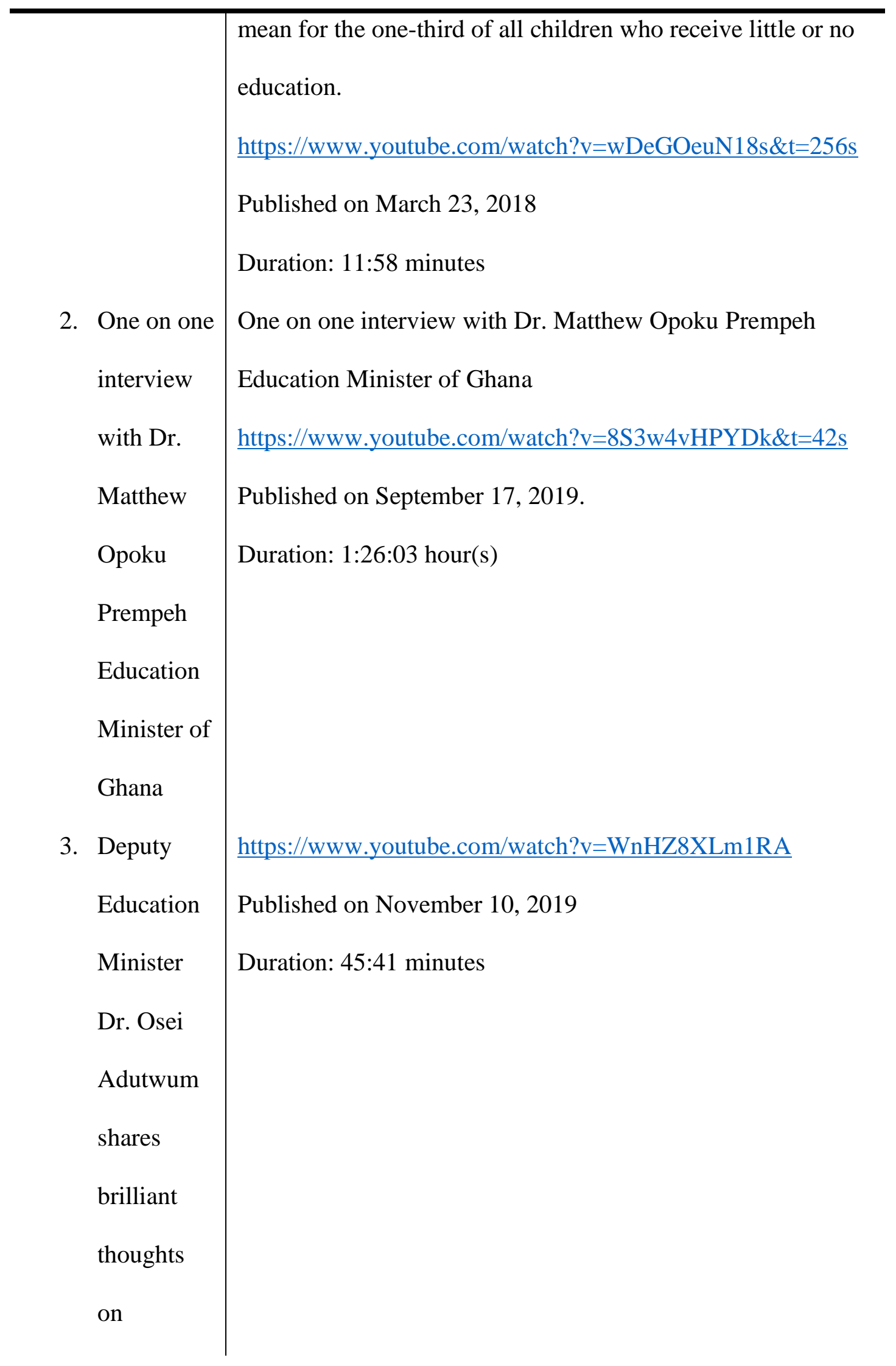




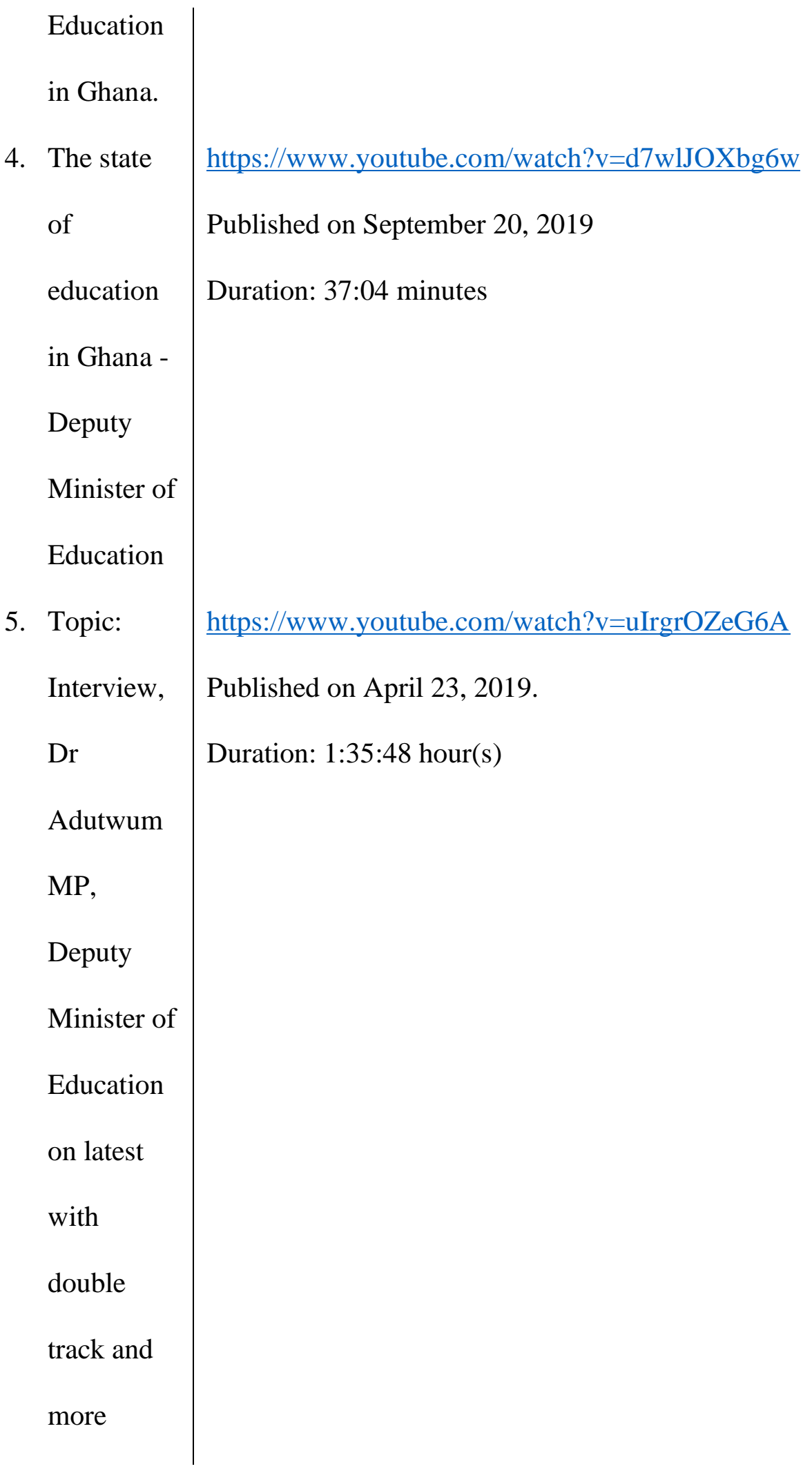


6. Education

Minister

Meet the

Press,

Discusses

Important

issues on

Education

7. Education

Ministry

Responds

To

Pertinent

Questions

On New

Curriculum

- AM Talk

on

JoyNews

$(3-9-19)$

8. Face to

face with

Dr. Yaw https://www.youtube.com/watch? v=yhnBwCMZYkw\&t=291s

Published on November 20, 2018

Duration: 1:37:29 hour(s)

Education Ministry Responds To Pertinent Questions On New

Curriculum - AM Talk on JoyNews (3-9-19)

Improving Education In Ghana: New Curriculum is meant to cure defects in the old system - Ekow Vincent

https://www.youtube.com/watch?v=RP0aHt9d77g

Published on September 3, 2019

Duration: 44:44 minutes

Godfred Akoto Boafo hosts the deputy minister for education,

Dr. Yaw Osei Adutwum on this edition of Face to Face.

https://www.youtube.com/watch?v=DrbKY-2Aq3U 


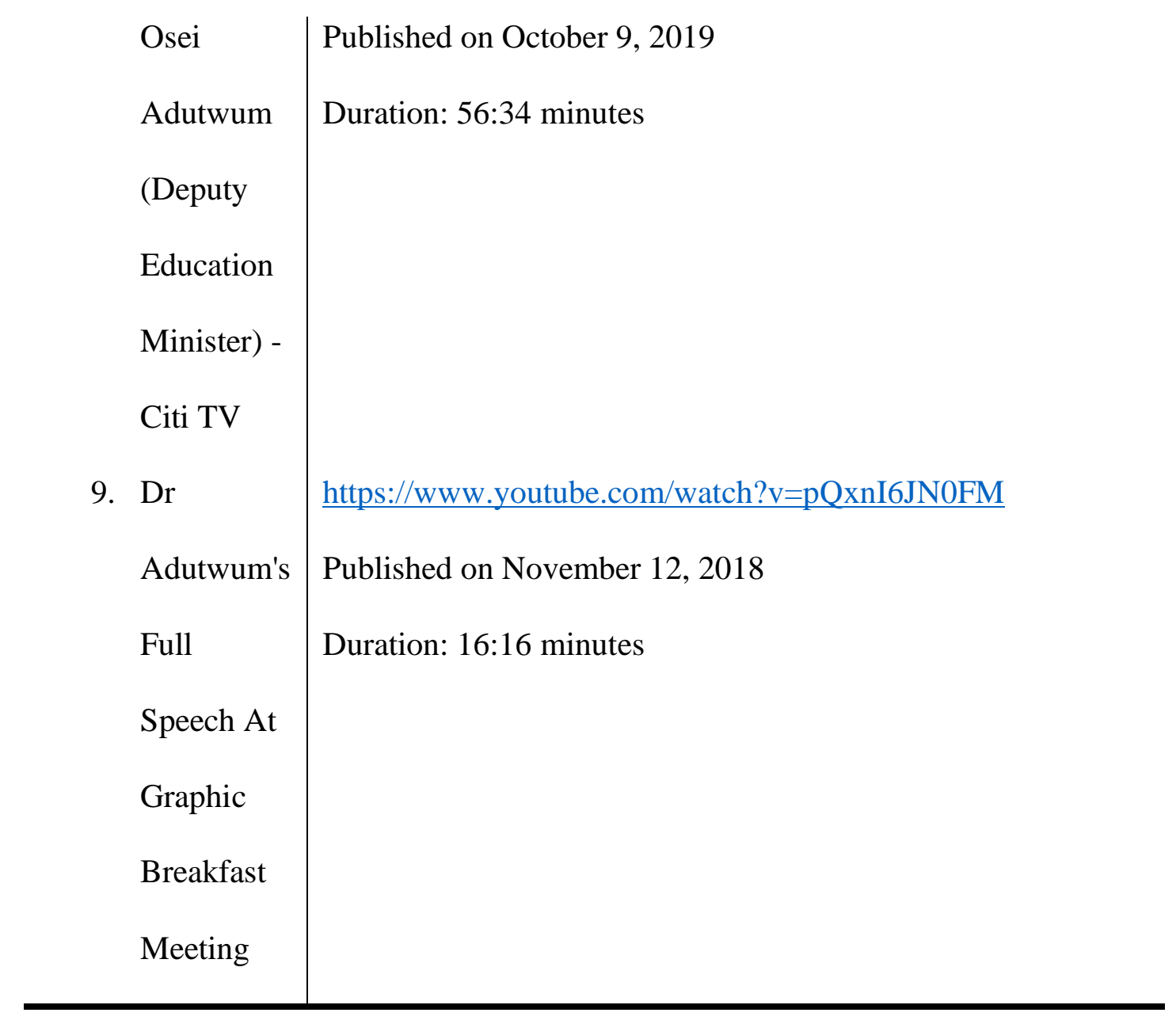

\section{Data Analysis}

There are several approaches to CDA and while I drew from Gee (2014) in how to segment data, I primarily applied Fairclough's (2013) approach to my data analysis. Fairclough (2013) explains that each discursive practice, text, and event, that is, any piece of data that contains discourse, has three dimensions, "[1] it is spoken or written language text, [2] it is an instance of discourse practice involving the production and interpretation of text, and [3] it is a piece of social practice" (p. 94). Each of these dimensions provides a way of examining data. Even though most of my data was primarily written or spoken language text, it was also related to all these dimensions because the curriculum I was 
examining generates "real" discourse and social practices in the classroom where teachers and students negotiate enact what the spoken and written language texts in my data expects them [teachers and students] to embody. The analysis of the spoken and written language texts was generally in its form-and-meaning (Fairclough, 2013).

To analyze the form-and-meaning of data, Fairclough (2013) recommends asking questions about representation and signification, the constitution (establishment, reproduction, and negotiation) of identities, the distribution of given versus new and foregrounded versus backgrounded information, and the structure of texts. I explain below how this worked in terms of how I analyzed the data I collected.

\section{Step-by-Step Process to CDA}

I primarily drew on two types of data, written and spoken language text - data from the curriculum and data from educational leaders respectively. I first explain how I analyzed the written language text and then the spoken language text. I first uploaded all my data to a qualitative research software, MaxQDA, to make it easier to handle coding and writing memos in the documents and also easily work across texts in finding what's common and uncommon.

Analysis of Written Language Text. I initially read through all of the document data, to immerse myself in the data, and to get a sense of what the data might include. I wrote memos for each document to track analytical thoughts throughout the analysis process. On my second read, I began open coding by categorizing in MaxQDA the main ideas discussed in each paragraph. Using these open codes, I began segmenting the data into Gee's (2014) stanzas, where each stanza contained only one main idea. Gee (2014) suggests that it makes it easier to examine the large piece of the written text in this study 
by segmenting them and finding connections across stanzas. Applying my theoretical framework, I selected any stanza that was directly or indirectly related to discussions of English and Ghanaian language and literacies for further analysis. I then applied Fairclough's (2013) CDA approach by asking questions of each selected stanza. Fairclough's CDA. For each selected stanza I examined (1) what topics were introduced, taken up, and dropped; (2) what aspects of the stanza created coherence and flow, conflict and disharmony; (3) how was this stanza drawing on other texts/stanzas (intertextuality) (Fairclough, 1992); (4) what ideas were represented; (5) how were they represented in terms of choices of word choices, verbs, and pronouns; (6) what idea was emphasized; (7) what information was possibly excluded or silenced; (8) what aspects within the stanza expressed obligation, permission, and probability; (9) what identities were being encouraged or discouraged; and (10) how were some ideas positioned to other ideas? Answering these questions with each selected stanza helped uncover the discourse(s) in the data (Gee, 2014; Rogers \& Wetzel, 2013).

Next, taking the discourse(s) found using the ten questions above, I examined each discourse(s) using the four components of critical literacy in my framework asking what did the discourse(s) say about how (i) Power, (ii) Access, (iii) Diversity, and (iv) Design (See Table 3 for a Sample CDA of my data). After analyzing each data selected, I wrote memos to document the various discourses found. This made it easy to look across all the various pieces of data in order to broader conclusions.

Analysis of Spoken Language Text. I went through a similar step-by-step process with the video data but I first transcribed each video using Otter, a transcription software. Using Jefferson's (1984) notations, in the transcriptions, I only marked up 
words or phrases that were emphasized by the speakers because I was more interested in what was said (and unsaid) about the curriculum in this study (See Appendix B for a sample transcript). I followed the same process in segmenting the transcript into stanzas and combed through the data using Fairclough's CDA questions above. After all the data had been analyzed, I looked across the discourse in the curriculum and of educational leaders to understand the broader discourse at large concerning English and Ghanaian language and literacies in the data. This comparison also served as a means of data triangulation that informed initial conclusions.

\section{Table 3.3}

Sample CDA Analysis

Data Selected: "The intention of the government to prioritise the fundamental building blocks for success at the basic school level is in line with the global thinking regarding quality education, socio-economic development, the skills requirement and the focus of the Africa Union. Ghana's entrepreneurial sector is a key target for development, while the government is simultaneously embarking on the most comprehensive industrial transformation programmes in the country. This requires policies necessary to promote better cognitive skills development for all, addressing the fact that scientific literacy and entrepreneurial knowledge and skills development is in urgent need of attention in Ghana. This framework therefore has at its heart educational strategies that ensure that all learners leave school as scientifically-literate citizens. Good foundations must be laid in mathematics and the other STEM 


\begin{tabular}{|c|c|c|}
\hline \multicolumn{3}{|c|}{$\begin{array}{l}\text { transformed into a mathematics friendly one in which Science, Technology, } \\
\text { Engineering and Mathematics (STEM) education is at the fore." (National Pre- } \\
\text { tertiary Education Curriculum Framework, p. 1, para. 3-4) }\end{array}$} \\
\hline Stanzas & First-level analysis & Second-level analysis \\
\hline (Stanza 1) & (1) what topics are & What does the \\
\hline The intention of the & introduced, taken up, and & discourse in the first \\
\hline government to & dropped & level say about the \\
\hline prioritise the & - In both stanzas is scientific & following: \\
\hline fundamental building & literacy, STEM education at & Power: although I \\
\hline blocks for success at & the primary school level is & would need to see the \\
\hline the basic school level is & considered a driving force & whole curriculum to \\
\hline in line with the global & of Ghana's industrial & see how this idea is \\
\hline thinking regarding & development is taken up. & expressed \\
\hline quality education, & - Also, education as a way & throughout, at least \\
\hline socio-economic & to equip students with skills & based on this data, \\
\hline development, the skills & in nation building is also & students who are \\
\hline requirement and the & taken. & interested and do \\
\hline focus of the Africa & - The focus of the African & well in science and \\
\hline Union. Ghana's & Union is not explained or & math may benefit the \\
\hline entrepreneurial sector is & developed further. Why & most and they would \\
\hline
\end{tabular}




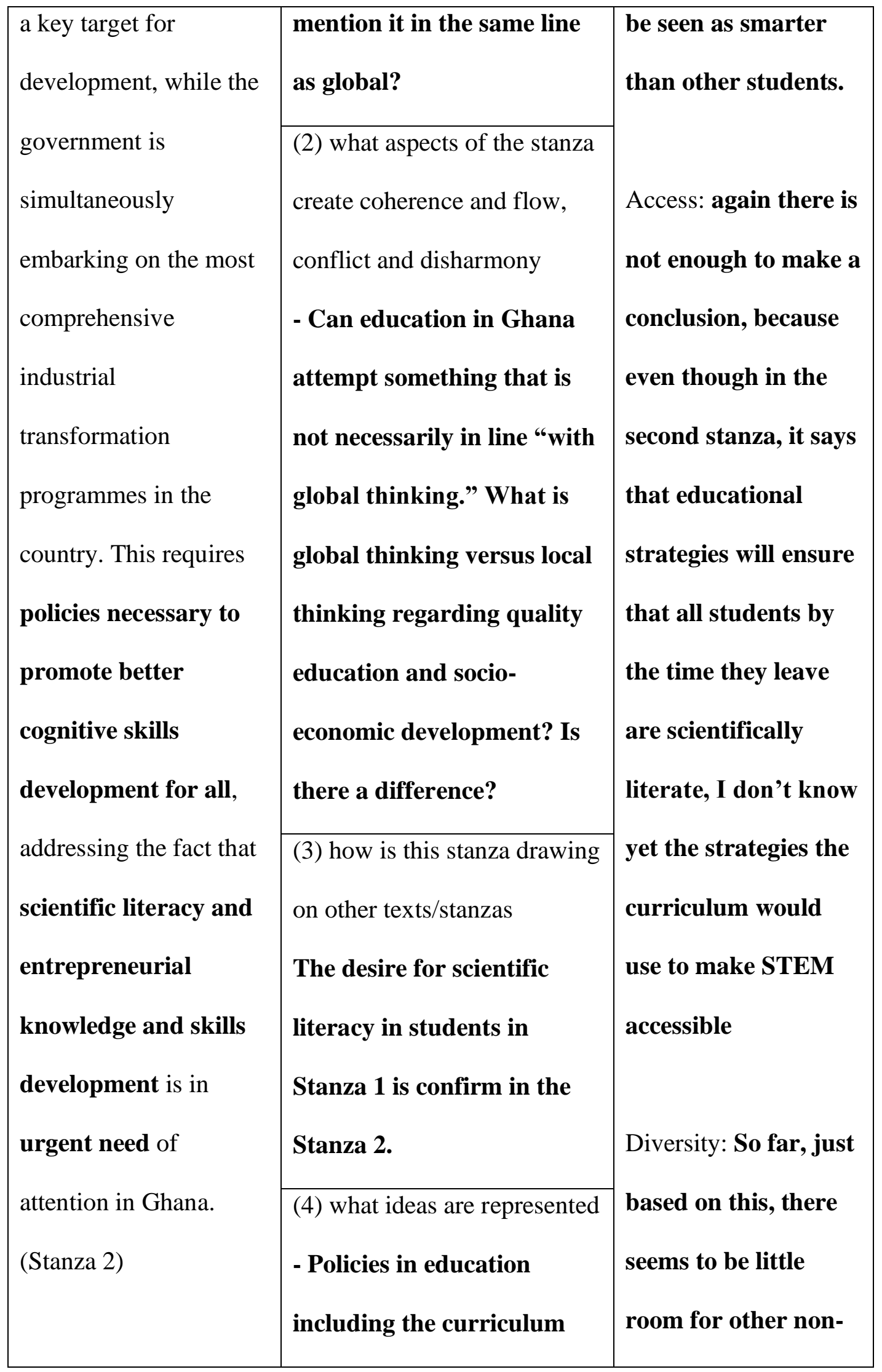




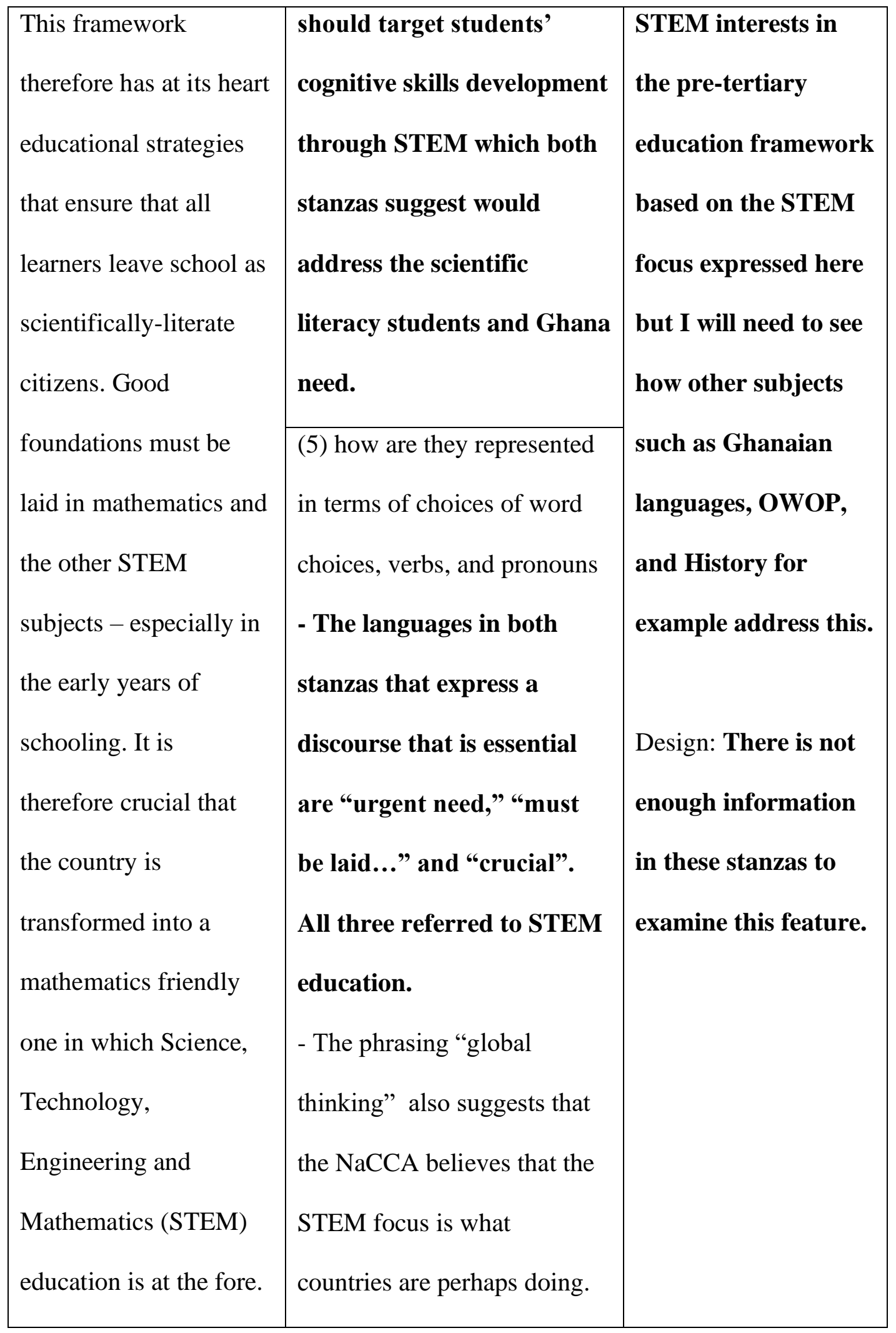




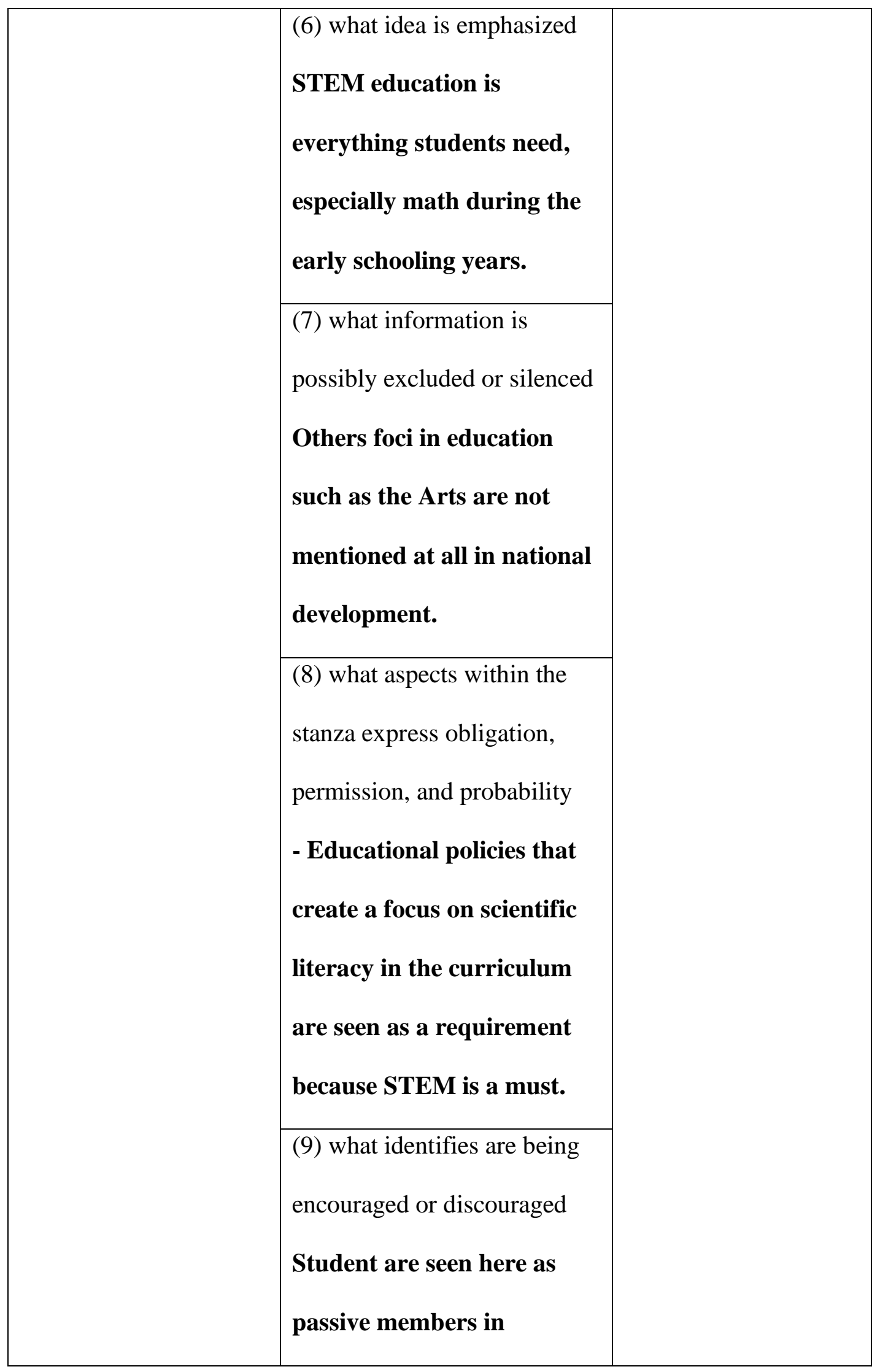




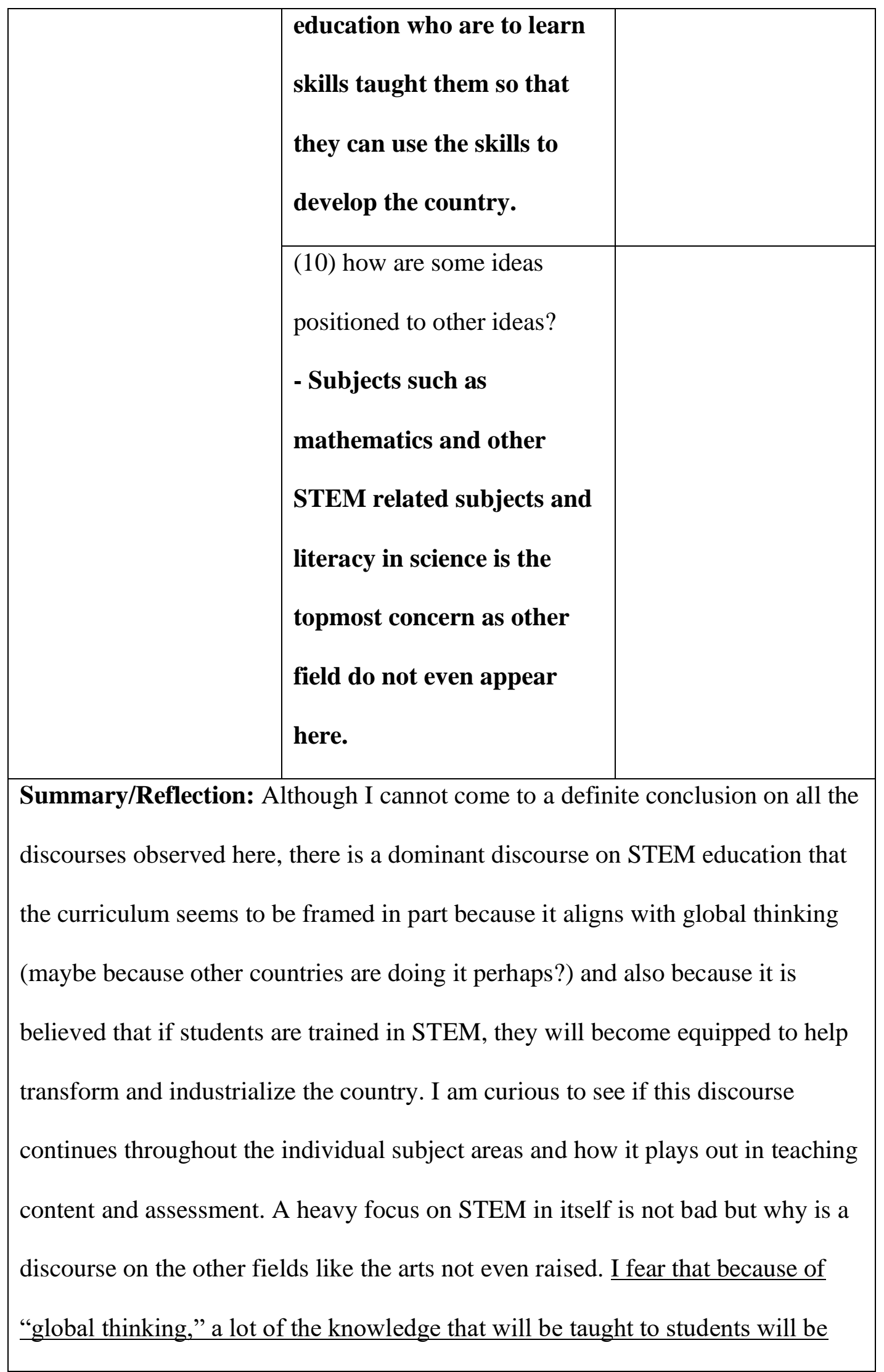


imported from industrialized Global North countries and that might imply less

focus on Ghanaian literacies, languages, cultures, and histories. This also means

looking at which organization(s) apart from the NaCCA are a part of designing

the curriculum. It may indicate if there are many other external voices/influences

in creating the curriculum.

\section{Credibility, Trustworthiness, and Bias}

Validity and reliability are terms synonymous with quantitative research traditions and designs where researchers make sure that their studies test exactly what they hypothesized and also that each time the same study is repeated the same results would occur (Creswell \& Creswell, 2017). In qualitative research, however, the importance of credibility and trustworthiness is highlighted (Merriam \& Tisdell, 2016). Researchers employ various ways to establish that their findings are credible and trustworthy by asking others to re-analyze individual portions of data, by writing memos that detail the researcher's analytical thoughts and processes, using multiple sources of data to ask the same question, and triangulating findings from different sources of data (Emerson, Fretz, \& Shaw, 2011; Merriam \& Tisdell, 2016).

To address the above, I analyzed a large part of the curriculum rather than just picking from a few curriculum documents that might answer my questions because ethically to uncover the discourse in education, leaning on a few sources of data such the English language curriculum and Ghanaian languages curriculum only would have obscured the other competing discourses that run through the entire curriculum and it would have painted a poor picture of how one language might be centered or not 
throughout the curriculum. I also wrote several memos to document my thought process and reflections through the analysis to serve as an audit trail for each step. I also asked peers including former and current Ghanaian students to comment on emerging findings throughout the process to enable me to confirm or disconfirm findings. I also confirmed or disconfirmed findings by triangulating them using my two sources of data - data from the curriculum and data from educational leaders - by discussing my findings with several instances and examples how widespread the discourses were in the educational curriculum.

I also brought both an insider and outsider positionality to this study, which I viewed as an advantage especially in data analysis. As a student in Ghana, I did not think much about Ghanaian languages and how valuable they could be as part of learning. Most of my education focused on English acquisition, English literacy, and English proficiency and so I was trained to see Ghanaian languages and literacies not necessarily as critical to my education. However, because I have lived and schooled in other countries as well, those experiences allowed me to see how dominant discourses in society often marginalize groups of people and often because of my work in those communities (Bonney, Bonney \& Sweeney, 2021). I argue that insiders are not fully aware of all the ways dominant discourses marginalize others. This is a realization that just insiders or just outsiders may not see but having both positions enabled me to see the various discourses, the dominant discourses, and the ones that are silenced. Nevertheless, I conducted constant peer checks, wrote memos, and triangulated my data to ensure that what I presented in chapter four is representative of the discourse in the data. I contend that if we do not constantly question, challenge, and critique dominant English 
discourses, as is the case of this study, then education in Ghana runs the risk of silencing or marginalizing Ghanaian languages, cultures, and histories, rendering them extinct to history.

\section{Summary}

The purpose of this chapter was to explain why a critical discourse analysis was appropriate in deconstructing dominant English discourses and hegemony in the curriculum. Additionally, I specified the research questions that guided this study and I also discussed why the data I collected and analyzed was the best means to answer my research questions. I then explained the CDA method I applied to examine the data and I concluded by discussing a few ethical considerations about my study. 


\section{CHAPTER FOUR: FINDINGS}

In this chapter I share representative findings from my analysis of the public discourse of educational leaders and the primary school curricula for K-6 education including the Pre-tertiary Education Curriculum Framework. I explained in the previous chapter that the National Pre-Tertiary Education Curriculum Framework (NPTECF), distinct from the K-6 primary school curricula, is a document that explains the aims and objectives of education, assessment policies and practices, and structure of schooling. The K-6 primary school curricula, on the other hand, are made up of 10 curriculum for 10 subjects such as Ghanaian Languages, English, Science, Mathematics, Computing, Religious and Moral Education (RME) to name a few, and this also includes a Teacher Resource Pack for each of these subject area with sample lesson plans and worksheets. Framed by theories of English linguistic imperialism and critical literacy, my research examined the representation of Ghanaian languages and cultures and discourses of English linguistic imperialism in the curriculum and how educational leaders and the K-6 curriculum in Ghana position English and Ghanaian languages.

I found in my analysis that the language-in-education policy is not specific about the use of Ghanaian languages at the lower primary school level. The Ghanaian Languages Curriculum is also structured and modelled after the English Curriculum, but the time periods allocated the teaching and learning of English is double that of Ghanaian languages. Also, the teaching and learning of Ghanaian languages because of the design of the curriculum is mostly separate from the teaching and learning of Ghanaian histories, cultures, and knowledge. This happens because subjects such as Creative Arts, RME, History, and Our Word Our People (OWOP) that emphasize content in Ghanaian 
histories, cultures, and knowledge are taught in English by primary four. I also found that educational leaders in addressing how to make education and the curriculum more equitable referenced what foreign countries were doing in education when they discussed addressing educational equities and developing curriculum. Because educational leaders look at what other countries are doing, their discourse does not consider the role of Ghanaian languages in the curriculum. These findings are grouped, expanded, and discussed under each main and sub-research question below.

\section{Discourse in the K-6 Curriculum}

In this section I discussed findings from the analysis of the K-6 curriculum. I divide the findings into two main sections framed by my research questions focused on exploring the discourses of English linguistic imperialism and discourses of Ghanaian languages and literacies. Discourses of English linguistic imperialism are shaped by several elements in the curriculum. Firstly, the language-in-education as written in the NPTECF is vague on the importance and place of Ghanaian languages in education. Secondly, students receive more time and content in English compared to Ghanaian languages and as such the curriculum places higher expectations from students in English. Another key element is that the Ghanaian Language Curriculum is written in the English language and framed in English ways of speaking and as such treats all Ghanaian languages as similar. Discourses of Ghanaian languages and literacies are also shaped by several elements in the curriculum. Firstly, in the teaching and learning of history for example, development of Ghana is shown to have begun when colonizers arrive. The curriculum white-washes history and portrays a favorable view of European colonialism. Secondly, students learn more about Ghanaian cultures, knowledge, belief systems, and 
histories in other subject areas that are taught in English and not in the Ghanaian Language Curriculum.

\section{Discourses of English Linguistic Imperialism}

The research questions that guided the analysis for this section are as follows: What discourses of English linguistic imperialism are in the Ghanaian primary school (K6) curriculum? Specifically (a) How does the curriculum including content, assessment, and teaching and learning activities maintain the exclusionary force of dominant English practices and discourses? (Design/Power) (b) In what ways does the discourse of the curriculum critically resist English linguistic imperialism? (Power/Design). The findings below demonstrate the following. First, the discourse of the language policy as written in the Pre-tertiary Education Curriculum Framework is not explicit about the importance of educating Ghanaian students with Ghanaian languages such that it creates more room for English dominance. In addition, there is more time and content in the study of English than in Ghanaian languages. As a result, there are higher expectations from students in English than in Ghanaian languages and assessment practices places more weight on languages, especially English. Finally, linguistic imperialism or more broadly, imperialism permeates every subject, as shown through an example analysis of the History Curriculum, which takes a more than favorable view of European colonization.

\section{Flexible or Vague: What Exactly is the Language Policy?}

The pre-tertiary curriculum framework describes that the current language policy in education recommends Ghanaian languages as the language of instruction (LOI) as early as Kindergarten $(\mathrm{KG})$ for students in communities who have not previously been exposed to English. The policy follows from 2007 where Ghanaian language as a LOI 
was expanded from primary one (grade 1) to start much earlier in KG. However, English is also to be introduced to students at the same time in $\mathrm{KG}$ in addition to Ghanaian languages. The policy states that schools should use "70\% local language and $30 \%$ English language from Kindergarten to primary three with English Language thereafter" (Pre-tertiary Curriculum Framework, 2019, p. 68). Although the policy suggests Ghanaian languages as the main LOI, implementation looks different when the policy also insists on the introduction of English at this early stage especially when it is the first year of schooling for many students who are perhaps now seeing their own language in written form. Opoku-Amankwa and Brew-Hammond's (2011) research has confirmed that some teachers and school leaders interpret the necessity to teach English in early years of schooling as directive to prioritize teaching English since it is seen as more valuable higher up the educational ladder (Edu-Buandoh \& Otchere, 2012).

Out of 86 pages in the Pre-tertiary Education Curriculum Framework, there is only one page dedicated to the "Language of Teaching and Learning" (p. 68). The other pages outline the structure of schooling, the reasons for a new curriculum, assessment policies, overall goals of education in Ghana, and pedagogical approaches. Three-fourths of the "Language of Teaching and Learning" page discusses the various language policies that Ghana has used from the year 1529 to present day. The initial paragraph recognizes that there are 11 Ghanaian languages approved for teaching and learning in schools but also that "the use of Ghanaian languages as the medium of instruction at the lower primary level has had a ${ }^{8}$ chequered history [emphasis added]" ( $p$ 68). In resolving this "chequered" history, there no mention of why Ghanaian languages are essential to the

\footnotetext{
${ }^{8}$ Bold emphases in data excerpts throughout this chapter are mine
} 
teaching and learning process or to students. Rather, the authors of this documents draw from "many national contexts" to explain that "school teachers base their daily routines on 'three assumptions of normality':

“a. society wants only a smaller proportion of a student cohort to qualify for professional (academic careers); b. learners are competent native speakers in the dominant language of schooling; and c. they are used to the school's particular patterns of language use since in their (learners) families, reading and writing is a major concern" (p. 69).

These assumptions are perhaps explaining why educators and other stakeholders in education resist the use of Ghanaian languages because it may be seen as acceptable if few students can master English, pass exams and progress to higher education and then to professional. In other words, it is assumed according to the framework of the curriculum that it is normal (1) if few students do well in school, (2) that students have to become competent in English, the dominant language of schooling, and (3) that because of the background of some students they cannot read or write in English. All these assumptions center English as normal and required for students, without even considering the native languages of students which is likely not the dominant language of schooling. The curriculum presents these assumptions as the reasons why language policies may be "chequered" but in the curriculum these assumptions are not countered or opposed. The curriculum does not defend/promote the native language of students against the dominant language of schooling - English. By not disagreeing with these assumptions, the curriculum supports them. The "Language of Teaching and Learning" section in the Pretertiary Education Curriculum Framework concludes by suggesting to educators and 
other stakeholders that "school is a discourse community with its ways and means to use language as a medium or tool for making meaning, i.e. teaching and learning content across the curriculum" (p. 69).

It is undeniable that language is a tool for making meaning but for Ghanaian students, their native languages is more than just a tool. Their native language is a part of their identity and how they interact with the world. The position that English is a tool for making meaning so educators and students should embrace it, is equally and even more applicable to the use Ghanaian languages. What the curriculum does not do here is overtly defend the importance of Ghanaian languages which creates a reason for educators to do what they think is best, and they often think English is best. The conclusion that "school is a discourse community" and that language is a tool for making meaning could be interpreted by the educators, schools, and the system as English is the [emphasis added] tool students must learn to use if they want "qualify for professional (academic careers)." If students have academic challenges with existing status quo where English is the main and arguably the only tool for meaning making then, is a students' failure to progress academically their fault if their own language is not considered an adequate tool? Without defending or challenging the "assumptions of normality" raised in the framework, the curriculum agrees with the assumptions.

\section{More Time in English}

The rejection of the assumptions of normality above are crucial especially considering the position of Ghanaian languages as the main LOI and English in KG. The Kindergarten Curriculum directs that activities at this stage are "to encourage learners to listen carefully, recite, sing, carry out instructions and speak both the Ghanaian and the 
English languages with confidence" (KG Curriculum, p. xvii). However, the next paragraph then insists that, “

The teacher must endeavour to do frequent read aloud with learners especially in the English language so that they will be exposed to the oral aspect of the languages. The daily/frequent reading must integrate the instruction of the language skills. This practice will facilitate their language skills, enrich their vocabulary and inculcate in them the habit of reading" (KG Curriculum, p. xix).

English is seen as so crucial even at the beginning stage where students are to enjoy seeing and interacting in their home language perhaps for the first time in print. As a result, Ghanaian languages are never given full attention. English acquisition is tied to vocabulary and the habit of reading. The same assumption is not applied to the learning Ghanaian language even at this early stage:

"Above all, the teacher must endeavour to use the mother tongue-based bilingual medium of instruction (MTB-BMoI) and consciously teach the languages as much as possible in play-based activities so that learners will be able to acquire effective skills in speaking" (KG Curriculum, p. xix).

Readers can contrast quite easily the place of both English and Ghanaian languages in the language of the text: Teachers must read aloud in English often so that students can enrich their vocabulary and reading skills versus teachers should allow children to play using Ghanaian languages so that they can speak it well. (See Figures 4.1, 4.2, 4.3, 4.4, 4.5 and Tables 4.3, 4.4) Students are to acquire higher forms of literacy in English even at this stage and the contrast is surprising since students have already been exposed to 
speaking their language at home rather than reading or seeing it in print. The focus here could have been flipped where students through play and enjoy read loud activities in English to build on their speaking skills in English. In Ghanaian languages students can rather add to this and develop reading skills in their own languages since they are more likely to speak in Ghanaian languages from home. The curriculum expects students are to gain higher literacies first in their second language which could set them up to fail later in higher levels of schooling. The approach of the KG Curriculum normalizes and centers English as the standard of higher forms of literacy and learning. Throughout this chapter I share more evidence from my analysis that supports the value placed on oral skills in the Ghanaian language curriculum compared to writing and reading in the English language curriculum.

The normalization and centering of English especially comes through in terms of how much time is dedicated to the teaching and learning of English and Ghanaian languages. As we have seen in the KG curriculum, Ghanaian languages right from the beginning share time in the classroom with English. This trend increases as students progress, with English taking more and more class time when it comes to teaching and learning. The teaching of languages according to the Pre-tertiary Curriculum Framework is allocated the highest number of periods per week compared to other subjects. See Table 4.1 (Also see Pre-tertiary Education Curriculum Framework, 2019, p. 75; Teacher Resource Pack, 2019, p. 14-15).

\section{${ }^{9}$ Table 4.1}

\section{Period Allocation}

\footnotetext{
${ }_{9}^{9}$ Period $=30$ minutes of class time
} 


\begin{tabular}{lll}
\hline Mathematics & 10 & 10 \\
${ }^{10}$ Languages & 15 & 15 \\
Creative Arts & 5 & 4 \\
Science & 4 & 4 \\
History & 4 & 4 \\
Religious and Moral Education & 2 & 2 \\
Our World Our People (OWOP) & 4 & 4 \\
French & 0 & 2 \\
Computing & 2 & 2 \\
Physical Education & 2 & 2 \\
\hline
\end{tabular}

$\overline{\text { Although Languages are presented as one in this table, an analysis of the individual }}$ subject curriculum for Ghanaian languages helped explained the period allocated to Languages. In the English Curriculum for primary one to three, it is stated that "a total of ten periods a week, each period consisting of thirty minutes, is allocated to the teaching of English Language at the Primary level. It is recommended that two periods of English Language be taught per day" (p. xiv). In the Ghanaian Languages Curriculum for primary one to primary three, however, the statement of allocated period only refers to the upper primary level (primary four to six): "a total of five periods a week, each period consisting of thirty minutes, is allocated to the teaching of Ghanaian Languages at the Upper Primary level."

\footnotetext{
${ }^{10}$ See Table 4.2 for further breakdown
} 


\section{Table 4.2}

Period Allocation for Languages

\begin{tabular}{lll}
\hline Subject Area & Lower Primary (1-3) & Upper Primary (4-6) \\
\hline English & Not Stated & 10 \\
Ghanaian Language & Not Stated & 5 \\
\hline
\end{tabular}

From the current language-in-education policy students who have not been exposed to English before school are to be taught in Ghanaian languages at least 70 percent of the time and 30 percent in English in kindergarten, with the understanding that the percentage of English increases till Primary 4 when English is used throughout. Because the language of the policy is not specific on how much Ghanaian languages can be used from kindergarten, each school is opened to apply this policy liberally.

The absence of a prescribed numbers of period allocated to the teaching and learning in Ghanaian Languages Curriculum at the lower primary and the specificity of the number of periods assigned to Ghanaian languages at the upper primary level highlights this vagueness seen in the policy given to Ghanaian languages, even in earlier schooling years especially when it is so critical to students' learning. If the designers of the curriculum somehow believed Ghanaian languages are important to students acquiring literacy in their own languages so that students can transfer their learning from their native languages to a second language (L2) - English - the discourse/design of curriculum does not support this belief.

What is encoded in the language of the overall curriculum is not just that students should use and learn more English but that the teaching and learning of Ghanaian languages appears less valuable to students' learning. It is also noticeable that the 
curriculum is intentionally designed not to enforce the use and teaching and learning of Ghanaian languages over English especially at the lower primary level where research shows it is needed the most for students whose first language is a Ghanaian language. Consider that by upper primary, Ghanaian students are exposed to Ghanaian languages only 150 minutes per week ( 5 periods) compared to the 1,350 minutes teaching and learning occurs in English (See Table 4.1). Although the minutes allocated to Ghanaian languages could be higher in KG and lower primary (1-3), the discourse of the curriculum is unclear such that learning in Ghanaian languages could vary across schools in the country. Some could argue that the curriculum by including some teaching and learning in Ghanaian languages is in a way showing its value in education. I will therefore show in the subsequent findings why that argument is not supported by further discourse analyses of teaching lesson and content of the English and Ghanaian languages curricula.

\section{More Content in English}

The analysis of the teaching lessons and content in the English and Ghanaian languages curricula for lower primary confirmed the findings that more time in the curriculum is allocated to English than to Ghanaian languages and also revealed distinct expectations for students in learning English and Ghanaian languages, especially in lower

primary where teachers were expected to use Ghanaian languages more in teaching. The English language curriculum for lower primary has more teaching and learning content compared to the Ghanaian languages curriculum for lower primary. The gap between both curricula is especially widened when it comes to the writing domain. Topics such as Narrative, Creative, Descriptive, Persuasive and Informative Writing all start in primary 
four in the Ghanaian languages curriculum but in the English language curriculum a topic such as Descriptive Writing starts early in primary 1 (See Table 4.3).

\section{Table 4.3}

When Writing is Introduced

\begin{tabular}{lll}
\hline Writing Sub- & English Curriculum & Ghanaian Languages \\
Strands & & Curriculum \\
\hline Narrative & Primary 2 & Primary 4 \\
Creative & Primary 4 & Primary 4 \\
Descriptive & Primary 1 & Primary 4 \\
Persuasive & Primary 3 & Primary 4 \\
Informative & Primary 3 & Primary 4
\end{tabular}

It is surprising that even though the language policy in education suggests that Ghanaian languages should be at the center of learning for many Ghanaian students at least during the lower primary years, the curriculum does not emphasize writing skills in Ghanaian languages like it does in English. If Ghanaian students do not start actively writing in Ghanaian languages till primary four, then transfer from L1 to L2 cannot occur (Cardenas-Hagan, Carlson \& Pollard-Durodola, 2007). Here the introduction of writing early in English in lower primary confirms that more time is allocated to teaching this content which does not exist in the Ghanaian Languages Curriculum at the same level.

Also, most of the content for in the Ghanaian languages curriculum is similar to the English curriculum although the ways of speaking in Ghanaian languages are not homogenous but also distinct from English ways of speaking (See Figure 4.1 and Figure 4.2). 


\section{${ }^{11}$ Figure 4.1}

\section{Content Strands in the English Curriculum}

\begin{tabular}{|c|c|c|c|c|c|c|c|}
\hline STRANDS & SUB-STRANDS & B1 & B2 & B3 & B4 & B5 & B6 \\
\hline \multirow{10}{*}{$\begin{array}{l}\text { 1. ORAL LANGUAGE: } \\
\text { LISTENING AND SPEAKING }\end{array}$} & SONGS & $\mathrm{d}$ & $\mathrm{v}$ & $\checkmark$ & $\checkmark$ & $\sqrt{2}$ & $\checkmark$ \\
\hline & RHYMES & v & v & $\checkmark$ & & & \\
\hline & POEMS & & & & v & v & v \\
\hline & STORY TELUING & 2 & $\mathrm{v}$ & 2 & v & 2 & v \\
\hline & DRAMATISATION \& ROLE PLAY & $\mathrm{v}$ & 2 & $\mathrm{v}$ & $\sqrt{ }$ & $\sqrt{2}$ & $\checkmark$ \\
\hline & $\begin{array}{l}\text { CONVERSATION TALKING ABOUT ONESELF. } \\
\text { FAMILY, PEOPLE, PLACES, CUSTOMS, EVENTS, } \\
\text { CULTURAL VALUES, MANNERS, AND OTHER } \\
\text { THEMES }\end{array}$ & $\checkmark$ & $\mathrm{v}$ & $\checkmark$ & $\checkmark$ & $\checkmark$ & $\checkmark$ \\
\hline & LSTENING COMPREHENSION & 政 & 2 & v & v & v & v \\
\hline & ASKING AND ANSWERING QUESTIONS & v & v & v & $\mathrm{v}$ & $\mathrm{v}$ & v \\
\hline & $\begin{array}{l}\text { GINING AND FOLLOWING COMMANDSI } \\
\text { INSTRUCTIONSDIRECTIONS AND MAKING AND } \\
\text { RESPONDING TO REQUESTS }\end{array}$ & $\checkmark$ & $\mathrm{v}$ & $\checkmark$ & $\checkmark$ & $\checkmark$ & $\checkmark$ \\
\hline & PRESENTATION & v & 2 & $\checkmark$ & v & $\checkmark$ & v \\
\hline \multirow[t]{3}{*}{ 2. READING } & $\begin{array}{l}\text { PRE-READINGG ACTIVITIES: } \\
\text { PRINT CONCEPT } \\
\text { PHONOLOGICALPHONEMIC AWARENESS }\end{array}$ & $\checkmark$ & & & & & \\
\hline & $\begin{array}{l}\text { PHONICS } \\
\text { LETTER-SOUND KNOWLEDGEE } \\
\text { VOWEL SOUNDS and CONSONANT SOUNDS }\end{array}$ & $\checkmark$ & $\mathrm{v}$ & $\checkmark$ & $\checkmark$ & $\checkmark$ & $\checkmark$ \\
\hline & $\begin{array}{l}\text { WORD FAMILES, RHYMING ENDINGS AND } \\
\text { COMMON DIGRAPHS }\end{array}$ & $\checkmark$ & 2 & $\checkmark$ & $\checkmark$ & $\mathrm{v}$ & $\checkmark$ \\
\hline & DIPHTHONGS & & & 2 & $\mathrm{v}$ & $\checkmark$ & v \\
\hline & BLENDS AND CONSONANI CLUSTERS & & & 2 & 2 & 2 & 2 \\
\hline & $\begin{array}{l}\text { VOCABULARY } \\
\text { SIGHT VOCABULARY } \\
\text { CONTENT VOCABULARY } \\
\end{array}$ & $\checkmark$ & $\checkmark$ & $\checkmark$ & $\checkmark$ & $\checkmark$ & $\mathrm{v}$ \\
\hline & COMPREHENSION & $\checkmark$ & $\mathrm{v}$ & 2 & $\checkmark$ & $\checkmark$ & $\mathrm{v}$ \\
\hline & SILENT READING & & & & 2 & $\checkmark$ & v \\
\hline & FLUENCY & $\sqrt{ }$ & $\sqrt{2}$ & v & 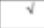 & $\sqrt{ }$ & $\sqrt{2}$ \\
\hline & SUMMARISING & & & & & $\checkmark$ & 2 \\
\hline \multirow{12}{*}{$\begin{array}{l}\text { 3. GRAMMAR USAGEAT } \\
\text { WORDAND PHRASE } \\
\text { LEVELS }\end{array}$} & NOUNS & & & & $\checkmark$ & $\checkmark$ & $\mathrm{v}$ \\
\hline & DETERMINERS & & & & $\checkmark$ & $\checkmark$ & $\mathrm{v}$ \\
\hline & PRONOUNS & & & & v & $\mathrm{v}$ & $\mathrm{v}$ \\
\hline & \begin{tabular}{|l} 
ADJECTIVES \\
\end{tabular} & & & & 2 & 2 & 2 \\
\hline & \begin{tabular}{|l|l|} 
VERBS \\
\end{tabular} & & & & $\mathrm{v}$ & v & $\mathrm{v}$ \\
\hline & ADVERBS & & & & $\checkmark$ & $\checkmark$ & $\mathrm{v}$ \\
\hline & IDIOMATIC EXPRESSIONS & & & & $\checkmark$ & $\checkmark$ & $\mathrm{v}$ \\
\hline & CONJUNCTIONS & & & & $\mathrm{v}$ & $\mathrm{v}$ & $\mathrm{v}$ \\
\hline & MODALS & & & & $\checkmark$ & $\checkmark$ & $\sqrt{2}$ \\
\hline & PREPOSITIONS & & & & $\checkmark$ & $\checkmark$ & 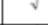 \\
\hline & \begin{tabular}{|l} 
ADJECTVE PHRASE \\
ADVERB PHRASE
\end{tabular} & & & & $\frac{1}{4}$ & $\frac{1}{8}$ & 更 \\
\hline & DIRECT AND REPORTED SPEECH & & & & $\frac{1}{2}$ & 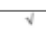 & $\frac{1}{4}$ \\
\hline \multirow{15}{*}{ 4. WRITING } & PRE-WRITING ACTIVITIES & $\checkmark$ & & & & & \\
\hline & PENMANSHIP/HANDWRITING & $\checkmark$ & v & v & v & 2 & v \\
\hline & $\begin{array}{l}\text { WRITING/COPYING LETTERS-SMALL AND CAPTAL } \\
\text { LETTERS }\end{array}$ & $\checkmark$ & & & & & \\
\hline & LABEUING ITEMS & v & & & & & \\
\hline & WRITING SIMPLE WORDS AND SENTENCES & v & v & $\nabla$ & & & \\
\hline & PARAGRAPH DEVELOPMENT & & & & v & v & $\mathrm{v}$ \\
\hline & CONTROLLED WRITING & $\checkmark$ & $\mathrm{v}$ & & & & \\
\hline & GUIDED COMPOSITION & & v & $\mathrm{v}$ & & & \\
\hline & WRITING AS A PROCESS & & & $\mathrm{v}$ & v & v & v \\
\hline & NARRATIVE WRITING & & $\checkmark$ & v & v & v & $\checkmark$ \\
\hline & CREATIVE/FREE WRIIING & & & & v & 1 & v \\
\hline & DESCRIPTIVE WRITING & v & $\nabla$ & v & v & T & $\mathrm{v}$ \\
\hline & PERSUASIVEIARGUMENTATIVE WRITING & & & $\mathrm{v}$ & $\checkmark$ & 2 & v \\
\hline & INFORMATIVEIACADEMIC WRITING & & & $\sqrt{ }$ & v & v & v \\
\hline & LETTER WRITING & & & & $\sqrt{ }$ & $\sqrt{ }$ & $\sqrt{ }$ \\
\hline \multirow{10}{*}{$\begin{array}{l}\text { 5. USING WRITING } \\
\text { CONVENTIONS } \\
\text { IGRAMMAR USAGE }\end{array}$} & USING CAPITALIZATION & 2 & $\mathrm{v}$ & v & $\checkmark$ & $\mathrm{v}$ & $\mathrm{v}$ \\
\hline & USING PUNCTUATION & & v & v & v & $\sqrt{2}$ & $\sqrt{ }$ \\
\hline & USING NAMING WORDS & v & v & v & 勺 & 而 & 的 \\
\hline & USING ACTION WORDS/VERBS & $\checkmark$ & $\checkmark$ & v & $\checkmark$ & v & $\sqrt{2}$ \\
\hline & USING QUALIFYING WORDS: ADJECTIVES & $\checkmark$ & v & 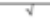 & 2 & $\mathrm{v}$ & $\mathrm{v}$ \\
\hline & USING QUALIFYING WORDS: ADVERBS & & & $\checkmark$ & $\checkmark$ & 2 & $\checkmark$ \\
\hline & USING SIMPLE PREPOSITIONS & $\mathrm{v}$ & v & $\mathrm{v}$ & v & v & v \\
\hline & USING CONJUNCTIONS & & & & v & v & v \\
\hline & $\begin{array}{l}\text { USING SIMPLE, COMPOUND AND COMPLEX } \\
\text { SENTENCES }\end{array}$ & & $\checkmark$ & $\checkmark$ & $\checkmark$ & $v$ & $\checkmark$ \\
\hline & SPELUNG & 2 & v & v & 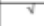 & v & v \\
\hline 6. EXTENSIVE READING & BUILDING THE LOVE AND CULTURE OF READI & $\mathrm{v}$ & $\mathrm{v}$ & $\checkmark$ & $\checkmark$ & $\checkmark$ & $\checkmark$ \\
\hline
\end{tabular}

${ }^{11}$ English language curriculum for B1-B3, 2019, p. 1-4 


\section{${ }^{12}$ Figure 4.2}

Content Strands in the Ghanaian languages curriculum

\begin{tabular}{|c|c|c|c|c|c|c|c|c|c|}
\hline STRANDS & SUB STRANDS & KGI & KG2 & BI & B2 & B3 & B4 & Bs & B6 \\
\hline \multirow{11}{*}{$\begin{array}{l}\text { I. ORAL LANGUAGE: } \\
\text { USTENING AND SPEAKING }\end{array}$} & ISongs & $\sqrt{ }$ & $\checkmark$ & 8 & 社 & 1 & 8 & 8 & v \\
\hline & 2. Rhymes & $\mathrm{v}$ & $\checkmark$ & $\checkmark$ & $\checkmark$ & v & & & \\
\hline & 3Poems & & & & & t & $\sqrt{ }$ & $\checkmark$ & 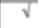 \\
\hline & 4.Scory Telling & $\sqrt{ }$ & $\bar{v}$ & $\checkmark$ & $\checkmark$ & $\checkmark$ & $\checkmark$ & $\checkmark$ & $\sqrt{ }$ \\
\hline & 5.Dramatiation and Role Pay & a & $\checkmark$ & v & v & v & $\checkmark$ & $\checkmark$ & $\sqrt{ }$ \\
\hline & 6.Conversation & 到 & $\checkmark$ & $\checkmark$ & $\sqrt{ }$ & t & $\checkmark$ & $\checkmark$ & t \\
\hline & $\begin{array}{l}\text { 7.Talking about Oneself, family, People and } \\
\text { Places. }\end{array}$ & $\checkmark$ & $\checkmark$ & $\checkmark$ & $\checkmark$ & $\checkmark$ & $\checkmark$ & $\checkmark$ & $\checkmark$ \\
\hline & 8.Listening Comprehension & $\sqrt{2}$ & $\checkmark$ & $\checkmark$ & v & T & & & \\
\hline & \begin{tabular}{|l} 
Assking and Answering Questions \\
\end{tabular} & $\sqrt{ }$ & $\checkmark$ & $\checkmark$ & $\checkmark$ & $\sqrt{ }$ & $\sqrt{ }$ & $\checkmark$ & $\sqrt{ }$ \\
\hline & \begin{tabular}{|l} 
10.Giving and following Commands' \\
Instructions
\end{tabular} & $\sqrt{ }$ & $\checkmark$ & $\checkmark$ & $\sqrt{ }$ & $\sqrt{ }$ & $\sqrt{ }$ & $\checkmark$ & $\sqrt{ }$ \\
\hline & \begin{tabular}{|l|}
11. Presentation \\
\end{tabular} & $\sqrt{ }$ & $\checkmark$ & $\checkmark$ & 的 & v & $\checkmark$ & $\checkmark$ & v \\
\hline \multirow{6}{*}{ 2. READING } & \begin{tabular}{|l|} 
IPre-Reading Activities \\
\end{tabular} & $\sqrt{ }$ & $\checkmark$ & $\bar{\checkmark}$ & & & & & \\
\hline & 2Print Concept & $\sqrt{ }$ & $\checkmark$ & $\sqrt{ }$ & & & & & \\
\hline & 3Phonological and Phonemic Awareness: & $\sqrt{ }$ & $\checkmark$ & $\checkmark$ & $\checkmark$ & $\sqrt{ }$ & & & \\
\hline & 4. Phonics: (Letter and sound knowledge) & $\sqrt{ }$ & $\checkmark$ & $\checkmark$ & $\sqrt{ }$ & $\sqrt{ }$ & $\checkmark$ & $\checkmark$ & $\sqrt{ }$ \\
\hline & $\begin{array}{l}\text { 5.Vocabulary } \\
\text { (Sight and Concent Vocabulary) }\end{array}$ & & & $\checkmark$ & $\checkmark$ & $\checkmark$ & $\checkmark$ & $\checkmark$ & $\checkmark$ \\
\hline & 6.Comprehension & & & $\checkmark$ & $\sqrt{ }$ & $\sqrt{ }$ & $\sqrt{ }$ & $\checkmark$ & $\sqrt{ }$ \\
\hline & 7. Silent Reading & & & $\bar{v}$ & $\bar{v}$ & $\bar{v}$ & $\sqrt{ }$ & $\checkmark$ & $\bar{v}$ \\
\hline & 8.Fluency & & & $\checkmark$ & $\sqrt{ }$ & $\sqrt{ }$ & $\sqrt{ }$ & $\sqrt{ }$ & $\sqrt{ }$ \\
\hline & 9.5ummarising & & & & & & $\sqrt{ }$ & $\checkmark$ & $\bar{v}$ \\
\hline \multirow[t]{5}{*}{ 3. WRITING } & & & & & & & & & \\
\hline & 1.Penmanship//Handwriting & $\sqrt{ }$ & $\sqrt{ }$ & $\sqrt{ }$ & $\sqrt{ }$ & $\sqrt{ }$ & $\sqrt{ }$ & $\sqrt{ }$ & $\sqrt{ }$ \\
\hline & 2.Writing Letters-Small and Capial Letters & & $\sqrt{ }$ & & & & & & \\
\hline & $\begin{array}{l}\text { 3. Writing Simple Words /Names of People and } \\
\text { Places (Proper Nouns) Labeling Iterms in the } \\
\text { Environment/Classroom }\end{array}$ & & $\sqrt{ }$ & $\sqrt{ }$ & $\sqrt{ }$ & $\sqrt{ }$ & & & \\
\hline & $\begin{array}{l}\text { 4. Writing/Copying Simple Sentences with } \\
\text { Correct Spacing }\end{array}$ & & & $\sqrt{ }$ & $\sqrt{ }$ & $\sqrt{ }$ & & & \\
\hline \multirow{8}{*}{$\begin{array}{l}\text { 4. COMPOSITION } \\
\text { WRITING }\end{array}$} & 1.Creativelfree Writing & & & & & & $\sqrt{ }$ & $\sqrt{ }$ & $\sqrt{ }$ \\
\hline & 2.Narrative Writing & & & & & & $\sqrt{ }$ & $\sqrt{ }$ & $\sqrt{ }$ \\
\hline & 3.Descriptive Writing & & & & & & $\sqrt{ }$ & $\sqrt{ }$ & $\sqrt{ }$ \\
\hline & 4.Persuasive Writing & & & & & & $\sqrt{ }$ & $\sqrt{ }$ & $\sqrt{ }$ \\
\hline & 5.Argumentative Writing & & & & & & $\sqrt{ }$ & $\sqrt{ }$ & $\sqrt{ }$ \\
\hline & 6.1mformative/Academic Writing & & & & & & $\sqrt{ }$ & $\sqrt{ }$ & $\sqrt{ }$ \\
\hline & 7.Literary Writing & & & & & & $\sqrt{ }$ & $\sqrt{1}$ & $\sqrt{ }$ \\
\hline & 8. Letter Writing & & & & & & $\sqrt{2}$ & $\sqrt{ }$ & $\sqrt{ }$ \\
\hline \multirow[t]{8}{*}{$\begin{array}{l}\text { 5. WRITING } \\
\text { CONVENTIONS/ USAGE }\end{array}$} & $\begin{array}{l}\text { 1.Integrating Grammar in Written Language } \\
\text { (Capialisation) }\end{array}$ & & & & $\sqrt{ }$ & $\sqrt{ }$ & $\sqrt{ }$ & $\sqrt{ }$ & $\sqrt{ }$ \\
\hline & $\begin{array}{l}\text { 2Integrating Grammar in Written Language } \\
\text { (Punctuation) }\end{array}$ & & & & $\sqrt{ }$ & $\sqrt{ }$ & $\sqrt{ }$ & $\sqrt{ }$ & $\sqrt{ }$ \\
\hline & $\begin{array}{l}\text { 3integrating Grammar in Written Lansuage } \\
\text { (Use of Action Words) } \\
\end{array}$ & & $\sqrt{ }$ & $\sqrt{ }$ & $\sqrt{ }$ & $\sqrt{ }$ & $\sqrt{ }$ & $\sqrt{ }$ & $\sqrt{ }$ \\
\hline & $\begin{array}{l}\text { 4integrating Grammar in Written Lansuage } \\
\text { (Use of Qualiffing. Words) }\end{array}$ & & $\sqrt{ }$ & $\sqrt{ }$ & $\sqrt{ }$ & $\sqrt{ }$ & $\sqrt{ }$ & $\sqrt{ }$ & $\sqrt{ }$ \\
\hline & $\begin{array}{l}\text { S. Integrating Grammar in Written Lansuage } \\
\text { (Use of Postpositions) }\end{array}$ & & $\sqrt{ }$ & $\sqrt{ }$ & $\sqrt{ }$ & $\sqrt{ }$ & $\sqrt{ }$ & $\sqrt{ }$ & $\sqrt{ }$ \\
\hline & $\begin{array}{l}\text { Sintegrating Grammar in Written Lansuage } \\
\text { (Use of Simple and Compound Sentences) }\end{array}$ & & & & $\sqrt{ }$ & $\sqrt{ }$ & $\sqrt{ }$ & $\sqrt{ }$ & $\sqrt{ }$ \\
\hline & $\begin{array}{l}\begin{array}{l}7 \text { Integrating Grammar in Written Language } \\
\text { (Spelling) }\end{array} \\
\text { (a) }\end{array}$ & & & $\sqrt{ }$ & $\sqrt{ }$ & $\sqrt{ }$ & $\sqrt{ }$ & $\sqrt{ }$ & $\sqrt{ }$ \\
\hline & $\begin{array}{l}\text { 8integrating Grammar in Written Language } \\
\text { (Use of Conjunctions) }\end{array}$ & & & & & & $\sqrt{ }$ & $\sqrt{ }$ & $\sqrt{ }$ \\
\hline \multirow{3}{*}{$\begin{array}{l}\text { 6. EXTENSIVE } \\
\text { READING/CHILDREN'S } \\
\text { UTERATURE LIBRARY }\end{array}$} & $\begin{array}{l}\text { 1.Building the Love and Culture of Reading in } \\
\text { Learners }\end{array}$ & & $\sqrt{ }$ & $\sqrt{ }$ & $\sqrt{ }$ & $\sqrt{ }$ & $\sqrt{ }$ & $\sqrt{ }$ & $\sqrt{ }$ \\
\hline & 2 Read Alloud with Children & & $\sqrt{ }$ & $\sqrt{ }$ & $\sqrt{ }$ & $\sqrt{ }$ & $\sqrt{ }$ & $\sqrt{ }$ & $\sqrt{ }$ \\
\hline & $\begin{array}{l}\text { Reading Texts, Poems, Narratives and Short } \\
\text { Stories and Respond to them }\end{array}$ & & & & & $\sqrt{ }$ & $\sqrt{ }$ & $\sqrt{ }$ & $\sqrt{ }$ \\
\hline
\end{tabular}

${ }^{12}$ Ghanaian languages curriculum for B1-B3, 2019, p. xix- xxi 
The structure for the Ghanaian language curriculum and content follows the same pattern as English. Further discourse analysis of the content showed how the content in the English curriculum was more than the Ghanaian languages curriculum. In Table 4.4 below I compare the content in English and Ghanaian languages via topic areas specified in the curriculum above.

\section{Table 4.4}

Comparison 1: Content Strands in the Ghanaian Languages and English (K-6)

\section{Curriculum}

\begin{tabular}{lcclcc}
\hline Topic Area & GL & Eng & Topic Area & GL & Eng \\
1. Songs & $\checkmark$ & $\checkmark$ & 30. Adjective Phrase & X & $\checkmark$ \\
2. Rhymes & $\checkmark$ & $\checkmark$ & 31. Adverb Phrase & X & $\checkmark$ \\
3. Poems & $\checkmark$ & $\checkmark$ & 32. Direct and Reported & X & $\checkmark$ \\
& & & Speech &
\end{tabular}

4. Storytelling

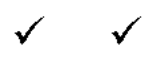

33. Prepositions

$\mathrm{X}$

5. Dramatization \&

34. Pre-writing activities

X Role Play

6. Conversation \&

35. Penmanship/Handwriting talking About

Oneself

7. Listening

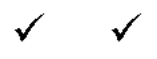

36. Writing Small and Capital

Comprehension

Letters 
8. Asking \&

37. Labeling Items

Answering

Questions

9. Giving \&

$\checkmark \quad \checkmark$

38. *Paragraph Development $\mathrm{X}$

Following

Commands

10. Presentation

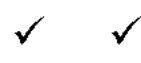

39. Writing and Copying

$\checkmark \quad X$

Simple Sentences with

Correct Spacing

11. Pre Reading | Print $\checkmark$

40. *Controlled Writing

X

Concept |

Phonological

Awareness

12. Phonics | Letter $\quad \checkmark \quad \checkmark$

41. *Guided Composition

$\mathrm{X}$

Sound Knowledge

| Vowel Sounds

and Consonant

Sounds

13. Word Families $\mid X \quad \checkmark$

42. *Writing as a Process

$\mathrm{X}$

Rhyming

Families |

Common

Diagraphs 

14. Diphthongs
X $\checkmark$
43. Narrative Writing
15. Blends and
X $\checkmark$
44. Descriptive Writing

\section{Consonant}

\section{Clusters}

16. Vocabulary

$\checkmark \checkmark$

45. Creative /Free Writing

46. Persuasive/Argumentative

Writing

18. Silent Reading

19. Fluency

20. Summarizing

21. *Nouns

22. *Determiners

23. *Pronouns

24. *Adjectives

25. *Verbs

26. *Adverbs

27. Idiomatic

Expressions
47. Informative/Academic

Writing

48. Letter Writing

49. Literary Writing

50. Capitalization

51. Punctuations

52. Using Naming Words

53. Using Action Words + Conjunctions

X $\checkmark$

54. Using Qualifying Words

$X \quad \checkmark$

55. Using Pre/post-positions

$X \quad \checkmark \quad 56$. Spelling

28. *Conjunctions $\quad X \quad \checkmark \quad$ 57. Simple and Compound Sentences 

respond to them

\footnotetext{
* topic does not have a sole teaching and learning focus like in the English Curriculum but are integrated into other parts of the Ghanaian languages Curriculum with other content.
}

At a first glance topics 21 to 33 in Table 4.4 do not appear in the Ghanaian languages curriculum. However, in examining the overall curriculum for each class, topics such as Nouns, Verbs, Adjectives, Prepositions, and Conjunctions are integrated into writing activities as Naming Words, Action Words, Pre/post-positions but are not taught as main content areas in Ghanaian languages curriculum like it occurs in the English curriculum. Topic areas such Nouns, Verbs, Adjectives, Prepositions, and Conjunctions are taught as part of Topics 52, 53, 54, and 55 in Table 4.4. As an example, in Figure 4.3, as part of a lesson in primary 4 students in the Ghanaian languages curriculum learn about Adjectives as part of a broader writing topic. However, in the English curriculum at this same level, there is a focus placed on learning Adjectives as a concept first before integrating the content in writing tasks (see Figure 4.4). This is seen throughout the curriculum with the content strands in bold in Table 4.4 such as Nouns, Pronouns, Adjectives, Adverbs, Adjective Phrase, etc. The design of the English curriculum creates several opportunities for students to work on expansive writing skills after they learn these concepts in English compared to the Ghanaian languages curriculum. In other words, in the English curriculum, after students have learned grammar concepts, there are content strands that focus on students integrating all concepts they have learned in writing different types of paragraphs (See Figure 4.5). You will also see in Table 4.4 that Topic 38 on paragraph 
development does not exist in the Ghanaian language curriculum as a content strand and this is because it is integrated with teaching grammatical concepts at the same time. This could be due to the reduced period allocation to Ghanaian languages so that teachers and students cannot spend too much on topics.

\section{${ }^{13}$ Figure 4.3}

Lesson on Adjectives in the Ghanaian languages curriculum

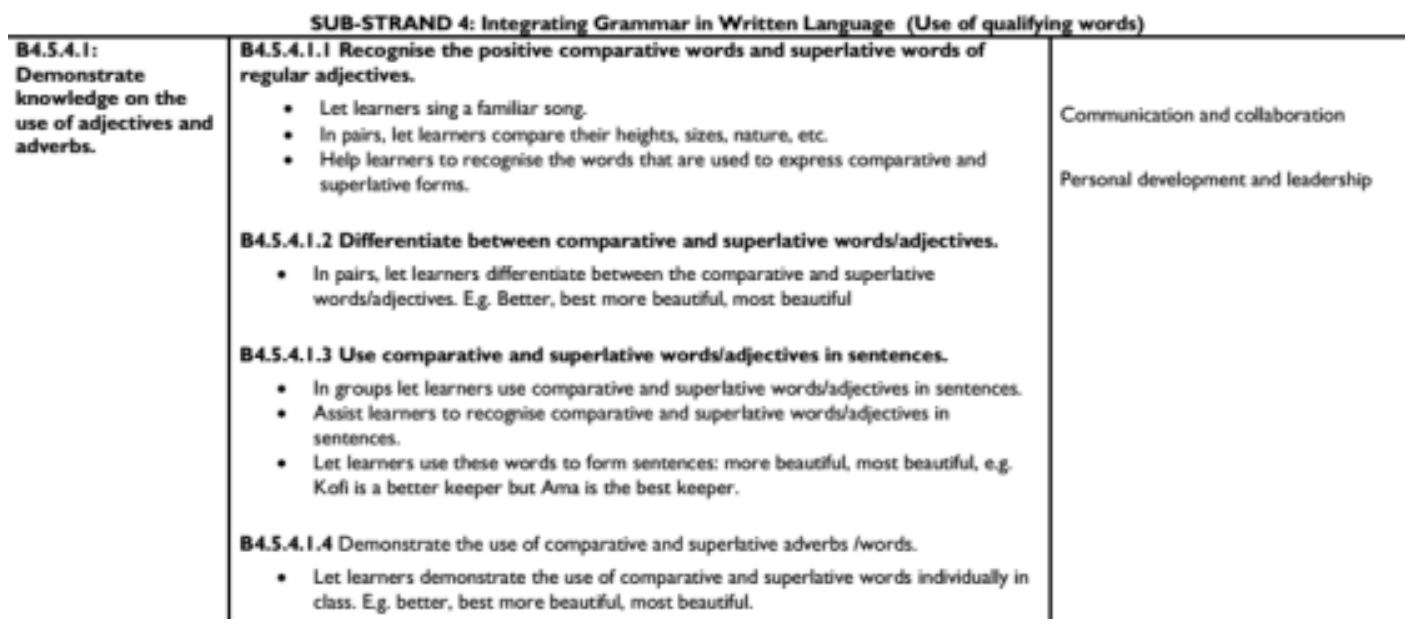

${ }^{14}$ Figure 4.4

Lesson on Adjectives in the English curriculum

\begin{tabular}{|c|c|c|}
\hline $\begin{array}{l}\text { CONTENT } \\
\text { STANDARDS }\end{array}$ & INDICATORS AND EXEMPLARS & $\begin{array}{l}\text { SUBJECT SPECIFIC } \\
\text { PRACTICES AND CORE } \\
\text { COMPETENCIES }\end{array}$ \\
\hline $\begin{array}{l}\text { B4.3.4.1: Apply the } \\
\text { knowledge of adjectives } \\
\text { in communication }\end{array}$ & $\begin{array}{l}\text { B4.3.4.I.I. I. Use adjectives to make comparison e. g: } \\
- \text { fast/slow (Ama is fast but Kofi is slow) } \\
- \text { good/bad } \\
- \text { fast/faster } \\
- \text { slow/slower } \\
\text { - Revise adjectives. Have learners identify adjectives in sentences and } \\
\text { use them in sentences of their own. } \\
\text { - Introduce regular adjective forms: } \\
\text { - Regular adjectives form their imperative by adding er } \\
\text { e.g. small-smaller, big-bigger, etc. } \\
\text { assist learners with examples to use comparative adjectives } \\
\text { appropriately. } \\
\text { e.g. } \\
\text { i. Ama is taller than Kwesi. } \\
\text { ii. This ruler is longer than that one. } \\
\text { - Learners form sentences with the comparative forms of adjectives. }\end{array}$ & $\begin{array}{l}\text { Communication and Collaboration } \\
\text { Critical Thinking and Problem } \\
\text { Solving }\end{array}$ \\
\hline
\end{tabular}

${ }^{13}$ Ghanaian languages curriculum for Basic 4-6, 2019, p. 27

${ }^{14}$ English language curriculum for Basic 4-6, 2019, p. 39 
${ }^{15}$ Figure 4.5

More Opportunities for Writing in English

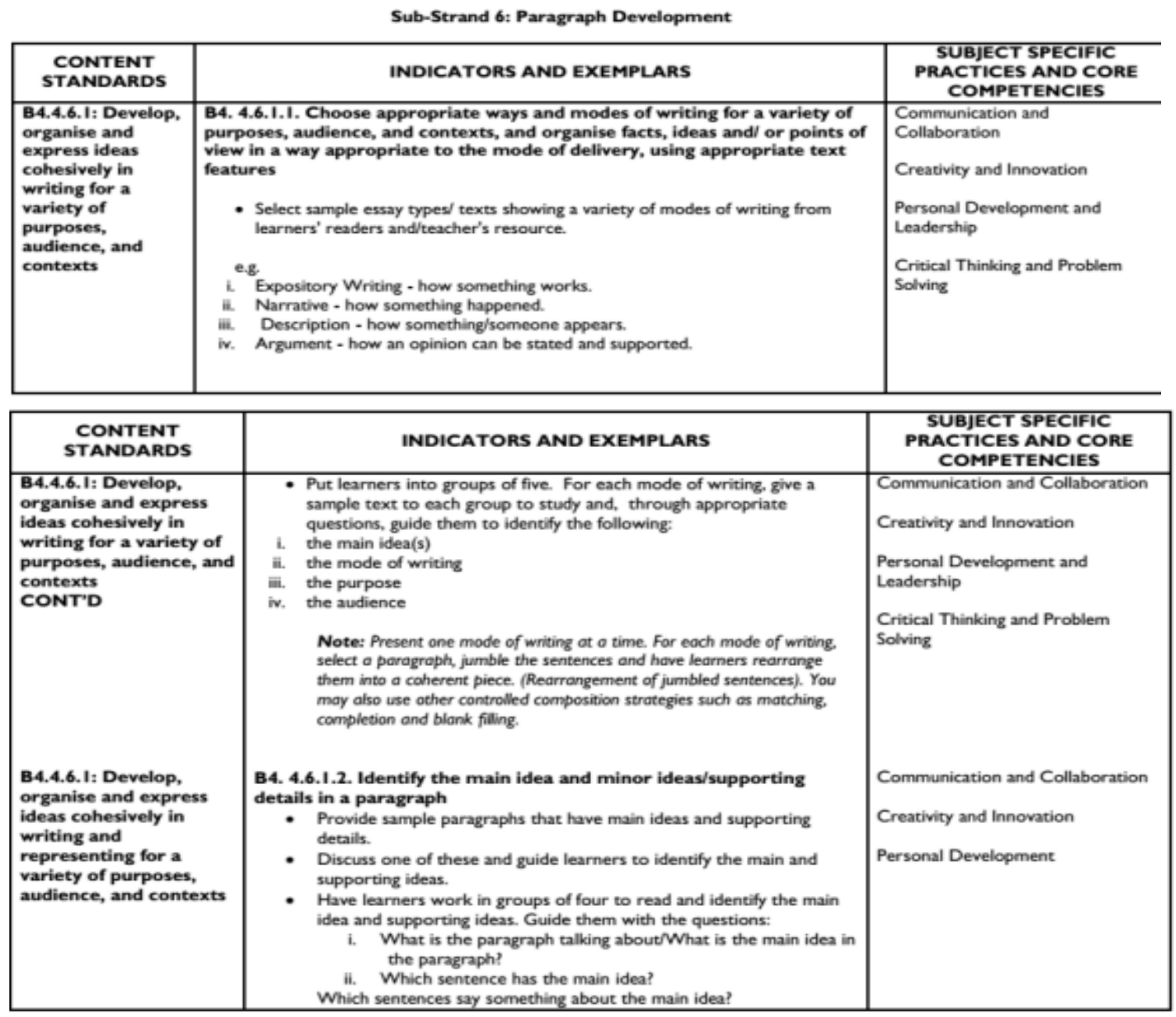

The discourse analysis shows that in the English curriculum, teachers are to teach these

important grammar concepts as a standalone concept and perhaps again to students as

part of teaching writing conventions. In Ghanaian languages, students only learn the latter

without much emphasis for these concepts such as Nouns, Pronouns, Determiners,

Prepositions, Adjectives, etc. One explanation of the lack of emphasis in certain areas in

the Ghanaian languages curriculum compared to the English curriculum could be

${ }^{15}$ English language curriculum, 2019, p. 48-49 
attributed to the notion that the ways of speaking Ghanaian languages are different from ways of speaking English hence the different approaches. However, analysis of the discourse of the curriculum does not support this explanation as the structure of the Ghanaian curriculum is modelled after the English curriculum expect that the content and time in the former is seems brief and reduced comparatively.

Put differently, the Ghanaian languages curriculum is framed and structured in an English language approach to learning language, emphasizing parts of speech and grammar and omitting other ways of speaking such as wise sayings and symbols. The Ghanaian languages curriculum, because it follows most of the same patterns of teaching English and looks to content and literacy in English to frame literacy in Ghanaian languages, misses the ways Ghanaian languages are embodied and used by Ghanaians. For example, in the Ghanaian Languages Curriculum, there is no teaching and learning content on the use of symbols, which is another way of speaking and conveying information in some Ghanaian cultures. For example, in this study I introduced each of the first three chapters with a symbol of the Akan ethnic group, explained their meaning and how it framed my study. Because these cultural symbols do not exist in English, the Ghanaian curriculum modelled after English ways of speaking and values hides and ignores this nature, structure, and ways of speaking Ghanaian languages.

Another key aspect or figure of speech of Ghanaian languages is the use of proverbs and wise sayings that are often inserted in day-to-day speech to convey deep knowledge and insight to reading and listening audiences. Again, because the Ghanaian language curriculum centers English language ways of speaking and literacies in how to teach Ghanaian languages, it also misses the many multiliteracies that are part of many 
Ghanaian languages such as the use of symbols, proverbs, and wise sayings, and some cultural groups' ways of speaking and interacting with the world.

Additionally, at the lower primary level the students are required to read more books in English than in Ghanaian languages:

"The teacher is further encouraged to use his/her initiative in improvising and planning new reading materials. It is a requirement that each learner should read five books on different topics each term, that is, fifteen books per year" (English Language Curriculum for Lower Primary, p. xx).

"The teacher is further encouraged to use his/her initiative in improvising and planning new reading materials. It is a requirement that each learner should read three books on different topics each term, that is, nine books per year. Apart from the prescribed books, the teacher should also encourage learners to read any Ghanaian Language book they find interesting" (Ghanaian Languages Curriculum for Lower Primary, p. xvii).

Again, it is noted here that for students who start school not speaking English from KG, the discourse is not about students learning more in their own language first and then adding or transferring their learning to English but right from the beginning, the expectation is more content in English. This fits into a pattern in the curriculum where English keeps taking center stage in teaching and learning confirming a persistent narrative of English linguistic imperialism.

\section{Ghanaian Language Curriculum, Written in English}

Another evidence for the persistence of English linguistic imperialism shows up in the language of the curriculum for Ghanaian languages: all lessons plans and sample 
worksheets for this part of the curriculum are written in the English language. The French curriculum is written in French, the English curriculum in English, but the Ghanaian languages curriculum is also written in English. Remember that there are only 11 Ghanaian languages approved for teaching and learning in schools, so at least at the national level where these documents are produced, translations of the curriculum, lesson plans, and worksheets could be provided in these 11 Ghanaian languages. The discourse here shows that Ghanaian languages are treated as a monolith when they are not. Also remember that the structure of the Ghanaian languages curriculum, because it follows similar English literacy practices, does not differentiate between the language and knowledge systems of these 11 approved languages. Designing the Ghanaian curriculum first in English and translating them into different Ghanaian languages and ways of speaking is problematic because it treats all Ghanaian languages as similar and the English language as neutral and central. In addition, teachers are not provided with any guidance or materials in the languages that they are supposed to be teaching. Instead, with fewer class periods compared to English to deliver content, teachers of Ghanaian languages are instructed to translate into their own language areas (See note in Figure 4.6 below).

\section{${ }^{16}$ Figure 4.6}

Sample Worksheet for Ghanaian Languages

\footnotetext{
${ }^{16}$ Teacher Resource Pack, 2019, p. 270-271
} 


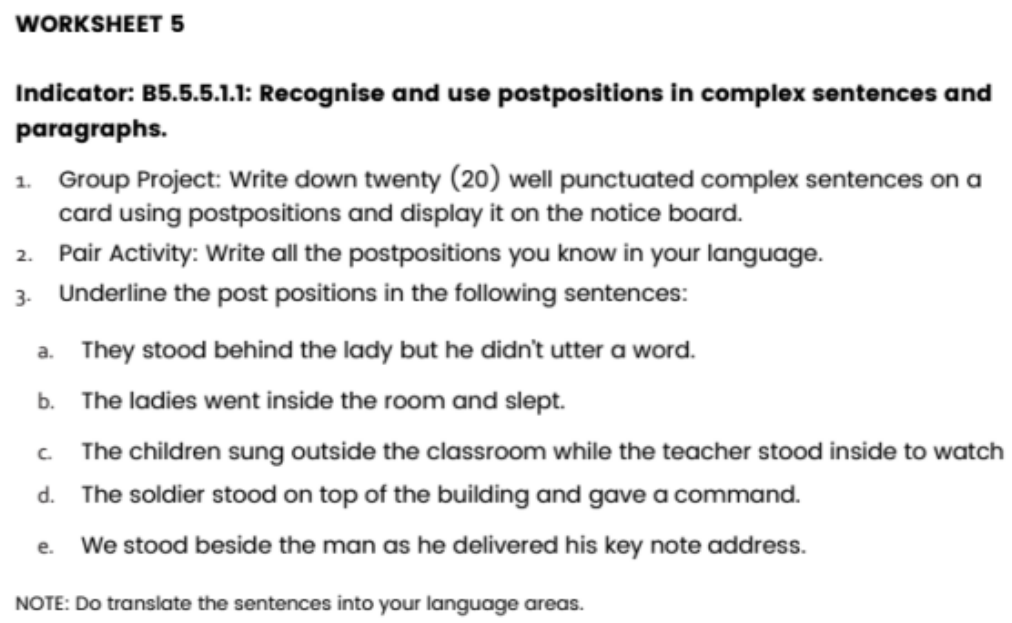

So far, the discourse analysis of the curriculum shows that discourses of English linguistic imperialism show up in (1) the failure of the curriculum to specify the use of Ghanaian languages in policies, (2) the double time and content given to learning English compared to learning Ghanaian languages, (3) the neglect of Ghanaian cultural symbols as important literacy because its centers the nature, structure, and value of English ways of speaking, and (4) the neglect of using Ghanaian languages in creating the Ghanaian languages curriculum. Next, I show how the curriculum expects more from students in English.

\section{Higher Expectations from Students in English}

Each subject area curriculum includes learning performance indicators and teaching activities that explain what students are expected to do for each topic learned. In 
the curriculum teaching and learning is organized with reference numbers that identify (1) content standard that "refers to the pre-determined level of knowledge, skill and/or attitude that a learner attains by a set stage of education," (2) strands that "are the broad areas/sections or the thematic content to be studied," (3) sub-strands that are "the subthemes or sub topics under each strand around which the content is organized," (4) learning performance indicator that is "a clear outcome or milestone that learners have to exhibit in each year to meet the content standard expectation. The indicators represent the minimum expected standard in a year," and (5) the exemplar that "explains the expected outcomes of an indicator and suggests what teaching and learning activities could take to support the facilitators/teachers in the delivery of the curriculum" (KG Curriculum, 2019, p. xiv). (See Figure 4.1 below).

\section{${ }^{17}$ Figure 4.7}

How Curriculum Teaching Content is Organized
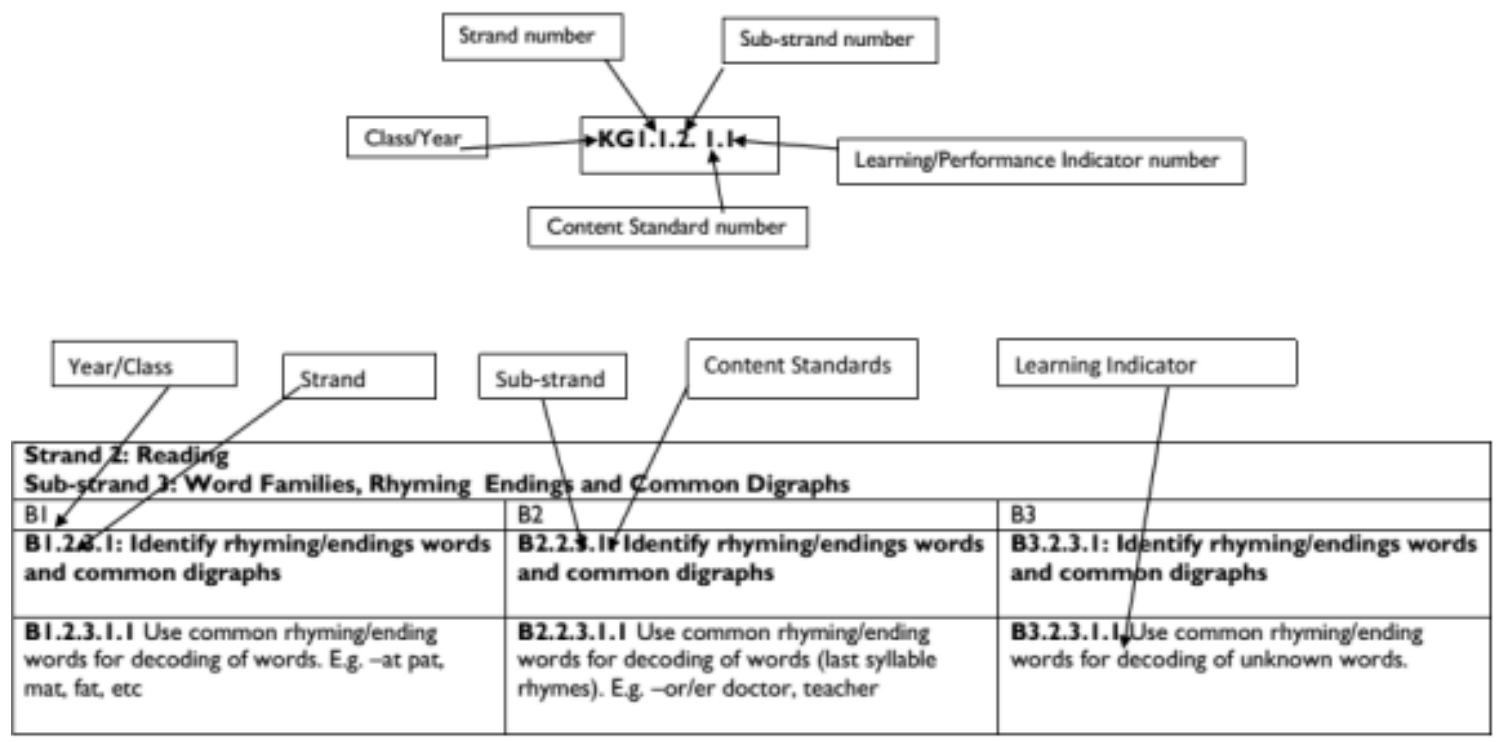

This organization is important especially in examining both the discourse in the English and Ghanaian languages curricula. The discourse in the English Curriculum provides

${ }^{17}$ English language curriculum for B1-B3, 2019, p. xix 
more guidance and direction for teachers regarding the teaching and learning process in English than it does in the Ghanaian Languages Curriculum (See Figure 4.7 and Figure 4.8).

\section{${ }^{18}$ Figure 4.8}

\section{Ghanaian Language Curriculum Content for Primary 4}

\begin{tabular}{|c|c|c|}
\hline \multicolumn{3}{|c|}{ SUB-STRAND 3: Poems } \\
\hline $\begin{array}{l}\text { B4.1.3.I: } \\
\text { Demonstrate } \\
\text { knowledge and } \\
\text { understanding of } \\
\text { selected poems by } \\
\text { discussing them. }\end{array}$ & $\begin{array}{l}\text { B4.1.2.I.I. Explore the poems of about five lines correctly and discuss the moral lessons } \\
\text { in the poem. } \\
\text { - Let learners sing a popular traditional song. } \\
\text { - Let them listen and take note of keywords words in the poem. } \\
\text { - Ask learners to mention the words they heard. } \\
\text { - Write the words on the board. } \\
\text { - Lead learners to say the words aloud. } \\
\text { - Let learners say the words and use them to form their own sentences. } \\
\text { - Let themern discuss che moral lessons in the poems in groups and tell the class. }\end{array}$ & $\begin{array}{l}\text { Communication and } \\
\text { collaboration }\end{array}$ \\
\hline
\end{tabular}

\section{${ }^{19}$ Figure 4.9}

\section{English Language Curriculum Content for Primary 4}

Sub-Strand 3: Poems

\begin{tabular}{|c|c|c|}
\hline $\begin{array}{l}\text { CONTENT } \\
\text { STANDARDS }\end{array}$ & INDICATORS AND EXEMPLARS & $\begin{array}{l}\text { SUBJECT SPECIFIC } \\
\text { PRACTICES AND CORE } \\
\text { COMPETENCIES }\end{array}$ \\
\hline $\begin{array}{l}\text { B4.1.3.1: Appreciate } \\
\text { poems and other pieces } \\
\text { of literary materials }\end{array}$ & 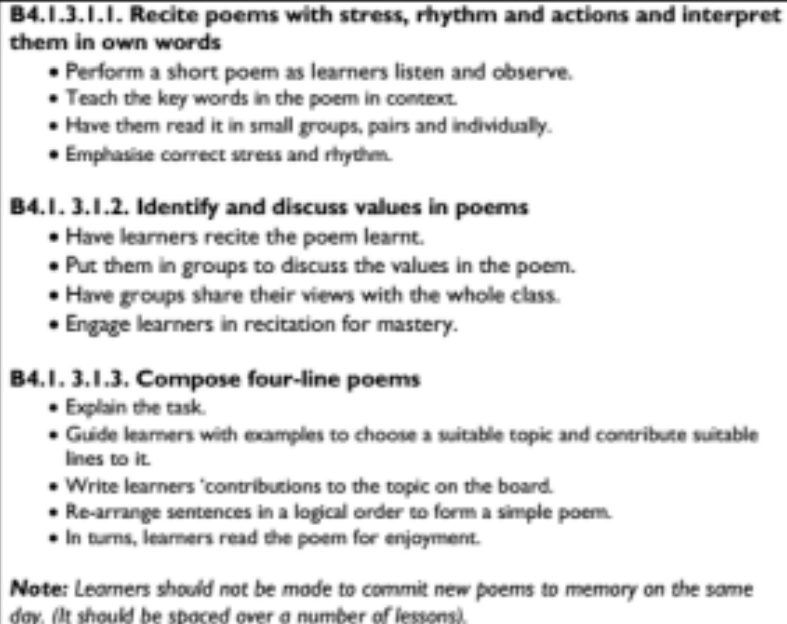 & $\begin{array}{l}\text { Communication and Collaboration } \\
\text { Personal Development and } \\
\text { Leadership } \\
\text { Creativity and Innovation }\end{array}$ \\
\hline
\end{tabular}

I share this representative finding above to highlight the differences in the teaching objectives and learning expectations for teachers and students respectively in

${ }^{18}$ Ghanaian languages curriculum for B4-B6, 2019, p. 5

${ }^{19}$ English language curriculum for B4-B6, 2019, p. 3 
both English and Ghanaian languages. Under the same sub-strand "Poems," the English Curriculum has three main learning indicators compared to only one in the Ghanaian Languages Curriculum. In English, students are to recite poems with stress, rhythm and action and interpret them in own words; identity and discuss values in poems; and compose four-line poems." The first eight bullet points in the English Curriculum are similar to the 10 bullet points in the Ghanaian languages curriculum. In Table 4.4 however there is an intentionality to how teachers are to systematically teach poems in primary 4 especially in English where teachers are to guide students to first understand poetry and then to later compose their own poems (See points 9 to 12 under In English in Table 4.5).

\section{Table 4.5}

Comparing Teaching Content for Poems in Primary 4

\begin{tabular}{lll}
\hline In Ghanaian & In English... & GL and Eng. Compared
\end{tabular}
Languages.... 


\begin{tabular}{|c|c|c|c|c|}
\hline \multirow{3}{*}{1.} & Let learners sing a & 1. & Perform a short poem as learners & What is present in both? \\
\hline & popular traditional & & listen and observe. & Point 1 in GL is similar to Point 1 in \\
\hline & song. & 2. & Teach the key words in the poem & Eng. (Introducing the Poem) \\
\hline \multirow[t]{2}{*}{2.} & Explore a poem to & & in context. & \\
\hline & learners. & 3. & Have them read it in small groups, & Points $2,3,4,5,6$ in GL are similar to \\
\hline \multirow[t]{3}{*}{3.} & Let them listen and & & pairs and individually. & Points 2, 4 in Eng (Exploring with \\
\hline & take note of keywords & 4. & Emphasise correct stress and & Students) \\
\hline & words in the poem. & & rhythm. & Points $8,9,10$ in GL are similar to \\
\hline \multirow[t]{3}{*}{4.} & Ask learners to & 5. & Have learners recite the poem & Points 3, 6, 7 in Eng. (Students' \\
\hline & mention the words & & learnt. & Self/Group Learning) \\
\hline & they heard. & 6. & Put them in groups to discuss the & \\
\hline \multirow[t]{2}{*}{5.} & Write the words on & & values in the poem. & What is NOT present in both? \\
\hline & the board. & 7. & Have groups share their views & From Points 9, 10, 11, 12, and 13 in \\
\hline \multirow[t]{2}{*}{6.} & Lead learners to say & & with the whole class. & Eng., students are guided in composing \\
\hline & the words aloud. & 8. & Engage learners in recitation for & poems. This is absent in GL. Point 7 in \\
\hline \multirow[t]{4}{*}{7.} & Let learners say the & & mastery & GL is not specific to composing \\
\hline & words and use them & 9. & Explain the task. & poems. \\
\hline & to form their own & 10. & Guide learners with examples to & \\
\hline & sentences. & & choose a suitable topic and & \\
\hline \multirow[t]{2}{*}{8.} & Let learners explore & & contribute suitable lines to it. & \\
\hline & the poem correctly. & 11. & Write learners 'contributions to & \\
\hline \multirow[t]{2}{*}{9.} & Put learners in & & the topic on the board. & \\
\hline & groups. & 12. & Re-arrange sentences in a logical & \\
\hline \multirow[t]{3}{*}{10.} & Let them discuss the & & order to form a simple poem. & \\
\hline & moral lessons in the & 13. & In turns, learners read the poem & \\
\hline & poems in groups and & & for enjoyment. & \\
\hline
\end{tabular}


Ghanaian Language Curriculum, at times, sounds vague when the curriculum instructs teachers to "explore poems to learners" or "let learners explore poems" (See points 2 and 8 in Table 4.5). It is not clear what else is meant by exploring beyond the having students pick out key words, reading the poem in groups or individually, and discussing moral lessons. In the English curriculum, the language used to direct teachers is specific. The word "explore" is never used but there is a specific step-by-step approach to teaching the subject. Also, a small but crucial statement in Table 4.5. point (13) under "In English" states that "in turns, learners read the poem for enjoyment." This discourse of student simply enjoying reads in Ghanaian languages does not show up in Ghanaian languages. Students should also enjoy reading in Ghanaian languages but not explicitly stating it in the curriculum does not draw attention to its importance so while it may happen in the Ghanaian language classroom, it might vary because it is an explicit and visual reminder to teacher to cultivate the habit in English. This pattern is similar to the KG Curriculum, discussed earlier where the teachers is to help students cultivate a literacy skill in English but not explicitly stated in Ghanaian languages. See Table 4.6 for more examples that highlight how widespread this pattern is across English and Ghanaian language curricula. In Table 4.6 there is more detailed and step-by-step direction provided to teachers not only about what they should teach but about how they should go about teaching in English than in Ghanaian languages. In the English curriculum teachers receive more guidance about the teaching process. In Table 4.6 under "Listening and Storytelling", in the Ghanaian languages curriculum, teachers are told to discuss the story with learners by talking about key issues but in the English curriculum, more direction is provided in terms of what students should be discussing "Why do you like the story? I like the 
story because... Which part of the story do you like the best? I like where...". Under "Vocabulary," the English curriculum goes to the extent of directing and encouraging students to use glossaries and dictionaries as part of learning, in addition to writing sentences using the vocabulary they are learning. This component does not exist in the Ghanaian language curriculum.

\section{Table 4.6}

Comparison 2: Differences Across Various Content Strand in English and

\section{Ghanaian languages}

\begin{tabular}{l|l}
\hline Ghanaian languages curriculum & English language curriculum \\
Indicators \& Exemplars & Indicators \& Exemplars
\end{tabular}

\section{Listening and Storytelling}

B1.1.4.1.1. Discuss the characters of
the story

- Show a clip or tell a story to learners

- Use questions to elicit names of characters in stories watched or told in class from learners

B1.1.4.1.2 Discuss the events in the story

- Show a movie/play to learners
B1.1.3.1.1 Listen to stories and be able to identify characters with their roles

- Mount appropriate story pictures

- Guide learners to tell the story logically, using the pictures at each stage

- Pause and show pictures for learners to ask questions or answer questions to predict the next stage 


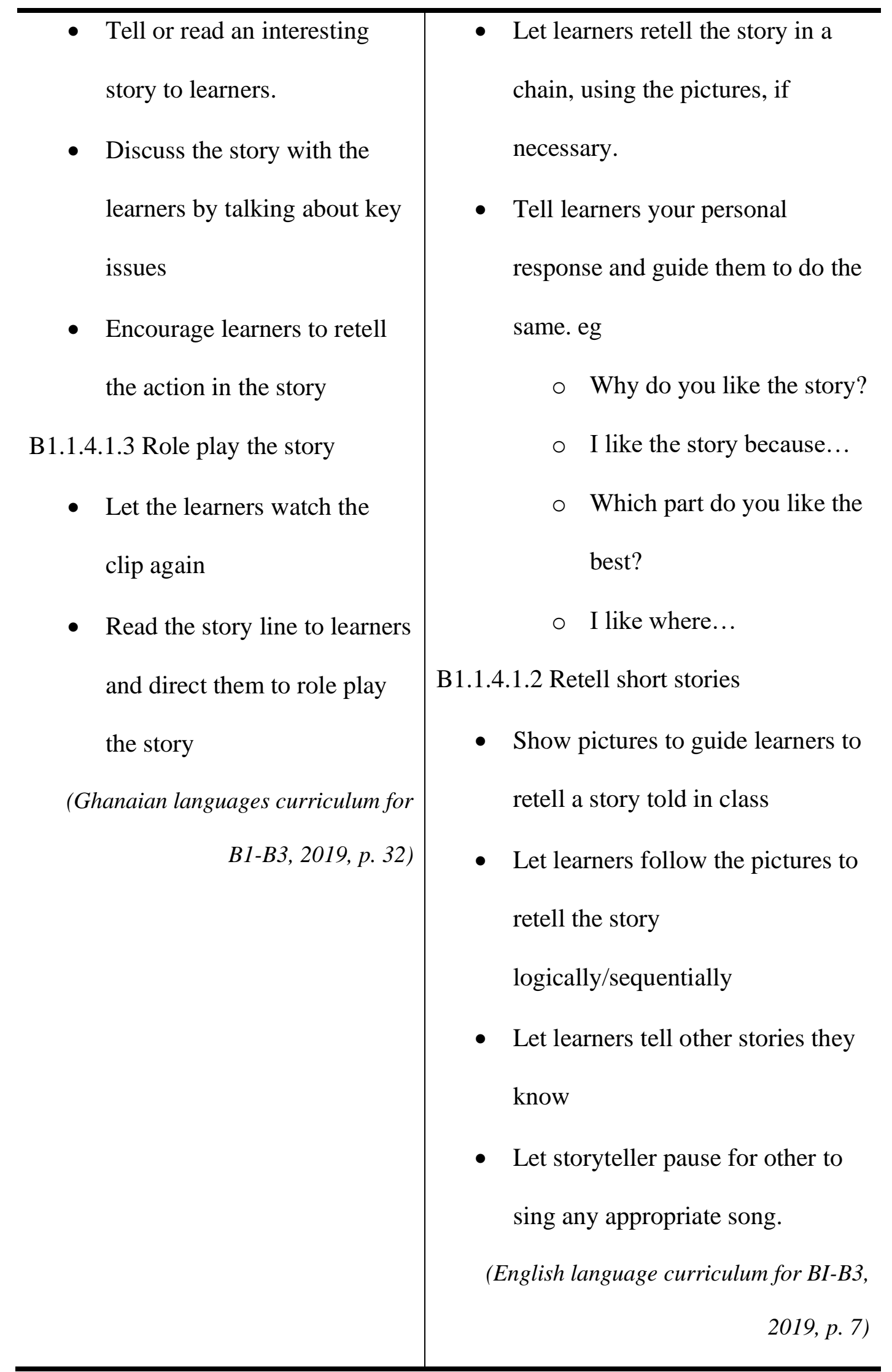




\section{Vocabulary}

B2.2.5.1.1. Recognise sounds that make up words.

- Revise sounds with learners

- Write some words on the board and lead learners to read them

- Assist learners to recognize sounds that make up words

B2.2.5.1.2. Make picture dictionaries

- Let learners cut pieces of different objects and arrange them in alphabetical order in their books

- Lead learners to write the names of the images in the pictures under them

B2.2.5.1.3. Match action words with corresponding pictures

- Display a picture showing actions of various kinds.

- Write the actions on the board and lead learners to
B2.2.6.1.1. Read level-appropriate sigh

words, understand and use many of them in meaningful sentences

- Introduce the selected sight words, one at a time, in context and write them on the board

- Start from the basic words they already know

- Have learners repeat the words aloud a number of times

- Write the words on the board

- Have learners read the words in order and at random

- Use think-pair-share to have learners form sentences with them

B.2.2.6.1.2. Use context clues to infer meanings of words

- Create a story around a theme, using specific key words or vocabulary items you wish to teach 


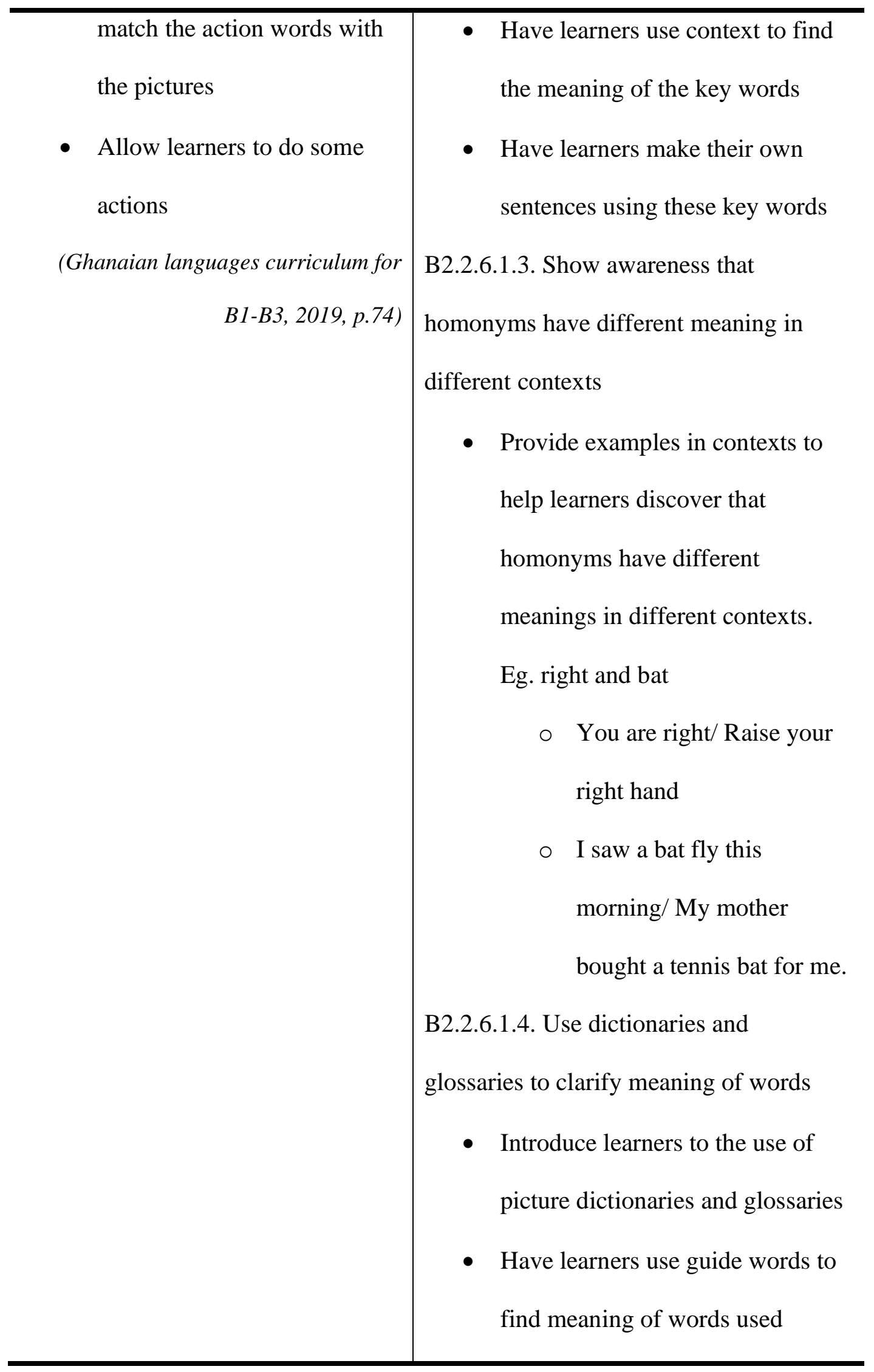




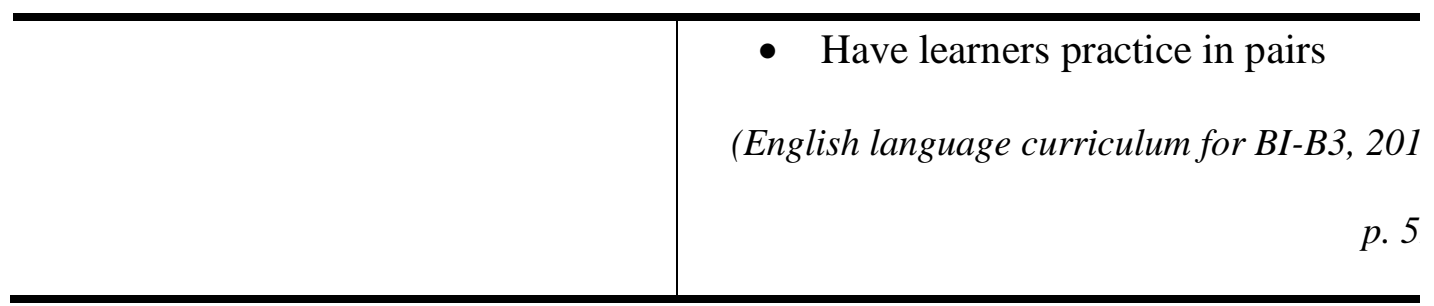

The specificity with how English should be taught compared to Ghanaian languages was also found in the Teacher Resource Packs for primary 1 to primary 6 . The Teacher Resource Packs contains sample weekly and term lessons plans for teachers in addition to worksheets for each subject area. It was developed as "as a complementary document to the Training Guide for in-service teachers on the implementation of the primary school curriculum...to serve as a source of reference to teachers during the preparation of their Scheme of Learning and lesson plans as well as teaching and assessment of learners" (Teacher Resource Pack, 2019, p. 5).

Below in Figure 4.4 and Figure 4.5, I present two sample lesson plans provided to teachers as a template that teachers can use in planning their lessons. In my analysis of the lesson 


\section{${ }^{20}$ Figure 4.10}

Lesson Plan Exemplar for Ghanaian Languages

\begin{tabular}{|c|c|c|c|c|}
\hline \multicolumn{3}{|c|}{ Period: 2} & \multicolumn{2}{|c|}{ Subject: Ghanaian Language } \\
\hline \multicolumn{3}{|c|}{ Duration: 30 Minutes } & \multicolumn{2}{|l|}{ Strand: Reading } \\
\hline Class: B2 & \multicolumn{2}{|c|}{ Class size: 35} & \multicolumn{2}{|c|}{ Sub-strand: Comprehension } \\
\hline \multicolumn{2}{|c|}{$\begin{array}{l}\text { Content Standard: B2.2.6.1 } \\
\text { Exhibit knowledge of } \\
\text { answering questions } \\
\text { based on texts presented. }\end{array}$} & \multicolumn{2}{|c|}{$\begin{array}{l}\text { Indicator: B2.2.6.1.5 Answer } \\
\text { simple questions based } \\
\text { on texts read. }\end{array}$} & Lesson 1 of 3 \\
\hline \multicolumn{3}{|c|}{$\begin{array}{l}\text { Performance Indicator: Learner should be able } \\
\text { to answer questions from texts read. }\end{array}$} & \multicolumn{2}{|c|}{$\begin{array}{l}\text { Core Competencies/Values: } \\
\text { Communication and } \\
\text { collaboration, Critical thinking } \\
\text { and Problem solving }\end{array}$} \\
\hline \multicolumn{5}{|l|}{ Key words: } \\
\hline $\begin{array}{l}\text { Phase/Duratio } \\
\text { n }\end{array}$ & \multicolumn{3}{|c|}{ Learner activities } & Resources \\
\hline $\begin{array}{l}\text { Phase 1: } \\
\text { Starter } \\
\text { (preparing } \\
\text { the brain } \\
\text { for } \\
\text { learning) } \\
5 \text { minutes }\end{array}$ & \multicolumn{3}{|c|}{$\begin{array}{l}\text { Review previous passages with learners. } \\
\text { Afterwards, distribute the readers to } \\
\text { learners. }\end{array}$} & \\
\hline $\begin{array}{l}\text { Phase } 2 \text { : Main } \\
\text { (new learning } \\
\text { including } \\
\text { assessment) } \\
20 \text { minutes }\end{array}$ & \multicolumn{3}{|c|}{$\begin{array}{l}\text { - Pre-reading } \\
\text { a. Have you seen the picture on the passage } \\
\text { in your book? Let's talk about it. Do you } \\
\text { have any knowledge on the passage we } \\
\text { are going to read? Write three or four } \\
\text { questions you want to answer from this } \\
\text { passage. }\end{array}$} & Word cards \\
\hline
\end{tabular}

\begin{tabular}{|l|l|} 
b. Go through the passage and identify all \\
words and expressions you do not \\
understand. Let learners guess the \\
meanings of the words and expressions \\
they have identified. Teach learners the \\
meanings of the words and expressions \\
they have identified in relation to the \\
understanding of the passage. Lead \\
learners to look for the opposites of \\
these words. \\
- Reading \\
a. Read aloud the first paragraph of the \\
passage as a model. \\
b. Call learners to read in turns until the \\
whole passage is read. Pay particular \\
attention to pronunciation and expression \\
and correct them where necessary. \\
Sometimes pause to let learners ask \\
questions about what they have read \\
and make further predictions of what \\
they envisage to see in the passage.
\end{tabular} \mid

${ }^{20}$ Teacher Resource Pack, 2019, p. 25-26 


\section{${ }^{21}$ Figure 4.11}

Lesson Plan Exemplar for English

\begin{tabular}{|c|c|c|c|}
\hline \multicolumn{2}{|c|}{ 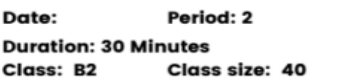 } & \multicolumn{2}{|c|}{$\begin{array}{l}\text { Subject: English Language } \\
\text { Strand 2: Reading } \\
\text { Sub strand 7: Comprehension }\end{array}$} \\
\hline \multirow{2}{*}{\multicolumn{2}{|c|}{$\begin{array}{l}\text { Content Standard: B2.2.7.2: Use } \\
\text { knowledge, skills and } \\
\text { techniques understand, interpret } \\
\text { and appreciate a variety of literary } \\
\text { texts. }\end{array}$}} & $\begin{array}{l}\text { Indicator: B2.2.7.2. } \\
\text { Read level-appropriate } \\
\text { texts with little support. }\end{array}$ & Lesson 3 of 3 \\
\hline & & $\begin{array}{|lrr|}\text { B2.2.7.2. } & 5 . & \text { Use } \\
\text { visualisation } & \text { strategy } \\
\text { when } & \text { reading } & \text { to }\end{array}$ & \\
\hline & & $\begin{array}{l}\text { enhance } \\
\text { understanding of level- } \\
\text { appropriate texts. }\end{array}$ & \\
\hline \multicolumn{2}{|c|}{$\begin{array}{l}\text { Performance Indicator: Learners } \\
\text { can read a level-appropriate } \\
\text { texts with comprehension. }\end{array}$} & \multicolumn{2}{|c|}{$\begin{array}{l}\text { Core Competencies/Values: Personal } \\
\text { Development and Leadership, Critical } \\
\text { thinking, Communication and collaboration, } \\
\text { Tolerance. }\end{array}$} \\
\hline \multicolumn{4}{|c|}{ Key words/expressions: birds, nest, perch } \\
\hline Phase/Duration & \multicolumn{2}{|l|}{ Learners activities } & Resources \\
\hline $\begin{array}{l}\text { Phasel: Starter } \\
\text { (preparing } \\
\text { the brain for } \\
\text { learning) } \\
5 \text { minutes }\end{array}$ & \multicolumn{2}{|c|}{$\begin{array}{l}\text { - Show a picture of a bird to learners to } \\
\text { activate the background knowledge of } \\
\text { learners. Have learners think-pair-share } \\
\text { what they already know about the text). } \\
\text { Write learners views in the } \mathbf{K} \text { column of the } \\
\text { KWL Chart. }\end{array}$} & $\begin{array}{l}\text { TLMs/Resources } \\
\text { A picture of a } \\
\text { bird, Word cards }\end{array}$ \\
\hline \multirow[t]{2}{*}{$\begin{array}{l}\text { Phase } 2 \text { : } \\
\text { Main (new } \\
\text { learning } \\
\text { including } \\
\text { assessment) } \\
20 \text { minutes }\end{array}$} & \multicolumn{2}{|c|}{$\begin{array}{l}\text { Before Reading } \\
\text { - Put learners into small groups to share } \\
\text { what they want to know about the text, } \\
\text { and write them in the } \mathbf{w} \text { (What the } \\
\text { learners want to know) column of the KWL } \\
\text { Chart. } \\
\text { Teach the key words using pictures and } \\
\text { gestures }\end{array}$} & $\begin{array}{l}\text { KWL Chart } \\
\text { Information text } \\
\text { about birds }\end{array}$ \\
\hline & \multicolumn{2}{|c|}{$\begin{array}{l}\text { During Reading } \\
\text { Have learners read the story in pairs and } \\
\text { individually. }\end{array}$} & \\
\hline
\end{tabular}

\begin{tabular}{|l|l|l|}
\hline & $\begin{array}{l}\text { Ask while reading questions to enhance } \\
\text { learners' understanding of the text. E.g. Ask } \\
\text { questions to help learners form mental } \\
\text { images (visualisation strategy) to } \\
\text { enhance understanding. } \\
\text { After Reading }\end{array}$ \\
$\begin{array}{ll}\text { End the lesson with after reading activities } \\
\text { that help learners to organise their ideas. } \\
\text { remember the story, use the information } \\
\text { acquired from the text and relate it to } \\
\text { their daily lives. } \\
\text { Have learners ask and answer } \\
\text { questions to enhance their } \\
\text { understanding of the text. } \\
\text { Ask learners to tell their partners what they } \\
\text { have learned from the text. Learners share } \\
\text { with the class what their friends havelearnt } \\
\text { about the text. Write learners' responses in } \\
\text { the L (What learners have learnt) column of } \\
\text { the KWL Chart. }\end{array}$
\end{tabular} \mid

${ }^{21}$ Teacher Resource Pack, 2019, p. 86-87 
plans in the Teacher Resource Pack for English and Ghanaian Languages, I found similar discourse that showed higher literacy expectations from students in English compared to Ghanaian languages.

For example, in the figures above, for same activity (reading comprehension) at the same grade level (primary 2) but in English and Ghanaian languages, by looking at the structure of the template: Pre-reading, During Reading, Post-Reading and Assessment, it appears that the approach to teaching English is the same as Ghanaian languages (See Figure 4.10 and 4.11). However, a closer examination of the discourse specifically focusing on the activities and what students are to produce in Ghanaian languages and English highlights differences. In the Ghanaian languages' lesson plan, there is an emphasis on students engaging with the text orally. The whole class is to "read the in turns until the whole passage is read" while the teacher stresses correct pronunciation of words (See point (b) under Reading in Figure 4.11). Also, students "answer orally" questions raised by the teacher (See point (b) under Post-Reading Assessment in Figure 4.11). Again, the same oral response in stressed in the Plenary/Reflection section of the Ghanaian languages' lesson plan where the teacher is to “ask more questions based on the passage read for learners to answer orally." Even at this point, the teacher is to "pay attention to their use of language and pronunciation".

Looking at this discourse without considering the English lesson plan may not raise any concerns but in examining the English lesson it shows that the focus on the oral nature of responses is not stressed in the English lesson like it is in Ghanaian languages. In the English lesson, students work with partners in think-pair-share activities, a core 
teaching technique that is absent in the Ghanaian languages lesson plan. In the English lesson students are also provided more guidance with how to "organize their ideas, remember the story" to "enhance their understanding of the text" (See Figure 4.4). While students in the English lesson use new words they have learned in "simple sentences" and to "write at least 3 sentences," in the Ghanaian languages' lesson, students are not using what they have learned in producing new writings but instead, "write answers to questions" already discussed orally in the classroom. This also confirms the earlier finding in the kindergarten curriculum, students are to learn more and do more in English than in Ghanaian languages. Also, the Ghanaian languages curriculum in multiple ways places more emphasis on students speaking Ghanaian languages well and pronouncing words correctly and less emphasis on writing skills. In English, however, more literary skills, including writing and reading are emphasized across different types of lessons.

\section{The High Weight in Assessing Languages}

The examination of the discourse on assessment procedures and policies in the Pre-tertiary Education Curriculum Framework also reinforces and centers English over Ghanaian languages. The final summative grade for primary school is made up of two types of assessments. The first is a continuous assessment (CA) or school-based assessment (SBA) that includes assessments of classroom activities, homework assignment, and projects conducted throughout the school year. The second type of assessment includes both an end of term test and end of year examination. For KG, however, "only informal continuous assessment is used in KG1-2. No end of term tests 
will be written. Five or six informal more structured assessment should be done (twice per term)" (Pre-tertiary Educational Curriculum Framework, 2019, p. 41).

These two types of assessments for primary schools are weighted differently for lower and upper primary. Later in upper primary they are again weighted differently for language subjects compared to other content areas. The analysis of how and why they are different reveals the discourse encoded. In lower primary:

"teachers can choose to grade and/or record more than the required continuous assessments if it is necessary for formative purposes. An end-of-year summative grade will be based only on the assessment tasks described in the syllabus. Endof-term tests should not contribute more than $30 \%$ towards the total mark for the term. Not more than $40 \%$ of the summative grade may be based on tests, which include topic tests, and end-of-term tests" (National Pre-tertiary Education Curriculum Framework, 2019, p. 41).

The framework provides teachers some flexibility is how they assigned final grades but it still places some limits, I argue for the benefits of students: "End-of-term tests should not contribute more than 30\% towards the total mark for the term... and not more than $40 \%$ of the summative grade..." This means that the majority of a students' final grade for a term and final grade for the year is based on the formative continuous assessment conducted throughout the school year. It places less emphasis students learning for a final test but rather encourages learning throughout the school year in all subject areas, especially since Grade A in the grading scheme is assigned for an overall score of 80 and above (See Figure 4.12). 
${ }^{22}$ Figure 4.12

Grading Scheme for Primary Schools

\begin{tabular}{|llll|}
\hline Grade A: & $80-100 \%$ & - & Excellent \\
Grade B: & $70-79 \%$ & - & Very Good \\
Grade C: & $60-69 \%$ & - & Good \\
Grade D: & $45-59 \%$ & - & Credit (Satisfactory) \\
Grade E: & $35-44 \%-$ & Pass & \\
Grade U & $\leq 34 \%-$ & Fail & \\
\hline
\end{tabular}

This position however changes by Primary 4 when English is officially the designated language medium for most subjects. Continuous assessments and examinations are weighted equally (50-50) for language subjects, which from this stage is English, Ghanaian languages, and French (See Table 4.7). Also, note that because more periods are allocated to English, it transmits a discourse to educators and students that the English language is more important in the classroom or in school given that all other nonlanguage subjects are also taught in English. Now a student's work through the term or year counts only as a Grade D if by whatever reason they do not do well in the final exam. Considering that primary 4 is when students are introduced perhaps to English as their only tool of meaning making, the structure of assessment practices creates an environment where students are heavily penalized even while they are still learning to navigate having English as the only language of teaching and learning and this continues in primary 5 and 6.

Examinations become much more important in upper primary than in lower primary and it can create a system where the teacher focuses on teaching students just what the curriculum requires so that students pass examinations in English rather than

\footnotetext{
${ }^{22}$ NPTECF, 2019, p. 36
} 
focusing on the formative learning process. This also applies to Ghanaian languages where the few periods allocated to learning of Ghanaian languages could focus just on the grammar content students need to know by the time they take an end-of-term test and final examinations as discussed earlier and not the multiliteracy, multimodal, multidimensional, and multisensory aspects of Ghanaian languages.

\section{${ }^{23}$ Table 4.7}

Weights for Continuous Assessment and Examination for Upper Primary

\begin{tabular}{lll}
\hline Subjects & Primary 4 & Primary $5 \& 6$
\end{tabular}

\begin{tabular}{lllll}
\hline & Continuous & Examination & Continuous & Examination \\
& Assessment & & Assessment & \\
Skills-based & $50 \%$ & $50 \%$ & $50 \%$ & $50 \%$ \\
Subjects & & & & \\
(Languages) & & & & \\
Content- & $65 \%$ & $50 \%$ & $50 \%$ & $50 \%$ \\
based & & & &
\end{tabular}

Subjects (All

other

subjects)

End-of-term tests and final examinations may be helpful in assessing students' abilities but by placing a lot of weight on these modes of assessments the framework does not recognize that in the context of the multilingual environment. The nature of examinations heavily penalizes the errors students make in the languages that can be

${ }^{23}$ Adapted from the National Pre-tertiary Education Curriculum Framework, 2019, p. 41 
counterproductive to language learning. The Pre-tertiary Education Curriculum Framework explains that "the purpose of these examinations is to focus on how well learners can demonstrate their thinking, communication, and problem-solving skills relevant to the areas of the syllabus which are most essential for continuing to the next grade... the purpose of the examination is to assess how far each learner can demonstrate their achievement in reaching the competences" (p. 41). Here is where the framework for assessment might fail students. Examinations might provide some measure of assessing how much a learner knows but a more precise measure can be found through the continuous assessments that are conducted throughout the year. If a student is able to demonstrate "their thinking, communication, and problem-solving skills" well throughout multiple assessments, those many demonstrations should count more when assessing how much they have achieved throughout the school year. Herein lies the fallacy of English linguistic imperialism; the current structure still supports the evidence that the English language is valued more highly because English as a language is not just the language of teaching and learning in all content areas but also the language students write assessments in, with regards to all other content areas. In this instance the design of the assessment policies works to reify the dominant position of English because even though Ghanaian Languages Curriculum appears to be held to the same standard, the curriculum does not provide students' access to also produce their work in Ghanaian languages in all subject areas.

\section{Discourses of Ghanaian Languages and Literacies}

This next section highlights how knowledge about Ghanaian cultures and people emerges in other non-language subjects and not in the Ghanaian Languages Curriculum, 
and how, as a result, students learn about Ghanaian culture in the English language. In other words, because English persists as the only language medium in all these subjects, the design of the curriculum separates the teaching and learning of Ghanaian languages from the teaching of Ghanaian histories, cultures, people, and other literacies. I share how discourses of Ghanaian languages, literacies, histories, cultures, and knowledge are shaped in other subject curricula other than the English and Ghanaian languages curricula discussed in the previous section. I specifically focus on subject curricula like History, Religious and Moral Education (RME), Creative Arts, and Our World Our People (OWOP) because these subjects more than the other non-language subjects like Mathematics, Science, Physical Education, Computing, and French are more likely to teach students about the ways of being of Ghanaians. From the literature review discussed in chapter two we learned that the History and RME curricula from the colonial to post-independence prioritized Western history and beliefs. It was important to include these two curricula in my analysis to understand how these subjects represented Ghanaian ways of being today. As discussed in chapter three I included the Creative Arts curriculum in my analysis because the content centered on Ghanaian visual and performance arts and the OWOP curriculum because like a social studies subject area, students learned about society and their role in it.

The research questions that guided the analysis for this section are as follows: What is the discourse about Ghanaian languages and literacies in the Ghanaian primary school (K-6) curriculum? Specifically (a) How are Ghanaian languages and literacies including various Ghanaian cultures and their histories, represented in the curriculum? 
(Diversity); (b) How does the design of the curriculum provide students access to diverse Ghanaian languages, literacies, cultures, and histories? (Access/Diversity/Design).

\section{Development Begins When the Colonizers Arrive}

In my analysis of the History curriculum for primary schools, findings supported the patterns of English linguistic imperialism already discussed in the previous section. The History curriculum covers 6 topics/strands such as History as a Subject, My

\section{Country Ghana, Europeans in Ghana, Colonization and Developments under}

Colonial Rule, Journey to Independence, and Independent Ghana. What is surprising about the History curriculum is that the historical timeline of Ghana in the curriculum leans heavily on the activities of European traders and colonizers from when they landed on the Gold Coast and Ghana. 11 out of 23 sub-strands focus on European and colonial activity and history during the colonial period (See sub-strands 10 to 20 in Table 4.8). Sub-strands 21 to 23 are about more recent political history after independence. Only sub-strands 5 and 6 teach student about the various ethnic groups in Ghana, traces how they came to be in Ghana, and touches on how they lived before the $15^{\text {th }}$ century. The first four strands use students' own personal histories as a tool to teach them about the relevance of history.

\section{${ }^{24}$ Table 4.8}

Strands and Sub-Strands in the History Curriculum

Strands Sub-Strands

History as a Subject 1. Why and how we study history

2. The learner's own history

3. Family history

${ }^{24}$ History Curriculum p. Xx 


\section{Community history}

\begin{tabular}{ll}
\hline My Country Ghana & 5. The people of Ghana \\
& 6. Inter-group relations \\
7. How Ghana got its name \\
8. Major historical locations \\
9. Some selected individuals
\end{tabular}

\begin{tabular}{ll}
\hline Europeans in Ghana & 10. Arrival of Europeans \\
& 11. International trade including slave trade \\
& 12. Missionary activities \\
& 13. Impact of European presence \\
\hline Colonization and & 14. Establishing colonial rule in Ghana \\
15. Social development \\
Development Under & 16. Economic development \\
Colonial Rule & \\
& \\
\hline Journey to Independence & 18. Early protest movements \\
& 19. Formation of political parties \\
& 20. The 1948 riots \\
& 21. Ghana gains independence \\
\hline Independent Ghana & 22. The republics \\
& 23. Military rule
\end{tabular}

There is more content on when the Europeans arrived and what the colonizers did than about the history of the people who lived in Ghana or about how they lived before White European traders and colonizers arrived. This quick brush over the early history of the people in Ghana is especially crucial because it sets up a discourse centering Whiteness and White ways of doing and being in teaching students the history of their own country. In short, the curriculum whitewashes the history of Ghana. There are two main ways this centering and white-washing of Ghana history are found in the curriculum. First, topics around the economic, social, and educational development of 
Ghana center especially around what Europeans missionaries and colonizers did in the country (See Figure 4.13, 4.14, 4.15 and also Table 4.8). Major developments that occurred in Ghana are attributed to colonialism and colonial activity. For example, even though the development of alphabets and schools were influenced by missionary presence and trade in Ghana, they occurred with and because of the work of Ghanaian scholars, priests, and chiefs who wanted to provided formal education to their own people like the colonizers were providing to their children in their forts and castles (Graham, 1971).

See Figure 4.15 for another example. The central question is "Which schools were built during the colonial period? Where were they located? What did the British do to promote education?" The history here is more complex because there are many local people and their local leaders who worked to expand education into their communities and not just the British colonial government. The question is leading because it centers only the work of the colonizer here. Yet below in the same excerpt is an example teachers could teach of an important figure who promoted education - Dr. Kwegyir Aggrey - a Ghanaian, but he is included as an addendum that teacher could choose to mention or not, even though he was a champion of education in the local language of his community.

It is true that some development happened under colonial rule but the curriculum frames "development" as a project that begins because of colonialism and not in spite of colonialism. The discourse here reinforces English linguistic imperialism that when a global south country and its people embrace more Western ideals and norms, then the country and its people will develop. 
${ }^{25}$ Figure 4.13

Developments in Ghana under Colonial Rule

\begin{tabular}{|c|c|c|}
\hline CONTENT STANDARDS & INDICATORS AND EXEMPLARS & $\begin{array}{l}\text { SUBJECT SPECIFIC PRACTICES } \\
\text { AND CORE COMPETENCIES }\end{array}$ \\
\hline $\begin{array}{l}\text { 84.3.3.1. Demonstrate } \\
\text { knowledge of Europeans' } \\
\text { engagement in other } \\
\text { activities other than trade in } \\
\text { Ghana }\end{array}$ & $\begin{array}{l}\text { B4.3.3.I.I Describe European missionary activities in Ghana } \\
\text { Enquiry Route: Which Europeon missionory society wos the first to come to } \\
\text { the Gold Coost? In which areas did they operote? Whot wos their } \\
\text { impoct on the lives of Ghonaians? } \\
\text { 1. Identify the missionary societies that came to Ghana (starting } \\
\text { from the first to the last) } \\
\text { 2. Locate places where they operated (eg, Basel-Akuapem, } \\
\text { Bremen-Peki etc) } \\
\text { 3. Discuss Christianity and formal education as some of the } \\
\text { major impacts of European presence in Ghana } \\
\text { 4. Show and discuss video/documentary of European activities } \\
\text { in Ghana } \\
\text { 5. Discuss other activities they engaged in (trade, vocational } \\
\text { training centres, health facilities, development of alphabets } \\
\text { for some local languages and translation of the Bible into } \\
\text { 6. Deabate the effects of European activities in Ghana }\end{array}$ & $\begin{array}{l}\text { As learners use evidence to } \\
\text { interpret other European } \\
\text { activities in Ghana, they become } \\
\text { critical thinkers, creative, } \\
\text { communicative learners }\end{array}$ \\
\hline
\end{tabular}

\section{${ }^{26}$ Figure 4.14}

\section{Economic Developments in Ghana under Colonial Rule}

\begin{tabular}{|c|c|c|}
\hline CONTENT STANDARDS & INDICATORS AND EXEMPLARS & $\begin{array}{l}\text { SUBJECT SPECIFIC PRACTICES } \\
\text { AND CORE COMPETENCIES }\end{array}$ \\
\hline $\begin{array}{l}\text { B5.4.3.2. Show } \\
\text { understanding of the } \\
\text { Economic policies and } \\
\text { projects during the } \\
\text { colonial period (1874. } \\
\text { 1957) }\end{array}$ & 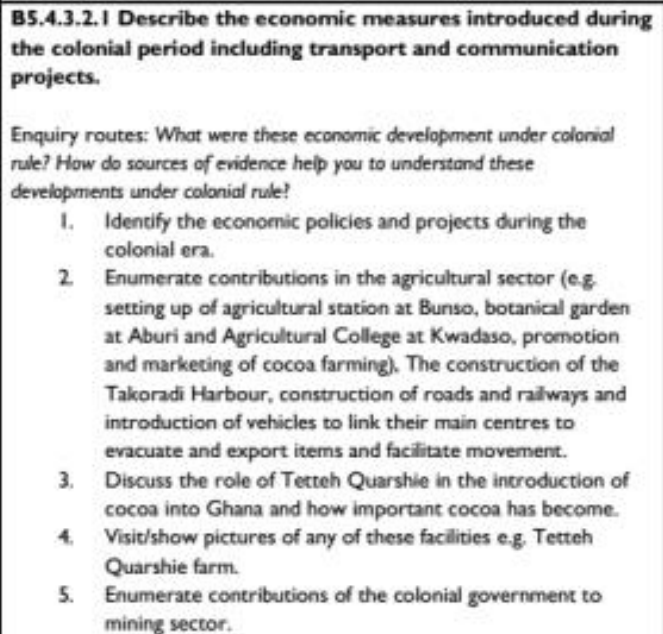 & $\begin{array}{l}\text { As learners use evidence to } \\
\text { analyse and reconstruct the } \\
\text { developments during the colonial } \\
\text { period, they develop critical } \\
\text { thinking and problem-solving } \\
\text { skills }\end{array}$ \\
\hline
\end{tabular}

${ }^{25}$ History Curriculum p. 25

${ }^{26}$ History Curriculum p. 34 
${ }^{27}$ Figure 4.15

Education and Health Developments in Ghana under Colonial Rule

\begin{tabular}{|c|c|c|}
\hline CONTENT STANDARDS & INDICATORS AND EXEMPLARS & $\begin{array}{l}\text { SUBJECT SPECIFIC PRACTICES } \\
\text { AND CORE COMPETENCIES }\end{array}$ \\
\hline $\begin{array}{l}\text { B5.4.2.I. Demonstrate } \\
\text { understanding of the social } \\
\text { developments that took } \\
\text { place during the colonial } \\
\text { period (1874-1957). }\end{array}$ & $\begin{array}{l}\text { B5.4.2.1.I Identify the developments in education during the } \\
\text { colonial era (1874-1957). } \\
\text { Enquiry routes: Which schools were buit during the colonial period? } \\
\text { Where were they locoted? Whot did the British do to promote } \\
\text { education? } \\
\text { 1. Identify schools that existed by } 1930 \text {, where they are } \\
\text { located and state some facts about these schools } \\
\text { 2. List some of the measures the British took to promote } \\
\text { education in the Gold Coast. E.g. Ordinances to make sure } \\
\text { all teachers were registered } \\
\text { 3. Discuss the role of the churches in Ghana's education } \\
\text { sector } \\
\text { 4. Recall the role of the important people in (a) the community } \\
\text { and (b) the country who played key role in the educational } \\
\text { sector. eg. Dr Kwegyir Aggrey. } \\
\text { NB: Display pictures of such people in the class. }\end{array}$ & $\begin{array}{l}\text { As learners use evidence to } \\
\text { analyse and reconstruct the } \\
\text { developments during the colonial } \\
\text { period, they develop critical } \\
\text { thinking skills }\end{array}$ \\
\hline & $\begin{array}{l}\text { B5.4.2.1.2 Identify some of the health facilities and housing } \\
\text { projects in the colonial period. } \\
\text { Enquiry routes: What heath focilties were buit during the colonial } \\
\text { period? How importont were these social services? } \\
\text { 1. Discuss the healch facilities and housing projects carried out } \\
\text { during the colonial period eg, the establishment of the } \\
\text { Korle Bu hospital- 1923, Kumasi hospital, Takoradi hospital, } \\
\text { 2. Brainstorm the significance of these social services } \\
\text { 3. Show pictures/documentaries of these facilities to highlight } \\
\text { the social facilities during the era }\end{array}$ & \\
\hline
\end{tabular}

Second, topics about the harm and trauma of colonialism are merely glossed over in the History Curriculum as just another thing that happened in the colonial era. Before the topic of slave trade is first introduced students have learned previously about all the "good" developments that occurred because of colonialism. By primary 5 when students learn about the slave trade, a defining moment in colonial history, it is presented as another commodity the colonizers traded in (See Figure 4.16). The defining questions around this extract from the curriculum are "Which Europeans took part in the trade in humans? Why did the Europeans begin trading in humans?"

${ }^{27}$ History Curriculum p. 33 
${ }^{28}$ Figure 4.16

Introduction to the Slave Trade

Strand 3: Europeans in Ghana

Sub-Strands 2: International Trade Including the Slave Trade

\begin{tabular}{|c|c|c|}
\hline CONTENT STANDARDS & INDICATORS AND EXEMPLARS & $\begin{array}{l}\text { SUBJECT SPECIFIC PRACTICES } \\
\text { AND CORE COMPETENCIES }\end{array}$ \\
\hline $\begin{array}{l}\text { B5.3.2.I. Understand that } \\
\text { what began as trade in } \\
\text { goods from } 1471 \text { soon } \\
\text { included trade in humans } \\
\text { by the } 16^{\circ} \text { century. }\end{array}$ & $\begin{array}{l}\text { B5.3.2. I.I Investigate why the Europeans began trading in } \\
\text { humans by the } 16^{\mathrm{*}} \text { century. } \\
\text { Enquiry Route: Which Europeons took part in the trode in humans? } \\
\text { Why did the Europeans begin troding in humans? } \\
\text { 1. Use a map to explain the concept of Trans-Atlantic slave trade } \\
\text { 2. Role playlshow documentary on how the slave trade was } \\
\text { conducted. } \\
\text { 3. Brainstorm the reasons why the Europeans began trading in } \\
\text { humans } \\
\text { 4. Visit/show pictures of some forts and castles } \\
\text { 5. In small groups learners develop a poster on the Trans. } \\
\text { Actantic Slave Trade } \\
\text { 6. Groups present their work to the whole class }\end{array}$ & $\begin{array}{l}\text { As learners use evidence to } \\
\text { interpret and examine European } \\
\text { activities in Ghana, they become } \\
\text { creative, critical and innovative } \\
\text { thinkers }\end{array}$ \\
\hline
\end{tabular}

Students are to investigate why this happened, but the curriculum does not address the impact of it which is understanding the history of slave trade in Ghana, even more than "which Europeans took part in trade in humans." It is interesting that when it comes to the impact of European presence, the discourse around social, educational, and economic development is emphasized but the impact of slave trade is not considered crucial knowledge. The topic of slave trade is only raised just this once in primary 5 throughout the entire History Curriculum. The topic barely emerges again in primary six where students are to briefly and quickly to consider the negative effects of European presence (See Figure 4.17). In this content strand, the curriculum quickly lists the "good" things colonization brought such health facilities, development of local alphabet, etc.

\section{${ }^{29}$ Figure 4.17}

Impact of colonialization in Ghana

${ }^{28}$ History Curriculum p. 32

${ }^{29}$ History Curriculum p. 40 
Strand 3: Europeans in Ghana

Sub-Strand 4: Impact Of European Presence

\begin{tabular}{|c|c|c|}
\hline CONTENT STANDARDS & INDICATORS AND EXEMPLARS & $\begin{array}{l}\text { SUBJECT SPECIFIC PRACTICES } \\
\text { AND CORE COMPETENCIES }\end{array}$ \\
\hline
\end{tabular}

In the Teacher Resource Pack for History, a sample assessment indicator for an end-of-term exam asks students in primary 3 to "Discuss how Europeans settled on the Gold Coast," and "State three benefits the local peoples got from their interaction with the Europeans" (See Figure 4.18 under "Assessment of learning"). The two prompts are worded carefully in terms of how its positions the identity and activity of Europeans. The prompt uses the word Europeans rather than colonizers and "interaction with the Europeans" rather than colonialism. The discourses here centers Europeans as having done something for and Ghanaians as passive recipients, not having agency. The prompt does not even entertain the assumption that the Europeans/colonizers got something from their interaction with Ghanaians. Asking students to write the "benefits" of colonization so early in education, sets up the discourse and mental image that there was and there was some advantage to colonization. Also, interaction used here versus colonization in the framing of the question also generates a discourse that colonization was perhaps a mutual rather than violent domination of Ghana and Ghanaians. The curriculum by using "benefits" or "advantages" regarding colonization places a value judgement on the event for students that can shape how students view colonization. A content strand that leads 
students to consider the benefits of colonialization is offensive and unjust because it is also asking students to consider the benefits of slavery and slave trade.

${ }^{30}$ Figure 4.18

Sample Assessment in History

PEDAGOGY AND ASSESSMENT

- Sample Assessments

\begin{tabular}{|c|c|c|c|c|}
\hline $\begin{array}{l}\text { Content } \\
\text { Standard }\end{array}$ & Indicator & $\begin{array}{l}\text { Assessment } \\
\text { for learning }\end{array}$ & $\begin{array}{l}\text { Assessment } \\
\text { as learning }\end{array}$ & $\begin{array}{l}\text { Assessment of } \\
\text { learning }\end{array}$ \\
\hline $\begin{array}{l}\text { B3.3.1.1 Show an } \\
\text { understanding } \\
\text { of the } \\
\text { interactions } \\
\text { between the } \\
\text { local people } \\
\text { and early } \\
\text { European } \\
\text { settlers }\end{array}$ & $\begin{array}{l}\text { B3.3.1.1.1 } \\
\text { Describe } \\
\text { how the } \\
\text { Europeans } \\
\text { settled on } \\
\text { the Gold } \\
\text { Coast, } \\
\text { forming } \\
\text { alliances } \\
\text { with the } \\
\text { local } \\
\text { chiefs. }\end{array}$ & $\begin{array}{l}\text { In the course of } \\
\text { the lesson: } \\
\text { Which Europeans } \\
\text { were the first to } \\
\text { come to the Gold } \\
\text { Coast? } \\
\text { Mention other } \\
\text { European } \\
\text { nationals who } \\
\text { came to the Gold } \\
\text { Coast. }\end{array}$ & $\begin{array}{l}\text { Before the } \\
\text { lesson: } \\
\text { Give learners } \\
\text { an assignment } \\
\text { to find out: } \\
\text { 1. The names } \\
\text { of the } \\
\text { coastal } \\
\text { towns in } \\
\text { which the } \\
\text { Europeans } \\
\text { settled and } \\
\text { 2. How the } \\
\text { Europeans } \\
\text { interacted } \\
\text { with the } \\
\text { local } \\
\text { people. }\end{array}$ & $\begin{array}{l}\text { End of term } \\
\text { Exam: } \\
\text { Discuss how the } \\
\text { Europeans } \\
\text { settled on the } \\
\text { Gold Coast. } \\
\text { State three } \\
\text { benefits the } \\
\text { local peoples } \\
\text { got from their } \\
\text { interaction with } \\
\text { the Europeans? }\end{array}$ \\
\hline
\end{tabular}

Furthermore, the curriculum uses the word European as an identifier for the people group that colonized Ghana. The word European appears 58 times in the History curriculum but not the word "colonizer". The word colonial however appears 30 times and it is used to describe words such as [colonial] rule (15 times), [colonial] era (2 times), [colonial] period (5 times), [colonial]ism (1 time) and government (1 time). What is

\footnotetext{
30 Teacher Resource Pack p. 220
} 
telling is that even though Europeans are the ones that colonized Ghana and the History curriculum defines colonization in the glossary as "situation whereby a powerful nation establishes administrative control over a foreign territory" (p. 47), the curriculum does not call them as colonizers and like we have seen this shapes how the curriculum positions the colonial power.

At the end of the History curriculum, there is a glossary of words and definitions. The word colonization is defined as "situation whereby a powerful nation establishes administrative control over a foreign territory" (p. 47). The definition in light of the discourse of the History curriculum agrees with how the curriculum authors/designers represent the impact of colonization. Colonization is more than just one country establishing an administrative control. The History curriculum does not address the death and destruction that colonialism brought but on the other hand in the History curriculum students learn about Ghanaians who have contributed both in the recent past and present to Ghana's development and these individuals are of different cultural and ethnic backgrounds in Ghana. However, this particular focus on the people of Ghana and their contributions to Ghana covers is only above one out of six content strands (See Table 4.7). Within this content strand students also learn about which ethnic groups live in which administration regions in Ghana and about their way of life (See Figure 4.19). 
${ }^{31}$ Figure 4.19

Strand in History Curriculum Focused on Ghana People

\section{Strand 2: My Country Ghana \\ Sub-Strand I: The People Of Ghana}

\begin{tabular}{|c|c|c|}
\hline $\begin{array}{l}\text { CONTENT } \\
\text { STANDARDS }\end{array}$ & INDICATORS AND EXEMPLARS & $\begin{array}{c}\text { SUBJECT SPECIFIC } \\
\text { PRACTICES AND CORE } \\
\text { COMPETENCIES }\end{array}$ \\
\hline $\begin{array}{l}\text { B2.2.1.1. Demonstrate } \\
\text { knowledge of the ethnic } \\
\text { groups in Ghana }\end{array}$ & $\begin{array}{l}\text { B2.2. I. I.I Identify the ethnic groups in each region in Ghana } \\
\text { Enquiry route. Which ethnic groups are there in your region? } \\
\text { 1. Identily the administrative regions of Ghana } \\
\text { 2. Locate the ectnic groups in each region on a map of Ghana } \\
\text { 3. With the aid of a slidelvideo/TVhinternet, identify the regions and ethnic } \\
\text { groups in Ghana } \\
\text { 4. Match the ethnic groups with their region } \\
\text { 5. List the administrative regions in the order in which they created (starting } \\
\text { with the oldest region) }\end{array}$ & $\begin{array}{l}\text { Learners enhance their cultural } \\
\text { identity, critical thinking, and } \\
\text { digital literacy as they identify the } \\
\text { various ethnic groups }\end{array}$ \\
\hline $\begin{array}{l}\text { B2.2.1.1. Show } \\
\text { understanding of the } \\
\text { characteristics of some of } \\
\text { the ethnic groups in } \\
\text { Ghana }\end{array}$ & $\begin{array}{l}\text { B2.2. I. I.I State the characteristics of the ethnic groups in Ghana } \\
\text { Enquily route: What are the choracteristica of the ethic groups? What differentiates one } \\
\text { ethnic group from the ocher? } \\
\text { 1. Identify the characteristics (food, festivals, dressing, language, political } \\
\text { institutions, social and economic activities, taboos, oachs etc.) of some of the } \\
\text { ethnic groups in Ghana } \\
\text { 2. Show documentary/pictures/ internet of a hestival of one of the echnic groups } \\
\text { 3. Discuss what the documentary entails. }\end{array}$ & $\begin{array}{l}\text { As learners identify the } \\
\text { characteristics of the ethnic groups } \\
\text { in Ghana, they develop cultural } \\
\text { identity, tolerance and collaborate } \\
\text { with others }\end{array}$ \\
\hline
\end{tabular}

\section{Knowledge about Ghanaian Cultures Emerges in Other Content Areas}

Some subject areas include more representation of Ghanaian cultures, histories,

literacies and knowledge in subject areas like History, Creative Arts, Religious and Moral Education (RME), and Our World Our People (OWOP) than in the Ghanaian languages curriculum. Ghanaian languages as a learning area is separated from these other subjects like culture, history, creative arts, and other literacies. Earlier I have discussed that this separation of language and culture occurs because the Ghanaian languages curriculum centers English ways of speaking and topic areas. This section below highlights how some content area curricula included Ghanaian literacies and cultures.

In the Creative Arts curriculum students are to learn about art, music, and theatre composed and produced by Ghanaian and African artists. Students are also guided by

${ }^{31}$ History curriculum, 2019, p. 10 
their instructors to create similar arts inspired by their learning of these art forms to share with the school and community. For example, in primary 4, in one content strand:

"Learners are to:

- Study the visual artworks (e.g. wood carvings, printed fabrics, wall paintings, cartoons, posters, photographs, clay pots) created by some Ghanaian visual artists (such as Amon Kotei, Theodosia Okoh, Ablade Glover, Oku Ampofo, OffeiNyako, Kwame Amoah, Betty Acquah, Kofi Antubam) by:

$\circ$ gathering information from library books; surfing the internet; visiting art studios, galleries, museums or exhibitions;

○ watching videos, films or observing photographs of artworks of some Ghanaian visual artists;

- examining some artworks of the artists to find out how those artworks reflect the history and culture of the people of Ghana. For example, relate the colours and star in the Ghana Flag to the history of Ghana;

$\circ$ identifying and discussing symbols found in the artworks being studied that reflect the history and culture of the people of Ghana;

- writing brief notes about one visual artist using the following guidelines:

- Name

- Training

- Type of artworks

- Title of some works" (Creative Arts curriculum, 2019, p. 27)

The example is similar to many other activities in the Creative Arts curriculum where students learn (1) local knowledge in visual and performance artwork and (2) the meanings underlying these community and national Ghanaian and African literacies and their creators. Various strands and activities in the Creative Arts Curriculum emphasize that students from their learning are to:

"Generate own ideas for composing and performing own artworks that will reflect the natural and manmade environments of some communities in Ghana," (p. 32)

"Explore through brainstorming to develop ideas for creating own performing artworks that will reflect topical issues in Ghana" (p. 33) 
"Experiment with available visual arts media and methods to create artworks that express own views, knowledge and understanding of visual artworks that reflect the history and culture of the people in Ghana" (p. 35)

“Create own artworks using available visual arts media and methods to express own views, knowledge and understanding of the history and culture of the people of Ghana" (p. 38)

When you closely examine the language in the Creative Arts Curriculum represented by the examples above you notice the words such "generate," "explore," "experiment," and "create," which frames how learning should occur in the subject area. The discourse that frames learning here is not as prescriptive as it unfolds in the language subjects (see earlier sections on content strands in the English and Ghanaian languages curricula in Table 4.5, Figure 4.11, and Figure 4.12 ) but provides freedom for students to enjoy the learning process and encourages students to "go on out-of-the-classroom walk to observe the natural and manmade surroundings; collect samples of natural and manmade objects, take photographs, or make videos of objects that interest them" (p. 28). The exploration and experimentation in the Creative Arts curriculum also recenters learning around the history and culture of the people of Ghana, and the knowledge and understanding of the history and culture of the people of Ghana.

In the Religious and Moral Education (RME) curriculum, learning is not only focused on the two dominant religions in Ghana, Christianity and Islam, but also includes African Traditional Religion. Each strand and sub-strand on festivals, prayer, religious leaders, religious songs and passages, and creation highlights the same theme in all three religions (See Figure 4.20). 
${ }^{32}$ Figure 4.20

Content Strand in RME

\begin{tabular}{|c|c|c|}
\hline CONTENT STANDARDS & INDICATORS AND EXEMPLARS & $\begin{array}{l}\text { SUBJECT SPECIFIC } \\
\text { PRACTICES AND } \\
\text { CORE COMPETENCIES }\end{array}$ \\
\hline $\begin{array}{l}\text { BI.2.I.1. Demonstrate the } \\
\text { understanding of religious } \\
\text { worship }\end{array}$ & $\begin{array}{l}\text { BI 2.I.I.I: Name the three main types of worship in Ghana. } \\
\text { - Show pictures, video clips of people worshipping among the three main religions } \\
\text { in Ghana. } \\
\text { - Christian worship, } \\
\text { - Islamic worship and } \\
\text { - Traditional worship. } \\
\text { B1 2.1.1.2: Recite religious passages and sing religious songs. } \\
\text { - Show pictures, video clips, etc. of songs and recitations from the three main } \\
\text { religions. } \\
\text { - Let learners sing and recite texts from the three main religions: } \\
\text { - The Lord's Prayer, Psalm } 23 \text { (Christian). } \\
\text { - Al- Fätihah (Islamic) and } \\
\text { B1.2.2.1.I: Describe religious festivals in Ghana. } \\
\text { - Guide learners to mention festivals celebrated in the three religions. } \\
\text { - Christian: Christmas, Easter, etc. } \\
\text { - Islamic: Edd-ul-Fitr, Eid-ul-Adha, etc. } \\
\text { - African Traditional Religion (ATR): Odwira, Damba, Homowo, }\end{array}$ & $\begin{array}{l}\text { Commitement. Dedication } \\
\text { Cultural Identity, Sharing } \\
\text { Reconciliation, } \\
\text { Togetherness, Unity } \\
\text { Communication and } \\
\text { Collaboration, } \\
\text { Critical Thinking } \\
\text { Creativity and Innovation } \\
\text { Digital Literacy }\end{array}$ \\
\hline
\end{tabular}

The RME curriculum however lumps many ethnic and cultural groups' religious

practices under one African Traditional Religion umbrella, especially when the religious practices mentioned are particular to only Ghana in the curriculum. This naming is shaped by colonial discourse that saw the religious practices of these ethnic groups as similar and distinct from religious practices of the colonizers and missionaries (Miescher, 2005). Often the religious practices of the indigenous groups were seen as "savage" and "barbaric" and therefore this naming as African Traditional Religion (ATR) in the RME Curriculum feeds into this narrative. This can be particularly seen in how the curriculum clearly distinguishes between Christianity, Islam, and ATR. The ATR festivals in Figure 4.20 like Homowo and Odwira are celebrated by Ghanaian ethnic groups and often these celebrations include Christians because they are also cultural and ethnic celebrations and

${ }^{32}$ RME, 2019, p. 3 
not just religious. The division however situates indigenous Ghanaian cultural activities and practices only in ATR but in reality, the lines are more blurred when it comes to religion.

The Our World Our People Curriculum (OWOP) also includes some content on Ghanaian cultures, knowledge, literacies, and histories. OWOP is also similar to a Social Studies type curriculum where the content includes topics such family and community, geography, religion, the environment, citizenship, science, etc. (See Figure 4.21)

\section{${ }^{33}$ Figure 4.21}

\section{Strands and sub-strands in $O W O P$}

\begin{tabular}{|l|l|}
\hline \multicolumn{1}{|c|}{ STRAND } & \multicolumn{1}{c|}{ SUB-STRAND } \\
\hline ALL ABOUT US & Nature of God \\
\cline { 2 - 2 } & Myself \\
\cline { 2 - 2 } & My Family and the Community \\
\cline { 2 - 2 } & Home and School \\
\hline ALL AROUND US & The Environment and the Weather \\
\cline { 2 - 2 } & Plants and Animals \\
\cline { 2 - 2 } & Map Making and Land Marks \\
\cline { 2 - 2 } & Population and Settlement \\
\hline \multirow{5}{*}{ VUR BELIEFS AND } & Worship \\
\cline { 2 - 2 } & Festivals \\
\cline { 2 - 2 } & Basic Human Rights \\
\cline { 2 - 2 } & Being a Leader \\
\hline OUR NATION GHANA & Being a Citizen \\
\cline { 2 - 2 } & Authority and Power \\
\cline { 2 - 2 } & Responsible use of Resources \\
\cline { 2 - 2 } & Farming in Ghana \\
\hline MY GLOBAL & Our Neighbouring Countries \\
\cline { 2 - 2 } COMMUNITY & Introduction to Computing \\
\cline { 2 - 2 } & Sources of Information \\
\cline { 2 - 2 } & Technology in Communication \\
\hline
\end{tabular}

OWOP, however, repeats content already covered in other subject areas. Forms of worship in the three religions and festivals for example are already covered in RME. OWOP also introduces Computers and Information Technology to students in Primary 1 to 3 even though by Primary 4, there is a separate Computing Curriculum. The first strand in OWOP under "All About Us" includes content and activities that already show up in RME (See Figure 4.20). According to the curriculum, OWOP aims at "producing a

\footnotetext{
${ }^{33}$ OWOP, 2019, p. xvii
} 
morally upright Ghanaian, who is responsible and capable of maintaining a healthy lifestyle and preserving their environment for sustainability" (OWOP, 2019, p. v). It is therefore not surprising that the content is also somewhat similar to RME and often emphasizes learning good behavior and moral lessons in content activities. When students discuss family and community, it is in the context of learning good moral behavior. Here is an example below:

"Learners mention behaviours and attitudes needed to be a committed family member e.g. taking part in family activities, obedience to elders of the family, respect for family members, accepting responsibility (performing assigned duties), taking initiatives, helping needy relatives, be present at family meetings, respond to family needs, etc.” (p. 25)

"Learners in groups, discuss attitudes and behaviours of a responsible family member:

i. taking part in family activities responsibly

ii. obedience to elders of the family

iii. respect for family members

iv. accepting responsibility (performing assigned duties)

v. taking initiatives

vi. helping needy relatives" (OWOP, p. 48)

Nonetheless, learning Ghanaian cultures and knowledge appears in the OWOP curriculum but it is very limited to examining the why Ghanaians celebrate festivals and national occasions, identifying the sixteen administrative regions, religious leaders, and Ghanaian agricultural products. Because OWOP takes a wholesale approach to tackling 
varied learning areas, the curriculum does little overall to teach students about the diverse Ghanaian groups and people, their cultures, languages, and way of life, not to even mention the nuances between the different Ghanaian people groups living in Ghana.

Considering the discourse of the curriculum uncovered here, the next section will share findings from my analysis of how educational leaders talk about the Curriculum for Primary Schools. Importantly, I consider how the public discourse of educational leaders matches the discourse of the curriculum for primary schools.

\section{Discourse from Educational Leaders}

In this section I discuss findings to How do educational leaders talk about the K-6 curriculum and what it should include/exclude? There are three main themes that emerged from my analysis how educational leaders talk about the K-6 curriculum and what it should include and or exclude. When the two topmost educational leaders in Ghana spoke publicly about education, they mostly spoke indirectly about the K-6 curriculum. Generally, the educational leaders painted a picture about the aims of education, the place of students, and how to make the system equitable for students. In nine public events, including five speeches and five radio/television interviews, educational leaders frequently addressed several inequities in education such as low proficiencies of students, access to senior secondary education and college, lack of infrastructure, and inexperienced teachers. I found that in the data that educational leaders did not consider how some of these inequities result from the ways Ghanaian languages are deemphasized in teaching students who primary speak Ghanaian languages. Rather in their discourse they doubled down on the need for students to become literate and proficient in English and propose testing students in English proficiency by primary two. 
Educational leaders also compared and made reference quite often to what other economically advanced countries are doing to guide how to address inequities in Ghanaian education. Connected the first two findings, educational leaders made the case that focusing the curriculum on English proficiency is connected to future employment for students. This discourse is similar to the curriculum that positions English language acquisition and proficiency a necessary skill that students need for academic progress. There are Many Problems in Education and [Ghanaian] Language is not one of them

\section{Students Should Wait till They are Proficient in English to Progress}

The Deputy Minister of Education during his speech to leaders of corporate organizations in Ghana spoke about the inequity in education that has created barriers for students from low socio-economic background and those who live in rural communities. He pointed to a better system in the past, decades ago, when students from such disadvantaged backgrounds spent more years in primary school so that by the time they got to secondary school, they were mature enough to "compete" with peers from affluent backgrounds.

"When we changed from old middle school that helped some of us from the rural areas to this JHS program and it was nine years across the board for everyone. Those who came from homes and backgrounds that was used to going up to primary six and then going to high school probably did not see any huge change but if you go to the rural areas for somebody like me, how was I able to compete in senior high school? I went there [because] I was more mature. I could compete with those who went to the international schools because it took me 
three years more and when I went in, I could compete with my maturity. The moment you say that everyone should have the same number of years, then you don't leave out the equity component" (Deputy Education Minister, "Transcript of Video 9")

In the excerpt above, the deputy education minister shared his own story about how being older than his peers from affluent backgrounds was an advantage when he got to secondary school. What is encoded in the excerpt is that students from rural communities are more likely to speak only a Ghanaian language at home compared to their peers who attended international schools who were proficient in English. The deputy minister does not acknowledge that perhaps if the system valued his Ghanaian language and designed teaching and learning in his own Ghanaian language then he would not have needed more years in schools in order to "compete" with peers from English-speaking homes. Rather, he proposes that for already disadvantaged students to become "ready" for school, in other words, "proficient in English," like their peers from international schools they should spend more years in school compared to their peers as a way to give them an advantage. The educational leader sees making these students stay longer in primary school as a way to foster equity. Instead of the system being designed to value and incorporate the ways of speaking and being of the students, students are rather being asked to adjust and fit into a system that denies them their ways of speaking and being. According to the deputy minister's proposal, if students want access to secondary education and codes of power, then they need more years in school compared to their peers. The deputy minister's discourse does not disrupt but reinforces the dominance of 
English linguistic imperialism and suggests that the student, instead of system, must change if the student wants to be successful.

He justifies this discourse because he believes that solving access to secondary school from primary schools could make education more equitable. He said, "If you look at our system, if you happen to go to Achimota then you get all the resources and who are the ones who were able to go? But if you happen to go to my school, Jaase Prameso, you are at the short end of the stick. You have limited facilities. You have the most inexperienced teachers teaching you and these are communities that are educating the poor among the poor, the poorest among the poor" (Deputy Education of Minister, "Transcript of Video 9")

He identifies that schools in low-economic communities and rural areas are more likely to have inexperienced teachers and limited facilities that shapes their educational outcomes. However, what he does not mention is that, even with all these inequities, students are being asked to conduct their learning in an unfamiliar language. From the discourse of the curriculum discussed earlier in this chapter, the curriculum expects these students to acquire writing and reading literacies in English right from $\mathrm{KG}$ but not in Ghanaian languages, such that students might be unable to fully develop literacy first in their first language, possibly affecting them later in higher levels of schooling. Focusing on mainly access to senior secondary schools only helps students who can embody enough English language practices to pass examinations.

Student Get Access to Higher Levels of Education if They Pass Exams Written in English 
As discussed earlier in chapter three, it is important to note that these public discourses occurred around the time the government created a Frees SHS program in addition to creating a new pre-tertiary education curriculum. The discourse in the deputy minister's speech above was similar to the discourse in an interview the Minister of Education gave at a conference. He also pointed to the Free SHS program as one of the major solutions to solve educational access. Here is an excerpt from the interview below:

Minister of Education (ME): One of the big campaign issues that we've made as a party since $2008,2012,2016$ was to close a loop we have an education and access. That was secondary education.

Interviewer (I): Right.

ME: About a third lose out from the junior high schools to the senior high school simply because they don't have finances. And it translated to about 100,000 students a year who fall out, not because they didn't qualify for senior high school education, but plainly because they didn't have the wherewithal right to be there. So we thought it was a lost talent 100,000 falling on to your streets every year with no ambition, no hope, nothing. You were lost in our system" (Minister of Education, "Transcript of Video 1")

Again, the Minister's discourse here is similar to his deputy when identifies the problem of access to secondary education as inequitable but it is who he is not counting here that is key. He goes on to say in the interview that,

"those are the challenges that we are confronted with, that we are dealing with, the access, opening up, because we have an exam between the year 14,15 15,16 
which we call the basic education certificate [BECE]. So what we have done, we said, anybody who passes, because that dropout rate is for anybody who passes and qualifies but couldn't go. So we said that anybody who passes now, we are going to guarantee you a place irrespective of your financial capacity. So that is what we've done. So we put 90,000 more people than previously and the reason why we have not achieved 100 percent, people elect to opt to go to private schools" (Minister of Education, "Transcript of Video 1").

The discourse here suggests that by creating avenues for students who did not have the financial means but passed the exams to transition from primary to secondary school, access is now equitable. Examining this discourse I am led to ask the question - what about students who do not pass the BECE because their teaching and learning is rooted in enacting English literacies throughout primary school to their disadvantage? What the Minister of Education does not mention is that there are still many who do not have access to secondary education and drop out because they did not pass the BECE. When he says "So we put 90,000 more people than previously and the reason why we have not achieved 100 percent, people elect to opt to go to private schools," the educational leader is only counting students who passed the national examinations set in English language. Although access to higher level of education is a challenge that is being addressed, it only applies to those who can embody English literacies and proficiencies to pass the BECE.

From the literature, scholars have shown that assessment in English that is rooted in teaching and learning in mainly English does not allow students to grasp concepts to do well in exams (Collison, 1974; Davis \& Agbebyegah, 2012; Owu-Ewie, \& Eshun 
2015). This study has also shown the assessment weights placed on English as part of learning right from K-6 schooling, unjustly favors students with high proficiencies in English such that students have to quickly acquire literacy skills in English even though they may not yet have those skills in their own language. Those students are already denied access to secondary school starting in primary school because of the discourse of the K-6 curriculum. A Free SHS program does not solve this inequity emanating from the primary school K-6 curriculum discussed in this chapter.

\section{Students Need to Embody English Literacies in Primary Two}

In a press conferences, the Minister of Education spoke about how Ghana is still working to improving the quality of education because "Ghana has been last in international assessment.” In this public meeting he spoke about teacher reform being another issue to address to improve education.

"We in this country have been subject to bad news internationally about quality of education. So we keep hearing that Ghana has been last in international assessment. We keep hearing only $2 \%$ of primary two pupils achieve a certain proficiency at that age. It's bad news, but that bad news didn't start a few years ago. It has been with us. The last time I read and I checked, Educational for All year 2020 attainment, there were six outcomes. Ghana in Sub-Saharan African countries, achieved five of the six, the one we couldn't achieve, was of course quality education. MDG [Millennium Development Goals] goals and everything we are trying to do is to improve quality. So why is it that we have not been able to knock on the door that gemstone called quality to crack it, so that Ghana benefits. And that one of the pillars on which quality education is rest 
assured, is teacher reform... We believe that quality of education can never be enhanced, if the teacher is not at the center of whatever you are doing. Placing the teacher at the center means a lot and we are trying to tackle all the issues to do with teacher education, training, retention, to ensure that the quality we so desire is met in the shortest possible time..." (Minister of Education, "Transcript of Video 6")

In this excerpt he puts out several discourses. First, that Ghana has not been doing well in international assessments although when compared to other neighboring countries Ghana seems to be doing better. He did not say which international assessments he was referring to but was is key here is that "only $2 \%$ of primary two pupils achieve a certain proficiency at that age." This is a startling and troubling finding, but he suggests that this "bad news" did not start recently or a few years ago. However, only $2 \%$ of students in primary two having proficiency whether in writing, reading, and speaking or proficiency in Ghanaian languages or in English should make a reader or listener pause. Although the type of proficiency being referred to here by the Minister of Education is unclear, elsewhere in data the educational leaders make public their plan to prioritized English and testing in English right from the primary school. The Deputy Minister of Education is clear about prioritizing English when he discusses the state of the education in Ghana and expected changes to education:

"We believe that there should be national assessment and that should not be after eleven years of education. From primary two, students should be assessed to know if they are proficient in English and Mathematics and then moving on to 
primary four there is a national comparable to the BECE where everybody is assessed" (Deputy Minister of Education, "Transcript of Video 4")

The proposal above does not even contend with the language-in-education policy and consider that students by primary 2 are still learning in their Ghanaian languages but suggests testing students early in English. Both discourses of the Minister of Education and Deputy Minister show how much English literacy skills in reading and writing are emphasized at this stage in school. The discourse echoes the findings in the discourse of the curriculum where writing and reading literacies in English are emphasized in those in Ghanaian languages are not especially at the lower primary level. Rather than testing for English proficiency at primary two, since only 2 percent of students showing proficiency, there should be a critical examination of the curriculum to understand how students learn including an examination of perhaps the language in which students learn and why only few are proficient in English.

The Minister of Education points to teacher reform as a major issue but he briefly suggested a curriculum reform when he said, "a lot of the things that our curriculum reform is doing is using the best examples around the world to situate it in Ghana and see how we can put ourselves on that pathway of progression" (Minister of Education, "Transcript of Video 6"). I do not deny that it might be helpful to learn from other countries but the danger of looking outward to other countries without first critically examining inward, can lead to placing band-aids that temporarily solve one issue but does not fix the underlying system. In the next section, I share another frequent discourse from educational leaders about looking to other economically advanced countries to learn how to address educational issues in Ghana. 


\section{"The Singapores, the Malaysia and the South Koreans...Have Left Us"}

In a one-on-one interview with the Minister of Education at the global conference he said, “...we [Ghana] compare ourselves to countries that are at the time of independence, we were at par economically with. The Singapores, the Malaysias and the South Koreans and now all of them have left us" (Transcript of Video 1). The Minister in this excerpt was speaking about how Ghana can fund the Free SHS program as a way to solve inequities in education. He explained that Ghana looks at Singapore, Malaysia, and South Korea because at Ghana's independence, these countries including Ghana were similar economically. The Deputy Minister in his speech to heads of corporate organizations in Ghana also repeats this same discourse. He shared a story about South Korean bankers who came to the Ministry of Education to present ideas about how Ghana can develop economically through education like South Korea has. According to the South Korean bankers, although South Korea and Ghana were at par economically at independence, the reason was Ghana's slow development since then was due to Ghana's failure in education. The deputy minister told the story:

"I happened to chair the meeting and they showed us some graph as part of the presentation and we were all ears because hey they are there to give us money! The first graph was about per capita income of South Korea and Ghana in 1960, and of course we know the story of how our per capita income was higher. Then they showed us the per capita income now. South Korea and Ghana, way ahead of us [Ghana] and they asked us, why do you guys think we have performed better than you? And of course we were scratching our heads in shame and they said, let's see the third graph. The third graph was the gross tertiary enrollment ratio of 
Ghana South Korea compared. That is, if you look at the youth between the ages of 18 and 23 and you want to find out if some of them are in some kind of tertiary education in Ghana, our average was 17 percent actually 16 point something but I have rounded it up to 17 percent and South Korea is 93.6. So they asked us, this is why we are ahead of you, and this is why we came here, to give you a loan" (Deputy Education Minister, “Transcript of Video 9").

The discourse gives an idea why educational leaders look outward to foreign countries like South Korea in this excerpt. It is because "they [South Korean bankers] are there to give us [Ghana] money." Not only do they provide loans to Ghana, but they also recommend and maybe shift focus to other areas that benefits those providing funds. These bankers from South Korea included higher education experts and according to the deputy minister, they came to Ghana "to give us a loan to build the Campus of the Eastern University” (Deputy Education Minister, “Transcript of Video 9"). Their presentation focused on Ghana's low tertiary enrolment numbers as the issue to fix. I have made this point several times in this chapter but I will reiterate it here: the Ghanaian educational system denies students the opportunity to learn in their own language and so students do not have access to secondary school and then to tertiary schools because they are unable to embody English literacy skills well to pass national examinations to qualify to secondary and higher education. Obviously, low tertiary enrolment numbers should be expected because the root problem right in the K-6 primary school curriculum has not been addressed. Nonetheless, looking out to other countries first for solution allows other countries to determine what issues we should address even if it is not the most concerning like only two percent of students in primary 2 have grade level proficiency. 
The Minister of Education himself critiqued looking outward to other countries such as Finland but use parental educational achievement in Finland to critique Ghanaians who asked him why Ghana could not have an educational structure like that of Finland. He said,

"One of the biggest issues about education and children's attainment in education is that level of education of that child's parent. Every research around the world - the more educated your parents are, the more better educated your kids become. So we in this country, when we compare ourselves to Finland, we shouldn't only compare the children's attainment in class, we should probably start looking at parental attainment and it is not the same. So sometimes it's a bit unfair, but we compare Finland or a country of high resources in their trillions to Ghana where even tertiary education status is nearly 90 percent where we are, but we are getting there. And it's good in the country to hit above your, your level to want to be there with Singapore, and, and Finland" (Minister of Education, “Transcript of Video 6").

The educational leader points to the low educational attainment of Ghanaian parents overall as the reason for the inequities in education and why Ghana's education is not like Finland's. The minister is putting out several encoded discourses here. The better educated kids he references, in Ghana, are students who are proficient in English and do well in exams conducted in English. The more educated your parents are, he said refers to parents who have been through the educational system and are able to enact the English literacies and identities, so they can support their kids' learning these literacy skills too. It is a discourse similar to the deputy minister when he suggested that students 
from disadvantaged background should spend more years in school till they are matured enough to progress to higher levels. It blames the students for the failure of the curriculum. This discourse also blames parents for the failure of the educational leaders to address systemic problems in the educational system and curriculum. Of course, when a parent is able to climb the educational ladder, their children are more likely to do the same because of their parent's acquired cultural and social capital. However, if parents did not have the opportunity when they were young because of systemic issues, should the parent's level of educational attainment be an issue that denies future children an equitable education? No, it should not because it is a system issue not a parent issue.

\section{English Proficiency for Employability}

As discussed in the findings above, the discourse from educational leaders does not focus on how to disrupt the system to make it better for everyone and not just for students who have either linguistic advantages and higher socio-economic status. With that framing it was not surprising that in the data that educational leaders spoke at length about the need for a curriculum that prepares students with the skills necessary for future employment. In his speech, the deputy minister echoed these ideas:

"Sometimes we talk about graduate unemployment and all, there are times, I am also an entrepreneur, there are times when you interview people you don't feel like hiring anyone of them. So education has work to do. If we turn out the kind of graduates with the requisite skills who did not just memorize to get excellent grades, I am sure we would reduce graduate employment because the companies would be so enticed to hire more" (Deputy Education Minister, “Transcript of Video 9"). 
The educational leader imagines schools as a factory/industry that manufactures a good a certain type of student - so that they can be enticing to the corporate machine. The Deputy Minister argues that if schools produced students who do not just memorize, that is, have the required skills, students will find jobs when they complete school. The deputy minister in this speech still captures what he sees as the aims of education, “...preserving the harmony of civic life...providing opportunities for individuals to grow...improving artistic creativity...enhancing our scientific progress...empowering individual to choose wisely...preparing citizens to enter the labor force.” However, he focused at length on how education should prepare students with global competencies. He describes the schools as the "human resource department" for the corporate industry in the excerpt below.

"So when you look at a field like education, we are preparing ourselves, preparing the next workforce generation. We have the immediacy problem of unemployability in the country that is becoming a national security issue. So we have to do skilled training, to get people the jobs and prepare the future generation for the future jobs as well. So our job is cut out for us. We are the human resource department of the ministry of corporate Ghana. We have to put in place process outcomes and things that will let us get the right workforce for the next generation. So that is what we are doing. And learning outcomes is so important, because now we are in a global world. And we need global competencies to let our kids fit everywhere" (Deputy Education Minister, “Transcript of Video 9") 
In the context of the macro discourse of the data, the reference to global world and global competencies also suggests that students should enact and embody identities and literacies as students from economically advanced countries like the US, UK, Malaysia, Finland, etc. so they can fit everywhere. These countries come up quite often in the discourse from the educational leaders. Ghanaian language literacies is not what is being included in the subject of global competencies because it does not emerge anywhere in the data (See Table 4.9). It might be helpful to learn from other countries but the danger of looking outward to other countries without first critically examining inward, can lead to placing band-aids that temporarily solve one issue but does not fix the underlying system. In the context of the overall discourse of educational leaders in the data, this discourse about global competencies and preparing students for the labor force is a connects to the idea that (1) students need to be proficient in English before they can progress to higher levels of education and (2) the proposal to begin testing students in low primary school to make sure they are already embodying English literacies. Undeniably English is the main focus. The discourse of educational leaders promises access to every student that acquires English proficiency and passes national examinations. It also promises employment to everyone who follows this path. Unfortunately, this discourse reinforces the inequities present in the educational system and especially in the curriculum right from the start of school.

\section{Table 4.9}

\section{Educational Leaders References to other countries}

"One of the biggest issues about education and children's attainment in education is that level of education of that child's parent. Every research around 
the world - the more educated your parents are, the more better educated your kids become. So we in this country, when we compare ourselves to Finland, we shouldn't only compare the children's attainment in class, we should probably start looking at parental attainment and it is not the same."

\section{(Minister of Education, “Transcript of Video 6”)}

"That is, if you look at the youth between the ages of 18 and 23 and you want to find out if some of them are in some kind of tertiary education in Ghana, our average was 17 percent actually 16 point something but I have rounded it up to 17 percent and South Korea is 93.6..."

(Deputy Minister of Education, “Transcript of Video 9”)

“...but this same student who is doing Visual Arts will go to America and he will come back an engineer. He will come back a medical doctor. I have a nephew who did Sociology, first degree, and now he is a medical doctor in America. We have to begin to look at our curriculum and begin to look at how we can break down the barriers that is preventing us from getting our best and brightest in the right places so that we can transform our country..."

(Deputy Minister, “Transcript of Video 4”)

“...we [Ghana] compare ourselves to countries that are at the time of independence, we were at par economically with. The Singapores, the Malaysias and the South Koreans and now all of them have left us" 
(Minister of Education, "Transcript of Video 1")

"...a lot of the things that our curriculum reform is doing is using the best examples around the world to situate it in Ghana and see how we can put ourselves on that pathway of progression"

(Minister of Education, "Transcript of Video 6")

\section{Summary of Findings}

In this study I sought out to answer three main questions: (1) What discourses of English linguistic imperialism are in the Ghanaian primary school (K-6) curriculum?; (2) What is the discourse about Ghanaian languages and literacies in the Ghanaian primary school (K-6) curriculum?; and (3) How do educational leaders talk about the K-6 curriculum and what it should include/exclude? In the discourse of the curriculum, we learn that although the curriculum provides students some access to in teaching and learning Ghanaian languages, literacies, cultures, histories, and knowledge, the curriculum is also designed such that the teaching and learning of Ghanaian languages are restricted and disconnected from the teaching and learning of Ghanaian cultures, histories, knowledge, and cultures. English also enjoys more instruction time in the classroom and as a result more content compared to Ghanaian languages. Additionally, Ghanaian languages curriculum content is structured and framed in English literacies and grammar such that it misses other Ghanaian ways of speaking such us wise sayings, proverbs, and symbols. In terms of assessment, the weights placed on language subjects suggests the importance attached especially to English where final examinations are more 
likely to impact a student's overall performance especially from primary 4 when English official becomes the only language medium.

The discourse of educational leaders is intertwined with the discourse of the curriculum as there is however no recognition of teaching and learning in English and assessments conducted in English as part of the obstacles to equitable education for all students. There is no discourse that raises the issues of Ghanaian languages as important and pertinent to educating Ghanaian students and that is confirmed when we see more content and time given to English than Ghanaian languages. In both the curriculum and from educational leaders, students are expected to embody literacies in English if they want to progress academically. One educational leader even suggests that if students are not ready to compete with their English-speaking peers by secondary school, they should perhaps stay years in longer in primary and junior high school. I also discussed how educational leaders look to other countries for funding and reference to apply temporary band-aids that fail to fix systemic issues in education. In the next chapter, I invite curriculum policymakers, teachers, students, and leaders to consider the implications of the discourse of the K-6 curriculum and the discourse from educational leaders and reimagine with me a new curriculum centered on Ghanaian languages and literacies. 


\section{CHAPTER FIVE: DISCUSSION}

The purpose of this discourse analysis study was to understand how the preference for the English language has been constructed through the policies, practices, and content of the Ghanaian education curriculum. This final chapter discusses the findings of this study as related to the literature on Ghanaian languages as languages of instruction and languages of study in Ghanaian education, the dominance of the English language, English language literacies, and English language proficiency in Ghanaian education. This chapter also includes a discussion of the discourse of the K-6 curriculum, discourse of educational leaders, and how they relate to studies of English linguistic imperialism and theories of critical literacy. Next, the chapter discusses practical steps on how policymakers, curriculum designers, and educational leaders can reimagine/recreate a Ghanaian educational curriculum centered on Ghanaian languages, cultures, histories, knowledge, and literacies. The chapter concludes with a discussion of the limitations of the study, areas for future research, and a brief summary.

Earlier in chapter two I showed through the literature how researchers and historians explain how colonial practices and policies engineered the societal dominance of and preference for English in education over Ghanaian languages. However, in the literature there was no research yet on how the new curriculum and recent policies and practices in education reinforce or resist dominant English language discourse and literacies, potentially marginalizing Ghanaian languages and literacies. In prior research (Bonney, 2020b), I explored how dominant English discourses in education are reinforced through the books that are assigned to students in Senior High Schools (SHS) as part of the Literature curriculum. This current study therefore fills an important gap in 
our knowledge, not only by examining the earlier K-6 curriculum, but also further exploring whether and how curricular policies construct the dominance of English and push Ghanaian languages to the margins in education. The study was guided by the following research questions:

1. What discourses of English linguistic imperialism are in the Ghanaian primary school (K-6) curriculum?

a. How does the curriculum including content, assessment, and teaching and learning activities maintain the exclusionary force of dominant English practices and discourses? (Design/Power)

b. In what ways does the discourse of the curriculum critically resist English linguistic imperialism? (Power/Design)

2. What is the discourse about Ghanaian languages and literacies in the Ghanaian primary school (K-6) curriculum?

a. How are Ghanaian languages and literacies, including various Ghanaian cultures and their histories, represented in the curriculum? (Diversity)

b. How does the design of the curriculum provide students access to diverse Ghanaian languages, literacies, cultures, and histories? (Access/Diversity/Design)

3. How do educational leaders talk about the K-6 curriculum and what it should include/exclude? (Power/Design/Diversity/Access)

In this study I found that the discourse of the K-6 curriculum prioritizes and centers the teaching and learning of English and not Ghanaian languages. Discourses of English linguistic imperialism were rampant throughout the K-6 curriculum. In short, a 
critical literacy approach was entirely absent. The K-6 curriculum is designed such that the teaching and learning of Ghanaian languages is separated from the teaching and learning of Ghanaian histories, cultures, and knowledge. Students learn more about Ghanaian histories, cultures, and knowledge in other subject areas such as Creative Arts, Religious and Moral Education (RME), Our World Our People (OWOP), and History than they do in their study of Ghanaian languages. The study also found that in all the discourse around the period leading up to the implementation of the current K-6 curriculum, educational leaders reinforced the idea that a good student is one who embodies English proficiencies and successfully passes national examinations set in English.

\section{Interpretation of the Findings}

\section{The Persistent Dominance of the English Language}

In the study I found that the discourse of the language-in-education policy as spelled out in the curriculum was vague regarding the place and use of Ghanaian languages in education. The curriculum authors highlighted what they call 'assumptions of normality' discussed in chapter four. These are assumptions that many educators hold as true regarding the language needed to instruct students. The assumptions of normality centers around the beliefs (1) that students have to be taught in the dominant language of schooling - English, (2) being competent in school means being proficient in the English language, and (3) that only a few students are good enough to qualify for higher levels of schooling. The discussion on the language-in-education policy was an opportunity for the curriculum authors to stress and insist that Ghanaian languages should also (or primarily) be included in the teaching and learning process, especially at the early ages. 
Unfortunately, they did not. The document only spells out these assumptions, and without challenging these "assumptions of normality" discussed in the Pre-tertiary Education Curriculum Framework and positioning Ghanaian languages as relevant in teaching and learning, the curriculum indirectly agrees with the assumptions of normality. Several scholars have found that these assumptions are also the beliefs of many educators and educational leaders who believe that using and requiring the dominant language of schooling,- English - from the onset works best (Opoku-Amankwa \& Brew-Hammond, 2011).

The failure to resist or oppose the assumptions of normality as stated in curriculum represents a fallacy of English linguistic imperialism where English, when introduced early, is believed to increase educational success and achievement in a multilingual society; this is contrary to other research findings (Casely-Hayford \& Hartwell, 2010; Phillipson, 2009). Even though many students are probably seeing their language in print for the first time in kindergarten, in chapter four the findings indicate that the curriculum aggressively pushes English reading and writing literacies. For Ghanaian languages, teachers are to focus mainly on speaking literacies in kindergarten. It is surprising that right at the onset of formal schooling the curriculum expects student to embody more literacies in English than in Ghanaian languages. This trend does not stop but progresses through the K-6 curriculum such that writing literacies in Ghanaian languages are only introduced in primary four.

The assumption that students will do well when they are taught in the English language has been documented well in the literature and has been consistently proven to be false (Collison, 1974; Davis \& Agbenyegah, 2012; Mfum-Mensah, 2005; Owu-Ewie 
\& Eshun, 2015, 2019). Several scholars have shown that the persistent use of English hinders students' comprehension of course concepts (Owu-Ewie, \& Eshun, 2015), participation and engagement in class (Opoku-Amankwa, 2009a; Owu-Ewie \& Eshun, 2019), and the ability of students to create new knowledge with the concepts they are learning (Collison, 1974; Opoku-Amankwa, 2009b).

Nevertheless, the early start fallacy of English linguistic imperialism leads to a maximum exposure fallacy where the curriculum is designed so that students have more contact hours and curriculum content in the English language compared to any other subject. Collison's (1974) study, which is still relevant today because very little has changed with the structure of schooling, demonstrated that students in upper primary who had been instructed in English for about 6 years in school struggled to understand and explain in English simple science concepts at their grade level. When these students received the same lesson in their Ghanaian language and were given the chance to express what they had learned in their Ghanaian language, there was a significant difference in their output. Owu-Ewie and Eshun (2019) more recently documented qualitatively a similar observation in a Ghanaian classroom where a student in primary five, for example, confessed to have difficulty understanding concepts when the class teacher explained it in English, but the same student said he was able to follow the lesson when the teacher explained lessons in his Ghanaian language.

Because the design of the curriculum prioritizes literacies in English in the K-6 curriculum, critical literacies in Ghanaian languages that can help students transfer their learning from their first language to English are underdeveloped. Casely-Hayford and Hartwell (2010) conducted a longitudinal study of a non-governmental educational 
initiative where students received up to nine months of intense instruction in only their Ghanaian language before joining the public school. Findings shows that students who participated in the program performed better in English and Math compared to students who did not participate in the program. In this flipped format where curriculum focuses on students enacting and embodying literacies in their home language first, CardenasHagan, Carlson and Pollard-Durodola (2007) showed that students with higher literacies in their first language more easily transferred their knowledge and literacy skills from their first language (L1) to their second language (L2). But, as shown in this study, the Ghanaian K-6 curriculum directs educators and schools to do the exact opposite, where students are to gain higher literacies first in their second language while ignoring their first language; this potentially sets them up to fail later in higher levels of schooling. This unfortunate reality is documented in research studies across various multilingual countries in Africa (See Brock-Utne, Desai, Qorro, \& Pitman, 2010; Mutasa, 2015, Nyika, 2015; Qorro, 2013; Taylor \& von Fintel, 2016; Webb, Lafon, \& Pare, 2010). Unfortunately, the discourse in the K-6 curriculum matches educational leaders' discourses of what is expected from students. Both the curriculum and educational leaders expect students to prioritize the English language and literacies in English and not Ghanaian languages and literacies. Findings in chapter four indicated that educational leaders affirmed the narrative that students who passed the Basic Education Certificate Examination (BECE) would receive tuition-free opportunities to further their schooling. The BECE is a national examination, set in English, that ushers students from the K-9 education to senior secondary education. Janks $(2000,2013)$ would argue that here we see access with a theory of power that "leads to the naturalization of powerful discourses 
without an understanding of how these powerful forms came to be powerful" (See Table 2.1). Educational leaders do not consider how the language of power continues to work to marginalize and exclude students from pursuing secondary and higher education. By affirming in their public discourse that only one way of being, one way of speaking, one way of doing, one language - English - deserves educational advancement, they continue to prop up the same colonial structure by ensuring that those with the "right characteristics" make it up the educational ladder.

Findings showed that educational leaders did not consider the fact that for students to be able to pass the BECE, they had to have received educational support instruction in their own Ghanaian language (Owu-Ewie \& Eshun, 2019), developed literacy in their own language (Davis, Bishop \& Seah, 2015), so that with that strong Ghanaian language and literacy foundation they can also at least excel in today's dominant language of schooling - English (Ahadzi, Ameka, \& Essegbey, 2015).

Rather, educational leaders proposed that for already disadvantaged students to become "ready" for school, in other words, "proficient in English," like their peers from international schools, they should spend more years in school compared to their peers as a way to give them an advantage. The educational leaders portrayed more years in primary school as a way to foster equity -- but for who? If already disadvantaged students who are not proficient in English spend more than the average number of years in K-6 education and they still do not receive curriculum support and literacy development in their own Ghanaian language, their educational progress will still be hindered by a system that prioritizes English literacy and proficiency. Simply holding them back 
without the appropriate support would not be an equitable solution and would certainly not make them "ready" as educational leaders hope.

\section{The Silence of Ghanaian Languages}

Ghanaian cultures, histories, literacies, and knowledge are attended to in the primary curriculum but only in subject areas like Creative Arts, History, OWOP, and RME. However, in all these subjects, the English languages features prominently as the medium of instruction. Like the Ghanaian languages curriculum, these non-language curricula are not written in any Ghanaian language but English. Although nothing in the curriculum suggests that teaching and learning cannot occur in Ghanaian languages, at least during the lower primary level, I have addressed earlier how the vagueness of language-in-education policy favors teaching and learning in English, as also shown in a few studies (Edu-Buandoh \& Otchere, 2012; Owu-Ewie \& Eshun, 2015, 2019).

Ghanaian students, therefore, have access to diverse curriculum content about Ghanaian cultures, literacies, histories, and knowledge, however they are taught in English and not in Ghanaian languages. Paradoxically when Ghanaian students study Ghanaian languages in the Ghanaian language curriculum, Ghanaian cultures, histories, and knowledge do not feature prominently because the Ghanaian languages curriculum is modeled after ways of teaching the English language where there is a focus on students learning parts of speech like conjunctions, nouns, pronouns, adverbs, adjectives, etc. This approach to teaching literacy in the Ghanaian languages curriculum follows ways of teaching English, and it reinforces the power of dominant English forms such that students cannot see a social future where Ghanaian multiliteracy, multimodality, multisensory, and multidimensional diversity are valued (Janks, 2000, 2013). Janks' 
(2013) observation of a Mexican Studies curriculum in Arizona that centered Mexican American history, culture, and knowledge found that students were highly engaged in learning and that school was "no longer an alienating experience" (p. 229). Students could identify with what they were learning and were encouraged to read the world in order to change it. Here too, educational and national leaders saw this curriculum as a threat to the power structure and deemed it illegal. Janks (2013) argues that curricula that reifies dominant language forms will not change what is seen as dominant. If we want to resist the dominance of English over Ghanaian languages, the curriculum designers need to reimagine a different approach to teaching Ghanaian languages that sees the whole language, culture, history, and knowledge.

While the English parts of speech that are highlighted in the curriculum might also exist in some Ghanaian languages, the emphasis on these various parts in teaching Ghanaian languages is likely to portray the language as passive and boring to students since it may not reflect how students identify with and embody their Ghanaian language in practice outside of schools. Because students already receive twice the content that emphasizes grammar and parts of speech in the English curriculum and in double the time as in Ghanaian languages, when the Ghanaian language curriculum presents the same grammar and parts of speech emphases it may feel redundant for students; this would be an area for further research to explore. Such repetition and irrelevance/lack of connection to everyday ways of speaking/doing/being may easily lead to being disengaged in the Ghanaian language curriculum; moreover, students may feel, they already speak the language, so they do not need to learn it in school (Davis, Bishop \& Seah, 2015; Edu-Buandoh \& Otchere, 2016). As a result, students may not even 
understand why Ghanaian languages can be valuable to their learning (Mfum-Mensah, 2005).

\section{History Repeats Itself}

Although the new K-6 curriculum was recently implemented in 2019, the

discourse in the curriculum is similar to previous curricula. The discourse of educational leaders regarding the position of Ghanaian language as part of teaching and learning is also similar to the language of other educational leaders in Ghana's colonial and postcolonial history. Earlier in chapter two I reviewed how missionaries like the Wesleyan mission in their school curriculum classified all other subjects except English under Extra Studies. English was the top priority for students (Graham, 1971). Missionaries like the Bremen and Basel missionaries, on the other hand, prioritized education in the local language of the community because they realized that in order to convert the local people, it was better to teach them in their own local language (Anyidoho \& Kropp Dakubu, 2008; Graham, 1971). The Ghanaian language was seen as a tool for religious teaching and evangelism and today the discourse around the use of Ghanaian languages in the K-6 curriculum still views Ghanaian languages as a tool. This time it is viewed as the aid to English acquisition. In the colonial era, teaching English was also considered the way to civilize the native (Bening, 1976). In summary, the discourse of the curriculum and from educational leaders in chapter four demonstrated this unchanged narrative where the standard and marker of academic progress is in the student's ability to embody English language literacies and proficiencies.

Although in the colonial era, "the use of these [Ghanaian] languages was marked by quick grasping [of course concepts], increased pleasure and interest in learning" for 
students (Bening, 1976, p. 69), the progressive use of English in assessments practices, teaching and learning activities, and curriculum content called for more English use from students and parents. One thing that still exists today is the progressive use of English in the K-6 curriculum even though recent research provides evidence that it stifles learning (Davis, Bishop, \& Seah, 2015; Opoku-Amankwa, 2009b; Owu-Ewie \& Eshun, 2019). Even though curriculum after curriculum was created after independence and many Ghanaian languages were included as official school languages, the use of Ghanaian languages as a medium of teaching and learning never progresses beyond primary three. Sometimes it was limited to primary one and other times it was excluded all together (Ansah, 2014; Opoku-Amankwa, 2009a). The analysis of the new K-6 curriculum revealed a similar discourse where the acquisition of literacies in English are expected right from kindergarten.

Finally, we see how history is repeated in the discourse of educational leaders. In the colonial era, Bening (1976) documents that a governor of the Gold Coast visited one of the schools in the colony and insisted that "the school should aim at thoroughness in speaking, reading and understanding of English and no pupil was to be promoted until his progress in the English language was satisfactory" (p. 67). This discourse eerily echoes the same discourse in the findings of this study where educational leaders suggest that students should be held back until they were proficient enough and 'ready' to progress the higher levels of schooling. Overall, it seems very little progress has been made over time because discourses of English linguistic imperialism keep being reinforced both in the curriculum and in the discourse from educational leaders. 


\section{Implication for Theory}

In this section I discuss theoretical applications to curriculum development especially in spaces that are multilingual and/or have endured colonialism including spaces that are thriving to privilege indigenous, minoritized, and racialized languages. I suggest that in these spaces, decolonization efforts must be at the core of educational and curriculum reforms otherwise whatever is program or curriculum that is created will continue to in many ways marginalize non-dominant languages, cultures, and people. I also discuss this because English linguistic imperialism is a hegemonic force and one fallacy is enough for it to work. Finally, I discuss that literacy without the critical component favors whatever is already dominant.

\section{Decolonization, Decolonization, and Decolonization Cannot be Stressed Enough}

This study shows that without an intentional focus on decolonizing the educational curriculum and structure, there is little that changes for the benefit for most Ghanaians. Ghana has undergone several curriculum reforms and revision since independence including the most recent version implemented in 2019. None of these curricula centered and championed the use of Ghanaian languages in the way that would privilege Ghanaian languages in education. In this study, Ghanaian language is not the only area of learning that is deprivileged, Ghana's history is skewed favorably towards Ghana's colonizers too, in the curriculum. Scholars of decolonization like Quijano (2007) argue that the consequences of colonialism last long after the colonizing force leaves. Scholars of English linguistic imperialism like Phillipson (2009) and Pennycook (1998) also agree that after the colonizing force leaves, their symbols, images, mental models, and ways of being become deeply entrenched into the ways of the formerly colonized, 
especially the elites in power who embodied the ways of the colonial master. As such, educational leaders who have benefitted from the left-behind colonial educational infrastructure are convinced that the ways of being of the colonial master should be embodied by students who want to be as successful as they are (Césaire, 1972; Fanon, 1952/2008). The educational leaders in this study certainly affirm this belief. The curriculum also affirms this notion.

Because of the legacy of colonialism and coloniality, theories and studies of English linguistic imperialism are insufficient to aid efforts at decolonizing education and curriculum development. English linguistic imperialism still places the language of power at the forefront of discussions and examinations of how to give voice to indigenous, minoritized, and racialized languages. English linguistic imperialism helps to identify instances where the English language is overshadowing and silencing nondominant languages but that approach does not allow scholars to problematize other nonlanguage related areas where cultures, histories, and knowledge are likely to be erased or misrepresented. In this study, because theories of critical literacy that include power, access, design, and diversity as a framework were combined with English linguistic imperialism, I found other that in non-language areas such as RME, OWOP, History, and Creative Artsm although Ghanaian cultures, knowledge, histories, and literacies were included, it was minuscule, and it was still through a lens that deprivileged Ghanaian languages.

Also, calling for and including more minoritized, indigenous, and racialized languages in the classroom does not constitute a decolonized curriculum. Advocates for multiliteracies and champions for multilingualism and scholars of languages other than 
English should not only look at language subjects in the curriculum. Decolonization efforts should not be limited to the Language Arts, but it should be a wholesale approach to designing a curriculum that begins with asking how power is at work here to marginalize, silence, oppress, and negate other ways of being (cultures), speaking (languages), and doing (practices) (Dorner \& Cervantes-Soon, 2020; Palmer, CervantesSoon, Dorner, \& Heiman, 2019).

\section{One Fallacy is Enough for English Linguistic Imperialism}

The discourse in the curriculum and from educational leaders highlight the fallacies of English linguistic imperialism (Phillipson, 1992, 2009). To examine whether English linguistic imperialism exists in any educational context, researchers may not necessarily find all of Phillipson's (1992, 2009) five fallacies present. However, the presence of any one of the fallacies might signal that English linguistic imperialism might already be taking place in the system. In this study one persistent fallacy in the data was that education is best taught monolingually and we see this as English literacy becomes the only medium by primary four and arguably even earlier in primary education. Other fallacies of English linguistic imperialism are that the more English is taught to students and the earlier English is introduced, the better the results. The discourse of the curriculum supports this fallacy and educational leaders affirm this fallacy because even when the language policy evasively recommends Ghanaian languages as a medium for teaching and learning from kindergarten to primary three, English is still increasingly used at these levels and the literature shows that it does not lead to better outcomes (Casely-Hayford \& Hartwell, 2010; Collison, 1974; Owu-Ewie \& Eshun, 2015). Theoretically, as educators and curriculum designers we have to understand that English 
has power and continuing to use it reifies that power. In educational spaces where multiple languages and cultures exist, restricting learning to only one language denies many students the opportunity to express their linguistic and cultural identities, disengaging them in the learning process (Collison, 1974; Owu-Ewie \& Eshun, 2015).

The other two fallacies Phillipson $(1992,2009)$ found within contexts where English linguistic imperialism dominates are the notions that when other languages are used in teaching and learning, standards of English drop and that when the teacher is a native speaker of English, the better the results. Unfortunately, because of the scope of my analysis in examining curriculum documents I cannot fully address these two false discourses. However, I argue that perhaps because the curriculum does not insist on students fully acquiring literacies first in their Ghanaian language in order to transfer those skills to English later, standards of English are likely to drop anyway because students do not fully acquire literacies in their own languages (Ahadzi, Ameka \& Essegbey, 2015; Opoku-Amankwa \& Brew-Hammond, 2011; Owu-Ewie 2015).

One fallacy I found in my analysis that Phillipson $(1992,2009)$ does not mention is that non-English languages can be taught the same way as English is taught. This is a fallacy because, as discussed in my findings, when Ghanaian languages are taught like English, Ghanaian languages center English literacy and ways of speaking in teaching and learning such that Ghanaian languages are disconnected from Ghanaian cultures, histories, literacies, and knowledge. The inclusion of Ghanaian languages as a subject in the curriculum presents the illusion that students are learning and studying their own language and that language and curriculum policies and practices that are English-centric are inclusive. However, because the Ghanaian languages curriculum focuses on teaching 
mainly the grammar and form of the language like in English, the Ghanaian language is presented as passive, disjointed, and not as alive as students might embody it outside of school. I suggest that the fallacy that non-English languages can be taught in the same English is taught is likely to further the marginalization and devaluation of the language. The way the fallacy works in multilingual spaces needs more study in future.

\section{Critical Literacy Without 'Critical' is not just Literacy}

Earlier in chapter two, I discussed Hilary Janks' (2000) interdependent model of critical literacy explaining that power, access, diversity, and design work together to deconstruct and reconstruct what is seen as dominant in education (See Table 2.1). Without the focus on the critical component in the curriculum, Janks' explains that rather than just literacy, the system centers dominant literacies. From the findings in the curriculum and from educational leaders, there is an acceptance that English is a code of power that students need to embody to obtain opportunities and to have educational achievement and academic progress. Both the curriculum and educational leaders hold this discourse as normalized and institutionalized and so policies, practices, and what should and should not be studied in the curriculum develop from this initial discourse. You see that from chapter four when educational leaders discuss new policies to make access to post primary/basic education possible, the policies only benefit students who have mastered the English code of power.

Also, even though the K-6 curriculum includes subject areas like Creative Arts, History, RME, and OWOP that teach about diverse Ghanaian/African cultures, histories, and visual and performance literacies, the subjects are taught in English and disconnected from the study of Ghanaian languages associated with those histories, cultures, and local 
knowledge. Additionally, the findings in chapter four demonstrate that even with subjects and curriculum that emphasize content in Ghanaian cultures, histories, and knowledge, dominant colonial discourses are still centered. The History curriculum pays too much attention to what it sees as the benefits of colonialism in Ghana's colonial history and little attention to the histories of language and ethnic groups in Ghana. In RME, for example, all other religious beliefs other than Christianity and Islam were presented as African Traditional Religion. This reflects a colonial and missionary gaze of Ghanaian cultural practices and ways of being.

I agree with Janks $(2000,2013)$ that when there is not a critical approach to literacy in the curriculum where an intentional design or redesign of educational curriculum, policies, and practices highlights the diversity and multiplicity of semiotic systems including diverse languages, cultures, and histories and "different ways of reading and writing the world" while recognizing how power works, the curriculum maintains the exclusionary force of dominant language practices and literacies. In other words, critical literacy without the critical component is not just literacy but the literacy of the dominant. Considering Janks' theory, if educational leaders and curriculum designers only look at access, diversity, and design, without considering how power works to devalue Ghanaian languages in the curriculum, access will only benefit student who are proficient in English as discussed in chapter four. The diverse people groups, histories, and cultures that are included in the curriculum, do not encourage students to read their world differently. The design where most subjects are taught in English, still benefits students proficient in English. 
The findings of this discourse analysis support Janks' interdependent model of critical literacy that contends that in order to decenter dominant forms it is important to (1) examine how power works in education and whose interests, languages, and ways of being are served, (2) provide students' access to both dominant and non-dominant forms, (3) design a system of learning that recognizes, actively includes, and does not hierarchically classify the languages, cultures, literacies, histories, and varied ways of being in the curriculum. In order to do these well, educators, educational leaders, and curriculum designers need to first and then constantly examine what dominant and marginalizing discourses they have normalized and institutionalized. Without that examination, any curriculum reform and effort to deconstruct and reconstruct education might further reinforce dominant forms and silence non-dominant forms. Again, the findings of this study also indicate that critical literacy as a theory, when applied to previously colonialized spaces needs to center a decolonizing approach otherwise it can be easy to miss how other curricula and educational practices continue to repeat from and legitimize colonial practices that marginalize non-dominant cultures, languages, and ways of being (Akena, 2012; Love, 2019).

\section{Implications for Policy and Practice}

This study deconstructed the curriculum to understand how it centers the English language in order to reimagine a curriculum centered on Ghanaian languages and literacies. The first pieces that need to reconstructed are the assumptions of normality that undergird the curriculum. The lack of a language-in-education policy that directly defines the role and importance of Ghanaian languages arise from the assumption of normality. 
In the curriculum framework the following three assumptions of normality were outlined but not challenged:

"a. society wants only a smaller proportion of a student cohort to qualify for professional (academic careers); b. learners are competent native speakers in the dominant language of schooling; and c. they are used to the school's particular patterns of language use since in their (learners) families, reading and writing is a major concern" (Pre-tertiary Education Curriculum Framework, 2019, p. 69).

To center Ghanaian languages and literacies in the curriculum, policymakers and curriculum designers need to reject the above assumptions and defend the importance of Ghanaian languages, stating that

a. society should provide a rich educational environment for all students that allows them to be a critical thinkers in and out of school (Janks, 2013); b. learners can be competent and multiliterate users of multiple languages (New London Group, 1996); and c. schools should recognize learners and learners' families' funds of knowledge as important assets in educating them (Moll, Amanti \& Gonzalez, 1992).

If we start from these new set of assumptions and practices that are grounded in research, then curriculum designers can envision and create a curriculum where literacies and proficiencies in English are not the main focus of education but instead students are guided to become multiliterate users of multiple languages starting first with their Ghanaian language.

In the subsequent paragraphs I invite stakeholders in education such as educators, curriculum designers, policymakers, educational leaders, and students to see how we can 
begin to decenter English in the curriculum by using one of the subject curricula -

Creative Arts -- as an example. I present the Creative Arts curriculum here as an example

that this subject can be delivered completely in Ghanaian Languages even at the upper

primary level because it blends well with cultural artifacts and art produced by local

Ghanaian artists. Figure 5.1 below gives a snapshot of what the entire Creative Arts

Curriculum covers. I explain below why Creative Arts could have been designed to

center Ghanaian languages in the teaching and learning of Ghanaian knowledge produced

by Ghanaian artists.

\section{Reimagining a Non-Language Subject Taught in Ghanaian Languages}

${ }^{34}$ Figure 5.1

Content Standards in the Creative Arts Curriculum

\begin{tabular}{|c|c|c|}
\hline STRANDS & $\begin{array}{l}\text { SUB- } \\
\text { STRANDS }\end{array}$ & CONTENT STANDARDS \\
\hline \multirow{7}{*}{$\begin{array}{l}\text { 1. Visual Arts } \\
\text { 2. Performing } \\
\text { Arts }\end{array}$} & $\begin{array}{l}\text { Thinking and } \\
\text { exploring } \\
\text { ideas }\end{array}$ & $\begin{array}{l}\text { CSI: Demonstrate understanding of how to generate own ideas for artistic expressions on the } \\
\text { people based on their history and culture, the environment and topical local/national/global } \\
\text { issues }\end{array}$ \\
\hline & \multirow[t]{2}{*}{$\begin{array}{l}\text { Planning, } \\
\text { making and } \\
\text { composing }\end{array}$} & $\begin{array}{l}\text { CS2:Demonstrate understanding of how to organise own ideas through experimenting with } \\
\text { available media and techniques for creating/composing artworks based on the history, culture, } \\
\text { environment and topical local/national/global issues of other communities }\end{array}$ \\
\hline & & $\begin{array}{l}\text { CS3:Demonstrate understanding of how to create expressive artworks based on own ideas by } \\
\text { applying knowledge of media and methods of production to reflect other cultures in Africa, the } \\
\text { visual artists, their culture, the environment and emerging topical issues }\end{array}$ \\
\hline & \multirow{2}{*}{$\begin{array}{l}\text { Displaying } \\
\text { and sharing } \\
\text { through } \\
\text { exhibition } \\
\text { and } \\
\text { performance }\end{array}$} & $\begin{array}{l}\text { CS4:Demonstrate understanding of how to plan a display/presentation of a portfolio of own } \\
\text { artworks by identifying, and preparing a venue, selecting and grouping of artworks and inviting } \\
\text { target audience for the planned display/performance. }\end{array}$ \\
\hline & & $\begin{array}{l}\text { CS5:Demonstrate understanding of how to display/present a portfolio of art works that share } \\
\text { own knowledge, concepts, ideas and experiences with audience through display/presentation; } \\
\text { and using senses/manual/digital applications where necessary, to record for reporting on the } \\
\text { events. }\end{array}$ \\
\hline & \multirow[t]{2}{*}{$\begin{array}{l}\text { Appreciating } \\
\text { and } \\
\text { appraising }\end{array}$} & $\begin{array}{l}\text { CS6:Demonstrate understanding of how to analyse, appreciate, appraise/critique and present } \\
\text { report on own works and that of others based on established guide for judging artworks (the } \\
\text { theme, subject matter, media, techniques, elements and principles of design, social, aesthetic, } \\
\text { cultural and functional values), the recordings and reports }\end{array}$ \\
\hline & & $\begin{array}{l}\text { CS7:Demonstrate understanding of how to make informed decisions on displays, presentations, } \\
\text { performances, recordings and/or reports based on established guide for judging artworks (the } \\
\text { theme, subject matter, media, techniques, elements and principles of design, social, aesthetic, } \\
\text { cultural and functional values) for correlation, correction and future modifications }\end{array}$ \\
\hline
\end{tabular}

${ }^{34}$ Creative Arts Curriculum p. 25 
In the Creative Arts Curriculum, the first three content standards CS1, CS2, and CS3 state that students are to (1) learn about cultures in Ghana and in Africa through visual and performing arts like music, paintings, theatre, and sculpture and (2) create artworks themselves inspired by their exploration of culture through Ghanaian and African artworks. CS4, CS5, and CS6 focus on guiding students to appreciate artwork and by extension the cultures that inspired such works and also appreciate their own creations and those of their peers. In the Creative Arts Curriculum, there is a goal for students to share their work with the local community. The directive appears at least twice at each primary level after students have covered content in either visual or performing arts. Here are some examples below:

"B4 2.3.4.2 Plan a performance of compositions to share creative experiences based on own ideas, knowledge and understanding of performing artworks that reflect the natural and manmade environments of some communities in Ghana" (Creative Arts, p. 46).

"B4 1.3.5.3 Display own artworks to share creative experiences based on own ideas, knowledge and understanding of topical issues in Ghana" (Creative Arts, p. 50). These displays and performance according to the Creative Arts curriculum are to be shared with the school and local community such that "learners are to...develop a roadmap for the performances by fixing a date, selecting venue and inviting audience... send manual and/or electronic invitations (e.g. letters, postcards, WhatsApp, E-mail, Twitter, Instagram, Facebook, announcements, posters, jingles) to target audience, for example parents, PTA/SMC members, stakeholders, colleague learners...” (p. 46) and 
also "decide on the types and number of artworks to exhibit and mount them based on the space available to suit the theme for the exhibition (e.g. artworks that best reflect current topical issues of national concern in Ghana)...” (p.50).

From students' explorations and learning about culture through arts, to creating their own artworks and sharing those artworks with the community, I contend that the English language does not need to be the medium of instruction here. The Creative Arts period can afford Ghanaian language teachers the opportunity to guide students in exploring cultural artifacts and productions in Ghanaian languages, and as result show Ghanaian languages as significant beyond just learning how to read, write, and speak the language. Engaging with these visual and performance artforms in Ghanaian languages creates an environment where Ghanaian languages are significant beyond the Ghanaian Languages curriculum. Students could also benefit from sharing their work with the community while they speak the language of their community.

The strict use of English in delivering this Creative Arts curriculum might impede the teaching and learning process. A Ghanaian student's inability to enact English speaking proficiencies should not deny them either access to their rich cultural heritage and literacy or the pleasure of learning and producing artwork that reflects their community, cultural, and linguistic identity and heritage. The design of Creative Arts curriculum in terms of content could provide opportunities for community members who speak only Ghanaian languages to engage with students and also share local cultural histories. Centering English as a way for students to learn about these histories, cultures, and artwork and share their learning may create barriers that hinder local community involvement and partnership. Nonetheless, because of the progressive use of English 
from $\mathrm{KG}$ and soon after the use of English only by primary four, the curriculum misses how Ghanaian languages can feature prominently even in teaching Ghanaian culture and history. In short, the Creative Arts curriculum could be taught in a Ghanaian language, especially since the course focuses on Ghanaian and African performance and visual art literacies so that rather than separating the study of language from other cultural knowledge, students have a whole experience of Ghanaian languages and Ghanaian cultures, histories, and knowledge.

\section{Reimagining a Language-in-Education Policy}

The findings of this study also suggest that the language-in-education policy should be explicit in the use of Ghanaian languages in teaching and learning in K-6 education. The policy could draw from research to explain how the use of Ghanaian languages helps students not only develop transferrable multiliteracy skills but that it also ensures students' academic progress from lower to higher level of schooling. This means that instead of the colonial and post-colonial traditions of early exit transitional bilingual education where Ghanaian languages are used initially but quickly replaced with English in lower primary education, Ghanaian languages and English should be reconceptualized as a dual language medium in K-6 education. The subject areas in K-6 education can be delivered in both Ghanaian languages and English. This reimagination is possible as some teacher-education programs already prepare teachers who teach in both English and the Ghanaian languages (University of Education Winneba, 2020). When the national education curriculum specifies a dual language medium, it will provide more opportunity for the development of Ghanaian languages and increase the social value of Ghanaian languages. 
Furthermore, the Ghanaian languages curriculum itself should not be a generic curriculum for every Ghanaian language. In the findings of the discourse analysis, the Ghanaian curriculum is modeled after the English curriculum such that it does not attend to the differences in the many Ghanaian languages and ways of speaking. At the very least, there should be a Ghanaian language curriculum for each of the eleven approved Ghanaian languages allowed as mediums of teaching and learning in schools. Rather than a single Ghanaian language team that designs the entire curriculum for Ghanaian languages, eleven Ghanaian languages curriculum design teams should consider how their language is spoken, enacted, and embodied and reflect that in their separate curriculum. If this work is done at the national curriculum level, then teachers do not have to spend time translating work sheets from English into their Ghanaian language as seen in the findings of the study.

\section{Reimagining Assessment}

The discourse of curriculum saw greater weights in assessment in languages subjects like English. Class assignments and projects done throughout the school year contributed only 50 percent towards the final cumulative score in upper primary. The other 50 comes from final end-of-term and end-of-year exams. Because all other nonlanguage subjects are taught in English, especially for students who are still learning in a second language, this design rewards students who may be proficient enough in English to understand lessons taught in English and know enough to pass exams set in English. This assessment design, however, does not consider and reward as much formative progress through the year, and it should because students are still learning concepts in the language that is not their own. Class work, participation, and projects done through the 
school year should contribute at least 70 percent towards the final cumulative score and not 50 percent.

\section{Reimagining Curriculum Content}

In chapter four, the discourse analysis of the curriculum indicated that in the Ghanaian languages curriculum, students did not start curriculum content on writing until primary four while in the English curriculum students started the writing strand as early as primary one. Again, if the language-in-education is specific about the use and importance of Ghanaian language in teaching and learning, the curriculum may guide students to write early in Ghanaian languages right in kindergarten. This discourse of the curriculum shows how students can be hindered in their literacy development because they are unable to write in their own language till primary four but they are expected, on the other hand, to write in their second language three years earlier.

The content of the Our World Our People (OWOP) curriculum repeats contents from other courses such as Religious and Moral Education (RME), Computing, and History that seem repetitive. Because the Creative Arts curriculum focuses on teaching visual and performance arts, the History curriculum focuses on mainly teaching Ghana's political history, and RME focuses on teaching the religious beliefs of the groups in Ghana. The OWOP could be redesigned to teaching knowledge about the ethnic and language groups in Ghana. At higher levels beyond K-6 education, students can then learn about ethnic and language groups in other African countries. By refocusing the curriculum content in OWOP, in K-6 education, students can begin to see, know about, and experience the history, language, and culture of Ghanaians and Africans around them. 
Another subject area that needs redesigning is the History curriculum in light of the findings of the discourse analysis in chapter four. The History curriculum not only overrepresents and centers Ghana's colonial history but the curriculum also Whitewashes history by representing a favorable picture of colonialism emphasizing economic, social infrastructural, and educational developments during the colonial era and less about the harm and injustices brought by colonialism. Students should be encouraged to critique Ghana's colonial history and broadly consider how Ghana was impacted by colonialism and rather than the current approach where students are to consider the advantages of "Europeans" coming to Ghana. Additionally, the discourse in the History curriculum should be specific about naming "colonizers" in place of "Europeans." The use of "Europeans" waters down the impact of what the colonial government undertook in colonizing Ghana and taking over political control of the land and its people.

\section{Changing the Public Discourse Through Educational Leaders}

The discourse of educational leaders in the study reflected how the curriculum emphasizes the English language, proficiencies, and literacies in English. Especially since the discourse of educational leaders occurred around the time a new curriculum was being drafted and implemented, it highlights how the discourse of educational leaders shapes the educational curriculum including what the curriculum should include and exclude. The findings of the study suggest that if the public discourse on the importance, use, and value of Ghanaian languages in education will see a favorable change, educational leaders need to be intentional and direct in policy and practice about how students' and teachers' use of Ghanaian languages will be beneficial to all educational stakeholders. Educational leaders, especially at the Ministry of Education, are often in the 
public eye giving interviews, making speeches, and meeting with the press and so their reiteration, explanation, and presentation of the need to center Ghanaian languages in educating Ghanaian students will, at least, in the public space create dialogue and recognition on how Ghanaian languages are can be privileged and re-valued in education.

\section{Limitations and Future Research Directions}

The design of this study helps explain how the Ghanaian K-6 curriculum is structured in a way such that it centers and reinforces the English language in policy and in practice while pushing Ghanaian languages to the margins of education. What the study cannot fully address is how the discourse of the curriculum document remains the same in the physical classroom. The scope of this paper is unable to determine whether teachers follow the language of the curriculum to the letter or whether some teachers in their own classroom disrupt English language dominance and center Ghanaian languages, and that was not its focus. It is important for future studies to consider how the new K-6 curriculum is currently taught in the classroom because by observing and learning directly from the classroom, researchers might learn other ways the curriculum continues to push Ghanaian languages to the margins or how teachers resist this decentering that is clear in the state policy; in other words, the next step from a study like this is to examine policy enactment (Ball, 2015; Menken, 2013). Currently there is no focus in research on how Ghanaian students actually experience the Ghanaian language classroom and how that is different or similar to how they experience our language and non-language subjects.

The persistent absence of discourse around Ghanaian languages in the discourse of educational leaders seen in the data could indicate that Ghanaian languages are used 
even less in teaching and learning even in the Ghanaian language curriculum for instance. Future research can also conduct in-depth interviews of various educational leaders and curriculum designers to learn why/how Ghanaian languages are deemphasized in the K-6 curriculum. This study looked only at the public discourse of educational leaders but perhaps educational leaders in private might inform knowledge on the politics behind the scenes of centering Ghanaian languages in the curriculum.

This study also showed that scholars interested in decolonizing education in multilingual societies and in former colonial contexts need to critically look at the language and discourse of the curriculum. The curriculum is a powerful tool that names and directs what language and literacy practices should be enacted and embodied by students. It guides the teaching and learning process by saying what it should include or exclude. Therefore, scholars should not only study what occurs in practice in the classroom when trying to recreate and reimagine an educational system that sees and centers the ways of speaking and multiliteracies of students living in former colonial and multilingual societies (Muiu \& Martin, 2009). Scholars should also pay attention to the discourse of the curriculum because what happens in the classroom could likely be guided by the language of the curriculum. Furthermore, because of the persistent dominance of English in the curriculum and in the discourse of educational leaders, scholars need to highlight the experiences of students who have difficulty navigating the current educational system because their languages are set aside in educating them.

\section{Conclusion}

The goal of the study was to understand how the Ghanaian educational curriculum perhaps reinforces the dominance of the English language and preference for English 
documented in the literature. Through the literature scholars have shown how the dominance of English in Ghanaian education was adversely impacting the experience of students. The literature also indicated that students continue to ask for English language mediums so they can have access to higher level of education. The study showed through the literature that English language dominance was engineered through colonial policies and practices that continue today to center English and view it as a marker of social and academic progress. The findings of the discourse analysis of the new K-6 curriculum including discourse of educational leaders demonstrate that the English language and literacies in English are intentionally designed to make it dominant in terms of language policies, curriculum content, teaching and learning activities, and assessment practices. Perhaps, students would call for their own languages if language policies, curriculum content, teaching and learning activities, and assessment practices did not favor English but their own language.

To disrupt the dominance of English in Ghanaian education and center Ghanaian languages and literacies, policymakers and curriculum designers need to reimagine (1) a dual language medium in K-6 education, (2) non-language subjects that are taught fully in Ghanaian languages, (3) assessment practices that reward formative progress, (4) and educational leaders who publicly affirm the importance of Ghanaian languages and constantly examine how their practices and policies institutionalize and normalize dominant forms and push other ways of speaking and being to the margins. When educational stakeholders realize these steps, we can begin to disrupt English linguistic imperialism in the K-6 curriculum. This approach resists the English early start fallacy because Ghanaian languages would be started and taught early. It also flips the English 
maximum exposure fallacy because students are exposed maximally to Ghanaian languages instead. This reimagination also disrupts the English monolingual fallacy because Ghanaian languages and English are used to the same degree in teaching and learning. Informed by Janks' (2013) work, Ghanaian educators and researchers must endeavor to constantly examine whose voice, ways of speaking, culture, history, and language are being left out 


\section{References}

“Adopting French.” (2019). Adopting French as Ghana’s second language 'disrepctfulful' - Okyeame Kwame. Myjoyonline. Retrieved from https://www.myjoyonline.com/entertainment/2019/March-21st/adopting-frenchas-ghanas-second-language-disrespectful-okyeame-kwame.php

Ahadzi, S., Ameka, F. K., \& Essegbey, J. (2015). Language use at home and performance in English composition in multilingual Ghana. Afrikanistik Aegyptologie Online. Retrieved from https://www.afrikanistik-aegyptologieonline.de/archiv/2015/4216/

Akena, F. A. (2012). Critical analysis of the production of Western knowledge and its implications for Indigenous knowledge and decolonization. Journal of Black Studies, 43(6), 599-619. DOI: 10.1177/0021934712440448

“Akufo-Addo reiterates." (2019). Akufo-Addo reiterates his position on sexuality education. Ghanaweb. Retrieved from https://www.ghanaweb.com/GhanaHomePage/NewsArchive/Akufo-Addoreiterates-his-position-on-Sexuality-Education-788671

Ansah, G. N. (2014). Re-examining the fluctuations in language in-education policies in post =-independence Ghana. Multilingual Education, 4(12), 1-15. DOI: $10.1186 / \mathrm{s} 13616-014-0012-3$

Ansah, M. A., \& Agyeman, N. A. (2015). Ghana language-in-education policy: The survival of two south Guan minority dialects. Per Linguam, 31(1), 89-104. DOI: $10.5785 / 31-1-592$ 
Anyon, J. (1981). Social class and school knowledge. Curriculum Inquiry, 11(1), 3-42. DOI: $10.1080 / 03626784.1981 .11075236$

Arthur, J. (1997). 'There must be something undiscovered which prevents us from doing our work well': Botswana primary teachers' views on educational language policy. Language and Education, 11(4), 225-241. DOI:

$10.1080 / 09500789708666730$

Arthur, J. (2001). Perspectives on educational language policy and its implementation in African classroom: A comparative study of Botswana and Tanzania. Compare: A Journal of Comparative and International Education, 31(3), 347-362. DOI: $10.1080 / 03057920120098482$

Anyidoho, A., \& Kropp Dakubu, M. E. (2008). Ghana: Indigenous languages, English, and an emerging national identity. In A. Simpson (Ed.), Language and national identity in Africa (pp. 141-157). Oxford University Press.

Aziabah, M. A. (2018). The politics of educational reform in Ghana: Understanding structural persistence in the secondary school system. Springer.

Ball, S. J. (2015). What is policy? 21 years later: Reflections on the possibilities of policy research. Discourse: Studies in the cultural politics of education, 36(3), 306-313. DOI: $10.1080 / 01596306.2015 .1015279$

Batibo, H. (2005). Language decline and death in Africa: Causes, consequences and challenges. Multilingual Matters Ltd.

Bening, R. B. (1976). Colonial control and the provision of education in Northern Ghana 1908-1951. Universitas, 5(2), 58-99. 
Billings, S. (2011). Education is the key of life': Language, schooling, and gender in Tanzanian beauty pageants. Language \& Communication, 31(4), 295-309. doi:10.1016/j.langcom.2011.02.003

Birdsall, N., Rodrik, D., \& Subramanian, A. (2005). How to help poor countries. Foreign Affairs, 84(4), 136-152. DOI: 10.2307/20034426

Bonney, E. N. (2020a). The curriculum transmits discourse about the position of English over Ghanaian languages. [Unpublished manuscript]

Bonney, E.N. (2020b). Under/Mis-representation of Ghanaian Languages in the literature curriculum in senior high schools. Journal of Language, Identity, and Education. DOI: $10.1080 / 15348458.2020 .1832498$

British Council. (2019). About us. Retrieved from https://www.britishcouncil.org/aboutus

Brock-Utne, B. (2010). Research and policy on the language of instruction issue in Africa. International Journal of Educational Development, 30(6), 636-645. DOI: 10.1016/j.ijedudev.2010.03.004

Brock-Utne, B., Desai, Z., Qorro, M. A. S., \& Pitman, A. (2010). Language of instruction in Tanzania and South Africa - Highlights from a project. Sense Publishers

Brock-Utne, B., \& Holmarsdottir, H. B. (2004). Language policies and practices in Tanzania and South Africa: Problems and challenges. International Journal of Educational Development, 24(1), 67-83. DOI: 10.1016/j.ijedudev.2003.10.002

Brown, G. N. (1964). British educational policy in West and Central Africa. The Journal of Modern African Studies, 2(3), 365-377. 
Canagarajah, S. (2007). Lingua franca English, multilingual communities, and language acquisition. The Modern Language Journal, 91(1), 923-939. DOI: $10.1111 / j .1540-4781.2007 .00678 . x$

Cárdenas-Hagan, E., Carlson, C. D., \& Pollard-Durodola, S. D. (2007). The crosslinguistic transfer of early literacy skills: The role of initial L1 and L2 skills and language of instruction. Language, Speech, and Hearing Services in Schools, 38(3), 249-259. DOI: 10.1044/0161-1461(2007/026)

Casale, D. \& Posel, D. (2011). English language proficiency and earnings in a developing country: The case of South Africa. The Journal of Socio-Economics, 40(4), 385393. DOI: $10.1016 /$ j.socec.2011.04.009

Casely-Hayford, L., \& Hartwell, A. (2010). Reaching the underserved with complementary education: Lessons from Ghana's state and non-state sectors. Development in Practice, 20(4/5), 527-539. DOI: 10.1080/09614521003763152

Césaire, A. (1972). Discourse on Colonialism (J. Pinkham, Trans.). Modern Reader. Chabal, P. (1996). The African crisis: Context and interpretation. In R. Werbner \& T. Ranger (Eds.). Postcolonial identities in Africa (pp. 29-54). Zed Books Ltd

Cleghorn, A., Merritt, M., \& Abagi, J. O. (1989). Language policy and science instruction in Kenyan primary schools. Comparative Education Review, 30(1), 21-39.

Collison, G. O. (1974). Concept formation in a second language: A study of Ghanaian school children. Havard Educational Review, 44(3), 441-457. DOI: /10.17763/haer.44.3.d70567743hm20170 
Cope, B., \& Kalantzis, M. (2015). The things you do to know: An introduction to the pedagogy of multiliteracies. In B. Cope, \& M. Kalantzis (Eds.). A pedagogy of multiliteracies (pp. 1-36). Palgrave Macmillan.

Creswell, J. W., Creswell, J. D., (2017). Research design: Qualitative, quantitative, and mixed methods approaches. Sage

Davis, E. K., \& Agbenyegah, J. S. (2012). Language policy and instructional practice dichotomy: The case of primary school in Ghana. International Journal of Educational Research, 53(1), 341-347. DOI: 10.1016/j.ijer.2012.04.007

Davis, E. K., Bishop, A. J., \& Seah, W. T. (2015). "We don't understand English that is why we prefer English": Primary school students' preference for the language of instruction in Mathematics. International Journal of Science \& Mathematics Education, 13(3), 583-604. DOI: 10.1007/s10763-013-9490-0

Dei, G. J. S. (2005). The challenge of inclusive schooling in Africa: A Ghanaian case study. Comparative Education, 41(3), 267-289. DOI:

$10.1080 / 03050060500211641$

Dei, G. J. S., \& Asgharzadeh, A. (2001). The power of social theory: The anti-colonial discursive framework. The Journal of Educational Thought (JET)/Revue De La Pensée Éducative, 35(3), 297-323.

Dorner, L. M., \& Cervantes-Soon, C. G. (2020). Equity for Students Learning English in Dual Language Bilingual Education: Persistent Challenges and Promising Practices. TESOL Quarterly, 54(3), 535-547. DOI: 10.1002/tesq.599

Dorner, L. M., \& Layton, A. (2014). “¿ Cómo se dice?” Children's multilingual discourses (or interacting, representing, and being) in a first-grade Spanish 
immersion classroom. Linguistics and Education, 25(1), 24-39. DOI:

10.1016/j.linged.2013.12.001

Drummond, A. (2016). An analysis of language policy versus practice in two South African universities. Southern African Linguistics \& Applied Language Studies, 34(1), 71-79. DOI: $10.2989 / 16073614.2016 .1159522$

Edu-Buandoh, D. F. \& Otchere, G. (2012). “Speak English!” A prescription or choice of English as a lingua franca in Ghanaian schools. Linguistic and Education, 23(3), 301-309. DOI: 10.1016/j.linged.2012.06.003

EGRA [Early Grade Reading Assessment], \& EGMA [Early Grade Mathematics Assessment]. (2015). Ghana 2015 Early Grade reading Assessment and Early Grade Mathematics Assessment: Report of finding. Retrieved from http://nacca.gov.gh/wp-content/uploads/2019/04/Ghana-2015-EGRA-

\section{EGMA_22Nov2016_FINAL.pdf}

Emerson, R. M., Fretz, R. I., \& Shaw, L. L. (2011). Writing ethnographic fieldnotes. University of Chicago Press.

Fairclough, N. (2013). Critical discourse analysis: The critical study of language. Routledge.

Fairclough, N. (1992). Discourse and text: Linguistic and intertextual analysis within discourse analysis. Discourse \& Society, 3(2), 193-217. DOI: $10.1177 / 0957926592003002004$

Fanon, F. (2008). Black skin, white masks. (R. Philcox, Trans.). Grove Press. (Original work published 1952). 
García, O., \& Wei, L. (2014). Translanguaging: Language, bilingualism and education. Palgrave Macmillan.

Gee, J. P. (2014). Introduction to discourse analysis: Theory and method. Taylor \& Francis.

Gee, J. P. (2006). What is literacy? In P. Vandenberg, S. Hum, \& J. Clary-Lemon (Eds.), Relations, locations, positions: Composition theory for writing teachers (pp. 2939). National Council of Teachers of English

George, B. S. (1976). Education in Ghana. Washington, DC: Office of Education (DHEW).

Giroux, H. A., \& Penna, A. N. (1979). Social education in the classroom: The dynamics of the hidden curriculum. Theory \& Research in Social Education, 7(1), 21-42. DOI: $10.1080 / 00933104.1979 .10506048$

Graham, C. K. (1971). The history of education in Ghana from the earliest terms to the declaration of independence. F. Cass.

Hilliard, A. (2015). Tanzanian students' attitudes towards English. TESOL Journal, 6(2), 252-280. DOI: $10.1002 /$ tesj.147

Janks, H. (2000). Domination, access, diversity and design: A synthesis for critical literacy education. Educational Review, 52(2), 175-186.

Janks, H. (2013). Critical literacy in teaching and research. Educational Inquiry, 4(2), 225-242. DOI: 10.3402/edui.v4i2.22071

Jefferson, G. (1984). Notes on a systemic development of the acknowledgement tokens "yeah" and "mmhm". Papers in Linguistics, 17(2), 197-216. 
Knobel, M., \& Lankshear, C. (2006). Discussing new literacies. Language Arts, 84(1), 78-86.

Knobel, M., \& Lankshear, C. (2014). Studying new literacies. Journal of Adolescent \& Adult Literacy, 58(2), 91-101. DOI: 10.1002/jaal.314

Love, B. L. (2019). We want to do more than survive: Abolitionist teaching and the pursuit of educational freedom. Beacon Press.

Martin, C. A. (1976). Significant trends in the development of Ghanaian education. The Journal of Negro Education, 45(1), 46-60. DOI: 10.2307/2966541

Mazrui, A. (2012). Language and education in Kenya: Between the colonial legacy and the new constitutional order. In J. W. Tollefson (Ed.). Language policies in education: Critical Issues (2nd ed., pp. 139-155). Routledge.

McClintock, A. (1994). The angel of progress: Pitfalls of the term 'postcolonialism'. In F. Barker, P. Hulme, \& M. Iversen (Eds.). Colonial discourse/Postcolonial theory (pp. 253-266). Manchester United Press.

Menken, K. (2013). Restrictive language education policies and emergent bilingual youth: A perfect storm with imperfect outcomes. Theory into Practice, 52(3), 160-168. DOI: 10.1080/00405841.2013.804307

Menken, K., \& Kleyn, T. (2010). The long-term impact of subtractive schooling in the educational experiences of secondary English language learners. International Journal of Bilingual Education and Bilingualism, 13(4), 399-417. DOI: $10.1080 / 13670050903370143$

Merriam, S. B., \& Tisdell, E. J. (2016). Qualitative research: A guide to design and implementation. John Wiley \& Sons. 
Mfum-Mensah, O. (2005). The impact of colonial and postcolonial Ghanaian language policies on vernacular use in schools in two northern Ghanaian communities. Comparative Education, 41(1), 71-85. DOI: 10.1080/03050060500073256

Miescher, S. (2005). Making men in Ghana. Indiana University Press.

Moll, L. C., Amanti, C., Neff, D., \& Gonzalez, N. (1992). Funds of knowledge for teaching: Using a qualitative approach to connect homes and classrooms. Theory into Practice, 31(2), 132-141. DOI: 10.1080/00405849209543534

Muiu, M., \& Martin, G. (2009). A new paradigm of the African state: Fundi wa Afrika. Palgrave Macmillan.

Mutasa, D. E. (2015). Language policy implementation in South African universities visa-vis the speakers of indigenous African languages' perception. Per Linguam: A Journal of Language Learning/Per Linguam: Tydskrif vir Taalaanleer, 31(1), 4659. doi:10.5785/31-1-631

NaCCA [National Council for Curriculum \& Assessment]. (2019a). About us: Brief history of NaCCA. Retrieved from https://nacca.gov.gh/?page_id=4881

NaCCA [National Council for Curriculum \& Assessment]. (2019b). NEA EGRA/EGMA. Retrieved from https://nacca.gov.gh/?page_id=8917

NEA [National Education Assessment]. (2014). Ghana 2013 National education assessment: Technical report. Retrieved from http://nacca.gov.gh/wpcontent/uploads/2019/04/2013-NEA-TECHNICAL-REPORT.pdf

New London Group. (1996). A pedagogy of multiliteracies: Designing social futures. Havard Education Review, 66(1), 60-92. 
Ngula, R. S. (2019, October 13). Comprehensive sexuality education in Ghana: The truths beyond the misconceptions. Myjoyonline. Retrieved from https://www.myjoyonline.com/opinion/2019/October-13th/comprehensive$\underline{\text { sexuality-education-in-ghana-the-truths-beyond-the-misconceptions.php }}$

Nyika, A. (2015). Mother tongue as the medium of instruction at developing country universities in a global context. South African Journal of Science, 111(1/2), 1-5. DOI: $10.17159 /$ sajs.2015/20140005

Opoku-Amankwa, K. (2009a). English-only language-in-education policy in multilingual classrooms in Ghana. Language, Culture and Curriculum, 22(2), 121-135. DOI: $10.1080 / 07908310903075159$

Opoku-Amankwa, K. (2009b). 'Teacher only calls her pets': Teacher's selective attention and the invisible life of a diverse classroom in Ghana. Language and Education, 23(3), 249-262. DOI: 10.1080/09500780802582539

Opoku-Amankwa, K., \& Brew-Hammond, A. (2011). 'Literacy is the ability to read and write English': Defining and developing literacy in basic schools in Ghana. International Journal of Bilingual Education and Bilingualism, 14(1), 89-106. DOI: $10.1080 / 13670051003692857$

Owu-Ewie, C. (2017). Language, education, and linguistic human rights in Ghana. Legon Journal of the Humanities, 28(2), 151-172. DOI: 10.4314/ljh.v28i2.7

Owu-Ewie, C., \& Eshun, E. S. (2015). The use of English as medium of instruction at the upper basic level (primary four to junior high school) in Ghana: From theory to practice. Journal of Education and Practice, 6(3), 72-82. 
Owu-Ewie, C., \& Eshun, E. S. (2019). Language representation in the Ghanaian lower primary classroom and its implications: The case of selected schools in the Central and Western Regions of Ghana. Current Issues in Language Planning, 20(4), 365-388. DOI: 10.1080/14664208.2019.1585159

Palmer, D. K., Cervantes-Soon, C., Dorner, L., \& Heiman, D. (2019). Bilingualism, biliteracy, biculturalism, and critical consciousness for all: Proposing a fourth fundamental goal for two-way dual language education. Theory into Practice, 58(2), 121-133. DOI: 10.1080/00405841.2019.1569376

Pennycook, A. (1994). The cultural politics of English as an international language. Longman Publishing

Pennycook, A. (1998). English and the discourses of colonialism: The politics of language. Routledge.

Peyton, N. (2019, October 1). Ghana sex education programme sparks anti-LGBT+ outrage. Thomas Reuters Foundation News. Retrieved from https://news.trust.org/item/20191001181549-8k2du

Phaahla, P. (2014). Indigenous African Languages as agents of change in the transformation of higher education institutions in South Africa: Unisa. Nordic Journal of African Studies, 23(1), 31-56.

Phillipson, R. (1992). Linguistic imperialism. Routledge.

Phillipson, R. (2009). Linguistic imperialism continued. Routledge.

Plüddemann, P. (2015). Unlocking the grid: language-in-education policy realisation in post-apartheid South Africa. Language \& Education: An International Journal, 29(3), 186-199. doi:10.1080/09500782.2014.994523 
Qorro, M. A. S. (2013). Language of instruction in Tanzania: Why are research findings not heeded? International Review of Education, 59(1), 29-45. DOI: $10.1007 / \mathrm{s} 11159-013-9329-5$

Quijano, A. (2007). Coloniality and modernity/rationality. Cultural Studies, 21(2-3), 168178. DOI: $10.1080 / 09502380601164353$

Rogers, R., \& Wetzel, M. M. (2013). Designing critical literacy education through critical discourse analysis: Pedagogical and research tools for teacherresearchers. Routledge.

Rosa, J. (2016). Standardization, racialization, languagelessness: Raciolinguistic ideologies across communicative contexts. Journal of Linguistic Anthropology, 26(2), 162-183. DOI: 10.1111/jola.12116

Rosa, J., \& Flores, N. (2017). Unsettling race and language: Toward a raciolinguistic perspective. Language in Society, 46(5), 621-647. doi:10.1017/S0047404517000562

Satsi, J. K. \& Siabour, A. S. (2019, October 10). Coalition to organise national dialogue on Comprehensive Sexuality Education. Ghana News Agency. Retrieved from https://ghananewsagency.org/social/coalition-to-organise-national-dialogue-oncomprehensive-sexuality-education-157724

Saunders, B., Sim, J., Kingstone, T., Baker, S., Waterfield, J., Bartlam, B., Burroughs, H., \& Jinks, C. (2018). Saturation in qualitative research: Exploring its conceptualization and operationalization. Quality \& Quantity, 52(1), 1891-1907. DOI: $10.1007 / \mathrm{s} 11135-017-0574-8$ 
Savin-Baden, M., \& Howell-Major, C. (2013). Qualitative research: The essential guide to theory and practice. Routledge.

Serwornoo, M. Y. W. (2019). The coverage of Africa in Ghanaian newspapers: The dominant western voice in the continent's coverage. Journalism, 1-18. DOI: $10.1177 / 1464884919887311$

Ssentanda, M. E. (2014). Mother tongue education and transition to English medium education in Uganda: Teachers perspectives and practices versus language policy curriculum (Doctoral dissertation). Retrieved from Stellenbosch University Scholar Research Repository http://scholar.sun.ac.za/bitstream/handle/10019.1/95855/ssentanda_mother_2014. $\underline{\text { pdf }}$

Street, B. (2003). What's "new” in New Literacy Studies? Critical approaches to literacy in theory and practice. Current Issues in Comparative Education, 5(2), 77-91.

Swilla, I. N. (2009). Language of instruction in Tanzania: Contradictions between ideology, policy and implementation. African Study Monographs, 30(1), 1-14. DOI: $10.14989 / 71112$

Tackie-Ofosu, V., Mahama, S., Vandyck, E. S. T. D., Kumador, D. K., and Toku, N. A. A. (2015). Mother tongue usage in Ghanaian pre-schools: Perceptions of parents and teachers. Journal of Education and Practice, 34(6), 81-87.

Taylor, S., \& von Fintel, M. (2016). Estimating the impact of language instruction in South African primary schools: A fixed effects approach. Economics of Education Review, 50(1), 75-89. DOI: 10.1016/j.econedurev.2016.01.003 
Tembe, J. (2006). Teacher training and the English language in Uganda. TESOL Quarterly, 40(4), 857-860. DOI: 10.2307/40264317

Thomas, E. E. (2016). Stories still matter: Rethinking the role of diverse children's literature today. Language Arts, 94(2), 112-119.

Trudell, B., \& Piper, B. (2013). What the law says: Language policy and implementation and early-grade literacy achievement in Kenya. Current Issues in Language Planning, 15(1), 4-21. DOI: 10.1080/14664208.2013.856985

University of Winneba. (2021). Programmes. Retrieved from https://www.uew.edu.gh/faculties/ghanaian-languages-education/academicprogrammes

Vasquez, V. (2000). Language stories and critical literacy lessons. Talking Points, 11(2), 5-7.

Vasquez, V. (2010). Critical literacy isn't just for books anymore. The Reading Teacher, 63(7), 614-616. DOI: 10.1598/RT.63.7.11

Webb, V., Lafon, M., \& Pare, P. (2010). Bantu languages in education in South Africa: an overview. Ongekho akekho! - the absentee owner. Language Learning Journal, 38(3), 273-292. DOI: 10.1080/09571730903208389 


\section{APPENDIX A}

Sample of the First Few Pages of the 70-page History Curriculum for Ghanaian Primary Schools

\section{MINISTRY OF EDUCATION}

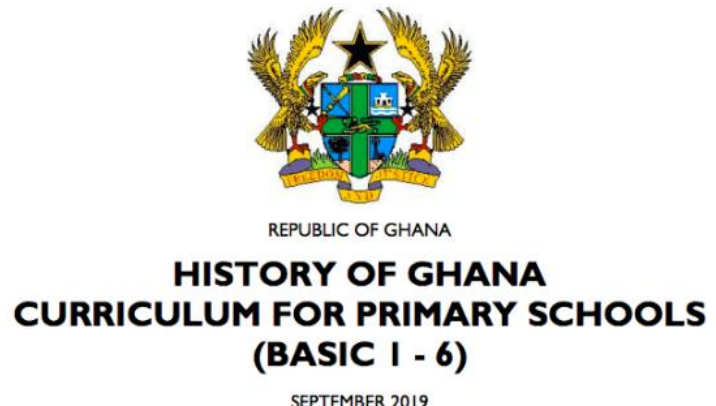

(- NoCCA Ministry of Education 2019

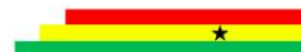

\section{History of Ghana Curriculum for Primary Schools}
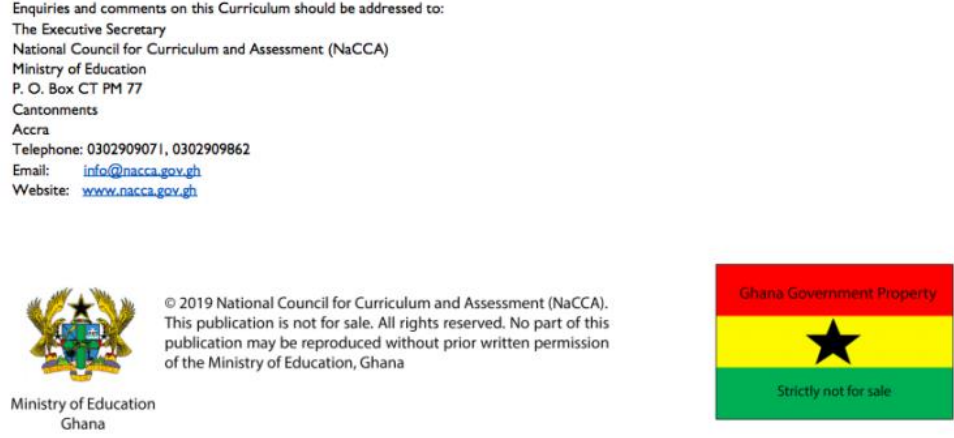


\section{FOREWORD}

The new curriculum for Ghana's primary schools is standards-based, which is our demonstration of placing learning at the heart of every classroom and ensuring that every learner receives quality education. Provision of accessible quality education for all is non-negotiable if we are to meet the human capital needs of our country, required for accelerated sustainable national development. It is for this reason that the new curriculum sets out clearly the learning areas that need to be taught, how they should be taught and how they should be assessed. It provides a set of core competencies and standards that learners are to know, understand and demonstrate as they progress through the curriculum from one content standard to the other and from one phase to the next. The curriculum and its related teachers' manual promote the use of inclusive and gender responsive pedagogy within the context of learningcentred teaching methods so that every learner can participate in every learning process and enjoy learning. The curriculum encourages the use of Information and Communication Technologies (ICTs) for teaching and learning - ICTs as teaching and learning materials.

The new curriculum has at its heart the acquisition of skills in the 4Rs of Reading, wRiting, aRithmetic and cReativity by all learners. It is expected that at any point of exit from a formal education, all learners should be equipped with these foundational skills for life, which are also prerequisites for Ghana becoming a learning nation. The graduates from the school system should become functional citizens in the 4Rs and lifelong learners. They should be digital literates, critical thinkers and problem solvers. The education they receive through the study of the learning areas in the curriculum should enable them to collaborate and communicate well with others and be innovative. The graduates from Ghana's schools should be leaders with a high sense of nationa and global identity. The curriculum therefore provides a good opportunity in its design to develop individuals with the right skills and attitudes to lead the transformation of Ghana into an industrialised learning nation.

For this reason, the Ministry of Education expects that learners, as a result of the new knowledge, skills and values they have acquired through the new curriculum, will show a new sense of identity as creative, honest and responsible citizens. These are our core values that underpin the identification and selection of the learning areas for this curriculum. These core values serve as fundamental building blocks for developing into our learners the spirit of teamwork, respect, resilience and the commitment to achieving excellence. The Ministry endorses a quality learning experience as an entitlement for each of Ghana's school-going girl and boy; the curriculum has rightly focused on learning and learning progression. The Ministry has also endorsed accountability as a critical domain for effective workings of standards-based curriculum.

More importantly the role of the teacher is to make this curriculum work for the intended purpose - to inculcate in learners the core competencies and values and to make learning happen; improve learning outcomes - and the support that teachers need is duly recognised and endorsed by my Ministry. The Ministry will support the implementation of the curriculum to include capacity development of all teachers in the new curriculum. Teachers matter in the development and delivery of the standards-based curriculum and we will continue to support our teachers on this journey that we have started together to put learning at the centre of what we do best; teach!

I thank all those who have contributed their time and expertise to the development of this curriculum for primary schools in Ghana.

Dr. Matthew Opoku Prempeh (MP)

The Honourable Minister of Education

\section{TABLE OF CONTENTS}

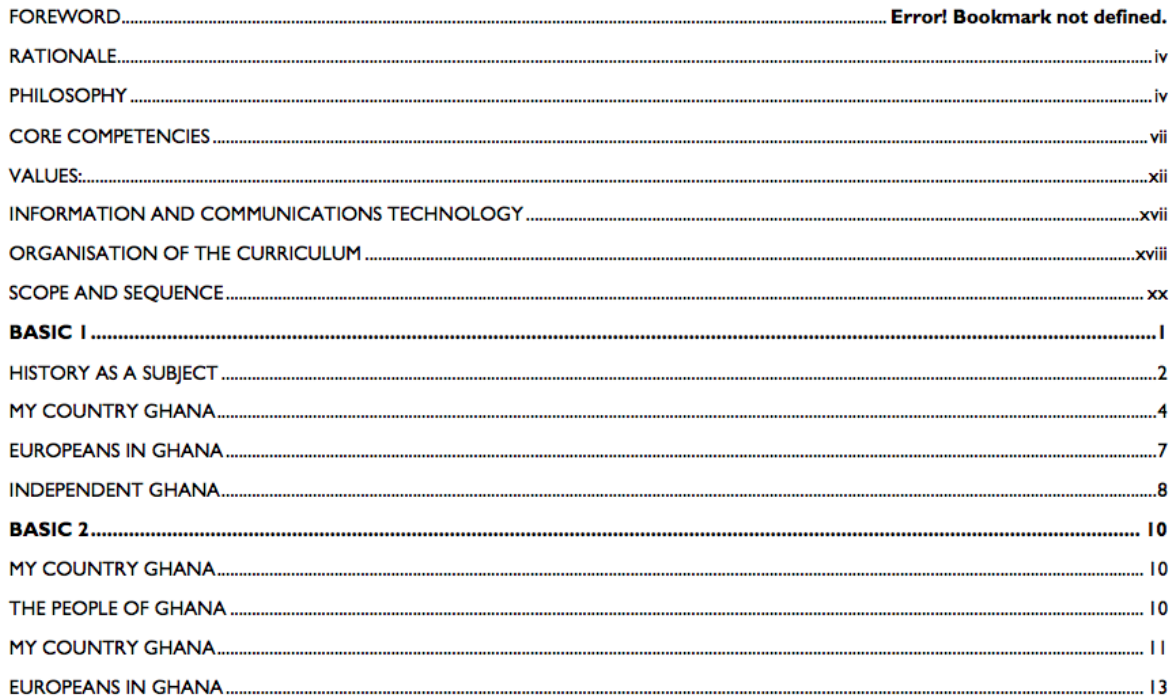


BASIC 3

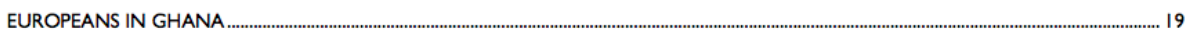

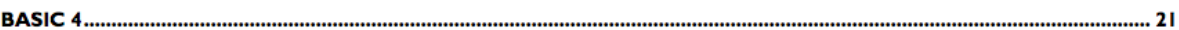

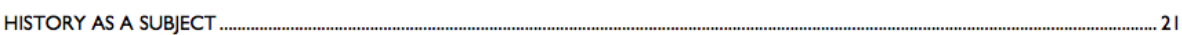

MY COUNTRY GHANA

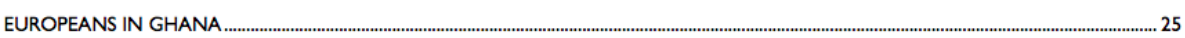

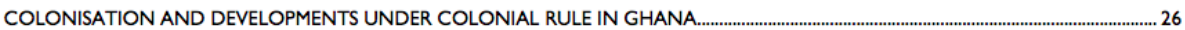

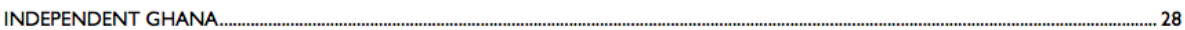

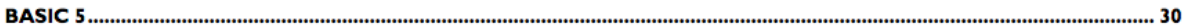

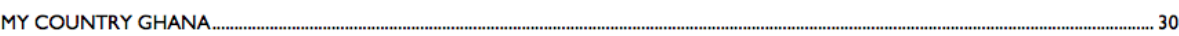

EUROPEANS IN GHANA $\ldots \ldots \ldots \ldots \ldots \ldots$

COLONISATION AND DEVELOPMENTS UNDER COLONIAL RULE IN GHANA ....................................................................................... 33

JOURNEY TO INDEPENDENCE

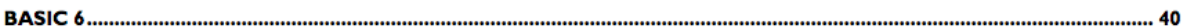

EUROPEANS IN GHANA

COLONISATION AND DEVELOPMENTS UNDER COLONIAL RULE IN GHANA

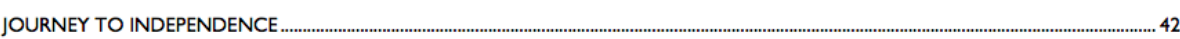

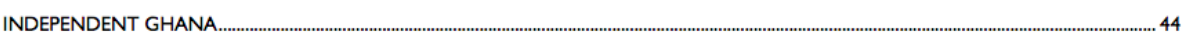

\section{RATIONALE}

History is a subject that explores the past with the aim of understanding the factors that have shaped our world. History deals with important past activities of a people so that we understand how we acquired our identity and culture. As an academic discipline, history helps to develop the imaginative abilities and critical thinking skills of learners because it teaches learners to analyse, evaluate and interpret past events carefully in order to make informed decisions. The study of history also teaches important moral lessons and provides clear guidelines for everyday life and interactions of people in the society.

As Ghanaian people, there is less understanding among us about important historical developments and events such as the evolution of the different ethnic groups in the country and their social and economic institutions; the development of state systems; their contact with the outside world and economic, social and political consequences of that contact, such as the loss of political independence, the recovery of sovereignty and the emergence of the modern state of Ghana. Furthermore, there is the need to appreciate the value of our own culture. As learners study Ghana's history, they would appreciate the life and sacrifices of our forebears and learn about the interconnectedness among the various ethnic groups to promote national integration, develop national pride and identity. Learners would learn about statesmen and women, chiefs and other individuals who played various roles to promote Ghana's development. In essence, the youth would consequently become patriotic, learn moral lessons, appreciate traditional Ghanaian values, and become useful national and global citizens.

\section{PHILOSOPHY}

The study of history helps people and societies to know their past, their culture and values which together are the essential elements for promoting nationalism, guaranteeing the survival of society and humanity in general. It is therefore not possible for any group of people to determine, reveal and establish values, ideals, goals, principles and norms for a society without reference to historical knowledge. The understanding of this underpins the learning and teaching philosophies envisaged for this curriculum.

\section{Teaching Philosophy}

The philosophy of learning history is based on the need to produce citizens who are able to reconstruct the past by describing, analysing and evaluating past events. Learners should critically trace patterns of human behaviour and communicate their views on how the past could influence the present from an informed position. In essence, learners would understand that present events have historical antecedents and parallels from which useful lessons could be drawn. Through the learning of history, learners would, specifically, acquire:

a. critical thinking skills by comparing, contrasting, evaluating, synthesizing, and applying historical information or knowledge with little or no supervision; creative thinking skills to be able to reconstruct important past events confidently;

digital literacy by using IT tools and resources efficiently for investigations and project work;

effective communication skills to be able to share information at varied levels of interaction; and

values to live as global citizens as they learn about other people and cultures of the world 


\section{Learning Philosophy}

The history classroom should be learning-centred, where the teacher introduces the topic for the day and assists learners to describe and analyse issues raised, trace patterns of societal and human behaviour and where necessary, give their views on current events (in the country) based on their knowledge of the history of Ghana. The class will be encouraged to explore topics through questioning. The history of Ghana curriculum is underpinned by seven historical concepts and classroom activities. The teacher should emphasise these important concepts in the day to day learning episodes as they are aimed to promote higher order thinking among learners. These concepts are:

a. context and chronology:

b. significance;

c. cause and consequence:

d. continuity and change;

e. similarity and difference,

f. evidence; and

g. interpretation.

Therefore, through the teaching and learning of History, learners are to:

appreciate the history of themselves, their families and communities:

b. acquire the skill of gathering and objectively analysing historical data, using scientific methods, that will enable them interpret past actions and behaviours of the people of Ghana from a Ghanaian perspective;

c. acquire more knowledge on the history of the people of Ghana;

d. apply historical concepts to the study of the history of Ghana;

e. develop a discerning approach to studying sources of historical evidence;

f. develop a sense of national consciousness and appreciate the factors that make for national unity:

g. acquire positive habits and attitudes, national identity as a Ghanaian and an African with a heritage worthy of pride, preservation and improvement; and

h. appreciate the relevance of the study of history in current and future development efforts of the nation.

\section{GENERAL AIM}

The curriculum is aimed at developing individuals to become literate, good problem solvers, with the ability to think creatively and have both the confidence and competence to participate fully in the Ghanaian society as responsible local and global citizens.

\section{SUBJECT AIMS}

The National Curriculum for the history of Ghana aims to ensure that learners can:

1. trace Ghana's origins and its past glories:

2. develop the critical skills of historical enquiry using scientific methods and participate as active, informed and responsible citizens:

3. develop a critical understanding of the past and its impact on the present to help them face the future with confidence;

4. explain how external factors have shaped the history of Ghana;

5. gain a sense of national consciousness, identity and appreciation of Ghanaian values in order to help instil values such as tolerance, good citizenship and national pride;

5. gain a sense of national consciousness, identity and appreciation of Ghana

7. make use of historical facts to acquire analytical skills, compare different periods and give their own structured account of past events

\section{INSTRUCTIONAL EXPECTATIONS}

The goal of introducing History of Ghana as a subject in the primary school is to effect positive change in values and attitudes of learners. It focuses on past events that have shaped our society. This can be achieved through well-planned lessons which involve learners in the learning process. This would let them yearn to know more and adopt skills which will be essential for them to function in the society. The enquiry approach of teaching is therefore encouraged in the history classroom. The learner should be guided to make enquiries from available sources of historical evidence. Historical evidence can come from primary sources and secondary sources.

Primary sources originate from the past. Essentially, primary sources are closer to the events in time and space. Examples could include pottery, wall paintings, carvings, coins, letters, newspapers, diaries, court records and verbal accounts from people who witnessed an event, archival documents and archaeological findings.

Secondary sources relate to accounts about past events produced based on the interpretation of primary sources. E.g. books, journals, books, articles etc.

- Plan lessons to meet the interests, knowledge, understanding, abilities, and experiences of learners,

- Design and manage learning environments that provide learners with the time, space, and resources needed for learning History of Ghana

- Generate discourse among learners and challenge them to accept and share responsibility for their own learning based on their unique individual differences.

- Use multiple methods and systematically gather data about learner understanding and ability to guide teaching and learning with arrangements to provide feedback to both learners and parents.

- Collaborate with colleagues within and across disciplines and grade levels to develop communities of learners who have the skills of inquiry and exhibit attitudes and social values conducive to learning 


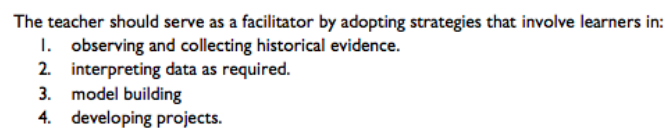

I. Sessions considering different sources of historical evidence including discussions with people with historical knowledge (resource persons) and visit to historical sites.

2. Debates among groups on various topics relating to history.

3. Projects using modern technologies to communicate findings clearly and effectively in the form of papers, exhibits/posters, drama and documentaries.

\section{CORE COMPETENCIES}

Historical Studies describe a body of skills that teachers in history at all levels should seek to develop in their learners. They are ways in which practitioners and learners in the history discipline engage with the subject matter as they learn the subject throughout the various phases in their education. The competencies presented here describe a connected body of core skills that are acquired throughout the processes of teaching and learning.

The core competencies describe a body of skills that teachers at all levels should seek to develop in their learners. They are ways in which teachers and learners engage with the subject matter as they learn the subject. The competencies presented here describe a connected body of core skills that are acquired throughout the processes of teaching and learning.

CRITICAL THINKING AND PROBLEM SOLVING (CP)

This skill develops learners' cognitive and reasoning abilities to enable them analyse and solve problems. Critical thinking and problem-solving skill enables learners to draw on their own experiences to analyse situations and choose the most appropriate out of a number of possible solutions. It requires that learners embrace the problem at hand, persevere and take responsibility for their own learning.

\section{CREATIVITY AND INNOVATION (CI)}

Creativity and Innovation promotes entrepreneurial skills in learners' through their ability to think of new ways of solving problems and developing technologies for addressing the problem at hand. It requires ingenuity of ideas, arts, technology and enterprise. Learners having this skill are also able to think independently and creatively.

\section{COMMUNICATION AND COLLABORATION (CC)}

This competence promotes in learners the skills to make use of languages, symbols and texts to exchange information about themselves and their life experiences. Learners actively participate in sharing their ideas. They engage in dialogue with others by listening to and learning from them. They also respect and value the views of others.

\section{CULTURAL IDENTITY AND GLOBAL CITIZENSHIP (CG)}

This competence involves developing learners to put country and service foremost through an understanding of what it means to be active citizens. This is done by inculcating in learners a strong sense of social and economic awareness. Learners make use of the knowledge, skills, competencies and attitudes acquired to contribute effectively towards the socioeconomic development of the country and the world at large. Learners build skills to critically identify and analyse cultural and global trends that enable them to contribute to the

global community.

\section{PERSONAL DEVELOPMENT AND LEADERSHIP (PL)}

This competence involves improving self-awareness and building self-esteem. It also entails identifying and developing talents, fulfilling dreams and aspirations. Learners are able to learn from mistakes and failures of the past. They acquire skills to develop other people to meet their needs. It involves recognising the importance of values such as honesty and empathy and seeking the well-being of others. Personal development and leadership enables learners to distinguish between right and wrong. The skill helps them to foster perseverance, resilience and self-confidence.PL helps them acquire the skill of leadership, self-regulation and responsibility necessary for lifelong learning.

DIGITAL LITERACY (DL)

Digital Literacy develops learners to discover, acquire, and communicate through ICT to support their learning. It also makes them use digital media responsibly.

LEARNING DOMAINS (EXPECTED LEARNING BEHAVIOURS)

A central aspect of this curriculum is the concept of three integral learning domains that should be the basis for instruction and assessment. These are:

- Knowledge, Understanding and Application

- Process Skills

- Attitudes and Values 
CURRICULUM REFERENCE NUMBERS

Example: B1.2.3.4.1

\begin{tabular}{|c|l|}
\hline ANNOTATION & MEANING / REPRESENTATION \\
\hline BI. & YEAR/CLASS \\
\hline 1 & STRAND NUMBER \\
\hline 2 & SUB-STRAND NUMBER \\
\hline 3 & CONTENT STANDARD NUMBER \\
\hline 4 & LEARNING/ PERFORMANCE INDICATOR NUMBER \\
\hline
\end{tabular}

\begin{tabular}{|c|c|c|c|c|c|}
\hline & Year/Class & \multicolumn{2}{|c|}{ Content Standard } & \multicolumn{2}{|c|}{ Learning Indicator } \\
\hline \multicolumn{6}{|c|}{$\begin{array}{l}\text { Strand I: History as a subject } \\
\text { Sub-strands: I-Why and how we study history }\end{array}$} \\
\hline KGI & KG2 & & & & B4 \\
\hline $\begin{array}{l}\text { KGI.I.2.I: Demonstrate understanding } \\
\text { of their own individual history }\end{array}$ & $\begin{array}{l}\text { KG2.1.2.I: Recount history about } \\
\text { and their families. }\end{array}$ & themselves & $\begin{array}{l}\text { BI.I.I. } \\
\text { history }\end{array}$ & $\begin{array}{ll}\text { erstanding } & \text { of } \\
\text { eryday life. } & \end{array}$ & $\begin{array}{l}\text { B4. I. I.I Show understanding of } \\
\text { importance of studying history. }\end{array}$ \\
\hline $\begin{array}{l}\text { KGI.I.2.I.I Share information about } \\
\text { themselves and acknowledge that since } \\
\text { they are past, they qualify to be called } \\
\text { history. }\end{array}$ & $\begin{array}{l}\text { KG2.I.2.1.I Share more detailed } \\
\text { about themselves e.g. where they } \\
\text { and their hometowns }\end{array}$ & $\begin{array}{l}\text { information } \\
\text { were born }\end{array}$ & $\begin{array}{l}\text { BI.I.I. } \\
\text { with pa }\end{array}$ & $\begin{array}{l}\text { at history deals } \\
\text { ivities. }\end{array}$ & $\begin{array}{l}\text { B4.1.1.I.I Explain how history } \\
\text { definges our identity as } \\
\text { Ghanaiaians - Akan, Ewe, Gonja } \\
\text { etc., }\end{array}$ \\
\hline
\end{tabular}

SCOPE AND SEQUENCE

\begin{tabular}{|c|c|c|c|c|c|c|c|}
\hline STRAND & SUB-STRAND & BI & B2 & B3 & B4 & B5 & B6 \\
\hline \multirow[t]{4}{*}{ HISTORY AS A SUBJECT } & Why and how we study history & & & & \multirow[t]{3}{*}{$v$} & & \\
\hline & The learner's own history & & & & & & \\
\hline & Family History & & & & & & \\
\hline & Community History & & & & & & \\
\hline \multirow{5}{*}{ MY COUNTRY GHANA I } & The People of Ghana & & & $\mathrm{v}$ & \multirow[t]{3}{*}{$\mathrm{v}$} & \multirow[t]{3}{*}{$\mathrm{v}$} & \\
\hline & Inter-Group Relations & & & $v$ & & & \\
\hline & How Ghana got its name & & & & & & \\
\hline & Major Historical locations & & & & $\mathrm{v}$ & & \\
\hline & Some selected Individuals & & & $v$ & $\mathrm{v}$ & $v$ & \\
\hline \multirow[t]{4}{*}{ EUROPEANS IN GHANA } & Arrival of Europeans & & & $v$ & & & \\
\hline & International trade including Slave Trade & & & & & $\mathrm{v}$ & \\
\hline & Missionary Activities & & & & $\mathrm{v}$ & & \multirow{3}{*}{$v$} \\
\hline & Impact of European presence & & & & & & \\
\hline \multirow{4}{*}{$\begin{array}{l}\text { COLONISATION AND } \\
\text { DEVELOPMENTS UNDER } \\
\text { COLONIAL RULE IN GHANA }\end{array}$} & Establishing Colonial rule in Ghana & & & & $\mathrm{v}$ & & \\
\hline & Social Development & & & & & $v$ & \\
\hline & Economic Development & & & & & $\mathrm{v}$ & \multirow{3}{*}{$v$} \\
\hline & Political Development & & & & & & \\
\hline \multirow[t]{4}{*}{ JOURNEY TO INDEPENDENCE } & Early Protest Movements & & & & & $\mathrm{v}$ & \\
\hline & Formation of Political Parties & & & & & \multirow{3}{*}{$v$} & $\sqrt{ }$ \\
\hline & The 1948 riots & & & & & & \\
\hline & Ghana gains independence & & & & & & $\mathrm{v}$ \\
\hline \multirow{2}{*}{ INDEPENDENT GHANA } & The Republics & \multirow[t]{2}{*}{ 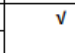 } & & & \multirow[t]{2}{*}{$\mathrm{v}$} & & $\mathrm{v}$ \\
\hline & Military Rule & & & & & & $\mathrm{v}$ \\
\hline
\end{tabular}




\section{BASIC I}

Strand I: History as a Subject

Sub-Strand I: Why and How We Study History

\begin{tabular}{|c|c|c|}
\hline CONTENT STANDARDS & INDICATORS AND EXEMPLARS & $\begin{array}{l}\text { SUBJECT SPECIFIC PRACTICES } \\
\text { AND CORE COMPETENCIES }\end{array}$ \\
\hline $\begin{array}{l}\text { BI.I.I.I. Demonstrate } \\
\text { understanding of what } \\
\text { history is about and how it } \\
\text { is part of everyday life. }\end{array}$ & $\begin{array}{l}\text { BI.I.I.I.I Explain that history deals with past human activities } \\
\text { Enquiry route: What event did you witness on your first day at school? Which people } \\
\text { took part in the event? } \\
\text { I. Mention the activity they witnessed on their first day at school } \\
\text { 2. Identify any activity performed in the past which has not been performed again } \\
\text { 3. List any past events they have witnessed } \\
\text { 4. Explain that since those activities were performed in the past, they qualify to be } \\
\text { 5. Learners sing a song, recite a rhyme or watch a documentary of any past } \\
\text { activity. } \\
\text { BI.I.I. I.2 Describe how sources of historical evidence help us find out about past human } \\
\text { activities } \\
\text { Enquiry route: where do we get information obout our past? Why do we celebrate birthdoys and } \\
\text { festivols? } \\
\text { I. Sing songs or recite rhymes related to celebrations such as birthdays, festivals and } \\
\text { weddings as part of history. } \\
\text { 2. Sketch/show a video of a scene depicting a birthday, funeral, wedding and festival } \\
\text { celebration } \\
\text { 3. Start a birthday partnership/register to make history alive in the classroom. Learners } \\
\text { write their date of birth chronologically on a manila card and this should be hanged in } \\
\text { the classroom. At the end of every history lesson, the class could refer to these } \\
\text { records for an upcoming birthday. } \\
\text { 4. Build an album of themselves and family members, starting with earlier pictures and } \\
\text { photographs to resent ones }\end{array}$ & $\begin{array}{l}\text { As learners identify and discuss } \\
\text { past events, they develop } \\
\text { imaginative and critical thinking } \\
\text { skills as well as chronological } \\
\text { understanding of historical events }\end{array}$ \\
\hline
\end{tabular}




\section{APPENDIX B}

\section{Transcript of Video Titled 'Dr Adutwum's Full Speech at Graphic Breakfast}

\section{Meeting"}

Transcription key (following Jefferson's notations and Gee's stanzas).

- Pauses: marked in seconds in parenthesis

- Contiguous utterances: =

- Intonation-stress: bold

- Intonation - louder: CAPITALIZED BOLD

- Intonation - rising: $\uparrow$, falling: $\downarrow$

- Prolonged/stretched sound: one colon : or two ::

- Transcriptionist doubt: (inaud)

- Other non-verbal information: (( ))

- Applause: xxXXXXXXXXXXXXXxxx for quiet and loud applause

- ? - a question

(Stanza 1: Corporations and students)

1a I am glad this is being done under uum

$1 \mathrm{~b}$ the auspices of Stanbic and other corporate heads are here $\uparrow$

1c What is the purpose of education whe:n we talk about building the skills of our students

$1 \mathrm{~d}$ and we are not involving business $(0.2)$

1e the eventual recipients of the very products that we claim to mold and train $=$

(Stanza 2: Corporations should have a say in how to educate)

$2 \mathrm{a}=$ When I came to the Ministry of education we had meeting with I think (0.2) the corporations in the companies in the cocoa industry

$2 \mathrm{~b}$ and what happened there kind of changed and emboldened me to do more $=$ 
2c these companies we there to hear $\uparrow$ us so that they will know how to support us $\uparrow$ $2 \mathrm{c}$ and one of the middle level staff we went there with who did the whole um um the organization of the event and did the presentation um made a comment

2d He said we like the fact that you companies are coming here to help us 2e but when you come to the Ministry of Education please do not tell us what to do $2 \mathrm{f}$ and I said "You stop right there.

$2 \mathrm{~g}$ They should rather we telling us what to do"

$2 \mathrm{~h}$ Because after you train all the students $\uparrow$

$2 \mathrm{i}$ they are the ones who are supposed to hire them

$2 \mathrm{j}$ and you are telling them not to tell you what to do

$2 \mathrm{k}$ so they would not also tell you whether they will hire your products or they are not hiring your products $=$

(Stanza 3: Unqualified graduates) $3 \mathrm{a}=$ Sometimes we talk about graduate unemployment and all there are times 3b I am also an entrepreneur $3 \mathrm{c}$ there are times when you interview people you don't feel like hiring anyone of them $(0.4)=$

(Stanza 4: how to entice employers)

$4 \mathrm{a}=$ So education has work to do.

$4 \mathrm{~b}$ If we turn out th:e kind of graduates with the requisite skills 4c who did not just memorize to get excellen:t gra:des 
4d I am sure we would reduce graduate employment

$4 \mathrm{e}$ because the companies would be so enticed to hire more $=$

(Stanza 5: Invitation to dialogue with corporations)

$5 \mathrm{a}=$ so I'm glad that um Stanbic is part of this program

$5 \mathrm{~b}$ and I hope more companies would come on board

$5 \mathrm{c}$ and help us dialogue as to the way forward in terms of education=

(Stanza 6: what is the aim of education)

$6 \mathrm{a}=$ and having said this someone may ask

$6 \mathrm{~b}$ what are the proper aims of education

$6 \mathrm{c}$ because invariably we hear one thing

$6 \mathrm{~d}$ and we have to do so many other things

6e Is it about preserving the harmony of civic life? $\uparrow$

6f Is it about providing opportunities for individuals to grow? $\uparrow$

$6 \mathrm{~g}$ It is about Is it about improving artistic creativity? $\uparrow$

6h Is it about enhancing our scientific progress? $\uparrow$

$6 \mathrm{i}$ Is it about empowering individuals to choose wisely?^

$6 \mathrm{j}$ Is it about preparing citizens to enter the labor force? $\uparrow$

$6 \mathrm{k}$ And the answer of course is all the above We have to do all the above $(0.1)=$

(Stanza 7: Education should not just be civic education)

$7 \mathrm{a}=$ and doing all the above means we have to create a robust education system 
$7 \mathrm{~b}$ that respond to the needs of our country in all these spheres

7c So it is not just about making sure there is some civic education and

$7 \mathrm{~d}$ but it is about doing more than that

7e but at the same time making sure that the fullest potential:I of every child in this country is realized $=$

(Stanza 8: A long way to go)

8a About a week ago, exactly a week ago, the World Bank launched its Human Capital index

$8 \mathrm{~b}$ and it was very $\uparrow$ insightful to say the least

8c I was not impressed

$8 \mathrm{~d}$ we may quibble with maybe the way they come up with the data and maybe other things

8e but at the end of the day we saw that we have a long way to go $\downarrow=$

(Stanza 9: A patchwork of arrangement)

$9 \mathrm{a}=$ the good news is that we realize that there is a lot to be done

$9 \mathrm{~b}$ and that is why sometimes I say in spite of our best efforts we have not create: $\mathrm{d}$ an

efficient system

9c or what we have really called a system of education

9d and sometimes I am quoted out of context

9e but $\mathbf{I}$ believe strongly that there is a lot that needs to be done

9f You see $\uparrow$ sometimes we have this patchwork of arrangement and we call it a system= 
(Stanza 10: students in the rural areas should spend more years in school)

$10 \mathrm{a}=$ when we changed from old middle school that helped some of us from the rural areas

$10 \mathrm{~b}$ to this JHS program and it was nine years across the board for everyone

10c those who came from homes and backgrounds that was used to going up to primary six

$10 \mathrm{~d}$ and then going to high school probably did not see any huge change

10e but if you go to the rural areas for somebody like me how was $\mathbf{I}$ able to compete in senior high school

10f I went there I was more mature

$\log$ I could compete with those who went to the international schools $\uparrow$

$10 \mathrm{~h}$ because it took me three years more $(0.1)$

$10 \mathrm{i}$ and when I went in I could compete with my maturity $(0.4)=$

(Stanza 11: Equity means more government support)

$11 \mathrm{a}=$ the moment you say that everyone should have the same number of years

$11 \mathrm{~b}$ then you don't leave out the equity component

$11 \mathrm{c}$ that says that if this area is going to be rural and poor then they need more government support and not less $=$

(Stanza 12: let's follow the US education system)

$12 \mathrm{a}=$ where we took our 6-3-3 model from um and if you look at the United States of 
America

$12 \mathrm{~b}$ where everybody goes up to junior high school for the same number of years

$12 \mathrm{c}$ communities that are poor get more government support

$12 \mathrm{~d}$ then if you look at our system if you happen to go to Achimota then you get all the resources

$12 \mathrm{e}$ and who are the ones who were able to go $\uparrow(0.1)$

12f But if you happen to go to my school Jaase Prameso

$12 \mathrm{~g}$ you are at the short end of the stick

12h you have limited facilities

$12 \mathrm{i}$ you have the most inexperienced teachers teaching you

$12 \mathrm{j}$ and these $\uparrow$ are communities that are educating the POOR AMONG THE POOR

the poorest among the poor

$12 \mathrm{k}$ and these $\uparrow$ are the one where there are no equity no intervention so that they can lift up those who are poor and break the cycle of poverty (4.0) =

(Stanza 13: Complaints from students who attended high performing schools)

$13 \mathrm{a}=$ So as we look at the need for quality education

$13 \mathrm{~b}$ and I know there are a number of people who complain that there is free senior high school

13c students with aggregate 30 are being sent to Presec and are being sent to Achimota $13 \mathrm{~d}$ and people are angry Old students call and they are angry $13 \mathrm{e}$ "Why should you send a student with aggregate 30 to my famous school?" $\uparrow$ 13f and I said to them "Why not?" $\uparrow(2.0)=$ 
(Stanza 14: High performing schools can handle low performing students)

14a $=$ If Presec happens to be or any other school for that matter the top 55 schools

$14 \mathrm{~b}$ they happen to have the best writh (inaud) of resources

$14 \mathrm{c}$ they have world trained teachers more experienced

$14 \mathrm{~d}$ they are better equipped to deal with students who are low performing (1.0)

$14 \mathrm{e}$ than the schools that are struggling=

(Stanza 15: high performing schools should reserve $30 \%$ of spots)

$15 \mathrm{a}=$ so when so when you talk about access you talk about quality you cannot forget

about equity

$15 \mathrm{~b}$ and for the last two years the Ministry of Education has done something uni:que under the directorship of the minister

$15 \mathrm{c}$ which required that all our category A schools about 55 of them reserve 30 percent of their se:ats to children who went to public schools

$15 \mathrm{~d}$ who are more likely to be poor and disadvantaged $(1.0)=$

(Stanza 16: Anecdote of impact of new policy)

16a =And a friend of mine who has a daughter at Wesley Girls high school

$16 b$ they just came went came from a PTA meeting

$16 \mathrm{c}$ and he said this time around there was so many parking spaces for parents to park

their cars

16d and I said why $\uparrow$ 
$16 \mathrm{e}$ and he said 30 percent of the parents were not driving $\uparrow$

$16 \mathrm{f}$ so you see the place has been decongested for those of us who were driving their cars

$\uparrow$ there

$16 \mathrm{~g}$ and he was so happy that he didn't have to struggle $=$

(Stanza 17: the poor is with us now)

$17 \mathrm{a}=$ but it is telling us something the poor (1.0) is now with us

$17 \mathrm{~b}$ the disadvantaged has found a way

$17 \mathrm{c}$ we have given them an opportunity to be among those of us who are educated and are elite

$17 \mathrm{~d}$ and the cultural exchange the diverse environment that has been created will enure to the benefits of our children

$17 \mathrm{e}$ even more than the benefit of these children who are coming from these backgrounds $=$

(Stanza 18: Why are we rushing)

18a Free senior high school and and this chasm double track are here with us ((laughs for

$18 \mathrm{~b}$ Today the first group of gold track students are reporting to school

$18 \mathrm{c} \mathrm{I} \mathrm{know} \mathrm{there} \mathrm{has} \mathrm{been} \mathrm{questions} \mathrm{about} \mathrm{why} \mathrm{why} \mathrm{are} \mathrm{we} \mathrm{rushing}$

(Stanza 19: Money from South Korean bankers)

19a about A year ago we had a meeting at the ministry of education 
$19 \mathrm{~b}$ and South Korean Exim bank executives and other senior um higher education experts were there

$19 \mathrm{c}$ and they have come to Ghana to give us a loan to build um the Eastern um the Campus of the Eastern University

$19 \mathrm{~d}$ and they met us in the Ministry of Education

19e the minister was not there

19f I happened to chair the meeting

$19 \mathrm{~g}$ and they showed us some graph as part of the presentation and we were all ears $19 \mathrm{~h}$ because hey they are there to give us money =

(Stanza 20: South Korea is doing better than us)

$20 \mathrm{a}=$ the first graph was about per capita income of South Korea and Ghana in 1960

$20 \mathrm{~b}$ and of course we know the story (0.4) of how our per capita income was higher $20 \mathrm{c}$ then they showed us the per capita income now

20d South Korea and Ghana way ahead of us

20e and they asked us why do you guys think we have performed better than you? $\uparrow$

$20 \mathrm{f}$ and of course we were scratching our heads in shame

$20 \mathrm{~g}$ and $\downarrow$ they said let's see the third graph

$20 \mathrm{~h}$ the third graph was the gross tertiary enrollment ratio of Ghana South Korea compared

$20 \mathrm{i}$ that is if you look at the youth between the ages of eighteen and twenty three $20 \mathrm{j}$ and you want to find out if some of them are in some kind of tertiary education 20k in Ghana our average was seventeen percent actually sixteen point something but I 
have rounded it up to seventeen percent

201 and South Korea is ninety three point six

$20 \mathrm{~m}$ So they asked us this is why we are ahead of you $\uparrow$

20n and this is why we came here to give you a loan=

(Stanza 21: Take loan now so avoid future loans)

21a =and I vowed to myself when we left that meeting that yes sixty years and they have come to give us a loan

$21 \mathrm{~b}$ and I don't want them to come and give the loans to my grandchildren another sixty years from no:w $\downarrow$

21c Yes there are certain elements of their education system that we do not have 21d but we need to do a better job than what we have done=

(Stanza 22: we are the best kid on the block)

$22 \mathrm{a}=$ of course Ghana finds itself in a unique situation,

22ba unique situation where we we look at ourselves and we are the best kid on the block $22 \mathrm{c}$ because when we talk about the gross tertiary enrollment of seventeen percent $22 \mathrm{~d}$ the African average is seven percent 22e so we are more likely to look at ourselves and say we are better off than them

(Stanza 23: power house in education)

23a When I I had a meeting where USAIDs education director said Ghana will be the power house for education in Africa 
$23 \mathrm{~b}$ and when it was my turn to speak I said "No we are not going to be the power house for 23c education in Africa we has to be the power house for education in the world not Africa $=$

(Stanza 24: the African syndrome)

$24 \mathrm{a}=$ when you box yourself into the African syndrome you are not going to move up $24 \mathrm{~b}$ and I want now us and our partners in business to find a way to get us out of this $24 \mathrm{c}$ and of course doing all this means you has to reform your education system $=$

(Stanza 25: 11 years is too late to intervene)

$25 \mathrm{a}=$ when you look at assessment for example um

$25 \mathrm{~b}$ the first time we get any data on student assessment in Ghana our formal one $25 \mathrm{c}$ would be after eleven years of education which is BECE

25d and others are just pilot assessment the NEA the EGRA and the EGMA

25 e so after 11 years what do you do with that data it is too late to do a serious intervention for the student=

(Stanza 26: Establishing a national assessment)

$26 \mathrm{a}=\mathrm{so}$ at the ministry of education as part of our curricula reforms

$26 \mathrm{~b}$ we are looking at establishing a national assessment

$26 \mathrm{c}$ so that students in primary two nationwide will be assessed in English and in Mathematics

26d Primary four Primary six 
26e so that you have a time to really look at what is going on at Twebede Primary School $26 f$ and be able to know whether the school is doing well or not

$26 \mathrm{~g}$ and what we can do to turn it around

$26 \mathrm{~h}$ so we have then then too we begin to look at intervention

$26 \mathrm{i}$ and we run away from this chew pour pass and forget syndrome

$26 \mathrm{j}$ which we I call it chew pour fail and forget

$26 \mathrm{k}$ because the vast majority of student don't pass (1.0) on the WASSCE

when they memorize they don't

(Stanza 27: $21^{\text {st }}$ century way of educating our children)

27a So we have to move away from it and have students seated in classrooms just like we are seated here

$27 \mathrm{~b}$ and have them dialogue with their peers

$27 \mathrm{c}$ and begin to look at the twenty first century way of educating our children

$27 \mathrm{~d}$ with peer collaboration critical thinking taking place in the classroom

27 e so students can voice their opinions

(Stanza 28: Every one of them wants to go to America)

28a I have done some unannounced visits to schools I go into the classrooms

28b I talk to students and they are excited to hear about my background

$28 \mathrm{c}$ and what I have done in America

$28 \mathrm{~d}$ since the kids every one of them wants to go to America anyway

28e they get excited when they get to know that you built schools in America wa:ow 
$28 f$ everything I say they will punctuate it with wa:ow

$28 \mathrm{~g}$ and after I finished I asked them any questions $\uparrow$

28 f No hand is up no hand $\downarrow$

$28 \mathrm{~g}$ and that is when I see that there is something wrong=

(Stanza 29: Sustainable funding)

$29 \mathrm{a}=\mathrm{so}$ as we look at sustainable ways of funding education

$29 \mathrm{~b}$ I also would venture to say that the best way of funding education is to fund it on things that are critical

$29 \mathrm{c}$ on things that can really improve the learning cultures in the schools

29d after you guarantee access

$29 \mathrm{e}$ and make sure that the very people that you are educating are the ones who are going to help you improve the economy

29f in such a way you not then begin to worry about funding for education

$29 \mathrm{~g}$ because the innovative ways of doing things and the creativity they bring to the fore to improve productivity in industry=

(Stanza 30: Improved economy, more money for education)

$30 \mathrm{a}=$ we want to improve our economy

$30 \mathrm{~b}$ and when the economy improves four percent is a lot of money four percent of the GDP

30c becomes a lot of money when the economy improves five percent of the GDP becomes a lot of money 
30d and then $\uparrow$ you are able to really look at how you can develop your education system how do you sustain it=

(Stanza 31: politicians are paid to talk)

$31=$ so I just want to say this our politicians are paid to talk so sometimes I have to remind myself that I may be talking too much ((laughs for 2.0)) Errm

(Stanza 32: how we fund free quality education)

32a and I just want to say I am very happy to be here this morning and

32b I hope the panelist emiment educationists who are here will help us

32c come up with various ideas as to how we fund free quality secondary education $32 \mathrm{~d}$ and free quality basic education and and beyond=

(Stanza 33: someone has to pay for it)

$33 \mathrm{a}=$ because at this point we don't have a choice

$33 \mathrm{~b}$ and the only choice we have is to make sure our children are in school

$33 \mathrm{c}$ and when they go to school somebody has to pay for it

$33 \mathrm{~d}$ and I hope that through this dialogue I will begin to look at how private sector involvement becomes important,

33e voluntary contribution becomes important

33f community participation become key

$33 \mathrm{~g}$ in ensuring that this funding regime becomes sustainable

$33 \mathrm{~h}$ and the children of this nation whether poor or rich get the opportunity for quality 
education $=$

(Stanza 34: Thank you)

$34=$ Thank you for the opportunity this morning

(Stanza 36: Applause)

$35 \mathrm{xxXXXXxx}$ 


\section{VITA}

Edwin Nii Bonney was born in Ghana. He came to United States in 2014 to pursue a master's degree in Romance Languages at the University of Missouri-Columbia. He went on to pursue a doctor of philosophy degree in Educational Policy Studies in the Department of Educational Leadership and Policy Analysis at the University of MissouriColumbia in the Spring of 2017. Edwin studies how educational policies marginalize and silence the languages, cultures, histories, knowledge, and voice of minoritized, racialized, and vulnerable students and families. He also studies the role of educational leaders in resisting or reinforcing the marginalization and silencing of their minoritized, racialized, and vulnerable students and families. Edwin's agenda to decolonize the educational system leads him to emphasize and tell stories of resistance from minoritized, racialized, and vulnerable students and family in his work and how those stories can inform educational policies and practices. 